\title{
Amphipods as biomonitors of marine coastal environments: a Chatham Island case study
}

\author{
Chanelle Seabrook
}

\begin{abstract}
A thesis submitted to Victoria University of Wellington in partial fulfilment of requirements for the degree of Master of Physical Geography.
\end{abstract}

School of Geography, Environment and Earth Sciences

Victoria University of Wellington 



\begin{abstract}
New Zealand's coastal marine environment has high economic, social and cultural importance. In order to manage, preserve and safely enjoy coastal environments and their resources, a good understanding of their biochemistry is required. Biomonitors provide a mechanism for monitoring changes in an environment especially in measuring metals entering the food chain. Trace metals are non-biodegradable, have the ability to become highly toxic to biota at relatively low concentrations, and bio-magnify up the food chain. Amphipods, a diverse order of crustacea, are widespread, abundant, relatively sedentary and important at the base of the food web. Furthermore, amphipods bioaccumulate pollutants through multiple sources, including seawater, sediment and their diet, and may thus provide a comprehensive insight into the chemistry of an environment.
\end{abstract}

This study investigates the trace metal chemistry of amphipods and associated algae, seawater and sediment, from coastal marine sites around Chatham Island. Samples were obtained from 11 coastal localities with the sampling sites located near potential point pollutants and on distinct basement lithologies, as well as a site identified by Te Aitanga o Ngā Uri o Wharekauri as relatively pristine. Three algal-dwelling amphipods (Aora sp. 1, Apohyale sp. 1, Eusiroides sp. 1) and one sand hopper species (Bellorchestia chathamensis (Hurley, 1956)) were found to be the most abundant and ubiquitous species collected. Sites were prioritised based on the abundances of these amphipod species and samples were analysed for $>35$ trace elements.

Spatial and interspecific variations were observed for all amphipod species investigated. Eusiroides sp. 1 was the most sensitive algal-dwelling amphipod species analysed and consistently had highest concentrations of trace metals at a given site. No size effect was found for most trace element concentrations in two amphipod species. All three algal-dwelling amphipod species and associated seawater samples from Hanson Point South had elevated concentrations for $>19$ trace metals, including potentially ecotoxic trace metals such as $\mathrm{Ti}, \mathrm{V}, \mathrm{Cr}, \mathrm{Co}, \mathrm{Ni}, \mathrm{Cu}$, and Fe. Arsenic was elevated in the algaldwelling amphipod species at Owenga and Cd at Kaingaroa West and Cape Pattisson. Trace metal concentrations in the algal-dwelling amphipod specimens were broadly reflected in their associated seawater and/or algae. However there were variations in this, with the Hanson Point South amphipods more closely matching seawater than 
algae concentration patterns, and the algae at Owenga not showing As elevations noted in the amphipods. This suggests amphipods accumulate metals from a variety of sources, both directly from seawater and variably from algae. Sediments appeared to have little influence on the trace metals bioaccumulated in the amphipod specimens.

Results from this research demonstrate that species and size effects must be considered to rigorously use amphipods as biomonitors. Amphipods appear to provide a better insight to bio-available trace metal contamination compared to the other sample types analysed here. This thesis aids in the development and application of amphipods as biomonitors in New Zealand coastal waters and provides a baseline for sites located across Chatham Island for $>30$ trace elements. This baseline may be utilized by future studies to investigate temporal variations in trace metal concentrations on Chatham Island. 


\section{ACKNOWLEDGEMENTS}

First and foremost, I would like to thank my supervisors - Dr Monica Handler, Dr Rachael Peart and Dr Richard Wysoczanski. Thank you all for your guidance, patience, support and encouragement over the past year. For the new skills and knowledge you have passed onto me, and for the invaluable experiences I have gained. Monica, thank you for your expertise in chemistry, patience with teaching me new concepts and methods, and for your feedback throughout this entire process. I extend my gratitude to Rachael for her Amphipoda expertise, help with fieldwork, consistent advice and ensuring I never strayed too far off track. Richard, thank you for kick-starting and organising the entire project, and for your feedback and assistance throughout my thesis.

I would like to extend a massive thank you and acknowledge Te Aitanga o Ngā Uri o Wharekauri for their input to this project. For their help with site selection, site history, sample collection and for welcoming NIWA scientists with open arms onto the island - Whakawhetai ki a koutou!

I would like to extend my appreciation to Dr Helen Bostock, Dr Kareen Schnabel, Lee Rauhina-August and Erina Watene-Rawiri for their help with fieldwork. A special thanks to those who provided technical and analytical assistance, including the SGEES and NIWA technical staff. I would like to give special mentions to Andrea Davies for her help with implementing chemistry. Luisa Ashworth, Lisa Northcote and Grace Frontin-Rollet for their guidance on laboratory methods. Sarah Bury, Josette Delgado and Julie Brown for processing isotope samples. Dr Roberta D'Archino for identifying algal specimens and Dr Helen Bostock and Dr Mark Hadfield for providing access to unpublished data and images.

Financial funding for this thesis was provided by NIWA and VUW through a Ministry of Business, Innovation and Employment (MBIE) grant which enabled the Crustacea as Indicators of Marine Environment Change" (CAIME) project.

Last but not least, I would like to thank my family (Matt, Debbie, Nigel, Jess and Nick) for their endless encouragement, love and support throughout my studies. Words cannot express the gratitude I have for you. 


\section{TABLE OF CONTENTS}

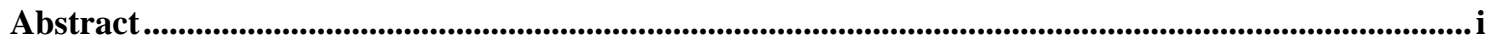

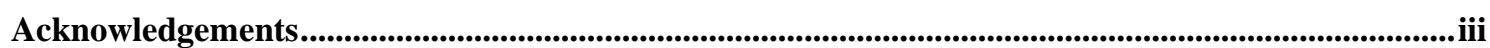

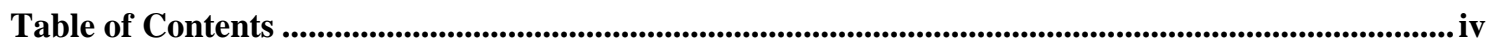

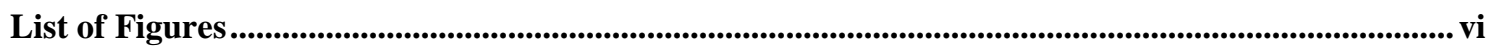

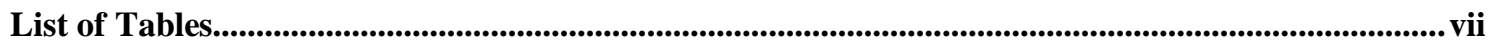

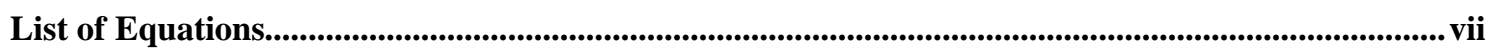

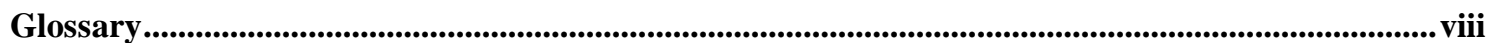

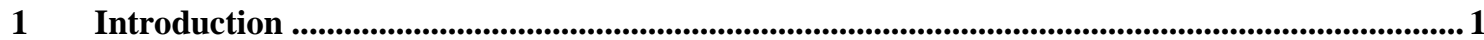

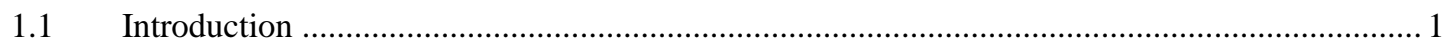

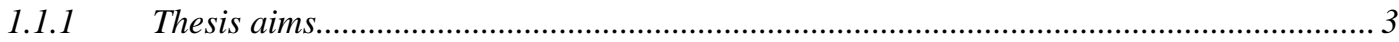

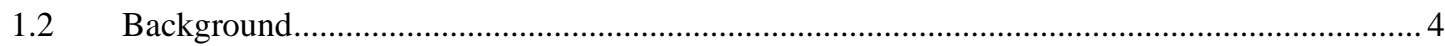

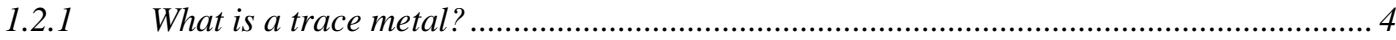

What is a biomonitor and why would you use them? ................................................... 6

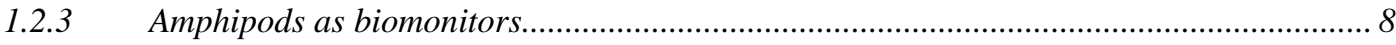

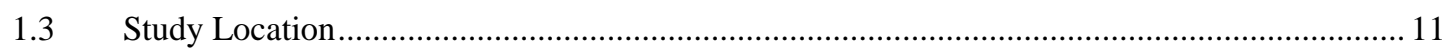

1.3.1 Geography and general land use .................................................................... 11

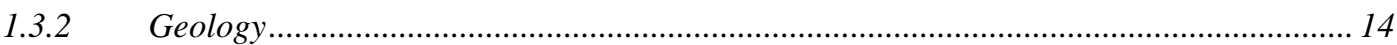

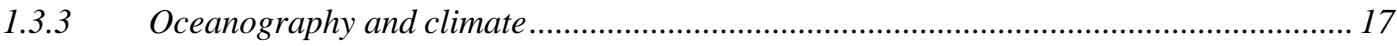

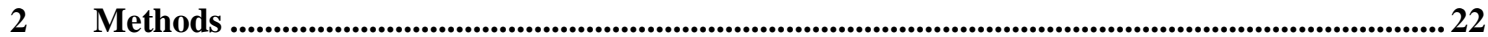

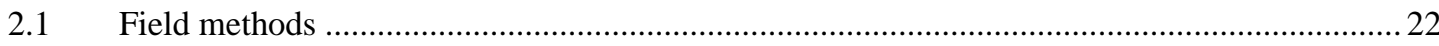

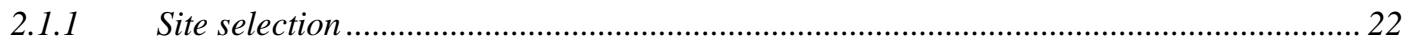

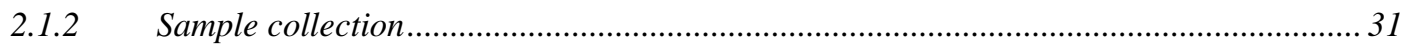

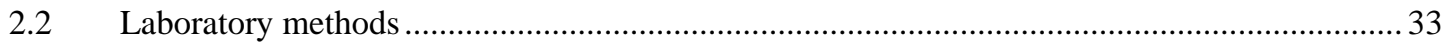

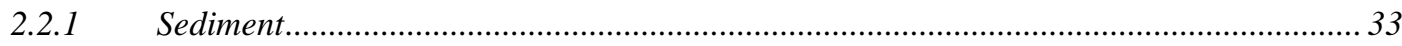

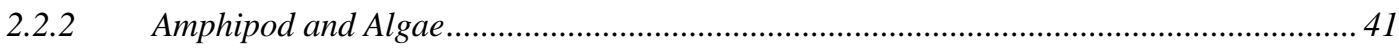

2.2.3 ICP-MS analysis and data processing .............................................................. 44

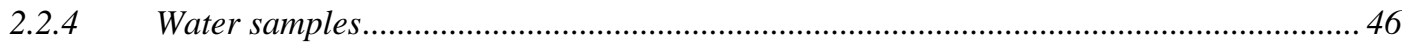

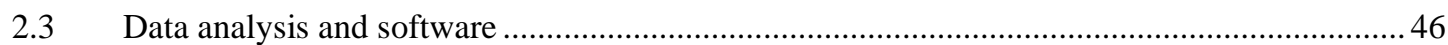

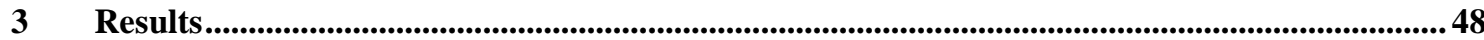




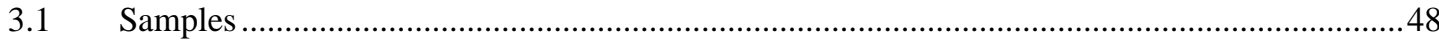

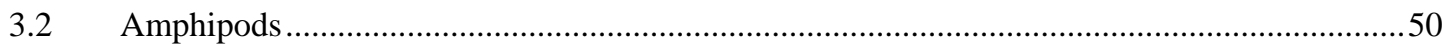

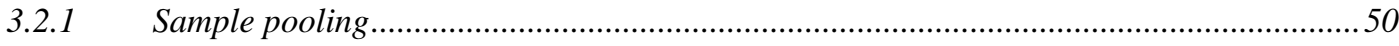

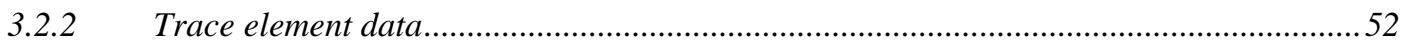

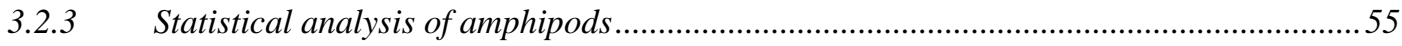

3.2.4 Interspecific variations of amphipod species ................................................................5

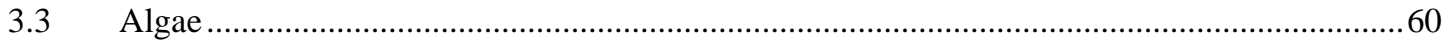

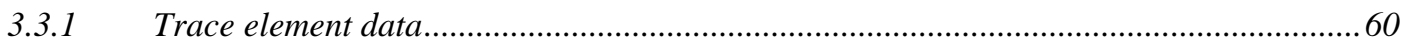

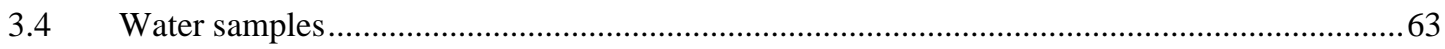

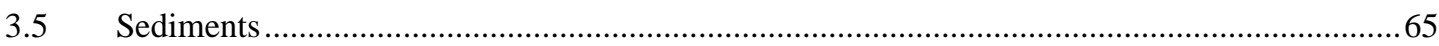

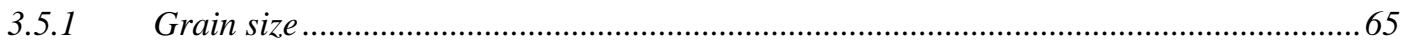

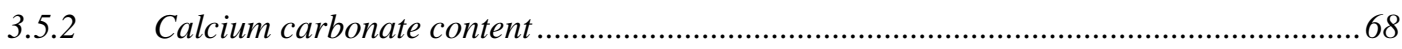

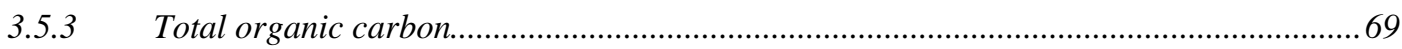

3.5.4 Major element compositions ….......................................................................... 70

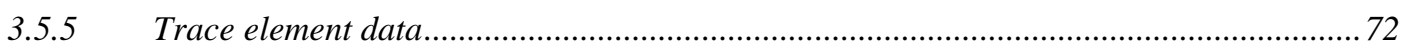

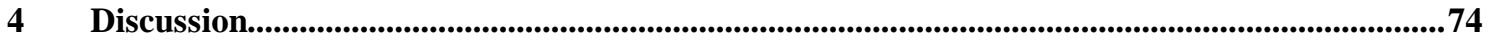

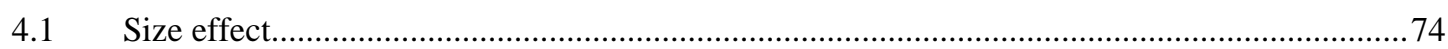

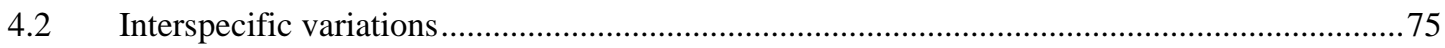

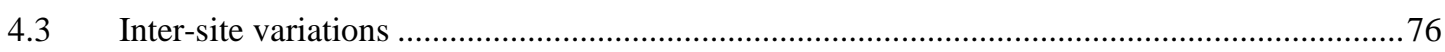

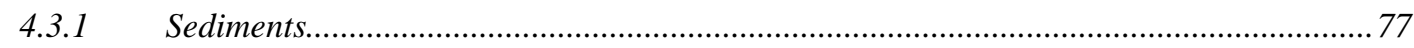

4.3.2 Elevated metal levels at Hanson Point South and Owenga ......................................... 79

4.3.3 Elevated Cd levels in the northern localities ......................................................... 82

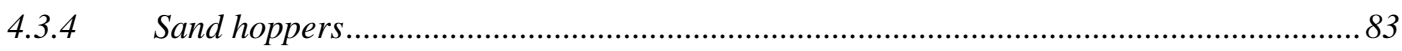

5 Conclusions and Future Work............................................................................................................85

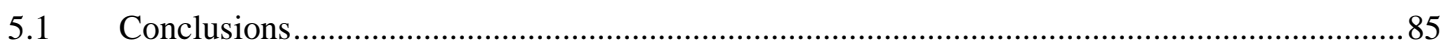

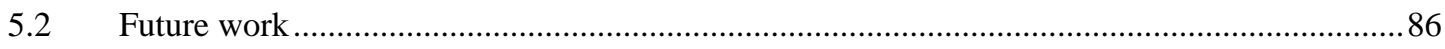

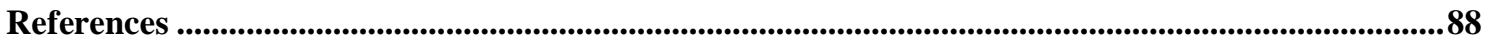

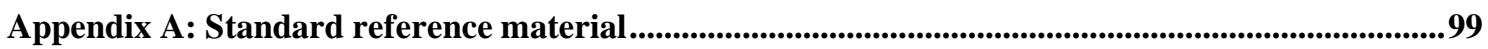

Appendix B: Indiviudal dry weight of amphipods ................................................................................104

Appendix C: Trace element data .................................................................................................106 


\section{LIST OF FIGURES}

Figure 1: Location of Chatham Islands and Chatham Island topography and geographical features of interest

Figure 2: Land cover of Chatham Island.

Figure 3: Generalised geology of Chatham Island 16

Figure 4: Surface circulation around New Zealand Error! Bookmark not defined.

Figure 5: Modelled ocean current speeds around Chatham Island 20

Figure 6: Surficial sediments characterized by the mud, sand, gravel and carbonate percent 21

Figure 7: Satellite image map showing site locations across Chatham Island. .22

Figure 8: Site images on day of collection.

Figure 9: Works involved in the 2018 Waitangi Wharf upgrade. 30

Figure 10: Weight range of algal-dwelling amphipods 51

Figure 11: The trace element data for all four amphipod species.

Figure 12: Elements vs average specimen dry weight 58

Figure 13: Concentration of select elements by amphipod species

Figure 14: The trace element data for all algae species 62

Figure 15: Textural groups of the 11 samples using a mud: sand: gravel ratio. 67

Figure 16: Grain size distribution of substrate for all sampling sites.

Figure 17: images of substrates anaylsed (sieved $<1 \mathrm{~mm}$ )

Figure 18: Major element relationships for substrate from all primary and secondary sites .71

Figure 19: Trace element concentrations of sediments collected from all five primary sites and three secondary sites.

Figure 20: Correlations between calcium carbonate and elements 


\section{LIST OF TABLES}

Table 1: Elements categorized as trace metals and trace elements ................................................5

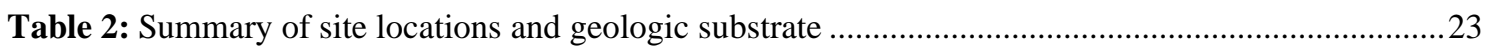

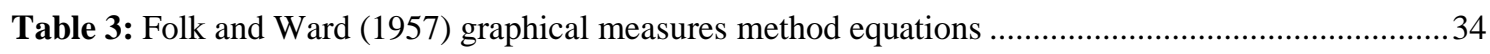

Table 4: Resolution of element masses measured on the ICP-MS ...................................................45

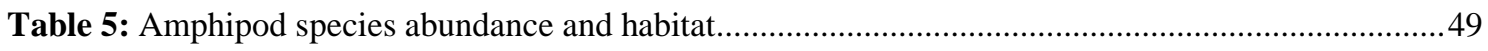

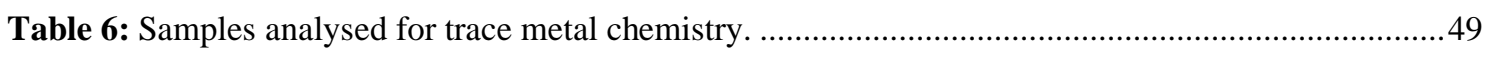

Table 7: Weight of sand hopper specimens analysed for trace metal chemistry................................51

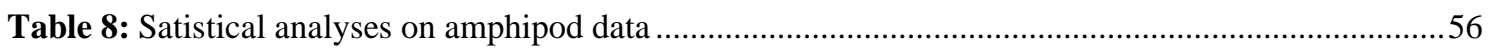

Table 9: Linear and exponential relationships between average weights and element concentrations ......57

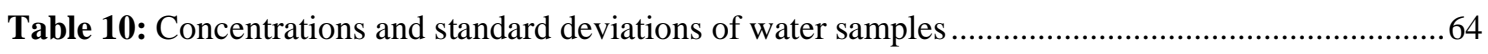

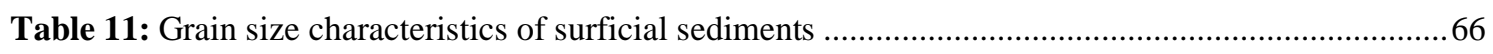

Table 12: Calcium carbonate proportion of the substrate from all sampling sites .................................6 68

Table 13: Percent of total organic matter in bulk sediments and sediments $<1 \mathrm{~mm}$ from all sampling sites.

\section{LIST OF EQUATIONS}

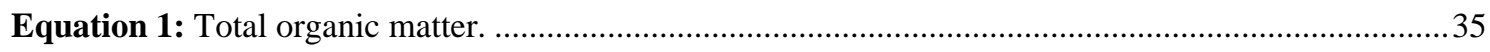

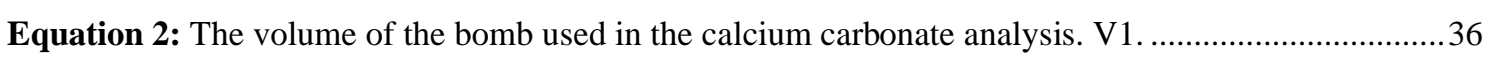

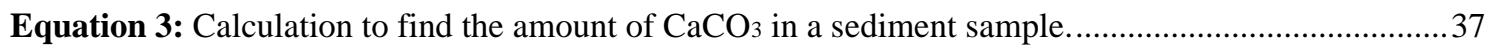

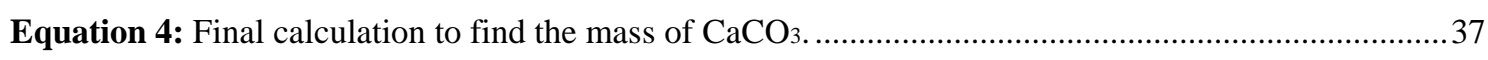




\section{GLOSSARY}

Biomonitor

\section{Trace Metals}

\section{Trace elements}

Geology

Substrate

Algal-dwelling amphipods

Sand hopper amphipods

SRM
An organism(s) that the analysis of allows quantification of the degree of ecological change through the organism's biochemical response to contaminants.

Elements categorized under class B and borderline using Nieboer \& Richardsons (1980) classifications (i.e. Au, Ag, Tl, Cu, Pd, Pt, Hg, Bi, Ti, Rh, Ir, Pb, Sn, Cd, Cu, Co, Fe, Ni, Cr, Zn, V, Mn, In, Fe, Ga, Sb, As \& $\mathrm{Sn})$.

Elements categorized under all categories (i.e. class A, class B and borderline) using Nieboer \& Richardsons (1980) classifications (i.e. $\mathrm{Cs}, \mathrm{K}, \mathrm{Na}, \mathrm{Li}, \mathrm{Ba}, \mathrm{Sr}, \mathrm{Ca}, \mathrm{Mg}, \mathrm{La}, \mathrm{Gd}$, $\mathrm{Lu}, \mathrm{Y}, \mathrm{Sc}, \mathrm{Be}, \mathrm{Al}, \mathrm{Rb}, \mathrm{Fr}, \mathrm{Ra}, \mathrm{Ac}, \mathrm{Ce}, \mathrm{Pr}, \mathrm{Nd}$, Nb. Pm, Sm, Eu, Tb, Dy, Ho, Er, Tm, Yb, Th, Pa, U, Np, Pu, Am, Cm, Bk, Cf, Es, Fm, Md, No \& Lr).

Basement lithology.

Surficial sediments.

Amphipods that inhabit macroalgae

Amphipods that inhabit the supralittoral zone on coastlines

Standard reference material 


\section{INTRODUCTION}

\subsection{Introduction}

Coastal environments provide many ecosystem functions and services. With over $15,000 \mathrm{~km}$ of coastline, New Zealand's coastal environment is of significant economic, social and cultural importance. However, these environments are delicate and can be negatively affected by anthropogenic influences (Dunne, 2007; Conti et al., 2016; Gonçalves \& Marques, 2017). Marine pollution occurs when contaminants enters the marine environment. Once there, contaminants either remain in the water column, attach to particulate material and settle out of the water column, or get taken up by biota (Carbines et al., 2013). Contaminants and pollutants can enter the marine environment via many routes, including river runoff, rainfall, sewage, industrial discharge, fallout from airborne inputs, and pollution from transport activities (Reish, 1993; Ujević et al., 2000). Contaminants may be toxic to the organisms living in these environments even in trace concentrations (Rainbow, 1995). Contaminants can influence physiological changes such as delays and interruptions in sexual development, changes in behavioral responses, and mortality, especially in larvae (Marsden \& Rainbow, 2004; Hyne, 2011; Rodrigues et al., 2017)

Metals are a common type of contaminant and can be introduced from both natural and artificial sources (Pan \& Wang, 2012). Volcanism, forest fires and the release of metalenriched particles from terrestrial vegetation include some of the natural sources of metals to the coastal environment (Burger, 2008). Different ecosystems evolve to thrive in naturally varying environments, however, changes to the environment caused by anthropogenic activities, direct or indirect, have potential to harm or unbalance these environments. Human activities linked to trace metal disturbance include mining, trawling, dredging, agricultural and industrial discharges, sewage runoff, rapid urbanization, land reclamation and fertilisers, especially phosphates (Wurl \& Obbard, 2004; Pan \& Wang, 2012; Mehanna et al., 2016; Chaalali et al., 2017; Karuppasamy et al., 2017; Morrison et al., 2017; Yong et al., 2017).

The non-biodegradable nature of trace metals leads to accumulation in the environment and in biota, and coupled with their variable toxicity, may have severe impacts on ecosystems (Duquesne \& Riddle, 2002; Pan \& Wang, 2012; Conti et al., 2016). These impacts may be long-lasting, despite restoration efforts (Ghrefat \& Yusuf, 2006; Pan \& 
Wang, 2012). Studies have demonstrated that marine sediments located near industrial and urban areas are typically contaminated by trace metals that may occur at levels several times higher than the natural background (Ujević et al., 2000). For example, a $30 \%-50 \%$ reduction of biological species richness in coastal waters has been observed as a consequence of heavy metal contamination in Southeast Korea (Wang et al., 2018). Increased anthropogenic activity over recent decades has led to increasing inputs of metals into coastal marine environments and an increasing pressure on marine ecosystems has developed (Wurl \& Obbard, 2004; Pan \& Wang, 2012).

The nature of coastal habitats makes them particularly susceptible to contamination as they are exposed to, and influenced by, both terrestrial and marine inputs (Company et al., 2011). Sediments in the nearshore environment commonly have high metal concentrations. This can, in part, be attributed to grain-size characteristics. Finer sediment grain sizes are typically dominated by clay minerals, which can increase the surface absorption and ionic attraction of metals into the sediment column (Krumgalz, 1989; Dos Santos et al., 2006). The extent of heavy metal contamination is a significant societal concern, producing a number of legislative measures and policies to address these concerns implemented by, for example, the European Union (Tornero \& Hanke, 2016). To allow for sustainable planning of future industries and to minimize the impact of anthropogenic influences on these environments, understanding the comparative trace metal pollution of coastal areas and reliable, cost-effective mechanisms for monitoring them are needed (Phillips, 1977).

In order to preserve, manage and safely enjoy our varied and diverse coastal marine environments a good understanding of their oceanography, including its chemistry, biology and geology, is required (Chiswell et al., 2015). Biomonitoring provides a successful tool that contributes to understanding and monitoring the chemistry of coastal marine environments. A biomonitor is an organism that the analysis of allows quantification of the degree of ecological change through the organism's behavioral, physiological or biochemical response to contaminants (Rainbow, 1995). Amphipod crustaceans have been identified as effective biomonitors for the marine environment and are used as a monitoring tool in locations including north-west Europe and North America (e.g. Rainbow et al., 1993). Studies have investigated the efficacy of amphipods as biomonitors in New Zealand waters, however, these studies are limited, 
localized and only two amphipod species and three trace metals $(\mathrm{Cu}, \mathrm{Zn}$ and $\mathrm{Cd})$ have been investigated thus far (Rainbow et al., 1993). Further investigation into biomonitoring in NZ is therefore warranted.

The Chatham Islands are renowned for their marine life and the economy of the Islands is reliant on fishing (Campbell \& Christie, 1994). The coastal marine environments around Chatham Island range from near pristine sites to sites potentially influenced by a suite of varying point pollutants, making it an ideal study area to investigate the use of amphipods for biomonitoring.

\subsubsection{Thesis aims}

The overarching aims of this study are to:

(1) provide an initial spatial assessment of trace metal contamination at different coastal marine sites around Chatham Island using amphipod species as biomonitors,

(2) aid in the development and application of a biomonitoring tool that can be applied to New Zealand's coastal marine environments, and

(3) provide a case study that can be used as an example in further research to understand temporal changes in the marine environment and the possible effects of human activities such as mining, urban development, trawling and ocean acidification. 


\subsection{Background}

\subsubsection{What is a trace metal?}

The terms 'heavy metals' and 'trace elements' are used inconsistently in the literature. Heavy metals are particularly poorly defined, and what elements are included or not varies greatly depending on the given study. They have been variously defined as metals and metalloids of relatively high density ( $>5 \mathrm{~g} \mathrm{~cm} \mathrm{-3}$ ) or atomic weight, metals associated with pollution and toxicity, or metals that do not play an essential metabolic role (Adriano, 2001; Madrid, 2010). Previous studies have commonly restricted the term trace metals to those metals identified as playing an essential role in the metabolism of an organism (e.g. Marsden \& Rainbow, 2004; Madrid, 2010). Earth scientists typically define trace elements as all metals and metalloids excluding the eight abundant rock forming elements found in the lithosphere (i.e. O, Si, Al, Fe, $\mathrm{Ca}, \mathrm{Na}, \mathrm{K}$ and $\mathrm{Mg}$ ) (Adriano, 2001). Other terms that have been associated with and used interchangeably with trace elements include trace metals, heavy metals, micronutrients, microelements and minor elements (Adriano, 2001). Due to the imprecise and ambiguous definitions associated with the terms heavy metals, trace metals, and trace elements it is important that the terms are clearly outlined and defined (Pourret, 2018).

For the purpose of this study the term 'heavy metals' is considered imprecise, meaningless and misleading (Pourret, 2018). Instead, the more consistent and defined terms 'trace metal' and 'trace elements' will be used. Trace metals are defined as metals that occur in trace amounts $(<0.01 \mathrm{wt} . \%)$ within the environment or within an organism, including both metals that are essential and non-essential to the metabolism of an organism (e.g. Dallinger \& Rainbow, 1993; Marsden \& Rainbow, 2004). Nieboer \& Richardson's (1980) classify elements on the basis that the coordination chemistry of metals ions in biological systems demonstrates the potential for groupings according to their binding preference (i.e. whether they seek out O-, N-, or S- containing ligands). Using this classification, related to atomic properties and the solution chemistry of metal ions, metal ions are spilt into class A (Oxygen seeking), class B (N \& S seeking) or borderline (intermediate) (Table 1). Here, the interpretation of Marsden \& Rainbow's (2004) is adopted where 'trace metals' is taken to include both class B and borderline metals and metalloids only. Separation of class B and borderline metals and metalloids is difficult as overlap occurs between different ionic states of the same metals between 
two classifications (e.g. $\mathrm{Cu}$ and $\mathrm{Pb}$ ) (Table 1). Class $\mathrm{B}$ ions are more toxic than borderline ions, which are more toxic than class A ions. Class A macronutrient elements are removed from the definition of 'trace metals' as they are the least toxic class from a biological perspective. Collectively, class A, class B and borderline metals and metalloids are considered here to comprise 'trace elements' (Table 1).

Table 1: Metal and metalloid ions and additional elements categorized using Nieboer \& Richardsons (1980) classifications.

\begin{tabular}{|c|c|c|c|}
\hline Classification & & $\begin{array}{l}\text { Trace } \\
\text { Elements1 }\end{array}$ & $\begin{array}{l}\text { Trace } \\
\text { Metals2 } \\
\end{array}$ \\
\hline \multirow[t]{4}{*}{ Class A } & Ions & \multirow[b]{2}{*}{$*$} & \\
\hline & $\begin{array}{l}\mathrm{Cs}_{+}, \mathrm{K}_{+}, \mathrm{Na}_{+}, \mathrm{Li}_{+}, \mathrm{Ba}_{2+}, \mathrm{Sr}_{2+}, \mathrm{Ca}_{2+}, \\
\mathrm{Mg}_{2+}, \mathrm{La}_{2+}, \mathrm{Gd}_{3+}, \mathrm{Lu}_{+}, \mathrm{Y}_{3+}, \mathrm{Sc}_{3+}, \mathrm{Be}_{2+}, \\
\mathrm{Al}_{3+}\end{array}$ & & \\
\hline & Other elements & \multirow[b]{2}{*}{$*$} & \\
\hline & $\begin{array}{l}\text { Rb, Fr, Ra, Ac, Ce, Pr, Nd, Pm, Sm, } \\
\text { Eu, Tb, Dy, Ho, Er, Tm, Yb, Th, Pa, U, } \\
\text { Np, Pu, Am, Cm, Bk, Cf, Es, Fm, Md, } \\
\text { No, Lr }\end{array}$ & & \\
\hline \multirow[t]{4}{*}{ Class B } & Ions & \multirow[b]{2}{*}{$*$} & \multirow[b]{2}{*}{$*$} \\
\hline & $\begin{array}{l}\mathrm{Au}_{+}, \mathrm{Ag}_{+}, \mathrm{Tl}_{+}, \mathrm{Cu}+, \mathrm{Pd}_{2+}, \mathrm{Pt}_{2+}, \mathrm{Hg}_{2+} \\
\mathrm{Bi}_{3+}, \mathrm{Ti}_{3+}\end{array}$ & & \\
\hline & Other elements & \multirow{2}{*}{$*$} & \multirow{2}{*}{$*$} \\
\hline & $\mathrm{Rh}, \mathrm{Ir}, \mathrm{Pb}$ & & \\
\hline \multirow[t]{4}{*}{ Borderline } & Ions & \multirow[b]{2}{*}{$*$} & \multirow[b]{2}{*}{$*$} \\
\hline & $\begin{array}{l}\mathrm{Pb}_{2+}, \mathrm{Sn}_{2+}, \mathrm{Cd}_{2+}, \mathrm{Cu}_{2+}, \mathrm{Co}_{2+}, \mathrm{Fe}_{2+}, \mathrm{Ni}_{2+}, \\
\mathrm{Cr}_{2+}, \mathrm{Ti}_{2+}, \mathrm{Zn}_{2+}, \mathrm{V}_{2+}, \mathrm{Mn}_{2+}, \\
\mathrm{In}_{3+}, \mathrm{Fe}_{3+}, \mathrm{Ga}_{3+}\end{array}$ & & \\
\hline & Other elements & \multirow[b]{2}{*}{$*$} & \multirow[b]{2}{*}{$*$} \\
\hline & $\mathrm{Sb}, \mathrm{As}, \mathrm{Sn}$ & & \\
\hline
\end{tabular}

1asterisks represent classifications and elements encompassed in the definition trace elements zasterisks represent classifications and elements encompassed in the definition trace metals 
Despite some trace elements being essential for metabolic processes, in excess, all trace elements become toxic to aquatic organisms (Marsden \& Rainbow, 2004; Rainbow, 2007; Morrison et al., 2017). For aquatic organisms the following metals are listed in order of decreasing toxicity: mercury $(\mathrm{Hg})$, cadmium $(\mathrm{Cd})$, zinc $(\mathrm{Zn})$, nickel $(\mathrm{Ni})$, lead $(\mathrm{Pb})$, aluminum (Al) and cobalt (Co) (Marsden \& Rainbow, 2004). Metals occur in the environment in varying forms or species, which ultimately influences their toxicity (Marsden \& Rainbow, 2004). For example, arsenic (As) can occur as either inorganic or organic species, of which only the inorganic form is considered ecotoxic (Ratnaike, 2003; Lewis, 2007). Moreover, the toxicity of metal mixtures often cannot be predicted based on the toxicity of individual metals (Marsden \& Rainbow, 2004).

\subsubsection{What is a biomonitor and why would you use them?}

One of the most robust methods used to monitor marine environments involves investigating the bioaccumulation of trace metals in organisms. Organisms in the marine environments have the ability to chemically interact with their surrounding environment by up taking and accumulating potentially toxic trace metals within their body: a process termed bioaccumulation (Phillips, 1977; Guerra-García et al., 2010; Schäfer et al., 2015; Morrison et al., 2017). These bioacumulated contaminants provide a direct reflection of their environment (Guerra-García et al., 2010; Carbines et al., 2013). Due to this uptake, biomonitors are a successful means of assessing natural environments and how they vary spatially or how they may change temporally in response to pollution and other environmental degradation or remediation (e.g. Rainbow, 1995). Bioaccumulation of an element primarily depends on the exposure time and the concentration of pollutants in the surrounding medium. However, it is also affected by other factors including pH, salinity and temperature (Canli \& Atli, 2003; Muniz et al., 2004; Gust \& Fleeger, 2005). Trace metals are either net accumulated or regulated by an organism, depending entirely on the mechanisms of the organism (Vijayram \& Geraldine, 1996). When an element is net accumulated it is not excreted when initially absorbed by the organism and will cumulatively increase with exposure (Marsden \& Rainbow 2004). Some organisms, including decapods, regulate internal abundances of certain essential metals by detoxifying or excreting these metals (Vijayram \& Geraldine, 1996). 
Analysis of a living organism is preferable to the traditional method of direct analysis of seawater (Guerra-García et al., 2009; Marin, 2017; Turesmis et al., 2018). This is because abundances of potentially ecotoxic trace metals are commonly below analytical detection limits in water and can also vary due to water movement and the patchy nature of inputs (Carbines et al., 2013). These effects can cause a 10-fold difference in concentrations of trace elements encountered at any one location depending on the time of sampling (Phillips, 1977). Since most biota accumulate contaminants over time (e.g. weeks to years), regardless of ambient levels in the water column, trace element concentrations are still reflected in the organism (Carbines et al., 2013; Morrison et al., 2017). These organisms thus represent a moving time average of the biological availability of metals and show less temporal variation compared to the dissolved metals in the overlying water column. Consequently, this is considered a more reliable representation of the chemical environment (Phillips, 1977; Morrison et al., 2017). Since one of the principal concerns of marine pollution is the effect it has on the ecosystem, measuring the bioavailable amount of trace metals also has greater ecotoxicological relevance (Rainbow 1995; Morrison et al., 2017).

Organisms commonly considered as biomonitors in the recent literature include filterfeeding bivalves (oysters \& mussels), fish, sea urchins, polychaetas and crustaceans. Not all organisms are equally useful as biomonitors and when selecting taxa for this method they must adhere to specific criteria to be successful. Key criteria for being a successful biomonitor include being widespread, ubiquitous, relatively sedentary, abundant, easily identifiable, resistant to stress, net accumulators of metals, having a lack of physiological variation, principal food for predatory fish and birds, diversity of feeding types, and accumulation of metals from multiple sources (Rainbow, 1995; Breitholtz et al., 2001; Kahle \& Zauke, 2003; Marsden \& Rainbow, 2004; King et al., 2006; Guerra-García et al., 2010; Guerra-Garcia et al., 2014; Conti et al., 2016; Eisenring et al., 2016).

In Europe, biomonitoring is commonly implemented (e.g. Rainbow et al., 1993; Rodriguez-Romero et al., 2013; Marin, 2017). In New Zealand, a discontinued biomonitoring program was implemented by Auckland Council to investigate the bioaccumulation of trace metals in mussels and oysters from Auckland coastal waters from 1987 to 2013 (Carbines et al., 2013). 


\subsubsection{Amphipods as biomonitors}

Amphipods are an order of malacostraca crustacean comprising more than 10,000 species. Amphipods are crustaceans that have segmented bodies where the first thoracic segment is joined to the head, lack a carapace, have non-stalked eyes, and have three pairs of both pleopods and uropods. (Friend \& Richardson, 1986; Horton et al., 2019). The name Amphipoda comes from Greek origin and roughly translates to "different feet", in reference to the two varieties of legs they possess. Like all peracarida, amphipods brood their juveniles in a pouch and have no larval stage in their lifecycle.

Amphipod crustaceans inhabit a wide variety of environments that range from the abyssal depths to shallow marine, terrestrial, freshwater and groundwater environments (Marsden \& Rainbow, 2004; King et al., 2006). They are informally referred to as scuds, shrimp or side swimmers. Those that inhabit the coastal/supralittoral environment (i.e. beaches) are colloquially referred to as sand hoppers, land hoppers or beach fleas. Marine amphipods vary in size. Coastal amphipods are typically small (millimeter scale) however, deep-sea amphipods have been discovered that exceed $30 \mathrm{~cm}$ in length. In the marine environment, amphipods can be described as herbivores, detritivores, predators, scavengers or ectoparasites (Hurley, 1958; Gordon, 2013; Marsden \& Rainbow, 2004). Commonly residing in a variety of habitats, they form an important role in food webs (Marsden \& Rainbow, 2004; Gordon, 2013).

Previous studies, largely in Europe, have demonstrated the efficacy of amphipods as biomonitors for trace metal pollution (Rainbow et al., 1989). The use of amphipods as biomonitors allows the assessment of the relative bioavailable amount of toxic metals in coastal waters and is now routinely implemented in north-west Europe and North America (Rainbow et al., 1993). Some of these studies include the use of amphipod species to assess marine water quality in Europe, sediment quality in Spanish ports and agricultural toxicity testing in California (Rodriguez-Romero et al., 2013; Marin, 2017; Anderson et al., 2018).

Amphipods fulfill the criteria for being effective trace metal biomonitors. They accumulate metals from multiple sources, including water, sediment and their food source (Rainbow, 1995; Pastorinho et al., 2009; Al-Mur et al., 2017), are both prey and predator, and due to their abundance and range of species in marine environments, are often principal food for predatory fish and birds (Marsen \& Rainbow, 2004). Although 
certain crustaceans, particularly decapods, regulate internal concentrations of essential metals (Vijayram \& Geraldine, 1996), amphipods do not (Marsden \& Rainbow 2004). In addition to this they also meet other important criteria for being an effective biomonitors including being widespread, abundant, relatively sedentary, easily identifiable, and resistant to stress (Rainbow, 1995; Breitholtz et al., 2001; Kahle \& Zauke, 2003; King et al., 2006; Guerra-García et al., 2010; Guerra-Garcia et al., 2014; Conti et al., 2016; Eisenring et al., 2016; Marsden \& Rainbow, 2004).

Trace metals enter the food chain via aquatic organisms directly absorbing these from their surrounding environment or by the ingestion of food leading to absorption into soft tissue (Barka et al., 2010). Metals taken up by crustacea will enter in a form that is initially available to bind with metabolites in the receiving cell (Marsden \& Rainbow, 2004). These metals then have the potential to be transported via the hemolymph to other parts of the body (Marsden \& Rainbow, 2004). When an amphipod ingests metals via solution, the metals enter via the cell membrane of permeable surfaces, including gills, by one or more transport routes (i.e. carrier mediated transport or membrane channel) (Marsden \& Rainbow, 2004). When trace metals are ingested via diet they are stored in an insoluble form in the cells of the ventral caeca (Marsden \& Rainbow, 2004). These granules are discharged to and from the gut when the cells of the ventral caeca complete their cell cycle (Marsden \& Rainbow, 2004). This is not a process of regulation of the body concentration of accumulated trace metal, however it means that the concentration of metals stored in the central caeca varies with metal exposure (Marsden \& Rainbow, 2004) and feeding strategy (Keil et al., 2008).

Two examples of essential trace metals for amphipod species include $\mathrm{Zn}$ and $\mathrm{Cu}$. Zinc is found in all organisms and is required for metabolic processes and is a key component for many enzymes (Canli \& Atli, 2003; Pan \& Wang, 2012; Olmedo et al., 2013). Likewise, $\mathrm{Cu}$ is considered an essential element as it plays a functional part of the respiratory process in amphipods (Rainbow, 2002). Non-essential metals (including Cd, $\mathrm{Pb}$ and $\mathrm{Hg}$ ), are not required at any concentration and become highly toxic at even low concentrations (Ratte, 1999; Rainbow, 2002; Rainbow, 2007; Matthews \& Fisher, 2008; Garcia et al., 2012; Morrison et al., 2017). However, all trace metals, including those that are essential and required for biological function, have the potential to become toxic 
and potentially lethal to biota when they exceed a certain threshold (Dallinger \& Rainbow, 1993; Rainbow, 2007; Morrison et al., 2017).

The bioaccumulation of metals into an amphipod can have adverse impacts on their health. The most significant impact is the influence it can have on their energy expenditure in order to attempt removal of contaminants (Marsden \& Rainbow, 2004). Incurring an energy cost can disrupt growth as well as influence metabolic and reproductive processes which, in turn, can result in mortality (Marsden \& Rainbow, 2004; Rodrigues et al., 2017). In extreme cases, significant mortality rates have been observed, an example of this is the significant mortality observed in amphipod species (10-fold less spawning) near a major industrial point pollutant source of trace metals (Cd, Zn) in Sepetiba Bay, Brazil (Rodrigues et al., 2017). Increased mortality rates of amphipods species have also been directly linked to increased $\mathrm{Cu}$ concentrations (Marsden, 2002). Life stage and size are major factors that influence the survival rate of amphipods when exposed to contamination, with juveniles consistently more sensitive than adults (Marsden, 2002).

The bioaccumulation of metals in an organism that occupies low and varied trophic levels, such as an amphipod, directly impacts food webs. Metals tend to accumulate and magnify up the food chain and predatory organisms who graze on amphipod specimens are directly affected. This process of metals accumulating and biomagnifying up the food chain holds a potentially hazardous effect for the human consumption of seafood which can result in an increase in the dietary intake of heavy metals in the population (Duquesne \& Riddle, 2002; Pan \& Wang, 2012; Conti et al., 2016).

The bioaccumulation of all metals by amphipods is not equal, certain metals will accumulate differently under the same exposure conditions (Duquesne et al., 2000). For example, in certain species of amphipods, $\mathrm{Cd}$ is not accumulated to the same extent that $\mathrm{Cu}$ is (Duquesne et al., 2000). The uptake of one metal may affect the accumulation of another, as shown by depletion of Cd toxicity and accumulation in the amphipod Corophium volutator (Pallas, 1766) when $\mathrm{Zn}$ is also accumulated (Rainbow et al., 2000). Even closely related species can differ considerably in their sensitivity to heavy metal pollutants (Breitholtz et al., 2001). These differences are attributed to variations in their metal accumulation and detoxification abilities and mechanisms (Ikemoto et al., 2008). Trophic position, habitat, sex, size, life cycle stage and coping mechanisms are 
all additional influences that can influence the bioaccumulation of metals. Because of this, the use of amphipods for biomonitoring needs to be species specific to be able to compare metal abundances spatially and temporally. In addition, the different metal uptake patterns of different species mean that a single species will not fully capture the trace metal profile of an environment and ideally, a variety of species, filling different trophic levels, should be monitored (Sabater et al., 2007).

\subsection{Study Location}

\subsubsection{Geography and general land use}

The Chatham Islands (New Zealand), centred $44^{\circ} \mathrm{S}, 176^{\circ} 30^{\prime} \mathrm{W}$, are a group of islands that lie within the South Pacific Ocean. They are situated on the eastern end of the Chatham Rise (Figure 1) and is comprised of one primary island (Chatham Island), a secondary smaller island (Pitt Island), as well as a collection of smaller uninhabited islands, rocky islets and reefs. Chatham Island, the largest of the group, was selected as the study locality for this research due to the cultural, economic and social reliance on its marine environment. The fishing sector accounts for one third of employment, providing over 135 jobs, and generated 40\% (\$18.5 million) of the total GDP in 2016 (Leung-Wai \& Borren 2017).

Chatham Island is also known as Rēkohu by the original inhabitants (Moriori) and Wharekauri by Māori (Campbell, 1993; Pearce, 2016). Chatham Island covers an area of approximately $900 \mathrm{~km} 2$ and spreads over a maximum E-W width of $57 \mathrm{~km}$ and N-S length of $49 \mathrm{~km}$ (Campbell, 1993). There are five main settlements on the island that include Waitangi, Owenga, Port Hutt and Kaingaroa, which are all situated on ports, and Te One. Waitangi is located on the west coast of Chatham Island and hosts the main administrative centre (Figure 1). The primary economic activities of the island include fishing (crayfish, paua and fish), sheep farming (for wool) and eco-tourism. There are seafood processing facilities located at Waitangi (Aotearoa Fisheries Limited), Te One and Port Hutt (Waitangi Seafoods), and Owenga (Chatham Islands Food Company). Farming on the island is primarily sheep and beef cattle with reports demonstrating a livestock of 59,600 for sheep and 9,050 of cattle being farmed in 2016 (Leung-Wai \& Borren 2017). The gross extent of farming on the island can be seen by the portion of land cleared for grassland (Figure 2). Both high and low producing grasslands are likely to be predominantly used for agricultural grazing (Ministry for the Environment, 2010). 
The geomorphology of Chatham Island is significantly influenced by variations in the underlying lithology (Campbell \& Christie, 1994). The generally low-lying landmass has a maximum elevation of $294 \mathrm{~m}$ at Maungatere Hill (Campbell \& Christie, 1994) (Figure 1). Topographically Chatham Island can be split into three broad sections. The northern section is rolling country $(<80 \mathrm{~m}$ asl), with scattered volcanic cones and plugs (Hay et al., 1970). The central portion of the island is more or less flat and of lower elevation. A dissected tableland ( $<300 \mathrm{~m}$ asl) dominates the southern section of the island (Hay et al., 1970). The central and northern portions of the island host large areas of water, including fresh and saltwater lagoons, lakes, two rivers and various small streams and creeks (Campbell, 1993). Te Whanga Lagoon, a brackish water body, is the most dominant water mass on the island and spreads over an area of $186 \mathrm{~km} 2$, equivalent to $20 \%$ of the island (Holt, 2008; Pearce, 2016). Beach sands and unstable sand dunes dominate a large portion of the extensive coastline in the north, while the southern coastlines are typically cliffs (Campbell, 1993). Peat accumulations are prevalent over a large portion of the entire island (Hay et al., 1970). 

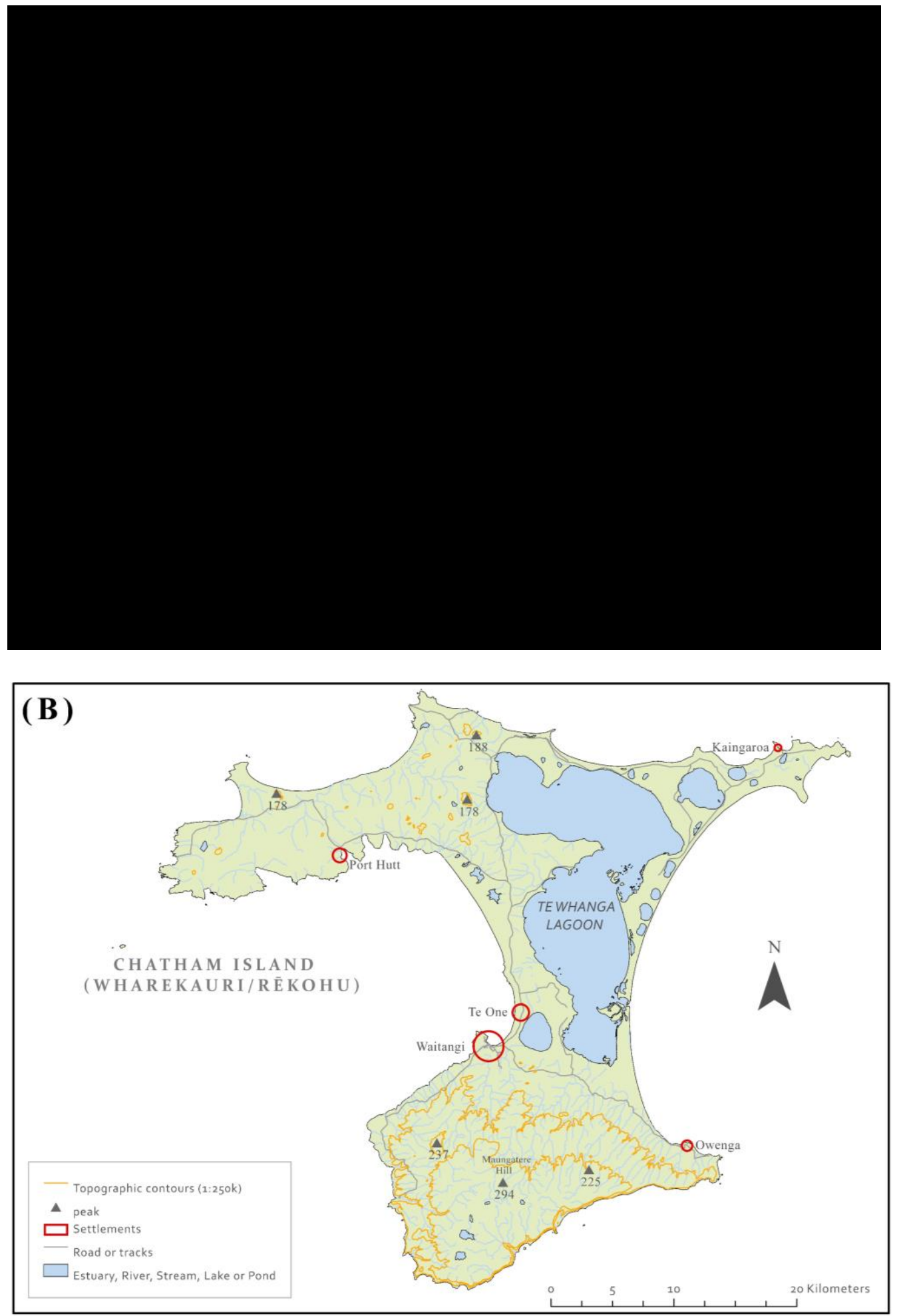

Figure 1: (A) Topographic and bathymetric map showing the location of Chatham Islands (red box) relative to mainland New Zealand. NZ 250m gridded bathymetric data set and imagery, 2008. Map sourced from Environmental Systems Research Institute and other contributors. (B) Chatham Island topography and geographical features of interest. Data sourced from Land Information New Zealand and Landcare Research New Zealand Ltd. 


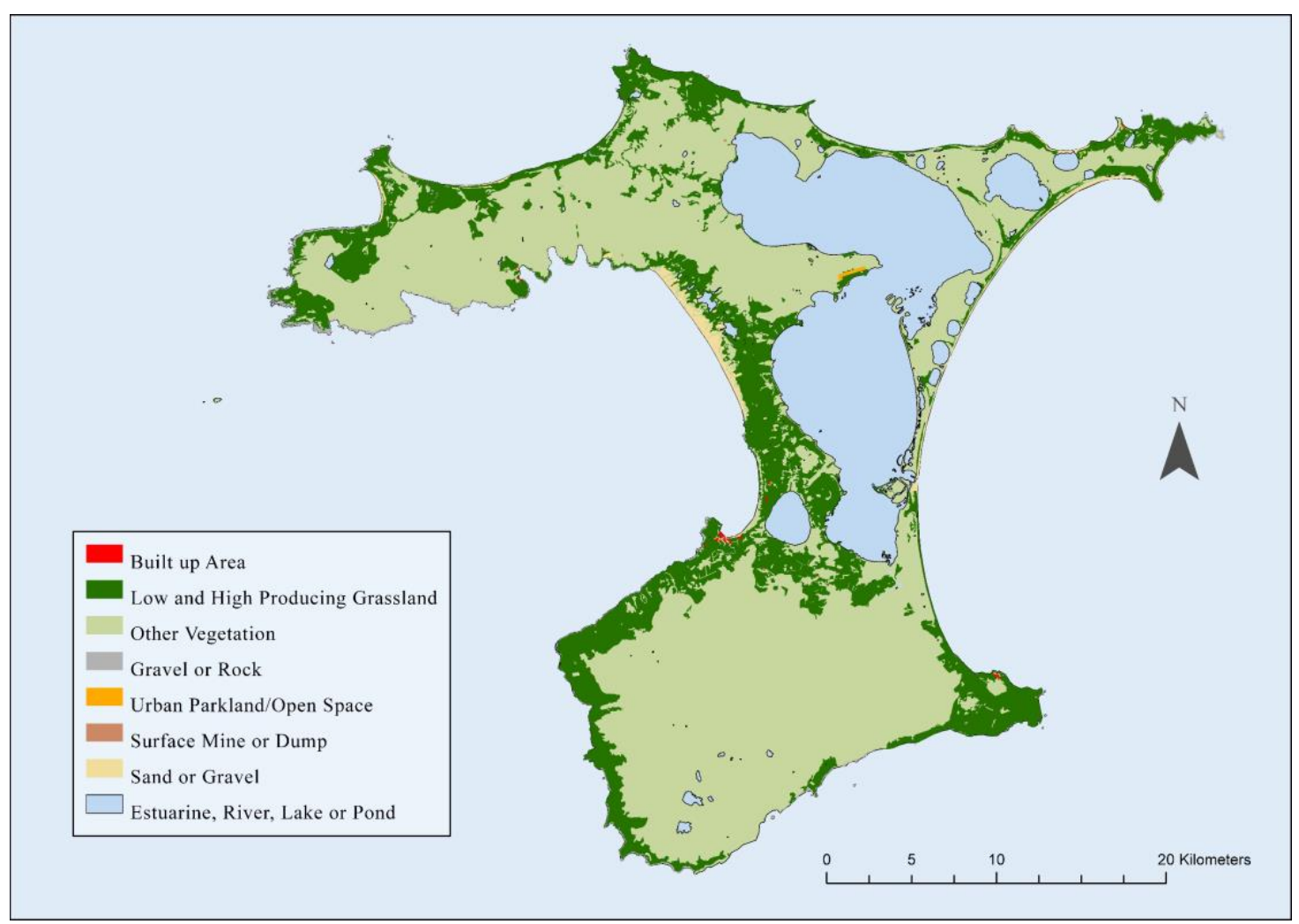

Figure 2: Land cover of Chatham Island. Vegetation categorized under "other vegetation" includes herbaceous freshwater vegetation, deciduous hardwoods, short-rotation cropland, broadleaved indigenous hardwoods, exotic forest, fernland, flaxland, dune shrubland, Gorse and/or Broom, herbaceous saline vegetation, peat shrubland, dune shrubland and indigenous forest. Data sourced from Landcare Research New Zealand Ltd.

\subsubsection{Geology}

Chatham Island is largely the result of widespread uplift and block faulting caused by the separation of New Zealand from Australia and Antarctica during the break-up of Gondwana in the Early Cretaceous (Wood et al., 1989; Campbell \& Christie, 1994). This rifting resulted in the formation of numerous E-W striking half-graben structures in the basement rock (Titjen, 2007; Campbell \& Christie, 1994), with Chatham Rise forming the northern side of a failed rift, the Bounty Trough (Wood et al., 1989). During the mid to Late Cretaceous, these grabens filled with alluvial to marginal marine sediment. Two sediment filled grabens are present on the Chatham Islands, one located in central Chatham Island and another in Pitt Island, with sediment fill comprised of Late Cretaceous fluvial and marginal marine, estuarine sediments as well as rhyolitic and basaltic volcanic rocks (Campbell \& Christie, 1994). This was followed by a period of thermal subsidence, peneplanation and alkaline basalt eruptions from volcanic 
centres (Woods et al., 1989; Campbell \& Christie, 1994) including formation of a major stratovolcano that forms the highland plateau on the southern section of Chatham Island (Figure 3) (Campbell, 1993). These rocks are predominantly basaltic lavas interbedded with scoria and tuff (Hay et al., 1970). Thermal uplift associated with the volcanism enhanced the emergence of basement fault block structures, resulting in the exposure of a basement horst in the northern section of the island that contains the oldest known rocks present on Chatham Island (Figure 3). The horst bedrock comprises indurated greywacke, argillite and their metamorphosed equivalent and a low-grade quartzofeldspathic schist correlative of the Permian - Early Cretaceous South Island Torlesse Terrane (Hay et al., 1970; Campbell, 1993; Campbell \& Christie, 1994).

During Paleocene times, the land areas on the crest of the rise were low lying (Wood et al., 1989). Tectonic stability prevailed during this time, allowing for the slow deposition of Tertiary sediments, including shallow marine greensand, sandstone, limestone and volcanic rocks (Wood et al., 1989). Limestone deposition occurred during the Late Paleocene to Early Oligocene (Wood et al., 1989). This was interrupted with volcanic deposits from periods of submarine basaltic volcanism occurring between the Late Paleocene and Early Eocene (Wood et al., 1989). During the latest Eocene and Early Oligocene, a significant period of explosive volcanism occurred, producing the Northern Volcanics (Wood et al., 1989). This is evident in the small volcanic cones $(\sim 180 \mathrm{~m})$ scattered over the north-western region of the island (Figures 1, 3). Additional volcanic activity up until the Pliocene created additional tuffs, breccia, phonolite and volcanic deposits (Wood et al., 1989).

The Chatham Islands remained dominantly submarine until the Late Pliocene when major uplift in this region occurred, postulated to be related to changes in the motion of the Pacific Plate, resulting in the emergence of the islands (Campbell \& Christie, 1994). These events resulted in a change in the sedimentation resulting in the present-day accumulation of shallow water marine quartzose sands and shell beds in the marine margins of the island (Campbell, 1993).

Unlike the Tertiary and older lithologies on the island, the Quaternary deposits are typically of terrestrial origin (Campbell \& Christie, 1994). Pleistocene peat formed over both the northern and southern parts of Chatham Island, thought to be a result of changes in eustatic sea level modifying the landscape (Campbell \& Christie, 1994; 
Titjen, 2007). This peat ranges from $0.5 \mathrm{~m}$ to $>10 \mathrm{~m}$ thick and covers an extensive area, $>50 \%$, of the surface area of the islands (Campbell, 1993; Hay et al., 1970). Silt and loess deposits of local origin, as well as rhyolitic tephra beds from the Taupo Volcanic Zone, have also been deposited (Holt, 2008). During this time there have been minimal marine deposits, restricted to a couple of high sea level events (Holt, 2008).

Although older basement rock (greywacke and schist) exists, the Chatham Islands can be generalised as eroded remnants of Late Cretaceous volcanic islands (Campbell, 1993). The formation of the islands can be summarised as being submerged during most of the Cenozoic, accumulating marine deposits with interruptions from local volcanism, and then aerial since the Late Pliocene. Chatham Island can be split into three generalised structural domains being the basement horst in the north of the island, graben fill sediment in the centre of the island and a stratovolcano that forms the southern section of the island (Figure 3).

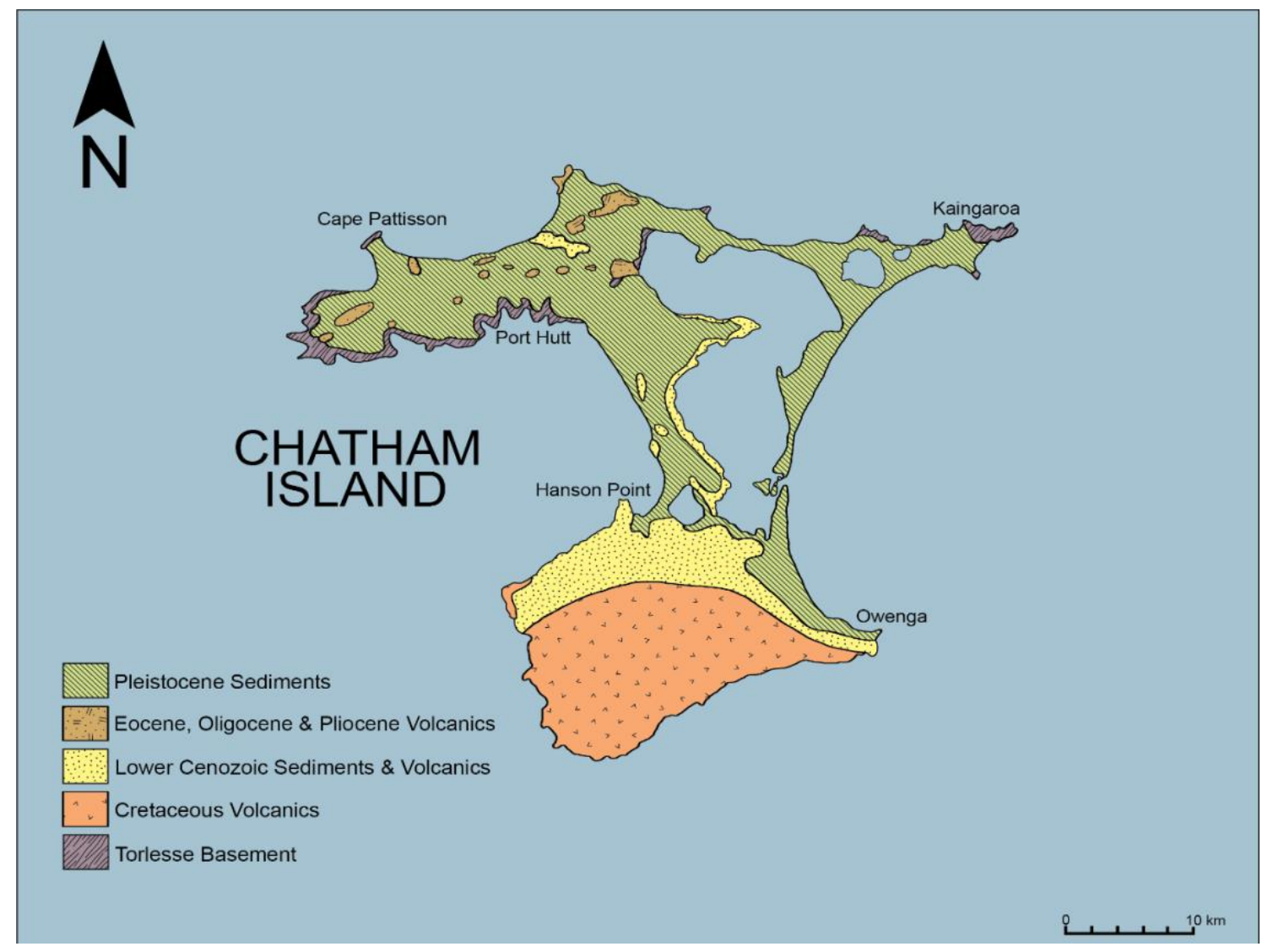

Figure 3: Generalised geology of Chatham Island. Figure adapted from Wood et al., (1989). 


\subsubsection{Oceanography and climate}

Chatham Island is heavily influenced by its location on the Chatham Rise. The rise, which has an average depth of $400 \mathrm{~m}$, acts as a barrier to ocean currents to the east of New Zealand (Wood et al., 1989). Warm subtropical waters from the East Australian Current flow along the north and east of the North Island of New Zealand and influence the northern section of the Chatham Rise (Figure 4). The interaction of these subtropical waters with the local topography influences the formation of semi-permanent eddies (Chiswell et al., 2015). The two most prominent being the Wairarapa Eddy and the Rekohu Eddy, immediately north of the Chatham Rise (Figure 4) (Chiswell et al., 2015)

The Chatham Islands are situated in the subtropical front (STF) (Figure 4), where warm, saline subtropical waters (STW) flowing from the north mix with the cold, less saline subantarctic waters from the south (Hayward \& Grenfell, 1999, Sutton, 2001). This mixing enables the region to have very high biological productivity (Hayward \& Grenfell, 1999), which is reflected in the marine fauna. Cooler water organisms are found predominantly south and west of the islands while warmer water species are prevalent off the northern and eastern coasts (Campbell, 1993). This strong convergence zone also contributes to the weather on Chatham Island, which is typically more unstable than most parts of mainland New Zealand (Campbell, 1993). 
Figure 4: Surface circulation around New Zealand based on drifter and hydrographic data.

Colours reflect flow temperature, red being warmest and dark blue being the coldest. The STF in the Tasman Sea is density compensated with little flow, as indicated by the shading (Chiswell et al., 2015).

The temperate weather of the Chatham Islands is marked by rapid changes in conditions which are commonly windy and cloudy (Pearce, 2016). The dominant prevailing surface wind direction on the Chatham Islands is from the south-westerly quarter (Pearce, 2016). The average wind speed is $\sim 24 \mathrm{~km} / \mathrm{h}$ and calm periods (wind speeds $<2 \mathrm{~km} / \mathrm{h}$ ) only occur $0.2 \%$ of the time (Pearce, 2016). Gale force winds can blow for several consecutive days but are only encountered $~ 14$ days a year (Pearce, 2016). Rainfall on the island is moderate and has a reliable winter maximum (Pearce, 2016). Rain falls on the Chatham Islands $~ 200$ days a year, however the amounts are usually small (Pearce, 2016). The majority of the precipitation falls as showers from the southerly airstream, while heavy rain is infrequent and is associated with warm northerlies (Pearce, 2016). The low elevated middle and northern sections of the island 
receive 800-1000 $\mathrm{mm}$ of annual rainfall, while the southern section experiences double this amount (Pearce, 2016). Since the Chatham Islands are situated in a zone of strong and persistent westerlies, temperature variations are small (Pearce, 2016). Mean annual air temperature for the low-lying portions of the island is $11-12^{\circ} \mathrm{C}$ (Pearce, 2016). The oceanic setting of the Chatham Islands has a strong influence on the local flora which is typically dominated by shrubbery (Department of Conservation, 2019). The flora in combination with the strong persistent winds has a profound effect on the erosional processes on the island and local land use. The climate of the Chatham Islands has been found suitable for sheep and beef cattle farming, and suitable protection from prevailing winds also permits certain agricultural and horticultural activities including highly productive orchards and vegetable gardens (Pearce, 2016).

There are not any detailed investigations of the oceanic circulation around Chatham Island. Using a Regional Ocean Model (ROM) for the entire New Zealand region, provided by Dr Mark Hadfield (NIWA), the predicted currents in this region exhibit a west to east flow north of the island and west to southeast flow south of the island (Figure 5). The current directions are heavily influenced by the large-scale circulation of the STW and STF currents. The STW and STF currents, in combination with the bathymetry, result in a modelled anticlockwise circulation around the island. The average velocity of these predicted currents is fairly slow $(<0.2 \mathrm{~m} / \mathrm{s})$. The strongest modelled currents in this region are located on the north-western tip of the island (Cape Pattisson) and are associated with a small anticyclonic eddy (Figure 5). Modelled currents along the eastern coast of the island are also significantly strong, relative to those around the rest of the island. Currents are noticeably slower on the western side of Chatham Island (Figure 5). 


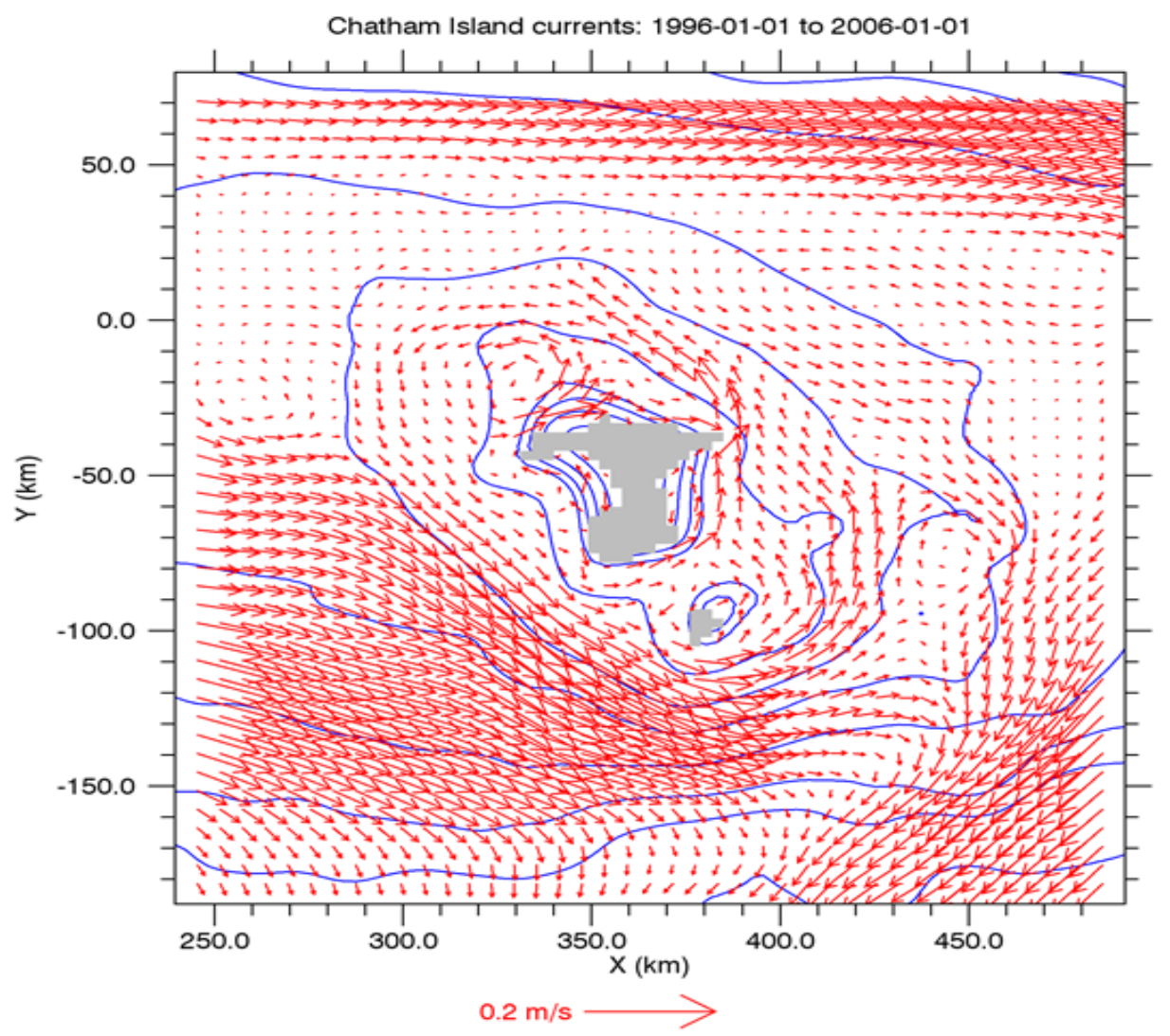

Figure 5: Modelled ocean current speeds (red arrows) around Chatham Island using the New Zealand ROM model. Simplified bathymetry contours are $10 \mathrm{~m}$ intervals (blue lines). Figure provided by Dr Mark Hadfield (NIWA).

Contrary to the slow currents predicted around Chatham Island, the wave energy is significant. The western side of the island receives a mean maximum wave height of $7-$ $8 \mathrm{~m}$, while the east and north coasts of the island receive a mean maximum height of 5 $\mathrm{m}$ (Godoi et al., 2017). Modelling of extreme wave events also indicate the occurrence of four to six of these events annually, predominantly occurring during the winter months (Godoi et al., 2017).

The high wave energy strongly influences the coastal marine environment, particularly the sediment substrate. The sediment substrate in the vicinity of Chatham Island is dominated by sands (40-100\%) (Figure 6) (Bostock et al., 2018). Muds do not become predominantly prevalent until $\sim 100 \mathrm{~m}$ offshore in the northeast and southwest direction (Figure 6). Small pockets of gravel are present along the coastline (0-40\%) but only become dominant $\sim 100 \mathrm{~m}$ offshore in the southeast and northwest (Figure 6). All nearshore sediments are dominated by carbonates (20-100\%) (Figure 6). 

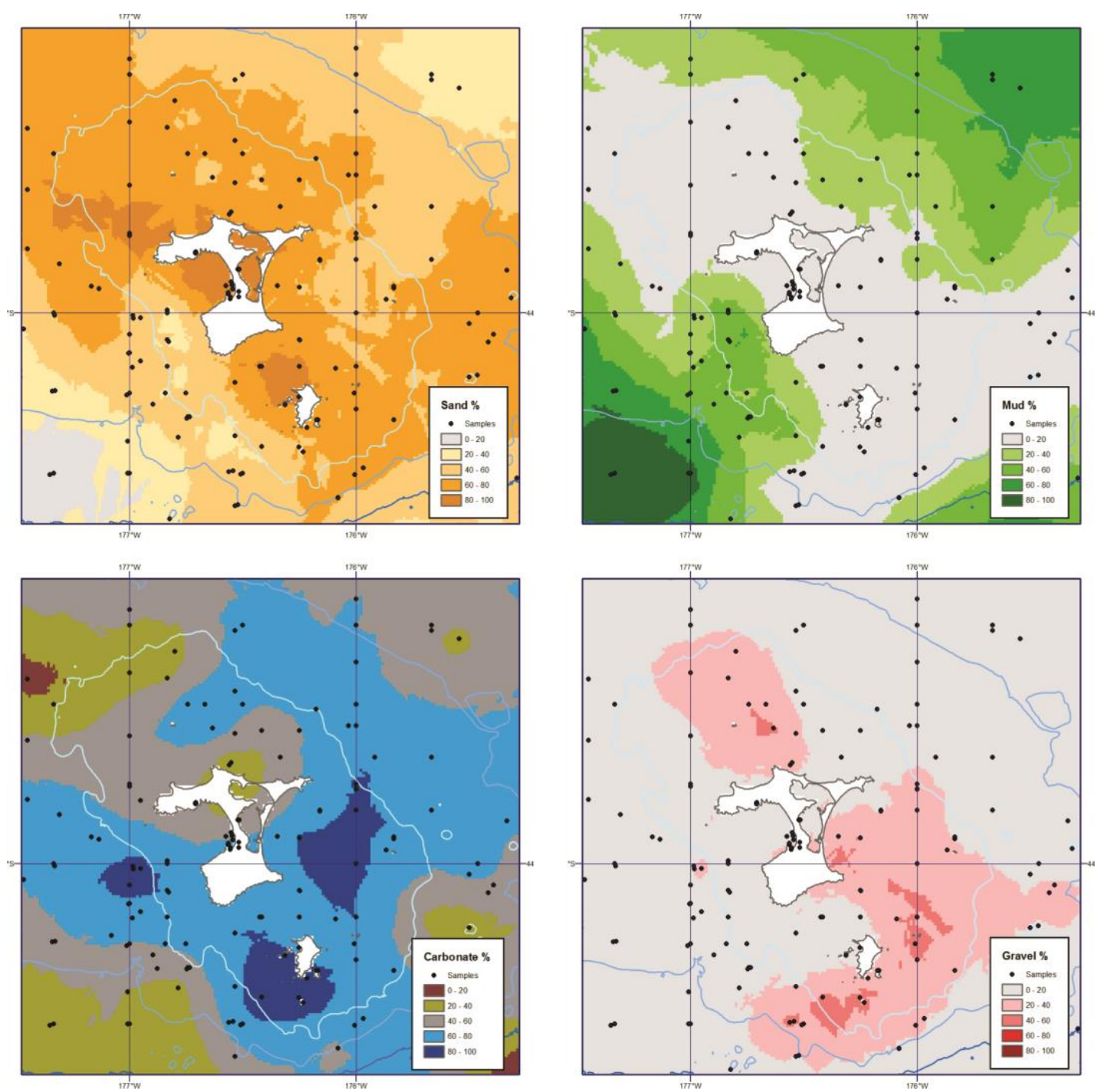

Figure 6: Surficial sediments characterized by the mud percent, sand percent, gravel percent and carbonate percent. Location of sediment samples currently in the nzSEABED database (black dots). Colours represent the estimated percentage of sand, mud gravel and carbonate from the sediment samples. The grey and blue lines illustrate the depths with lines at $50 \mathrm{~m}$, $100 \mathrm{~m}$ and $150 \mathrm{~m}$. Access to data and images obtained for this figure were provided by Dr Helen Bostock derived from Bostock et al., (2018). 


\section{METHODS}

\subsection{Field methods}

Sampling of sediment, water, algae and amphipods from Chatham Island was undertaken over a three-day period from 24/11/2018 - 26/11/2018. Samples were collected at a depth of $1 \mathrm{~m}$ unless stated otherwise.

\subsubsection{Site selection}

Sampling sites were chosen with the aid of local knowledge provided by Te Aitanga o Ngā Uri o Wharekauri. This allowed sites to be selected where the coastal marine environment was likely to be influenced by a range of anthropogenic factors and ensured the information gathered would be beneficial to the community. Collaboration with local iwi provided unique opportunities and access to some sites that have no public access points. This, in combination with the local assistance and knowledge, allowed a more extensive coverage of the island. Eleven sampling sites were visited and are described below with location details, including geological substrate, summarized in Table 2.

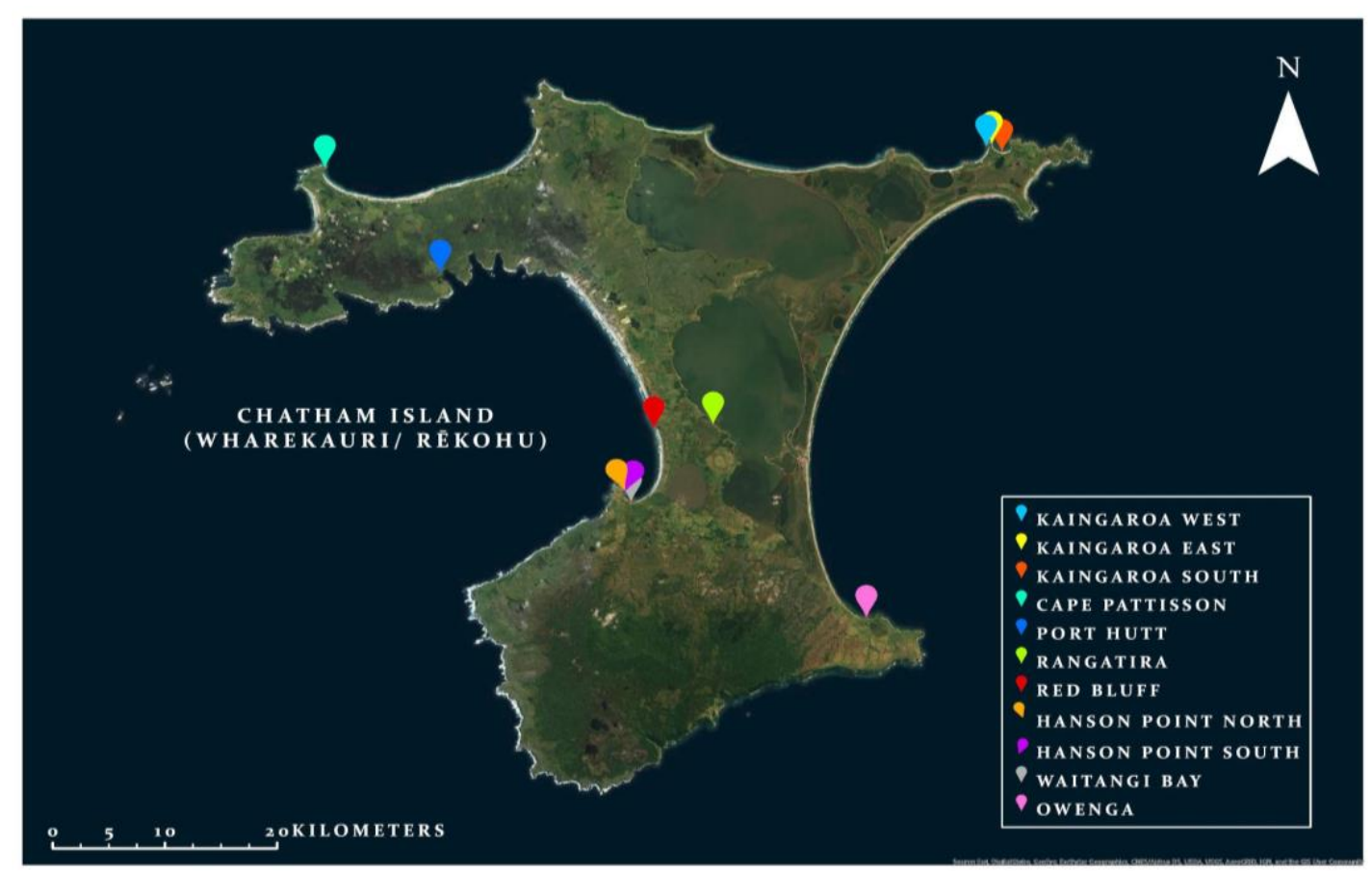

Figure 7: Satellite image map showing ample site locations across Chatham Island. Map sourced from Environmental Systems Research Institute and other contributors 
Table 2: Site locations and geologic substrate

\begin{tabular}{|c|c|c|}
\hline Site & Location & Basement lithologyı \\
\hline $\begin{array}{l}\text { Kaingaroa } \\
\text { West }\end{array}$ & $\begin{array}{l}43^{\circ} 43^{\prime} 52.5^{\prime \prime} \mathrm{S} \\
176^{\circ} 16^{\prime} 17.8^{\prime \prime} \mathrm{W}\end{array}$ & $\begin{array}{l}\text { CHATHAM SCHIST - Semi Schistose quartzofeldspathic } \\
\text { sandstone and black mudstone and quartzofeldspathic semischist } \\
\text { and schist with minor greenschist and chert. Metamorphosed to } \\
\text { pumpellyite - actinolite. }\end{array}$ \\
\hline $\begin{array}{l}\text { Kaingaroa } \\
\text { East }\end{array}$ & $\begin{array}{l}43^{\circ} 43^{\prime} 49.7 " \mathrm{~S} \\
176^{\circ} 16^{\prime} 04.0^{\prime \prime} \mathrm{W}\end{array}$ & $\begin{array}{l}\text { CHATHAM SCHIST - Semi Schistose quartzofeldspathic } \\
\text { sandstone and black mudstone and quartzofeldspathic semischist } \\
\text { and schist with minor greenschist and chert. Metamorphosed to } \\
\text { pumpellyite - actinolite. }\end{array}$ \\
\hline $\begin{array}{l}\text { Kaingaroa } \\
\text { South }\end{array}$ & $\begin{array}{l}43^{\circ} 44^{\prime} 09.7^{\prime \prime} \mathrm{S} \\
176^{\circ} 15^{\prime} 28.4^{\prime \prime} \mathrm{W}\end{array}$ & $\begin{array}{l}\text { KAREWA GROUP - Non-marine deposits of Chatham Islands, } \\
\text { including aeolian sand, peat and distal volcanic ash. }\end{array}$ \\
\hline $\begin{array}{l}\text { Cape } \\
\text { Pattisson }\end{array}$ & $\begin{array}{l}43^{\circ} 44^{\prime} 42.4^{\prime \prime} \mathrm{S} \\
176^{\circ} 48^{\prime} 07.1^{\prime \prime} \mathrm{W}\end{array}$ & $\begin{array}{l}\text { CHATHAM SCHIST - Semi Schistose quartzofeldspathic } \\
\text { sandstone and black mudstone and quartzofeldspathic semischist } \\
\text { and schist with minor greenschist and chert. Metamorphosed to } \\
\text { pumpellyite - actinolite. }\end{array}$ \\
\hline Port Hutt & $\begin{array}{l}43^{\circ} 48^{\prime} 38.0^{\prime \prime} \mathrm{S} \\
176^{\circ} 42^{\prime} 33.3^{\prime \prime} \mathrm{W}\end{array}$ & $\begin{array}{l}\text { CHATHAM SCHIST - Semi Schistose quartzofeldspathic } \\
\text { sandstone and black mudstone and quartzofeldspathic semischist } \\
\text { and schist with minor greenschist and chert. Metamorphosed to } \\
\text { pumpellyite - actinolite. }\end{array}$ \\
\hline Rangatira & $\begin{array}{l}43^{\circ} 54^{\prime} 12.6^{\prime \prime} \mathrm{S} \\
176^{\circ} 29^{\prime} 29.8^{\prime \prime} \mathrm{W}\end{array}$ & $\begin{array}{l}\text { TE WHANGA LIMESTONE - Coarse grained, variably } \\
\text { cemented, bryozoan limestone. }\end{array}$ \\
\hline Red Bluff & $\begin{array}{l}43^{\circ} 54^{\prime} 26.2^{\prime \prime} \mathrm{S} \\
176^{\circ} 32^{\prime} 16.9^{\prime \prime} \mathrm{W}\end{array}$ & $\begin{array}{l}\text { RED BLUFF TUFF - Fossiliferous, calcareous, basaltic tuff with } \\
\text { minor limestone lenses. }\end{array}$ \\
\hline $\begin{array}{l}\text { Hanson } \\
\text { Point North }\end{array}$ & $\begin{array}{l}43^{\circ} 56^{\prime} 44.1^{\prime \prime S} \\
176^{\circ} 33^{\prime} 41.0^{\prime \prime} \mathrm{W}\end{array}$ & $\begin{array}{l}\text { RED BLUFF TUFF - Fossiliferous, calcareous, basaltic tuff with } \\
\text { minor limestone lenses. }\end{array}$ \\
\hline $\begin{array}{l}\text { Hanson } \\
\text { Point South }\end{array}$ & $\begin{array}{l}43^{\circ} 56^{\prime} 47.9^{\prime \prime} \mathrm{S} \\
176^{\circ} 33^{\prime} 40.9^{\prime \prime} \mathrm{W}\end{array}$ & $\begin{array}{l}\text { RED BLUFF TUFF - Fossiliferous, calcareous, basaltic tuff with } \\
\text { minor limestone lenses. }\end{array}$ \\
\hline $\begin{array}{l}\text { Waitangi } \\
\text { Bay }\end{array}$ & $\begin{array}{l}43^{\circ} 57^{\prime} 10.1 " \mathrm{~S} \\
176^{\circ} 33^{\prime} 25.4^{\prime \prime} \mathrm{W}\end{array}$ & DUNE SAND - Beach sand or river sand dunes active \\
\hline Owenga & $\begin{array}{l}44^{\circ} 01^{\prime} 26.9^{\prime \prime} \mathrm{S} \\
176^{\circ} 22^{\prime} 05.9^{\prime \prime} \mathrm{W}\end{array}$ & $\begin{array}{l}\text { PITT ISLAND GROUP - Basaltic lava flows, pillow lava with } \\
\text { interstitial limestone, and interbedded fossiliferous tuff; minor } \\
\text { basaltic - trachytic dikes and sills }\end{array}$ \\
\hline
\end{tabular}

1. Lithology descriptions from Forsyth et al., (2008). 


\section{Kaingaroa West}

The north-eastern tip of Chatham Island hosts an anchorage and the small fishing village of Kaingaroa (Figure 7). The small bay located west of Kaingaroa Harbour was selected as concerns were raised regarding the possible impact that runoff from a nearby no longer used dumping ground may have on this coastal environment (Figure 8A, Table 2). Samples were collected in the northern section of an open sandy bay (Figure $8 \mathrm{~A})$. Seaweed at this sampling locality was abundant.

\section{Kaingaroa East}

The western tip of Kaingaroa Harbour (Figure 7, Table 2) was chosen due to concerns regarding the possible influence the high fishing activity and small settlement adjacent to the coastline has on the marine environment. Samples were collected north of the Kaingaroa wharf from sandy sediments adjacent to a wave cut platform (Figure 8B). Algae was abundant at this location.

\section{Kaingaroa South}

The southern section of Kaingaroa Harbour was selected as a third sampling site in this area of the island (Figure 7, Table 2). Samples were collected true left of the mouth of the outlet draining from Lake Te Wapu. This location was selected due to a concern raised regarding runoff from a recycling and dumping site located $\sim 300 \mathrm{~m}$ southwest of this coastal environment. Samples were collected in the middle of an exposed, high energy, sandy bay. Seaweed was absent, which is likely a reflection of the wave energy (Figure 8C).

\section{Cape Pattisson}

On the north western tip of Chatham Island, secluded from any residential areas, Cape Pattisson was considered by locals to be the most pristine coastal environment on the island (Figure 7, Table 2). Samples were collected from the eastern coast of Cape Pattisson from small rock pools in a shore cut platform in <1m deep water (Figure 8D). It was deemed to be unsafe to collect soft substrate material adjacent to the wave cut platform due to the depth and the known strength of the currents at this locality. 


\section{Port Hutt}

Port Hutt, a sheltered cove in Whangaroa Harbour, was deemed a site of concern due to the possible runoff from the local fish factory which is situated $\sim 500 \mathrm{~m}$ from this site and the number of abandoned ships that had been left in the bay (Figure 7, Table 2). Samples were collected on the western side of the sand beach at the head of the cove immediately adjacent $(<20 \mathrm{~m})$ to a boat ramp comprised of gravel (Figure $8 \mathrm{E}$ ). Algae was abundant at this locality.

\section{Rangatira}

The eastern section of Te Whanga Lagoon, south of Motuhinahina Island, was selected as the only lagoon site (Figure 7, Table 2). Selection of this site allows for comparison between different water bodies. Samples were collected from a sandy waterfront, shell layers on the adjacent shoreline were abundant and algae was absent (Figure 8F).

\section{Red Bluff}

This site was adjacent to a small bluff located on the western coast of the island within Petre Bay (Figure 7, Table 2). Concerns were raised regarding potential runoff from the Resource Recovery Centre, a landfill located $\sim 500$ m east of this site. Samples were collected immediately south $(\sim 10 \mathrm{~m})$ of the bluff from a coarse-grained substrate in $<1$ m depths (Figure 8G).

\section{Hanson Point sites}

Two sites were sampled in the vicinity of Waitangi Wharf. Constructed in 2018, Waitangi Wharf is located on the tip of Hanson Point and is the islands' main port which is utilized often. Concerns were raised in this area due to the potential impacts the recently built wharf may have, in addition to the high boating activity in Waitangi Harbour and close proximity to the island's main administrative settlement $(\sim 500 \mathrm{~m}$ south).

The Waitangi Wharf upgrade project involved the following (Figure 9):

- Building of a temporary landing area $\left(2,100 \mathrm{~m}_{2}\right)$ for unloading and loading of construction equipment. 
- Construction of a breakwater (185m long) comprised of "XBloc concrete armour" for wharf protection.

- Reclamation of land for enhanced port operations and new buildings for port handling

- Dredging the harbour and surrounding seabed $(>7,000 \mathrm{~m} 2)$ to enable the construction of the new coastal structures and to improve berthing for vessels.

- Beach replenishment of Waitangi Beach using material from dredging.

- Improvements to the existing livestock holding area and track.

Consultant planning reports regarding the wharf upgrade and construction state that the main concerns centred on the potential for changes in sediment movement, coastal processes and erosion patterns (New Zealand Department of Internal Affairs, 2016).

The two sampling sites selected in this locality were Hanson Point South and Hanson Point North. Hanson Point North (4356'44.1"S 176³3'41.0"W) was located $70 \mathrm{~m}$ northwest of the wharf structure, on a sandy substrate and $\sim 20 \mathrm{~m}$ from the concrete breakwater (Figure 7, Figure 8K, Table 2). Algae was present at this locality. Hanson Point South $\left(43^{\circ} 56^{\prime} 47.9^{\prime \prime} \mathrm{S} 176^{\circ} 33^{\prime} 40.9^{\prime \prime} \mathrm{W}\right)$ was located $\sim 70 \mathrm{~m}$ south of the wharf structure (Figure $8 \mathrm{~J}$, Table 2). Samples were collected in waters $<1 \mathrm{~m}$ from a wave cut platform emergent at low tide (Figure 8I). Collection of soft sediments adjacent to the wave cut platform was not possible due to the bathymetry of the region. In accordance with the health and safety plan, the conditions were deemed unsafe to collect in. Instead, sediment was collected from a rockpool on the wave cut platform. Algae was present in deeper water off the side of the wave cut platform.

\section{Waitangi Bay}

Waitangi Bay, an embayment stretching north-east within the larger Petre Bay was chosen as the third sampling locality in this region (Figure 7, Table 2). Waitangi Bay is situated within Waitangi Harbour, which hosts the islands' main port and settlement. Locals indicated it was common for children to swim in the nearby Nairn River which drained into this coastal environment and is easily accessible by both locals and tourists. 
Sampling was implemented in this sandy sheltered bay, 100 $\mathrm{m}$ left of the river mouth $\sim 50 \mathrm{~m}$ off shore (Figure 8L). Algae was present at this location.

\section{Owenga}

To the south of Hanson Bay, a large bay which dominates the eastern coast of the island, is the smaller embayment of Owenga. Owenga was chosen as one of the sampling sites due to the small settlement that resides here as well as the high boating activity in the area (Figure 7, Table 2). A row of boats permanently lines the high beach while the bay itself hosts many anchored boats. The wharf located in Owenga was constructed in 2010 and is one of the main locations to catch a boat over to Pitt Island. One of this island's main fish factories is located $\sim 50 \mathrm{~m}$ southwest from the wharf. Immediately $(<10 \mathrm{~m})$ northwest of Owenga wharf lies a boulder and cobble beach with small pockets of sand (Figure $8 \mathrm{M}$ ). Samples were collected from a sandy substrate. Algae at this location was abundant. 

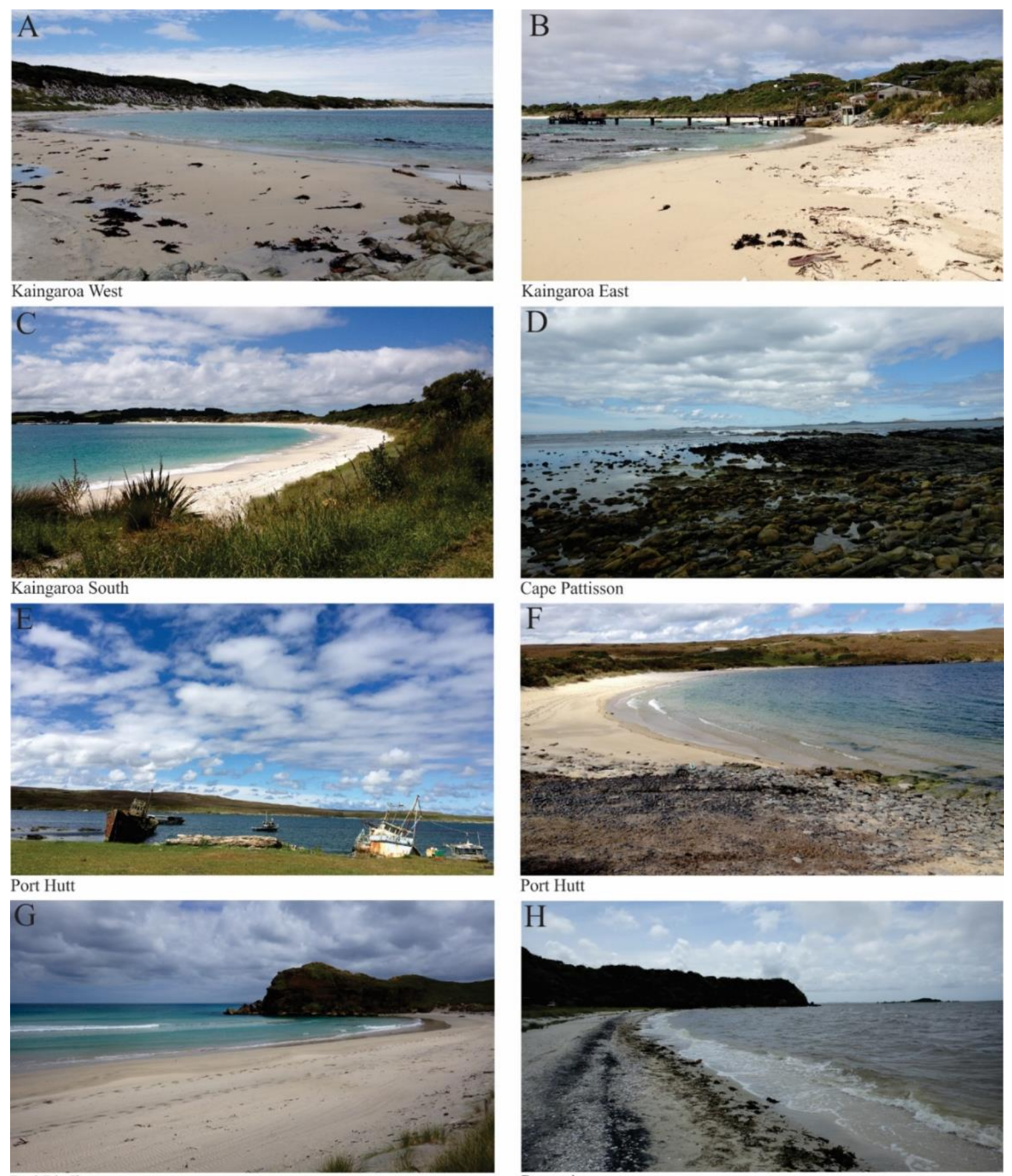

Red Bluff

Rangatira

Figure 8: Sites on day of collection. A-Kaingaroa West, B- Kaingaroa wharf, C- Kaingaroa South, D-shorecut platform samples were collected from at Cape Pattisson , E- Abandoned ships (left is Thomas Currell, a minesweeper from WW2) at Port Hutt, F- Port Hutt, G-Red bluff in the distance, $\mathbf{H}$ - Rangatira lagoon site. 


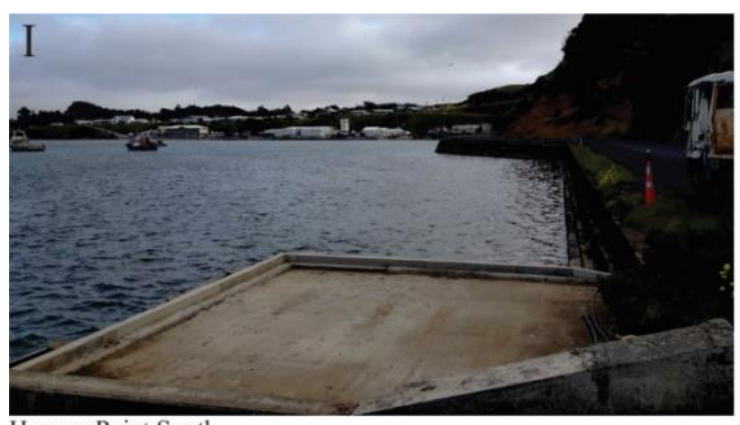

Hanson Point South

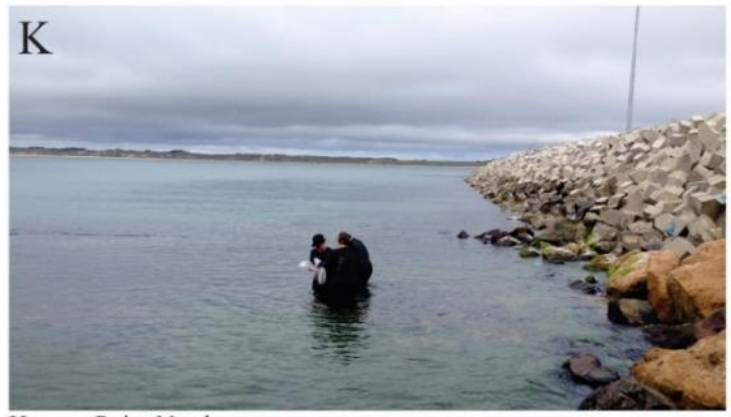

Hanson Point North

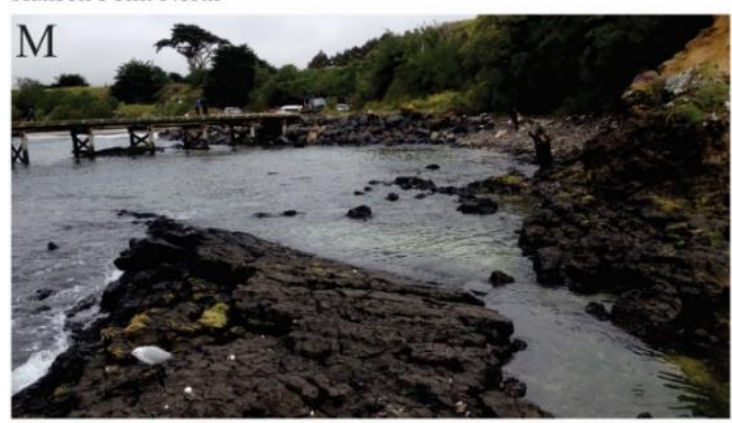

Owenga

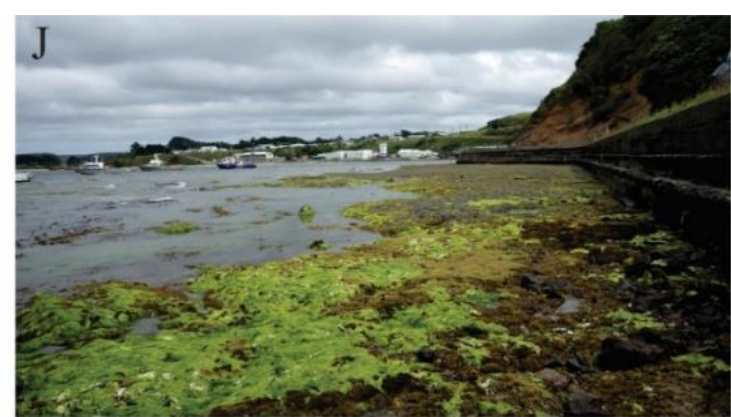

Hanson Point South

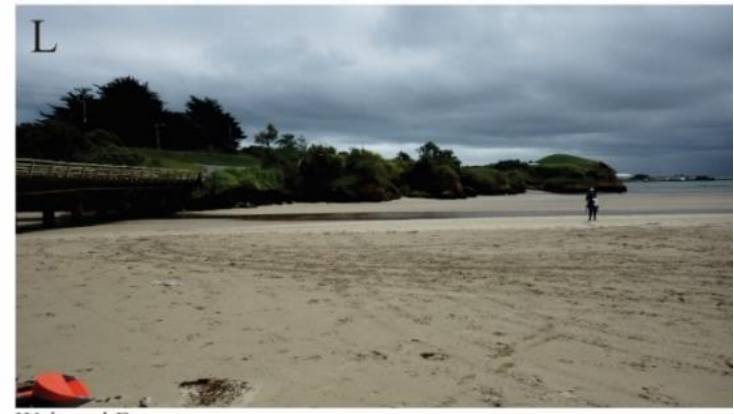

Waitangi Bay

Figure 8: $\mathbf{I}-$ is Hanson Point South at high tide, $\mathbf{J}$ - the wave cut platform at Hanson Point

South emergent at low tide, K- breakwater at Hanson Point North (constructed in 2018 for wharf protection) can be observed on the right side of the image, $\mathbf{L}$-Waitangi Bay, $\mathbf{M}-$ Owenga wharf in background. 


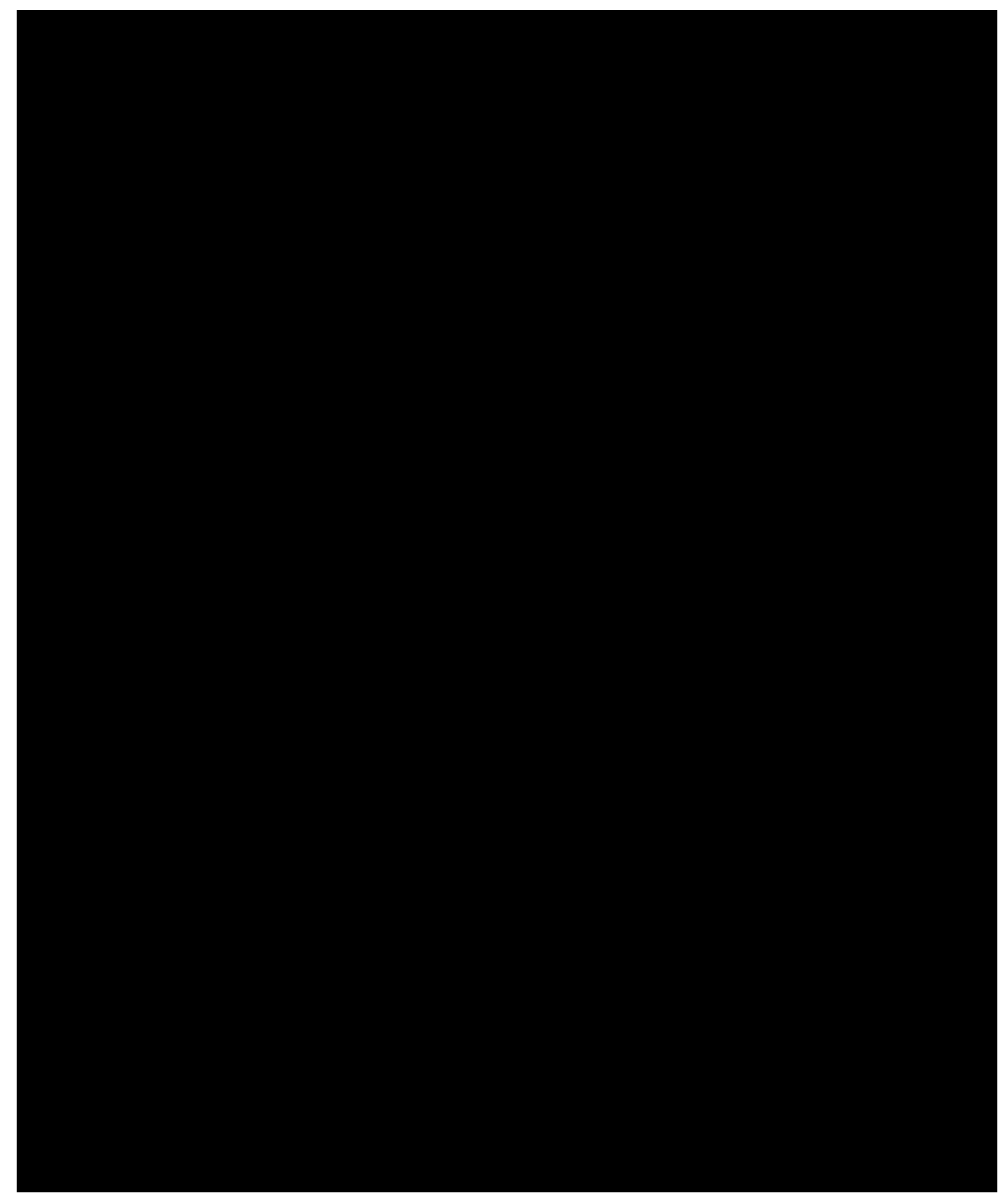

Figure 9: Works involved in the 2018 Waitangi Wharf upgrade. Hanson Point North (orange) and Hanson Point South (purple) are labelled. Figure adapted from New Zealand Department of Internal Affairs, (2016). 


\subsubsection{Sample collection}

Algal, Algal-dwelling amphipod \& Sand hopper samples

Algal samples and their associated amphipod population were collected in waters of approximately $1 \mathrm{~m}$ depth, using a plastic sampling bag. Collection involved capturing the plant in its entirety from the holdfast. This was completed swiftly to limit the number of animals residing on the plant from escaping. This was achieved by turning the bag inside out, holding the base of the plant and capturing the seaweed, while concurrently turning the bag the correct way. Three samples were collected at each sampling site and stored within a portable refrigerator. To maximise sampling during daylight hours, samples were collected from multiple sites throughout the day and rough sorting of all the samples undertaken at the field base at the end of the day. Rough sorting consisted of placing an algae sample into a deep plastic tray and extracting all visible amphipods and animals using plastic tweezers. Each specimen found was placed into a new, clean, $70 \mathrm{ml}$ PPE sample container (pottle). All faunal specimens found from any of the three algal samples from the same locality were pooled together within the same pottle. Once sorted, amphipods were covered with sample water and frozen for preservation purposes. Once the algal samples had been rough sorted and all amphipod specimens removed, the algae were dissected into 4 subsamples using plastic scissors: a section from each of the bottom and top, and two sections from the middle of one blade of algae from every sampling site. Once dissected, these subsamples were placed into a new, clean zip lock bag, labelled, and immediately frozen.

Sand hoppers were also collected at sampling sites where appropriate and time allowed. These samples were taken from beaches adjacent to the marine sampling site. Samples were extracted by digging up the upper layer of beach sediment or moving dried algal that specimens were residing in or grazing on. Sand hoppers were placed into a labelled zip lock bag. These samples were chilled in the field using a portable fridge and then placed into a freezer at the field base.

\section{Sediment \& benthic amphipods}

Two sediment samples were collected in pottles from each sampling site. One each for trace metal analysis, and for grain size, calcium carbonate and total organic matter analyses. This involved scooping benthic marine sediments into a pottle at a locality as close as possible to the other associated marine samples collected at each site. Once 
back at the field base sediment samples were refrigerated. Sediment samples intended for trace metal analyses were refrigerated as studies have demonstrated that freezethawing can cause the mobilization of certain trace metals (Frontin-Rollet, 2017).

Where practicable, an additional three sediment samples were also collected from each sampling site to obtain benthic amphipods. These sediment samples were collected using a scooping apparatus and plastic collection bag along the upper layer of the benthic marine sediment, close to the other samples collected. The samples were refrigerated until rough sorting. Sorting of these sediment samples involved sieving the sediment using plastic sieves and spoons. Amphipods and animals found from all sediment samples from the same locality, were pooled into a single pottle. To aid in preservation, these amphipod specimens were frozen in their sample water.

\section{Water}

One water sample was collected from each sampling site, approximately $0.5 \mathrm{~m}$ from the surface, in $\sim 1 \mathrm{~m}$ depth. Prior to the fieldwork, $125 \mathrm{~mL}$ Nalgene bottles were acid cleaned using ultrapure $6 \mathrm{M} \mathrm{HCl}$ (hydrochloric acid) and ultra-pure water (>18.2 $\mathrm{M} \Omega$; henceforth referred to as deionised water (DI water)). Using a pre acid-cleaned bottle, water samples were collected for trace metal chemistry. The bottles were rinsed with the seawater a minimum of three times before the final sample was collected. Once collected, samples were labelled and immediately chilled in a portable refrigerator and subsequently stored in the refrigerator at the field base.

\section{Sample transportation and storage}

During field work, samples were contained within a portable refrigerator, and then stored in a freezer or fridge, as appropriate, at the field base. While flying between Chatham Island and Wellington, all samples were stored in a portable refrigerator or freezer. This was to ensure that samples were kept chilled or frozen continuously after collection. Once back at Greta Point, NIWA, refrigerated samples were kept in the portable refrigerator while the frozen amphipod samples and sediment samples were placed into the NIWA Invertebrate Collection (NIC) freezer until processing. 


\subsection{Laboratory methods}

\subsubsection{Sediment}

\section{Grain Size}

Laser grain size analysis was conducted in the Sediment Laboratory at Greta Point, NIWA, using a Beckman Coulter LS 13320 Laser Diffraction Particle Size Analyser with an Aqueous Liquid Module. This technique uses the optical properties of different size particles to equate grain size to the diffraction angle of light. Grain size analysis was implemented using one of the refrigerated sediment samples collected from all 11 sampling sites. Each sample was shaken for $10 \mathrm{~s}$ to suspend settled particles, and a $\sim 10 \mathrm{~g}$ representative subsample was removed. Each subsample was individually placed into a $60 \mathrm{~mL}$ polypropylene pottle containing $\sim 45 \mathrm{~mL}$ of washing solution $(1: 4$, $\mathrm{NaHCO}_{3}: \mathrm{NaCO}_{3}$ ). This pottle was then placed in an ultrasonic bath for no longer than 10 seconds. This encouraged the dislodgement and deflocculation of particles without disintegration of individual grains. This solution was subsequently rinsed through a $160 \mu \mathrm{m}$ sieve with DI water into the Aqueous Liquid Module of the grain size analyser. Material $<160 \mu \mathrm{m}$ of each sample was analysed by the Particle Size Analyser for 180 seconds and an auto rinse occurred between each sample until there was no measurable obscuration.

Due to the samples containing coarse grains and the limitation of the Laser Diffraction Particle Size Analyser measuring particles $<160 \mu \mathrm{m}$, an additional representative subsample ( 40g) was extracted from each sample pottle. The purpose of these secondary subsamples was to calculate the portion of each sample that was greater than $160 \mu \mathrm{m}$. This was achieved by drying these subsamples in an individual pie dish overnight at $60^{\circ} \mathrm{C}$. Once dry, a dry bulk weight of each sample was measured and recorded. Dried samples were then individually wet sieved through a $160 \mu \mathrm{m}$ sieve using DI water. Residual grains that were caught on the sieve were rinsed onto a filter paper and dried for an additional 3 hours at $60^{\circ} \mathrm{C}$. Dried residual material $(>1.6 \mu \mathrm{m})$ was weighed. Using the bulk dry weight and dry weight of material $>1.6 \mu \mathrm{m}$ it was possible to back calculate the results from the Particle Size Analyser into a percentage. The percent of material >1.6 was incorporated into the results by representing the $2000 \mu \mathrm{m}$ portion of the associated sample. Data were entered into GRADISTAT (Blott and Pye 
2001; Blott 2010), a particle size analysis software package, and grain size statistics were calculated.

Grain size parameters in GRADISTAT are calculated arithmetically and geometrically (in microns) and logarithmically (using the phi scale) (Krumbein and Pettijohn, 1938; Blott \& Pye, 2001). Linear interpolation is also used to calculate statistical parameters by the Folk and Ward (1957) graphical method (Blott \& Pye, 2001). For the purpose of this research, the Logarithmic Folk and Ward (1957) graphical measures method was deemed the most appropriate to calculate and investigate the standard deviation (sorting) and mean (textural group) of each sample (Table 3). The major advantage of using this method is that it provides the opportunity to convert parameter values to descriptive terms. These describe the sorting (e.g. "very well sorted" - "extremely poorly sorted") and the textural group (e.g. "very coarse sand") of each sediment sample. Also investigated was the percentage of grains falling into each size fraction, modified from the Udden (1914) and Wentworth (1922) grade scales. Mud is defined as having a grain size $<63 \mu \mathrm{m}$, sand defined as having a particle size between $63 \mu \mathrm{m}$ and $<2 \mathrm{~mm}$ and gravel being between $>2 \mathrm{~mm}$ to $64 \mathrm{~mm}$. Sorting of a sample relates to the standard deviation.

Table 3: Folk and Ward (1957) graphical measures method equations

\begin{tabular}{cc} 
Logarithmic Folk and Ward (1957) Graphical Measures & \\
\hline Mean & Standard Deviation \\
\hline$M_{Z}=\frac{\phi_{16}+\phi_{50}+\phi_{84}}{3}$ & $\sigma_{I}=\frac{\phi_{84}-\phi_{16}}{4}+\frac{\phi_{95}-\phi_{5}}{6.6}$
\end{tabular}

\begin{tabular}{llc}
\hline \multicolumn{1}{c}{ Sorting $\left(\sigma_{l}\right)$} \\
\hline & Very well sorted & $<0.35$ \\
Well sorted & $0.35-0.50$ \\
& Moderately well sorted & $0.50-0.70$ \\
& Moderately sorted & $0.70-1.00$ \\
& Poorly sorted & $1.00-2.00$ \\
& Very poorly sorted & $2.00-4.00$ \\
& Extremely poorly sorted & $>4.00$ \\
\hline
\end{tabular}

Calculations used to derive the mean (textural group) and standard deviation (sorting) of each sediment sample. 


\section{Total Organic Matter}

Residual bulk material from each pottle used for grain size analysis was used to calculate total organic matter by loss on ignition. A representative $\sim 5 \mathrm{~g}$ of wet material from each pottle was dried in a tin dish at $60^{\circ} \mathrm{C}$ overnight. The dry weight of each sample was subsequently recorded using a Mettler Toledo AG245 Analytical Balance. Samples were individually powdered using a clean mortar and pestle. Equipment was cleaned using $80 \%$ ethanol and a Kimwipe between each sample to avoid cross contamination. Homogenized samples were combusted at $400^{\circ} \mathrm{C}$ in a muffle furnace for two hours to allow the removal of all volatile substances. They were then removed and cooled in a desiccator. Once cooled, the weight of the residual material was recorded. The wet, dry and post combustion weights of each subsample were used to calculate the percent of total organic matter for each sample (Equation 1). Saltwater from the wet weight is accounted for in these calculations (Equation 1). This process was implemented for both bulk sediment and material that had been sieved to $<1 \mathrm{~mm}$ from all sampling localities.

Equation 1: the equations involved to calculate the percent of total organic matter present in each sample, where: DW - dry weight, WW - wet weight, CW - post combusted weight. 0.0346 accounts for the density of seawater.

$$
\frac{(D W-(W W-D W) * 0.0346)-(C W-(W W-D W) * 0.0346)}{D W-(W W-D W) * 0.0346} * 100
$$

\section{Calcium carbonate analysis}

The calcium carbonate content of each sediment sample was measured using the vacuum gasometric method of Muller and Gastner (1971) and Dunn (1980) at Greta Point, NIWA. This carbonate bomb method quantifies the calcium carbonate content of the sediment by comparing the pressure in the bomb under vacuum before and after acid is introduced to the sample.

Residual material from grain size and total organic matter processing was wet sieved to $<1 \mathrm{~mm}$ and analysed for calcium carbonate. One teaspoon of wet material $(<1 \mathrm{~mm})$ from 
each sampling site was placed into a tin foil dish and dried overnight at $60^{\circ} \mathrm{C}$. Dried material was ground using a ceramic mortar and pestle. Ground samples and two standards $\left(\mathrm{CaCO}_{3}\right)$ were dried in an oven at $110^{\circ} \mathrm{C}$ for $\sim 2$ hours. Once dried, samples were stored in a desiccator until weighing. Approximately $0.333 \mathrm{~g}$ of powdered sample was weighed out onto paper and transferred into a carbonate bomb, ensuring no material fell into the arm of the bomb. This was repeated for every sample and both standards. Five drops of DI water were added to each sample, this minimized the sediment from puffing when acid was introduced. $5 \mathrm{~mL}$ of concentrated $70 \% \mathrm{H}_{3} \mathrm{PO}_{4}$ was added to the side arm of each bomb via a syringe. Ambient room temperature readings were recorded before, during and after processing. Greased O-rings and a lid were placed on each bomb. The bomb lid and body were secured with a clamp and the bomb was then attached to the carbonate line. The bomb lid was then opened to give the pressure inside the vessel, and the pressure recorded. The vacuumed cylinder (of which the volume is known) was then opened and this second pressure also recorded. The volume of the bomb could then be calculated using Equation 2.

Equation 2: The volume of the bomb used in the calcium carbonate analysis. V1 - initial volume, V2 - final volume, P1 - initial pressure, P2 - final pressure.

$$
V 1=\frac{P 2 * V 2}{(P 1-P 2)}
$$

The bomb was then pumped out to remove the air and create a vacuum and the pressure was recorded. The $\mathrm{H}_{3} \mathrm{PO}_{4}$ in the arm of the bomb was introduced to the sediment, and any carbonate in the sample reacted and form $\mathrm{CO}_{2}$, which thus, changed the pressure in the bomb. The samples were left for 90 minutes to ensure all $\mathrm{CaCO}_{3}$ in the sample had reacted. The bomb was then reattached to the carbonate line and the final pressure was recorded.

By using and rearranging the ideal gas law $(\mathrm{PV}=\mathrm{nRT})$ the amount of $\mathrm{CaCO}_{3}$ in the sample can be determined. The rearranged equation which was used is detailed below (Equation 3). 
Equation 3: Calculation to find the amount of $\mathrm{CaCO}_{3}$ in a sediment sample. $\mathrm{P} 3$ is the pressure of the bomb after the $\mathrm{H}_{3} \mathrm{PO}_{4}$ was added, $\mathrm{R}$ - ideal gas constant equal to $8.314 \mathrm{~J} / \mathrm{mol}, \mathrm{n}$ - the number of moles of $\mathrm{CO}_{2}, \mathrm{~T}-$ the average temperature (in Celsius) measured throughout the experiment.

$$
n=\frac{P 3-(P 2-P 1) *\left(\frac{V 1}{1000}\right)}{R * T}
$$

The mass of $\mathrm{CaCO}_{3}$ was then calculated using equation 4 .

Equation 4: Calculation to find the mass of $\mathrm{CaCO}_{3}, \mathrm{n}$ - mass, and $\mathrm{M}$ - molar mass of $\mathrm{CaCO}_{3}$.

$$
\boldsymbol{m}=\frac{\boldsymbol{n}}{\boldsymbol{M}}
$$

The percentage of $\mathrm{CaCO}_{3}$ could then be calculated by dividing the mass of $\mathrm{CaCO}_{3}$ by the initial sample weight added to the bomb. The accuracy and precision of these results were found to of high value, with the pure $\mathrm{CaCO}_{3}$ standard reporting a final reading of $98.6 \%$ and $100.8 \% \mathrm{CaCO}_{3}$.

\section{Trace metal geochemistry processing}

All reused equipment (i.e. beakers) and bench space used in pre-chemistry processing were cleaned before and between samples using kimwipes and 80\% ethanol and 3 rinses using DI water. New, single-use equipment was not pre-cleaned. All processing was undertaken on a piece of cling film which was replaced between each sample. Transfer pipettes were rinsed with DI water 3 times before use. All beakers and pottles were labelled throughout the entire process to ensure samples were identifiable at all stages. 


\section{Sieving}

In the geochemistry laboratory at Greta Point, NIWA, one of the refrigerated sediment samples collected in pottles from each sampling site were sampled for trace metal chemistry processing. This required pre-cleaning 500ml glass beakers. Sediment samples were individually wet sieved using a clean $1 \mathrm{~mm}$ plastic meshed sieve and DI water. Material $<1 \mathrm{~mm}$ was sieved into the glass beaker while the larger portion $(>1 \mathrm{~mm})$ of the sample caught on the plastic mesh was rinsed into a pottle. This $1 \mathrm{~mm}$ threshold was selected with the guidance of the grainsize distribution obtained from the grain size analysis previously discussed. Sieved samples allow for more direct comparisons of the chemical composition of the sediments across sites. A mesh size of $1 \mathrm{~mm}$ represents the boundary between coarse and very coarse sand according to the Udden (1914) and Wentworth (1922) grade scales and was selected as it ensured there was enough material in the smaller fraction to be analysed for all sampling sites. Furthermore, this fraction is more likely to represent the sediment that amphipods are associated with and could be consuming, as well as being more likely to interact (bio)geochemically with the environment than very coarse sand to gravels.

Once sieved, samples were left to rest until all particles had settled. While settling, parafilm was placed over the beakers and pottles were capped to prevent airborne contamination. Once all particles had settled the supernatant water was pipetted off the top of each sample and discarded. Using a transfer pipette was more precise than pouring to remove the supernatant and ensured none of the sample material was removed or suspended during this decanting process. Both portions of the sieved sediment samples were dried at $60^{\circ} \mathrm{C}$ for $\sim$ three days. Once dried, the smaller portion of the sieved sample $(<1 \mathrm{~mm})$ was transferred from the glass beaker into a pottle and all samples were stored in a desiccator until further processing.

\section{Powdering}

The dry $<1 \mathrm{~mm}$ material to be analysed for trace elements was homogenised into a powder using a small agate ring mill at the Victoria Univeristy of Wellington (VUW) Rock Crushing facility. Equipment was cleaned before and between each sample using compressed air, ethanol and kimwipes. To minimise cross contamination, pure silica 
sand was run through the agate mill between samples. Once powdered, samples were transferred into pottles and labelled, ready for chemical processing.

\section{Dissolution}

All reagents used for processing trace metal samples (sediment, amphipod and algae) and for beaker cleaning were Optimaтм ultra-trace element grade or equivalent, unless stated otherwise. Savillex ${ }^{\circledR}$ Teflon screw-top beakers (22 mL vials) used to process trace metal samples were cleaned between each use. This involved wiping each beaker with ethanol and rinsing three times with DI water. Analar grade $\mathrm{HCl}(50 \%)$ was added to each beaker to reflux at $120{ }^{\circ} \mathrm{C}$ for $>24$ hours. After refluxing, beakers were submerged in 50\% concentration Analar grade $\mathrm{HCl}$, sub-boiled for $>24$ hours on a hotplate at $120^{\circ} \mathrm{C}$, then rinsed three times with DI water. Beakers were then submerging in $50 \%$ concentration Analar nitric acid $\left(\mathrm{HNO}_{3}\right)$ for $>24$ hours at $120^{\circ} \mathrm{C}$. The beakers were then rinsed once with DI, then submerged in DI water in a $3 \mathrm{~L}$ glass beaker with a watch glass and placed onto a hotplate at $250^{\circ} \mathrm{C}$ until the water boiled. The glass beaker was then left to cool, the DI was replaced, and the step was repeated an additional two times. Beakers were transferred to the ultra-clean laboratory in Geochemistry Laboratory at the School of Geography, Environment and Earth Sciences, VUW. Approximately 2-3 $\mathrm{mL}$ of $6 \mathrm{M} \mathrm{HNO}_{3}$ was added to each of the Savillex beakers, which were capped and placed on a hotplate set at $120{ }^{\circ} \mathrm{C}$ for $>24$ hours. Each beaker was then rinsed three times with DI water, and this step repeated using DI water. Lastly, the rinsed Savillex beakers were air-dried in a laminar flow hood. New $15 \mathrm{~mL}$ centrifuge tube (c-tubes) and $100 \mathrm{~mL}$ Nalgene bottles were pre-cleaned by filling with dilute $\mathrm{HNO}_{3}$ and leaving to soak for 24 hours longer. Post soaking, the tubes and bottles were rinsed three times with DI water and air-dried in a laminar flow hood. All laboratory work was conducted on a cleaned surface lined with cling film. All pipette tips used in chemistry processing were rinsed with DI water before use and changed between each sample.

For each sediment an aliquot ( $80 \mathrm{mg})$ of powder was weighed into a cleaned Savillex ${ }^{\circledR}$ teflon beaker. Because of the high and variable carbonate content, $200 \mu \mathrm{L}$ of MQ was added to wet each sample, followed by $200 \mu \mathrm{L}$ of $7 \mathrm{M} \mathrm{HNO}_{3}$, and samples were left to react at room temperature. Low carbonate samples experiencing little reaction were placed on a hotplate at $60^{\circ} \mathrm{C}$ to evaporate. Other samples that had significant 
effervescence had an additional $7 \mathrm{M} \mathrm{HNO} 3$ added to them at room temperature to ensure full reaction of carbonate. Once the reactions had subdued these samples were also placed on the hotplate and the temperature was increased in $10{ }^{\circ} \mathrm{C}$ increments to $90^{\circ} \mathrm{C}$. Once all traces of $\mathrm{HNO}_{3}$ had evaporated the samples were left to cool. Once cooled, $100 \mu \mathrm{L}$ of concentrated $\mathrm{HNO}_{3}$ followed by $1 \mathrm{ml}$ of hydrofluoric acid (HF) was added to all samples. Beakers were capped and placed on a hotplate at $100^{\circ} \mathrm{C}$ for three days. Samples were removed from the hotplate, cooled and then placed back onto the hotplate with caps removed until evaporated to incipient dryness. The HF step is required for dissolving the sediment as silicate-based particles are not dissolved using $\mathrm{HNO}_{3}$ (Wiltsche \& Knapp, 2014). Once evaporated, $200 \mu \mathrm{L}$ of HNO3 was added to each sample and this evaporated on a hotplate at $120^{\circ} \mathrm{C}$ to ensure all traces of $\mathrm{HF}$ were removed. Once all traces of $\mathrm{HNO}_{3}$ had evaporated, $\sim 2 \mathrm{~mL}$ of $6 \mathrm{M} \mathrm{HCl}$ was added to samples, the beakers were capped and samples were left on a hotplate at $110^{\circ} \mathrm{C}$ overnight. Once cooled, samples were visually inspected to ensure they were fully in solution. For some samples, fine grains remained visible and likely represent accessory minerals that are resistant to dissolution by low pressure $\mathrm{HF}_{-} \mathrm{HNO}_{3}$ acid attack (e.g. zircon). Beaker caps were removed and the $\mathrm{HCl}$ was evaporated from the samples at $100^{\circ} \mathrm{C} . \mathrm{HNO}_{3}$ was again added to samples, evaporated and repeated, to ensure all traces of $\mathrm{HCl}$ were removed from the samples.

Samples were then ready to be brought up into dilute $\mathrm{HNO}_{3}$ for trace element analysis. Dilution involved adding $3 \mathrm{M} \mathrm{HNO}_{3}$ to each sample and refluxing overnight at $110^{\circ} \mathrm{C}$. The sample solution was then quantitatively transferred via a pipette into a pre-cleaned and weighed $15 \mathrm{~mL}$ c-tube. An internal standard of indium (In) was pipetted into the solution. Due to some samples not being entirely in solution, samples were centrifuged at this stage at $3000 \mathrm{rpm}$ for 10 minutes. A weighed aliquot of the solution was then pipetted into a pre-cleaned $100 \mathrm{ml}$ Nalgene bottle. $3 \% \mathrm{HNO}_{3}$ was added to each solution to reach a target dilution factor of $\sim 70,000$ times. $10 \mathrm{~mL}$ of this diluted solution was transferred from the bottle into a c-tube, which was spun down via centrifuge before being analysed. The weight of the solution was recorded at each step. The amount of acid, internal standard and aliquot of sample added at each step was calculated for each sample based on the dry weight of the sample, the acid molarity and the target dilution factor. To evaluate accuracy and reproducibility, duplicates of two samples, procedural blank(s), and standard reference materials (SRMs) were processed concurrently, 
following the same trace element geochemistry method. The SRMs used for the sediment samples were from the Geological Survey of Japan (JA-2) and the United States Geological Survey (BHVO-2). BHVO-2 is basaltic material from the Kilauea volcano, Hawaii, United States of America (Jochum et al., 2016) and was used for analysis calibration. JA-2 is andesitic rock sourced from Goshikidai sanukitoid, Sakaide, Kanagawa prefecture, Japan (Jochum et al., 2016), and was used as a secondary standard to evaluate accuracy of the method.

\subsubsection{Amphipod and Algae}

Trace metal geochemistry - pre-chemistry processing

As for the processing of sediment samples, all reused equipment (i.e. tweezers) and bench space used in pre-chemistry processing was cleaned before and between samples using kimwipes and $80 \%$ ethanol and 3 rinses using DI water. New equipment such as vials were not pre-cleaned. All processing was undertaken on a piece of cling film which was replaced between each sample. Transfer pipettes were rinsed with DI water 3 times before use.

\section{Cleaning}

All amphipod samples that were collected and rough sorted in field were removed from the NIC freezer, thawed and subsequently identified down to species level by Dr. Rachael Peart. Amphipods were pooled by species and location, and then prioritised based on their abundance and collection locality. Algal samples were identified to the lowest taxonomic rank possible by Dr Roberta D'Archino using infield sample images. Prioritised amphipod samples and all algal samples were cleaned and dried under clean conditions in the Geochemistry Laboratory at Greta Point, NIWA. Samples were cleaned by transferring each sample into a polypropylene beaker. The sample was then submerged in DI water and the beaker containing the sample and DI water was capped and placed into an ultrasonic bath for $10 \mathrm{~s}$. This ensured the specimens were cleaned of loose material without removing gut contents. Water and any residual material were removed and disposed of using a transfer pipette. This cleaning step was repeated three times for every sample to ensure sediment or other possible contaminants were removed. Cleaned samples were dried in an oven at $60^{\circ} \mathrm{C}$ for either $\sim 2$ hours 
(amphipods) or $\sim 20$ hours (algae). Dried samples were stored in a desiccator until weighing.

\section{Weighing and pooling}

Each amphipod was weighed separately on a Mettler Toledo MT5 7 d.p. microbalance and stored individually. For each sample, a new weigh boat was tared on the microbalance and the specimen was transferred onto the weigh boat. Once the Faraday cage was closed, for consistency, the final weight was recorded at 1 minute. One midsection of dried algae from each site was subsampled to $\sim 40-50 \mathrm{mg}$ and weighed using a Mettler Toledo AG245 5 d.p. analytical balance.

In order to have enough material for analysis, multiple individual amphipods were pooled into single samples. One to 25 individuals, depending on weight, were pooled into samples for analysis. Amphipods of the same species from the same locality were systematically pooled based on the individual weights of each amphipod. This allowed the range of weights of individuals within each sample to be minimized, and to group specimens so that there were samples of comparably sized individuals from each location. Where there were large numbers of individuals from single locations, this pooling of samples into specific weight ranges also allowed for comparison between different sized specimens of the same species from the same locality. This was done so as to test previous studies that noted that some amphipod species exhibit an exponential increase in elemental concentrations with decreasing size (Rainbow \& Moore, 1986). Further, by ensuring the pooling of specimen sizes was comparable between samples of the same species from different localities, this enabled confident comparisons across sites if a size effect was found to be present. Once individually weighed and appropriately pooled, samples were stored in a desiccator until further chemistry processing.

\section{Dissolution}

Cleaned, dried and weighed algae and pooled amphipod samples were transferred to the ultra-clean facility at VUW. Amphipod and algal samples were transferred from their vials into individual Savillex ${ }^{\circledR}$ Teflon beakers with the aid of a clean pipette tip and DI water. 
Samples were dissolved using Optimatm ultra-trace metal grade acids. This dissolution process involved adding $\sim 9$ drops of hydrogen peroxide $\left(\mathrm{H}_{2} \mathrm{O}_{2}\right)$ to each sample until fully wetted. Beakers were left open at room temperature in laminar flow hoods until any reactions had subsided. Uncapped beakers were then heated on a hotplate at $70^{\circ} \mathrm{C}$. The temperature was increased by 10 degree increments approximately every 30 minutes up to $110^{\circ} \mathrm{C}$. The temperature increase was undertaken incrementally to ensure any reactions were controlled. Once all traces of $\mathrm{H}_{2} \mathrm{O}_{2}$ had evaporated from the samples they were removed from the hotplate and left to cool. Once cooled, $\sim 0.5 \mathrm{~mL}$ of conc $\mathrm{HNO}_{3}$ was added to each sample and as before left at room temperature until any reaction had subsided, then heated incrementally on a hotplate beginning at $70^{\circ} \mathrm{C}$ until reaching $110^{\circ} \mathrm{C}$. Once the $\mathrm{HNO}_{3}$ had completely evaporated the samples were removed from the hotplate to cool. Approximately $200 \mu \mathrm{L}$ of concentrated $\mathrm{HNO}_{3}$ was added to each sample and evaporated at $110^{\circ} \mathrm{C}$. Once all traces of $\mathrm{HNO}_{3}$ had evaporated $\sim 0.5 \mathrm{~mL}$ of $6 \mathrm{M} \mathrm{HCl}$ was added to samples, beakers were capped and samples were left overnight on a hotplate at $110^{\circ} \mathrm{C}$. After cooling, the caps were removed and the $\mathrm{HCl}$ was evaporated from the samples at $100^{\circ} \mathrm{C} . \mathrm{HNO}_{3}$ was added a third time to the samples, evaporated and repeated, to ensure all traces of $\mathrm{HCl}$ had been removed.

Dissolved algal and amphipod samples were brought up into dilute $\mathrm{HNO}_{3}$ for analysis, such that the final solution represented a dilution of $\sim 3000$ times. The dilution processes were comparable to that for the sediment samples and involved adding $3 \mathrm{M} \mathrm{HNO}_{3}$ to each sample and refluxing overnight at $110^{\circ} \mathrm{C}$. The sample solution was then transferred via a pipette into a pre-cleaned and weighed $15 \mathrm{~mL}$ c-tube and an internal standard (In) was added into the algal samples. Samples were centrifuged. A weighed aliquot of this solution was then pipetted into a new c-tube and $3 \% \mathrm{HNO}_{3}$ added to each solution to reach the target dilution factor of 3000 .

Duplicates of four algae samples, procedural blank(s) and SRMs were concurrently processed with these samples following the previously described method. The SRM used was from the Canadian National Research Council, DOLT-5 (dogfish liver). There are no SRM that are direct equivalents to the sample matrices for amphipod samples (tissue and exoskeleton) and this standard reference material was used as the best available equivalent. The final solutions of the samples, SRM and procedural blank(s) were centrifuged immediately prior to be being analysed. 


\subsubsection{ICP-MS analysis and data processing}

Sediment, amphipod and algal samples were analysed for trace element concentrations using a Thermo Fisher Scientific Element 2 sector-field Inductively Coupled Plasma Mass Spectrometer (ICP-MS) in the Geochemistry Laboratory at the School of Geography, Environment and Earth Sciences, VUW. An ESI autosampler probe was used to take up the sample solution, with a $200 \mu \mathrm{L} / \mathrm{min}$ glass nebuliser and cinnabar spray chamber used to introduce the solution to the ICP-MS. A four-minute wash-out using 3\% $\mathrm{HNO}_{3}$ was undertaken between each solution analysis. Instrument background levels were measured every $\sim 4$ analyses throughout the analytical sequence by analysing $3 \% \mathrm{HNO}_{3}$ solution.

The ICP-MS was tuned to provide optimum signal intensity balanced with signal stability and low oxide generation. Forty-one element masses were routinely analysed for sediment samples and 35 for amphipod and algal samples, using three different resolution modes (low, medium, high) (Table 4). These resolutions are used to avoid spectral interferences that may be caused by isotopes of different elements or molecules with the same mass. Data were obtained as raw CPS for each mass. For the sediment analyses BHVO-2 was used to calibrate data and to account for any instrumental drift during the analytical sequence. In-house multi-element standards synthesised from certified individual element solutions were used to calibrate the amphipod and algae analyses. Additional SRMs (e.g. JA-2, DOLT-5) were analysed as secondary standards and run every $\sim 9$ analyses. These additional SRMs were used evaluate the accuracy and precision of the data. Where possible, sample duplicates were also analysed (i.e. algae and sediment samples).

The CPS data obtained from the ICP-MS were processed off-line in MS Excel worksheets. Data processing involved: subtracting instrument background levels (measured by $3 \% \mathrm{HNO}_{3}$ analyses) from the sample and standard CPS data; conversion of CPS to ppb concentrations in sample solutions using the SRM or in-house calibration data; and then conversion to parts per million (ppm) on a dry weight basis for each sample using the dilution factors calculated from the sample and solution weights. 
Table 4: Element masses measured on the ICP-MS in low, medium, and high resolution for amphipod, algal and sediment samples.

\begin{tabular}{|c|c|c|}
\hline Sample type & Amphipod \& Algae & Sediment \\
\hline $\begin{array}{l}\text { Low mass } \\
\text { resolution } \\
(\sim 300)\end{array}$ & 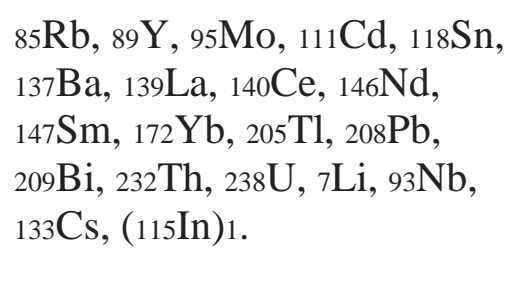 & 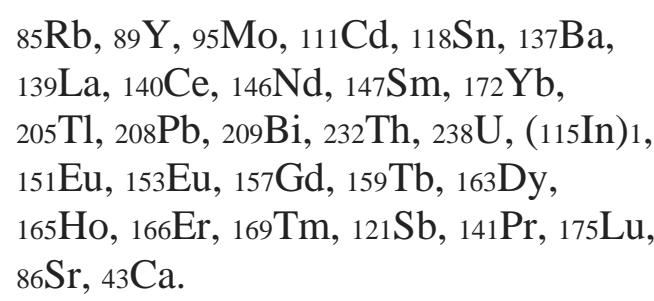 \\
\hline $\begin{array}{l}\text { Medium } \\
\text { Mass } \\
\text { resolution } \\
(\sim 4000)\end{array}$ & $\begin{array}{l}86 \mathrm{Sr},{ }_{43} \mathrm{Ca},{ }_{45} \mathrm{Sc},{ }_{47} \mathrm{Ti},{ }_{51} \mathrm{~V} \\
52 \mathrm{Cr}, 55 \mathrm{Mn},{ }_{59} \mathrm{Co},{ }_{60} \mathrm{Ni},{ }_{63} \mathrm{Cu} \text {, } \\
66 \mathrm{Zn},{ }_{69} \mathrm{Ga},{ }_{83} \mathrm{Kr} .\end{array}$ & $\begin{array}{l}{ }_{43} \mathrm{Ca},{ }_{45} \mathrm{Sc},{ }_{47} \mathrm{Ti},{ }_{51} \mathrm{~V},{ }_{52} \mathrm{Cr},{ }_{55} \mathrm{Mn},{ }_{59} \mathrm{Co} \text {, } \\
60 \mathrm{Ni},{ }_{63} \mathrm{Cu},{ }_{66} \mathrm{Zn},{ }_{24} \mathrm{Mg},{ }_{27} \mathrm{Al},{ }_{56} \mathrm{Fe} .\end{array}$ \\
\hline $\begin{array}{l}\text { High mass } \\
\text { resolution } \\
(>9500)\end{array}$ & ${ }_{25} \mathrm{Mg}, 27 \mathrm{Al}, 56 \mathrm{Fe},{ }_{75} \mathrm{As}$ & 75As. \\
\hline
\end{tabular}

IIn was added to the sediment and algal samples as an internal standard.

Thirty-five trace elements for amphipod and algal samples and 41 trace elements for sediments were measured, however not all the elements were reliably quantifiable in all samples. Analyses of the procedural blanks were used to evaluate which trace elements were at quantifiable levels and secondary standards (SRMs) to evaluate analytical accuracy.

Broadly, if the procedural blank signal was $\leq 5 \%$ of the sample signal these elements were considered quantifiable. In instances where the procedural blank was $\geq 5 \%$ of the sample signal, the uncertainty in reliable blank subtraction was considered too large, and these element data are not reported. Using this 5\% threshold allows confidence with interpreting elements with low concentrations. For most elements, the procedural blank signal was typically $\leq 1 \%$ for most samples. The SRM used as secondary standard for amphipod and algal samples: DOLT-5 (dogfish liver) (Appendix A). It should be noted that this standard is not a perfect matrix match to the amphipods (e.g. significantly lower calcium $(\mathrm{Ca})$ as it does not include exoskeleton components); it is only certified for a limited range of elements; and the values are certified for sample aliquots of 250 $\mathrm{mg}$ or larger, whereas only $\sim 50 \mathrm{mg}$ of material was used in the method here. 
Nonetheless, aside from $\mathrm{Ca}$ and $\mathrm{Al}$ where concentrations in the SRMs are several orders of magnitude lower than in the amphipods, accuracy was well within $10 \%$ for all elements.

Of the 35 elements measured for algae and amphipod samples, only Tin (Sn), Thallium (Tl), Bismuth (Bi) and Gallium (Ga) had consistently low signals and/or high procedural blank signals ( $>5 \%$ of sample signal) and were considered unquantifiable, with the addition of Lead $(\mathrm{Pb})$ for Bellorchestia chathamensis, and Molybdenum (Mo) for two algal species (Champia sp. and Gigartina clavifera (Agardh, 1876)). These elements are not considered further for their sample type.

For the sediment samples, JA-2 was used to evaluate accuracy. As with the organic SRMs, most elements were within $10 \%$ of certified values (Appendix A)

\subsubsection{Water samples}

Water samples were acidified in the Geochemistry Laboratory at Greta Point, NIWA, by adding $1 \mathrm{~mL}$ of high purity 3M HCL for every $100 \mathrm{~mL}$ of sample. Samples were kept refrigerated both before and after acidification to encourage trace elements to stay in solution and prevent precipitation and adsorption to bottle walls. Water sample analyses were undertaken by the Centre for Trace Element Analysis, Chemistry Department, University of Otago, Dunedin. Acidified water samples were filtered, buffered and then desalinised and preconcentrated by passing through resin-exchange chemistry via an automated Elemental Scientific SeaFAST sample introduction system. Trace element concentrations were measured using an Agilent $7500 \mathrm{cs} / \mathrm{ce}$ Quadrupole ICP-MS.

Calibration curves were determined using synthetic multi-element solutions. An inhouse seawater standard analysed was used to evaluate analytical precision, and a standard reference material, NASS-7 (Seawater) from the Canadian National Research Centre, was used to evaluate accuracy (Appendix A). Most metals were within 1-10\% of certified values, with $\mathrm{Cd}$ within $17 \%$ (Appendix A).

\subsection{Data analysis and software}

Statistical analysis of the amphipod trace element concentration data was undertaken. However, given the small samples sizes, interpretation of the statistical analysis should be taken with caution. Samples sizes range from 1-4 for any given sample type and location. A power analysis was run on appropriate data using $\mathrm{G}^{*}$ Power. This analysis 
computes the sample number required to run a t-test using the means and standard deviations of two groups (Faul 2009). A t-test was conducted in IBM SPSS Statistics 25 where there were enough samples. T-tests were used to determine whether a size effect was present in the trace element concentrations of the amphipod specimens. Since not all elements met the requirements for a t-test, a linear regression and exponential regression were also investigated for sites with at least four samples. This also allowed a more nuanced investigation of potential size effects for Aora sp. 1 where one location had four different size fractions analysed. Linear and exponential regressions of the data were conducted using Microsoft Excel $2016 \AA$ to examine the relationship between the average dry weights and trace metal concentration for each element. 


\section{RESULTS}

\subsection{Samples}

Sampling of amphipod, algal, seawater, and sediment was undertaken at 11 sites. However, due to the nature of some sampling sites and time limitations, not all sample types were attained at every locality. In addition, the amphipod species diversity and abundance varied significantly at different sites (Table 5). Eighteen amphipod species were identified, and four of these species were selected as the focus for this research as they were the most abundant across the sampling sites (Table 5). These species were three algal-dwelling amphipods - Apohyale sp. 1, Aora sp. 1 and Eusiroides sp. 1. A secondary species of interest was the sand hopper species - Bellorchestia chathamensis, which was selected to investigate different amphipod habitats. The sampling sites investigated in detail were selected based on the presence and abundance of these species. Cape Pattisson and Hanson Point South were selected as two of the five primary sites as all three algal-dwelling species of interest were present, with enough numbers to analyse. Kaingaroa West, Port Hutt and Owenga had two of the three algaldwelling species of interest, Apohyale sp. 1 and Aora sp. 1. In addition to these five primary sites, Kaingaroa East, Kaingaroa South and Waitangi Bay were also selected as secondary sites based on the presence of Bellorchestia chathamensis (Table 5). Water and sediment samples were collected from all sampling sites, however macroalgae samples were obtained from only nine of the sites due to the absence of algae at Kaingaroa South and Rangatira (Table 6). The variety of samples collected were analysed depending on availability and site (Table 5, Table 6). 
Table 5: Amphipod species abundance and habitat

\begin{tabular}{|c|c|c|c|c|c|c|c|c|c|c|c|c|}
\hline Species & Habitat & 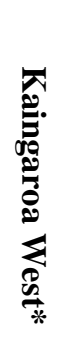 & 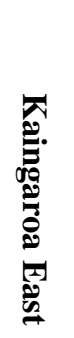 & 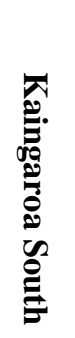 & 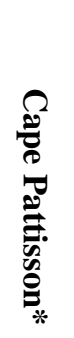 & $\begin{array}{l}\underset{0}{\Xi} \\
\underset{*}{\Xi}\end{array}$ & 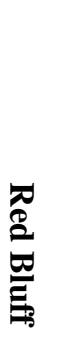 & 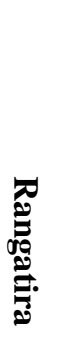 & 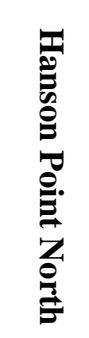 & 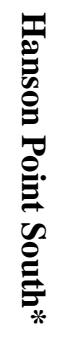 & 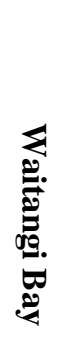 & 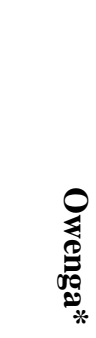 \\
\hline Ampithoe sp. 1 & Algal & & & & & & & & 2 & & & \\
\hline Aora sp. 1* & Algal & 46 & & & 15 & 18 & 6 & & 60 & 25 & 17 & $>15$ \\
\hline Apohyale sp. $1^{*}$ & Algal & 25 & & & 22 & 28 & 80 & & 80 & 26 & 60 & $>10$ \\
\hline $\begin{array}{l}\text { Bellorchestia } \\
\text { chathamensis * }\end{array}$ & Sand hopper & & 32 & 50 & & & & & & & 33 & \\
\hline Bellorchestia sp. 2 & Sand hopper & & & & & & & & & & & 2 \\
\hline Bircenna sp. 1 & Algal & & & & & 2 & & & & & 6 & \\
\hline Caprellina sp. 1 & Algal & & & & & 1 & 4 & & 4 & & 2 & 3 \\
\hline Eusiroides sp. 1 & Algal & & & & 35 & 14 & 25 & & 8 & 25 & 21 & \\
\hline Eusiroides sp. 2 & Algal & 4 & & & 1 & & & & 6 & & & \\
\hline Parawaldeckia sp. 1 & Epibenthic* & 7 & & & & 5 & 2 & & 42 & 1 & & many \\
\hline Podocerus sp. 1 & Algal & 2 & & & 7 & 8 & & & 1 & & & \\
\hline Stenothoe sp. 1 & Algal & 2 & & & 2 & & & & 2 & & & 5 \\
\hline Sunamphitoe sp. 1 & Algal & 18 & & & 3 & & & & & & & 10 \\
\hline Talorchestia sp. 1 & Sand hopper & & & & & & & 15 & & & & \\
\hline Amphilochidae spp. & Algal & & & & 3 & 1 & 1 & & 3 & & & \\
\hline Amphipoda & N/A & & & & & 7 & & & 2 & & & \\
\hline Ischyroceridae spp. & Epibenthic & 53 & & & 21 & 20 & 15 & & 115 & 15 & 6 & \\
\hline Melitidae sp 1 & Algal & 4 & & & 1 & & & & 1 & & & 2 \\
\hline
\end{tabular}


Table 6: Samples analysed for trace metal chemistry.

\begin{tabular}{|c|c|c|c|c|}
\hline & \multicolumn{3}{|c|}{ Trace metal chemistry } & \multirow{2}{*}{$\begin{array}{l}\text { Grainsize, } \mathrm{TOC}_{1} \\
\text { \& calcium } \\
\text { carbonate } \\
\text { Sediment } 2\end{array}$} \\
\hline Site & Amphipod2 & Algal & $\begin{array}{l}\text { Water/ } \\
\text { Sediment2 }\end{array}$ & \\
\hline $\begin{array}{l}\text { Kaingaroa } \\
\text { West }\end{array}$ & $\begin{array}{l}\text { Apohyale sp. } 1 \text { (x2) } \\
\text { Aora sp. } 1\end{array}$ & $\begin{array}{l}\text { Cystophora scalaris } \\
(2 \mathrm{x} \text { mid })\end{array}$ & $\begin{array}{l}\text { Water } \\
\text { Sediment }\end{array}$ & Sediment \\
\hline $\begin{array}{l}\text { Kaingaroa } \\
\text { East }\end{array}$ & $\begin{array}{l}\text { Bellorchestia } \\
\text { chathamensis }(\mathrm{x} 2)\end{array}$ & $\begin{array}{l}\text { Cystophora scalaris } \\
\text { (brown) } \\
\text { (1x mid) }\end{array}$ & $\begin{array}{l}\text { Water } \\
\text { Sediment }\end{array}$ & Sediment \\
\hline $\begin{array}{l}\text { Kaingaroa } \\
\text { South }\end{array}$ & $\begin{array}{l}\text { Bellorchestia } \\
\text { chathamensis }(\mathrm{x} 4)\end{array}$ & & $\begin{array}{l}\text { Water } \\
\text { Sediment }\end{array}$ & Sediment \\
\hline $\begin{array}{l}\text { Cape } \\
\text { Pattisson }\end{array}$ & $\begin{array}{l}\text { Apohyale sp. } 1 \text { (x2) } \\
\text { Aora sp. } 1 \\
\text { Eusiroides sp. } 1\end{array}$ & $\begin{array}{l}\text { Cystophora scalaris } \\
(2 \mathrm{x} \text { mid })\end{array}$ & $\begin{array}{l}\text { Water } \\
\text { Sediment } \\
(\mathrm{x} 2)\end{array}$ & Sediment \\
\hline Port Hutt & $\begin{array}{l}\text { Apohyale sp. } 1 \\
\text { Aora sp. } 1\end{array}$ & $\begin{array}{l}\text { Carpophyllum plumosum } \\
\text { (2x mid) }\end{array}$ & $\begin{array}{l}\text { Water } \\
\text { Sediment }\end{array}$ & Sediment \\
\hline Rangatira & - & & Water & Sediment \\
\hline Red Bluff & - & $\begin{array}{l}\text { Gigartina clavifera }(\mathrm{red}) \\
(1 \mathrm{x} \text { mid) }\end{array}$ & Water & Sediment \\
\hline $\begin{array}{l}\text { Hanson } \\
\text { Point North }\end{array}$ & - & $\begin{array}{l}\text { Champia (red) } \\
\text { (1x mid) }\end{array}$ & Water & Sediment \\
\hline $\begin{array}{l}\text { Hanson } \\
\text { Point South }\end{array}$ & $\begin{array}{l}\text { Apohyale sp. } 1 \\
\text { Aora sp. } 1(\mathrm{x} 4) \\
\text { Eusiroides sp. } 1 \\
\end{array}$ & $\begin{array}{l}\text { Carpophyllum } \mathrm{sp} . \\
(2 \mathrm{x} \text { mid) }\end{array}$ & $\begin{array}{l}\text { Water } \\
\text { Sediment } \\
(\mathrm{x} 2)\end{array}$ & Sediment \\
\hline $\begin{array}{l}\text { Waitangi } \\
\text { Bay }\end{array}$ & $\begin{array}{l}\text { Bellorchestia } \\
\text { chathamensis }\end{array}$ & $\begin{array}{l}\text { Carpophyllum } \\
\text { maschalocarpum (brown) } \\
(1 \mathrm{x} \text { mid) }\end{array}$ & $\begin{array}{l}\text { Water } \\
\text { Sediment }\end{array}$ & Sediment \\
\hline Owenga & $\begin{array}{l}\text { Apohyale sp. } 1 \\
\text { Aora sp. } 1\end{array}$ & $\begin{array}{l}\text { Cystophora scalaris } \\
(1 \mathrm{x} \text { mid })\end{array}$ & $\begin{array}{l}\text { Water } \\
\text { Sediment }\end{array}$ & Sediment \\
\hline
\end{tabular}

1Total organic matter

${ }_{2}$ Samples analysed, $\mathrm{n}=1$, unless stated otherwise.

\subsection{Amphipods}

\subsubsection{Sample pooling}

As previously discussed, amphipod samples were pooled by location based on the weight of individual specimen (Table 6; Figure 10; Appendix B). Apohyale sp. 1 specimens were pooled according to size into three groups, with average specimen weights of $<0.2 \mathrm{mg}, \sim 0.4 \mathrm{mg}$ and $\sim 0.8 \mathrm{mg}$ (Figure 10). There were enough specimens of Aora sp. 1 identified from Hanson Point South to group these into four size fractions with specimen weights of $<0.2,0.2-0.3,0.5-0.7$ or $0.8-1 \mathrm{mg}$ (Figure 10). To facilitate direct comparison between sites if a size effect was found, larger specimens of Aora sp. 
$1(>0.5)$, with mean sizes of $(0.6-1 \mathrm{mg})$, were pooled for the remaining four sites (Figure 10). Eusiroides sp. 1 were limited in numbers compared with Aora sp. 1 and Apohyale sp. 1, and were pooled into single samples from Cape Pattisson and Hanson Point South, with mean weights of 0.28 and $0.42 \mathrm{mg}$ (Figure 10). The sand hopper species, B. chathamensis, was larger than the marine amphipods and did not require pooling of multiple specimens. Therefore, one entire specimen was used for a single analysis. Bellorchestia chathamensis samples were split into two weight classes 6.5-8.5 mg and 16-19 mg (Table 7).

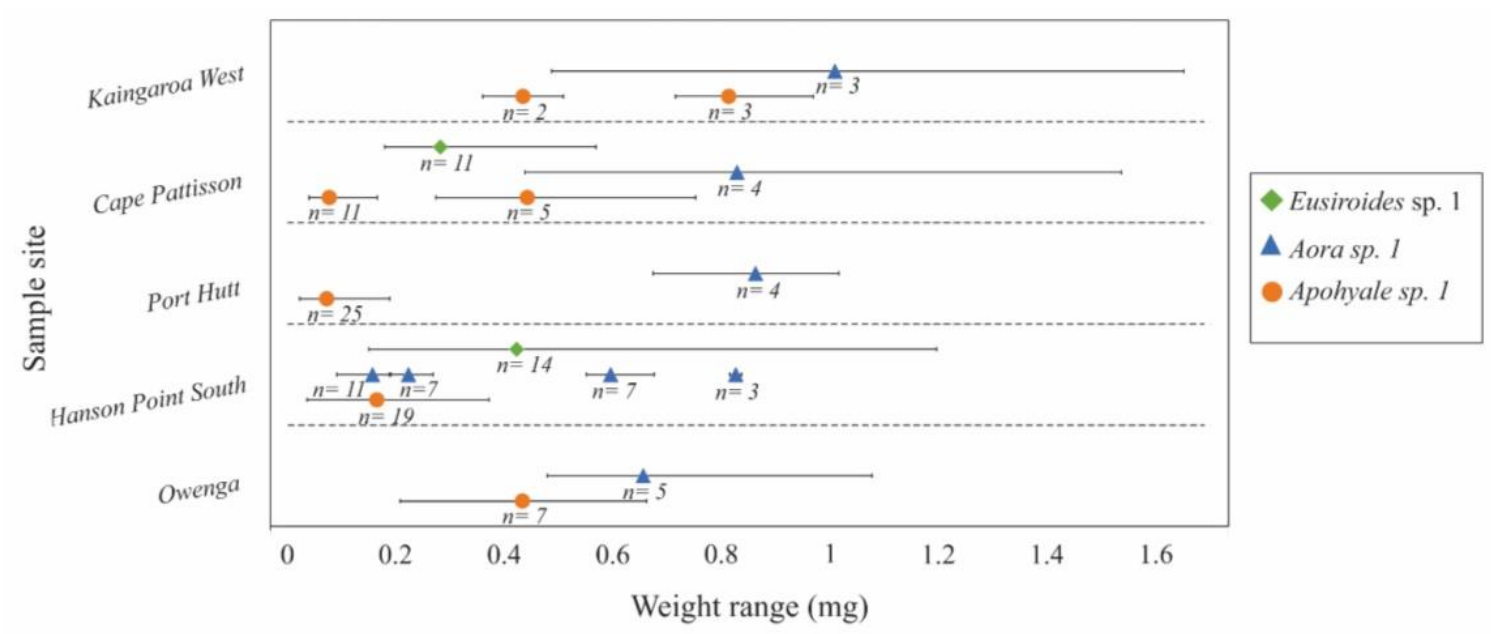

Figure 10: Weight range of algal-dwelling amphipods. Points represent the average weight of each sample while error bars represent the range of weights. Sample numbers of each sample represented by $n=x$.

Table 7: Weight of sand hopper specimens analysed for trace metal chemistry.

\begin{tabular}{lll} 
Location & Weight class & \\
\hline & $\mathbf{6 . 5 - 8 . 5 ~} \mathbf{m g}$ & $\mathbf{1 6 - 1 9} \mathbf{~ m g}$ \\
\hline Kaingaroa East & 8.16 & 18.24 \\
Kaingaroa South & 8.22 & 18.92 \\
Kaingaroa South & 8.23 & 16.49 \\
Waitangi Bay & 6.97 & \\
& & \\
\hline
\end{tabular}




\subsubsection{Trace element data}

Calcium (Ca), Magnesium (Mg) and Strontium (Sr) are the most concentrated elements present in all amphipod species analysed from all sites (Figure 11). Whilst concentrations of many of the trace metals overlap between different locations for each species, there are some systematic differences.

Apohyale sp. 1 (Figure 11a)

Hanson Point South samples have the largest number of elevated trace elements in Apohyale sp. 1, with the following elements having the highest concentration at this location: Lithium (Li), Niobium (Nb), Lanthanum (La), Cerium (Ce), Neodymium (Nd), Samarium (Sm), Ytterbium (Yb), Thorium (Th), Scandium (Sc), Titanium (Ti), Vanadium (V), Chromium (Cr), Manganese (Mn), Co (Cobalt), Nickle (Ni), Copper $(\mathrm{Cu})$, Gallium $(\mathrm{Ga})$, Aluminium $(\mathrm{Al})$ and Iron $(\mathrm{Fe})$. This is equivalent to over half (19/31) of the elements investigated. Notably, Mn, Al, Ti, Cu, Fe, Ce, Co and Ni are 3 to 9 times higher in concentration at Hanson Point South than at all other sites. Cadmium (Cd) levels are elevated at Kaingaroa West and Cape Pattisson by at least 17 times, relative to Port Hutt, Hanson Point South and Owenga. Arsenic (As) is elevated at Owenga, 3 times higher than all other sites.

Aora sp. 1 (Figure 11b)

The four samples of Aora sp. 1 from Hanson Point South represent four different sized specimens (Figure 10). These four samples and the Owenga sample all have similar trace element patterns and, for most elements have higher elemental concentrations than Kaingaroa West, Cape Pattisson and Port Hutt. Similar to Apohyale sp. 1, Aora sp. 1 from Hanson Point South has the highest values for many of the elements investigated including: Li, Rubidium (Rb), Yttrium (Y), Molybdenum (Mo), Barium (Ba), Caesium (Cs), La, Ce, Nd, Sm, Yb, Th, Ca, Sc, Ti, V, Mn, Co, No, Cu, Zinc (Zn), Ga, Sr, Al, Fe. By contrast, $\mathrm{Cd}$ is elevated by at least a factor of 30 at Kaingaroa West and Cape Pattisson relative to Port Hutt, Hanson Point South and Owenga. Arsenic and Cr concentrations are also elevated at Owenga, relative to the other sites. 
Eusiroides sp. 1 (Figure 11c)

Eusiroides sp. 1 only had sufficient numbers for analyses from two of the primary sites. As with Aora sp. 1 and Apohyale sp. 1, the Hanson Point South sample was elevated in most trace elements relative to Cape Pattison with the notable exception of $\mathrm{Cd}$, which is 17 times lower at Hanson Point South, and to a lesser extent, $\mathrm{Pb}$.

Bellorchestia chathamensis (Figure 11d)

Both Kaingaroa sites (East and South) follow a similar pattern of concentrations across all elements investigated. The following element are highest in B. chathamensis from Waitangi Bay; Ca, Sr, Al, Fe, Barium (Ba), Mn, Ti, U, Ce, Y, La, Nb, Nd, Ga, Sc, Th, $\mathrm{Sm}$ and $\mathrm{Yb}$. 

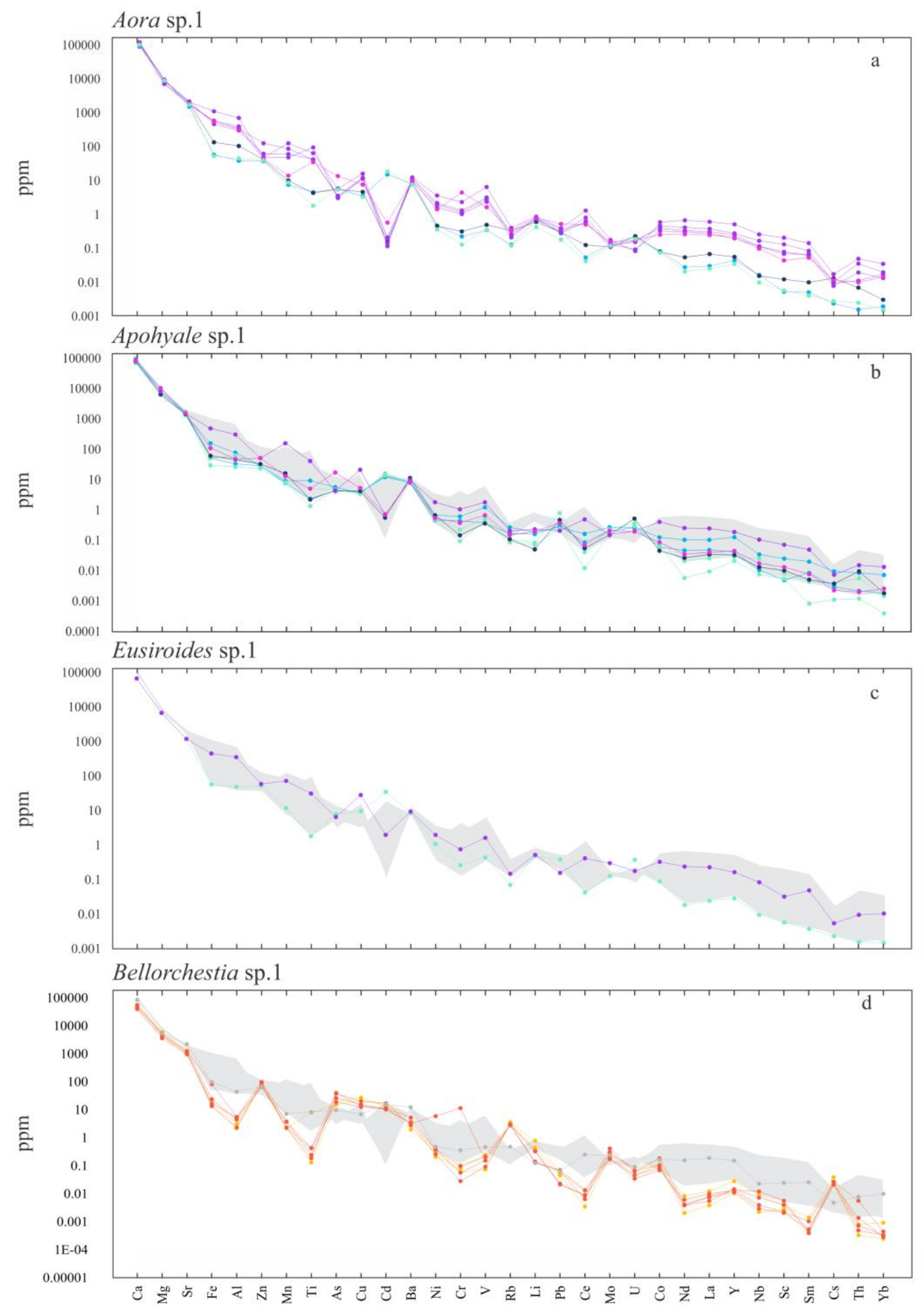

Priority sites

- Kaingaroa West $\rightarrow$ Cape Pattisson $\rightarrow$ Port hutt
- Hanson Point South $\rightarrow$ Owenga

Secondary sites

$\rightarrow$ Kaingaroa East $\rightarrow$ Kaingaroa East

- Waitangi Bay

Figure 11: The trace element data for all four amphipod species. Trace element concentrations ordered according to decreasing average concentration. (a) Aora sp. 1 (5 sites) (b) Apohyale sp. 1 (5 sites) (c) Eusiroides sp. 1 (2 sites) (d) Bellorchestia chathamensis (secondary sites). The Aora sp. 1 field is transposed onto the following graphs for comparison (grey shading). 


\subsubsection{Statistical analysis of amphipods}

T-test

Only two sampling localities had more than two amphipod weight delineated groups analysed: Aora sp. 1 from Hanson Point South and B. chathamensis from Kaingaroa South. At these two locations four samples were analysed representing at least two different weight pools. Aora sp. 1 samples from Hanson Point South had four weight delineated groups. In order to perform statistical tests such as a t-test, these four weight groups were combined to form two: Group one comprised two samples with average weights of $<0.3 \mathrm{mg}$ and Group two comprised two samples with average weights between $0.5-1 \mathrm{mg}$. B. chathamensis samples from Kaingaroa South had two samples in a 6.5-8.5 mg weight class and two in a 16-19 mg weight class.

Mean comparisons, such as t-tests, typically require a minimum sample size of $n=3$ per group. A larger data set is usually required as it increases power and decreases estimation error. Due to the small sample sizes in this project, a power analysis was used to calculate the sample size required to implement a t-test on individual elements between the two size classes, for both Aora sp. 1 from Hanson Point South and $B$. chathamensis from Kaingaroa South (Table 8). Using the power analysis results, a two tailed, unpaired t-test at the $95 \%$ confidence interval was run on elements that had sufficient samples (Table 8). A t-test was used to investigate whether a size effect was present between these two weight classes. The majority of the P-values, excluding $\mathrm{Sr}$ and $\mathrm{Mn}$ for B. chathamensis and $\mathrm{Pb}$ and Uranium (U) for Aora sp. 1, were statistically insignificant $(<0.05)$ (Table 8$)$. 
Chapter 3 - Results

Table 8: Power analysis1 and t-tests on different weight classes of Aora sp. 1 and Bellorchestia chathamensis

\begin{tabular}{|c|c|c|c|c|c|c|c|c|}
\hline & \multicolumn{4}{|c|}{$\begin{array}{l}\text { Aora sp. 1; Hanson Point South } \\
(n=4)\end{array}$} & \multicolumn{4}{|c|}{$\begin{array}{l}\text { Bellorchestia chathamensis; Kaingaroa } \\
\text { South }(n=4)\end{array}$} \\
\hline & $\begin{array}{l}\text { Sample } \\
\text { size } \\
\text { group 1 }\end{array}$ & $\begin{array}{l}\text { Sample } \\
\text { size } \\
\text { group } 2\end{array}$ & $\begin{array}{l}\text { Total } \\
\text { sample } \\
\text { size } \\
\text { required }\end{array}$ & $\begin{array}{l}\mathrm{P}- \\
\text { value }\end{array}$ & $\begin{array}{l}\text { Sample } \\
\text { size } \\
\text { group 1 }\end{array}$ & $\begin{array}{l}\text { Sample } \\
\text { size } \\
\text { group 2 }\end{array}$ & $\begin{array}{l}\text { Total } \\
\text { sample } \\
\text { size } \\
\text { required }\end{array}$ & $\mathrm{P}$ value \\
\hline Ca & 6 & 6 & 12 & & 3 & 3 & 6 & \\
\hline Mg & 3 & 3 & 6 & & 3 & 3 & 6 & \\
\hline $\mathbf{S r}$ & 3 & 3 & 6 & & 2 & 2 & 4 & 0.0439 \\
\hline Al & 2 & 2 & 4 & 0.5769 & 2 & 2 & 4 & 0.5122 \\
\hline $\mathrm{Fe}$ & 2 & 2 & 4 & 0.5629 & - & & & 0.3212 \\
\hline Zn & - & & & 0.4870 & 1043 & 1043 & 2086 & \\
\hline Cd & 74 & 74 & 148 & & 2 & 2 & 4 & 0.5008 \\
\hline Ba & 22 & 22 & 44 & & 2 & 2 & 4 & 0.4400 \\
\hline Mn & - & & & 0.1280 & - & & & 0.0011 \\
\hline Ti & 2 & 2 & 4 & 0.6377 & 6 & 6 & 12 & \\
\hline As & 2 & 2 & 4 & 0.3079 & 3 & 3 & 6 & \\
\hline $\mathrm{Cu}$ & 2 & 2 & 4 & 0.3367 & 2 & 2 & 4 & 0.6868 \\
\hline $\mathbf{P b}$ & - & & & 0.0425 & 22 & 22 & 44 & \\
\hline $\mathbf{N i}$ & 2 & 2 & 4 & 0.6537 & - & & & 0.4141 \\
\hline V & 2 & 2 & 4 & 0.5637 & - & & & 0.3106 \\
\hline $\mathbf{U}$ & - & & & 0.0202 & - & & & 0.0590 \\
\hline Mo & 2 & 2 & 4 & 0.3264 & - & & & 0.0894 \\
\hline $\mathrm{Cr}$ & 2 & 2 & 4 & 0.5763 & - & & & 0.4188 \\
\hline $\mathbf{R b}$ & 2 & 2 & 4 & 0.6539 & 32 & 32 & 64 & \\
\hline $\mathbf{L i}$ & 3 & 3 & 6 & & 9 & 9 & 18 & \\
\hline Co & 3 & 3 & 6 & & - & & & 0.2459 \\
\hline $\mathrm{Ce}$ & 2 & 2 & 4 & 0.6272 & 2 & 2 & 4 & 0.3519 \\
\hline Y & - & & & 0.6143 & 3 & 3 & 6 & \\
\hline La & 2 & 2 & 4 & 0.6221 & 3 & 3 & 6 & \\
\hline Nb & 2 & 2 & 4 & 0.6122 & 2 & 2 & 4 & 0.1332 \\
\hline Nd & 2 & 2 & 4 & 0.6059 & 6 & 6 & 12 & \\
\hline Sc & 2 & 2 & 4 & 0.7929 & 8 & 8 & 16 & \\
\hline Th & 2 & 2 & 4 & 0.4376 & 2 & 2 & 4 & 0.3080 \\
\hline Sm & 2 & 2 & 4 & 0.9593 & 14 & 14 & 28 & \\
\hline Cs & 2 & 2 & 4 & 0.4403 & 259 & 259 & 518 & \\
\hline $\mathbf{Y b}$ & 3 & 3 & 6 & & 115 & 115 & 230 & \\
\hline
\end{tabular}

${ }_{1}$ Power analyses were calculated for a two-tailed t-test using a medium (0.05) error probability, 0.80 power and allocation ratio of 1 . The effect size was calculated using the mean of each element from each weight class and an average of their standard deviation. - are element where the size effect was not calculated because the effect size being outside the admissible range. 


\section{Regression analyses}

Due to the low sample sizes, a t-test was not viable to run on all elements investigated.

Consequently, a R2 value, using a Pearson correlation, for both linear and exponential relationships between element concentrations and averaged dry weights was also investigated. As with the t-tests performed, these $\mathrm{R}_{2}$ value were used to aid in determining whether there is a relationship between element concentrations and specimen weight (Table 9; Figure 12). Due to the small sample size ( $n=4)$ these $R_{2}$ values must be used with caution (Table 9).

Table 9: Linear and exponential relationships between average weights and element concentrations (ppm).

\begin{tabular}{|c|c|c|c|c|c|c|}
\hline & \multicolumn{3}{|c|}{$\begin{array}{l}\text { Aora sp. 1; Hanson Point South } \\
(n=4)\end{array}$} & \multicolumn{3}{|c|}{$\begin{array}{l}\text { Bellorchestia chathamensis; Kaingaroa South } \\
(\mathrm{n}=4)\end{array}$} \\
\hline & $\begin{array}{l}\text { R2 value } \\
\text { (linear) }\end{array}$ & Linear line equation & $\begin{array}{l}\text { R2 value } \\
\text { (exponential) }\end{array}$ & $\begin{array}{l}\text { R2 value } \\
\text { (linear) }\end{array}$ & Linear line equation & $\begin{array}{l}\text { R2 value } \\
\text { (exponential) }\end{array}$ \\
\hline $\mathbf{C a}$ & 0.8616 & $y=29877 x+97115$ & 0.8469 & 0.9586 & $y=-1349.8 x+67026$ & 0.9402 \\
\hline $\mathrm{Mg}$ & 0.7289 & $y=2410 x+6929.7$ & 0.7424 & 0.7835 & $y=-117.76 x+6063$ & 0.7828 \\
\hline $\mathrm{Sr}$ & 0.819 & $y=646.78 x+1648.8$ & 0.8283 & 0.9465 & $y=-21.582 x+1374.8$ & 0.9548 \\
\hline Al & 0.4363 & $y=385.57 x+265.93$ & 0.3517 & 0.1115 & $y=-0.0876 x+5.5384$ & 0.1276 \\
\hline $\mathbf{F e}$ & 0.4595 & $y=633.5 x+393.27$ & 0.3773 & 0.4366 & $y=-3.8897 x+84.764$ & 0.5577 \\
\hline $\mathbf{Z n}$ & 0.2146 & $y=-54.95 x+96.281$ & 0.2055 & 0.0058 & $y=-0.2088 x+85.395$ & 0.0009 \\
\hline Cd & 0.1288 & $y=-0.0502 x+0.1881$ & 0.1738 & 0.1145 & $y=0.1969 x+9.7409$ & 0.0997 \\
\hline Ba & 0.0108 & $y=0.403 x+10.968$ & 0.0046 & 0.2469 & $y=-0.0982 x+5.0123$ & 0.2307 \\
\hline Mn & 0.8331 & $y=-99.809 x+125.66$ & 0.9167 & 0.9684 & $y=-0.1468 x+4.9359$ & 0.9698 \\
\hline $\mathbf{T i}$ & 0.3223 & $y=45.192 x+40.627$ & 0.2472 & $8 \mathrm{E}-05$ & $y=-0.0002 x+0.3232$ & 0.0025 \\
\hline As & 0.5515 & $y=-2.9951 x+5.2872$ & 0.6056 & 0.1679 & $y=-0.7371 x+40.374$ & 0.2091 \\
\hline $\mathbf{C u}$ & 0.5226 & $y=-4.9191 x+15.031$ & 0.5461 & 0.0212 & $y=0.0886 x+14.435$ & 0.0088 \\
\hline $\mathbf{P b}$ & 0.9561 & $y=0.1625 x+0.2592$ & 0.9451 & 0.0224 & $y=0.0007 x+0.036$ & 0.0144 \\
\hline $\mathbf{N i}$ & 0.3564 & $y=1.6923 x+1.5816$ & 0.2566 & 0.3283 & $y=-0.2893 x+5.4941$ & 0.3558 \\
\hline $\mathbf{V}$ & 0.4569 & $y=4.0094 x+1.9261$ & 0.3593 & 0.3401 & $y=-0.005 x+0.2178$ & 0.313 \\
\hline $\mathbf{U}$ & 0.8873 & $y=-0.1335 x+0.1863$ & 0.9206 & 0.9658 & $y=-0.0026 x+0.0861$ & 0.9442 \\
\hline Mo & 0.6571 & $y=0.0706 x+0.1058$ & 0.6435 & 0.7773 & $y=-0.0176 x+0.4997$ & 0.8206 \\
\hline $\mathrm{Cr}$ & 0.4377 & $\mathrm{y}=1.2321 \mathrm{x}+0.9061$ & 0.3569 & 0.326 & $y=-0.5849 x+10.495$ & 0.4418 \\
\hline $\mathbf{R b}$ & 0.3711 & $y=0.1591 x+0.2101$ & 0.2942 & 0.0031 & $y=0.001 x+2.8832$ & 0.0023 \\
\hline $\mathbf{L i}$ & 0.8445 & $y=0.1593 x+0.713$ & 0.8515 & 0.0358 & $y=-0.0039 x+0.2833$ & 0.0436 \\
\hline Co & 0.1944 & $y=0.1573 x+0.3725$ & 0.129 & 0.582 & $y=-0.007 x+0.2004$ & 0.6837 \\
\hline $\mathrm{Ce}$ & 0.3641 & $y=0.6473 x+0.5354$ & 0.2723 & 0.574 & $y=0.0004 x+0.0041$ & 0.5686 \\
\hline $\mathbf{Y}$ & 0.3991 & $\mathrm{y}=0.281 \mathrm{x}+0.183$ & 0.2906 & 0.4038 & $y=-0.0002 x+0.0152$ & 0.3884 \\
\hline $\mathbf{L a}$ & 0.3769 & $y=0.2898 x+0.2634$ & 0.2902 & 0.4801 & $y=0.0002 x+0.0048$ & 0.4617 \\
\hline $\mathrm{Nb}$ & 0.3576 & $y=0.1292 x+0.1061$ & 0.2795 & 0.6967 & $y=-0.0006 x+0.0147$ & 0.7597 \\
\hline Nd & 0.3911 & $y=0.3331 x+0.281$ & 0.3069 & 0.4293 & $y=0.0001 x+0.0028$ & 0.4093 \\
\hline Sc & 0.3348 & $y=0.1153 x+0.0697$ & 0.2553 & 0.8068 & $y=-0.0003 x+0.007$ & 0.8604 \\
\hline Th & 0.2715 & $y=0.0281 x+0.0163$ & 0.2297 & 0.4544 & $y=-0.0003 x+0.0058$ & 0.6217 \\
\hline Sm & 0.4034 & $y=0.0741 x+0.056$ & 0.3163 & 0.5904 & $y=4 E-05 x+0.0001$ & 0.6102 \\
\hline $\mathrm{Cs}$ & 0.3754 & $y=0.0081 x+0.0076$ & 0.2821 & 0.0219 & $y=9 E-05 x+0.0228$ & 0.0242 \\
\hline $\mathbf{Y b}$ & 0.3568 & $y=0.0178 x+0.0133$ & 0.2397 & 0.0886 & $y=-4 E-06 x+0.0004$ & 0.0573 \\
\hline
\end{tabular}

Red values are considered strong relationships ( $\mathrm{R}_{2}$ values $\left.>0.7\right)$.

Blue values are considered moderate relationships $\left(\mathrm{R}_{2}\right.$ values $\left.>0.5-<0.7\right)$.

Black values are weak relationships $\left(\mathrm{R}_{2}\right.$ values $\left.<0.5\right)$ and/or positive relationships.

Grey are negative relationships. 

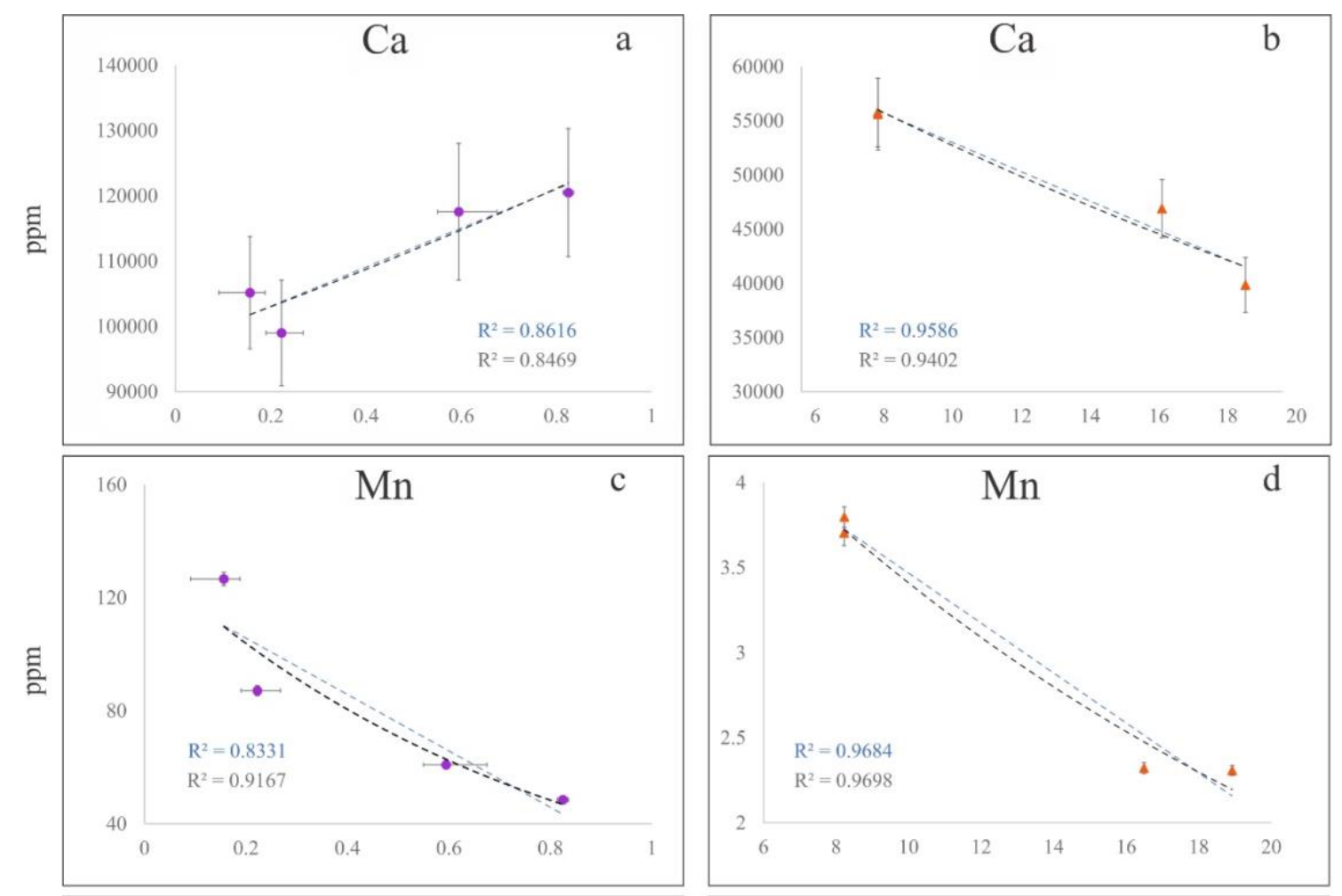

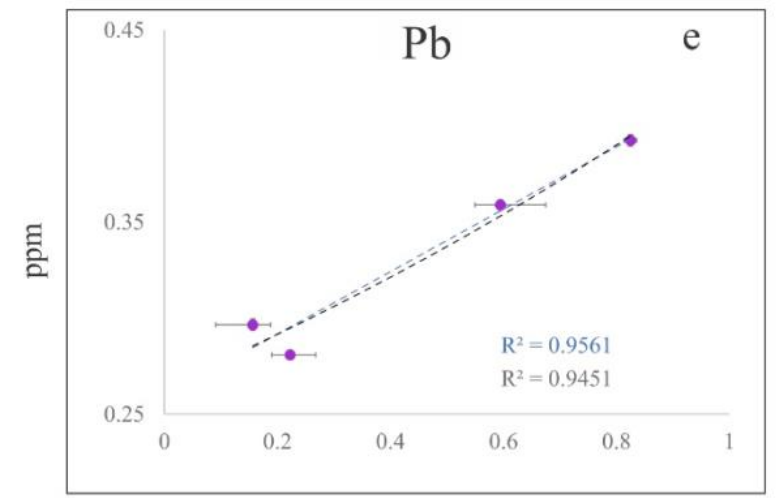

Weight range (mg)

- Aora sp.1 (Hanson Point South)

A Bellorchestia sp.1 (Kaingaroa South)

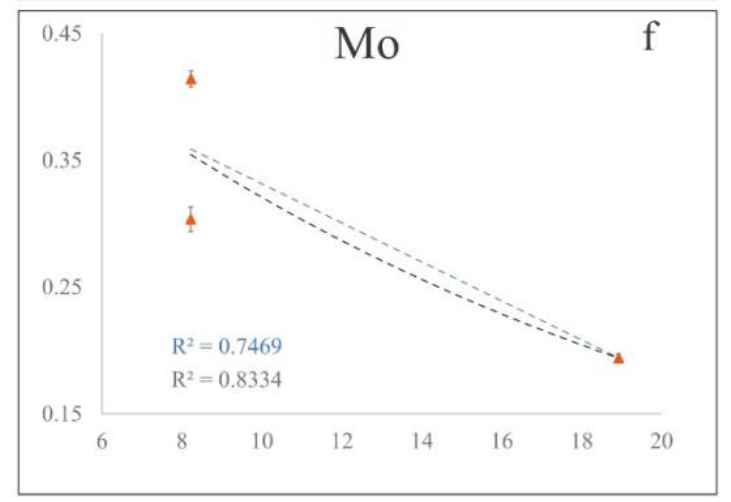

Weight range (mg)

Figure 12: Elements (showing the strongest size-concentration correlations for their species) vs average specimen dry weight (a) Ca of Aora sp. 1 from Hanson Point South. (b) Ca for $B$. chathamensis from Kaingaroa South. (c) Mn Aora sp. 1 from Hanson Point South. (d) Mn for $B$. chathamensis from Kaingaroa South. (e) Pb for Aora sp. 1 from Hanson Point South. (f) Mo for B. chathamensis from Kaingaroa South. 


\subsubsection{Interspecific variations of amphipod species}

The relative uptake of metals varies between different species. Eusiroides sp. 1 samples consistently have highest element concentrations, relative to the other two algaldwelling amphipods from the same site (Figure 13). The sensitivity of Aora sp. 1 and Apohyale sp. 1 are comparable to each other, and element concentrations in the sand hoppers have generally comparable values to the algal-dwelling amphipods (Figure 13).
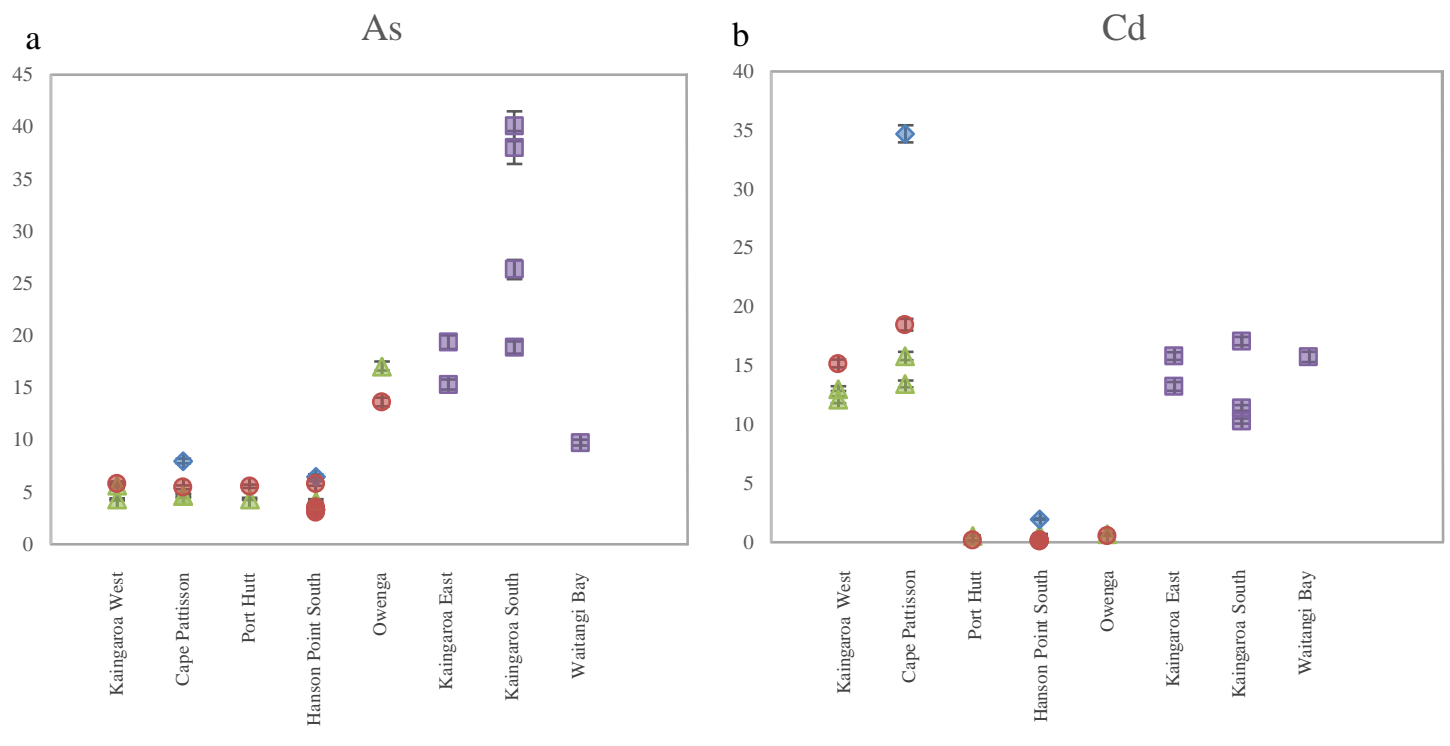

$\Delta$ Apohyale $\bullet$ Eusiroides $\bullet$ Aora $\square$ Bellorchestia

$\triangle$ Apohyale $\diamond$ Eusiroides $\bullet$ Aora $\square$ Bellorchestia
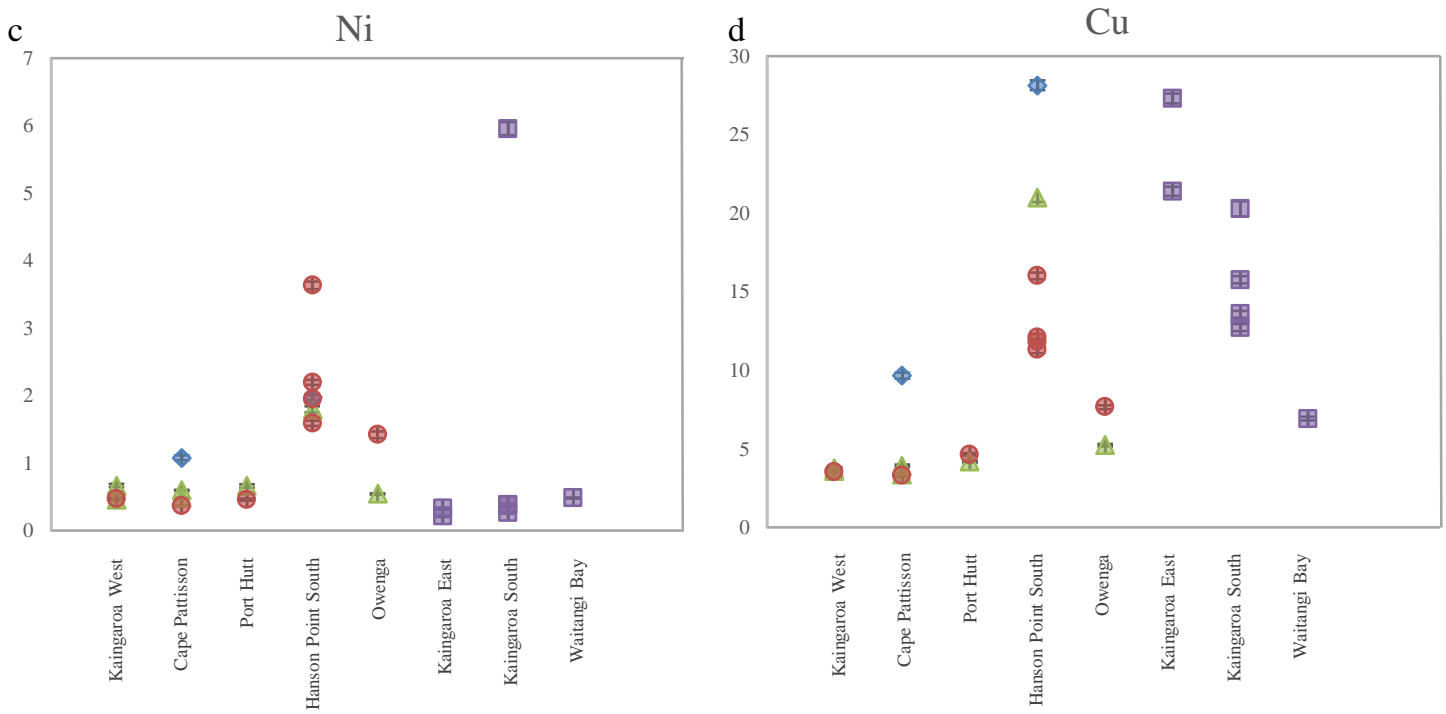

$\triangle$ Apohyale $\diamond$ Eusiroides $\bullet$ Aora $\square$ Bellorchestia

$\triangle$ Apohyale $\bullet$ Eusiroides $\bullet$ Aora $\square$ Bellorchestia

Figure 13: Concentration of select elements by amphipod species across the five priority sites and three secondary sites. (a) As concentrations (b) Cd concentrations (c) Ni concentrations (d) $\mathrm{Cu}$ concentrations. 


\subsection{Algae}

\subsubsection{Trace element data}

Studies have demonstrated that, like amphipods, the bioaccumulation of metals in algae is species-specific (Escobar et al., 2010). Consequently, inter-site variations should be made intraspecifically. Algae that were unable to be identified down to a species taxonomic rank will be compared across the same genus.

Cystophora scalaris (Agardh, 1870) (Figure 14a)

Of the four Cystophora scalaris samples (collected from Kaingaroa West, Kaingaroa East, Cape Pattisson and Owenga), Owenga consistently has the highest concentration for most elements, including; Fe, Al, Ti, Zn, Co, Cu, V, Cr, Li, Ce, Y, Nd, La, Sc, Nb, $\mathrm{Sm}$ and $\mathrm{Th}$. Of these elements, $\mathrm{Al}, \mathrm{Ti}, \mathrm{Cu}$ and $\mathrm{Nb}$ all have strikingly elevated concentrations relative to not only the other three $C$. scalaris but all algal samples. For many elements, Kaingaroa East consistently has the lowest values out of four sites. Notably, $\mathrm{Al}$, $\mathrm{Ti}$ and $\mathrm{Ce}$ are the lowest and $\mathrm{Cu}$ is the only element that Kaingaroa East has the highest concentration. Kaingaroa West and Cape Pattisson follow a very similar trend for all elements, with Kaingaroa West consistently having slightly lower values. Cadmium at both Cape Pattisson and Kaingaroa West have strikingly high values in relation not just to the other $C$. scalaris samples but to all algal species sampled. Little variation in As is observed for the C. scalaris samples (Figure 14).

\section{Carpophyllum sp. (Figure 14b)}

Carpophyllum sp. was analysed for three sites. One of these samples, collected from Hanson Point South, was identified to genus level. This sample is comparable to the other two Carpophyllum species analysed from Waitangi Bay and Port Hutt, which have been identified to a species taxonomic rank (Carpophyllum plumosum at Port Hutt and Carpophyllum maschalocarpum at Waitangi Bay). Consequently, the algae from these three sites can only be compared to each other with caution. Cobalt and $\mathrm{Cd}$ concentrations are considerably lower in algae from Hanson Point South in relation to Waitangi Bay and Port Hutt. Hanson Point South has higher concentrations of Ti compared to Waitangi Bay. Excluding the variations of $\mathrm{Co}, \mathrm{Cd}$ and $\mathrm{Ti}$ between Hanson Point South and Waitangi Bay, little variation is observed for the other elements measured. Port Hutt consistently has the highest concentration of most trace elements in 
relation to Hanson Point South, including; $\mathrm{Ca}, \mathrm{Mg}, \mathrm{Sr}, \mathrm{Fe}, \mathrm{Al}, \mathrm{As}, \mathrm{Ba}, \mathrm{Zn}, \mathrm{Co}, \mathrm{V}, \mathrm{Ni}$, Cr, Cd, U, Mo, Li, Ce, Pb, Y, Nd, La, Sc, Nb, Sm, Th, Cs, Yb. Hanson Point South has the highest values for $\mathrm{Mn}, \mathrm{Ti}, \mathrm{Rb}$, and $\mathrm{Cu}$. Of these elements, striking variations are observed for $\mathrm{Ni}, \mathrm{Cd}, \mathrm{U}$ and $\mathrm{Pb}$. 
Chapter 3 - Results
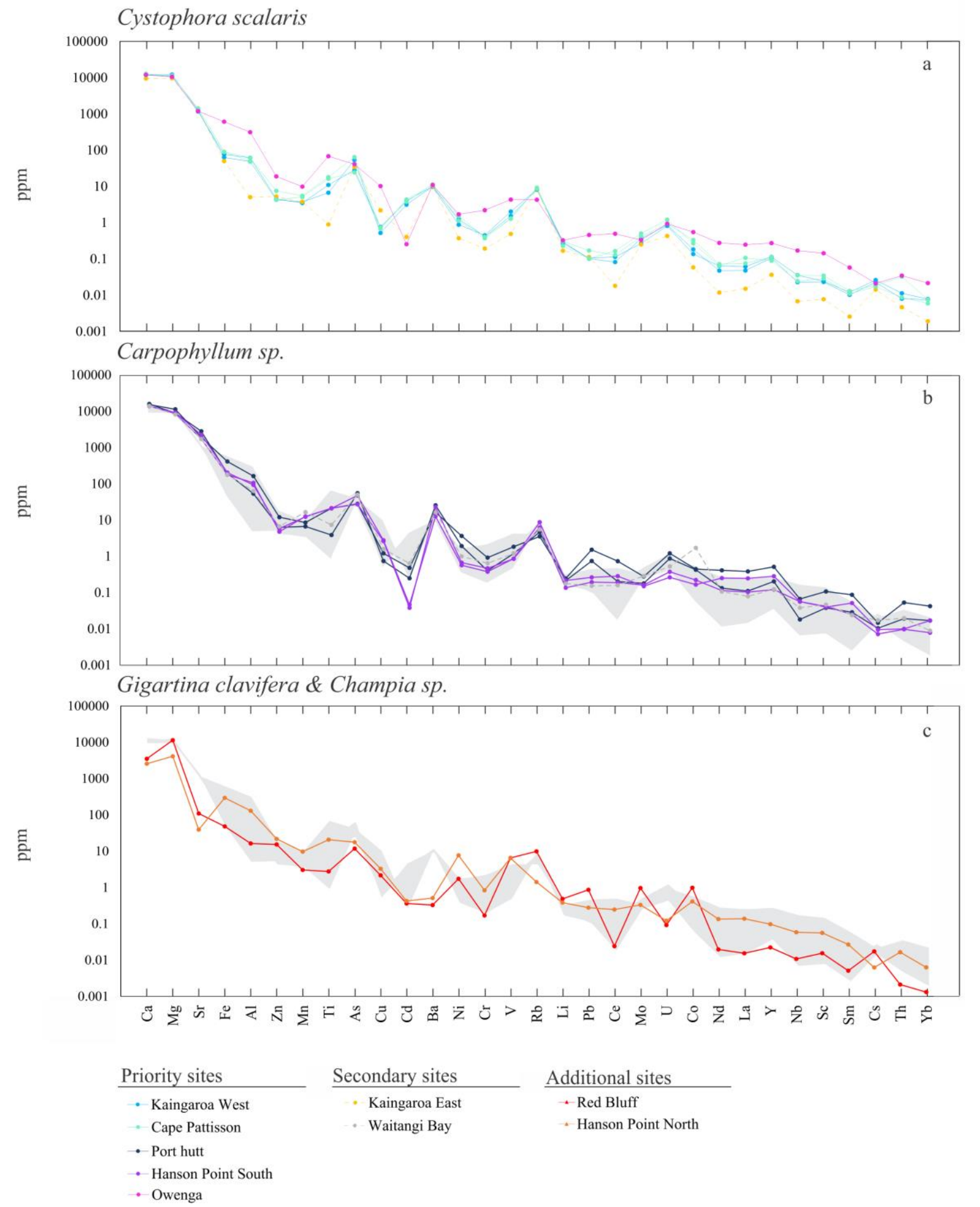

Figure 14: The trace element data for all algae species. Trace element concentrations ordered according to amphipod species order (a) Cystophora scalaris (4 sites) (b) Carpophyllum sp (3 sites) (c) Gigartina clavifera and Champia (2 sites). The Cystophora scalaris field is transposed onto the following graphs for comparison (grey shading). 


\subsection{Water samples}

The suite of elements analysed in the water samples was less than those for the macroalgae and amphipod samples (Table 10, Figure 11, Figure 14). Iron was consistently too high to be analysed at most of the sampling sites, with accurate measurements only obtained for the sample from Port Hutt (Table 10). Scandium, Co, $\mathrm{Ni}, \mathrm{Cu}, \mathrm{Zn}, \mathrm{Ga}, \mathrm{Y}, \mathrm{La}, \mathrm{Pb}$ are most concentrated at Hanson Point South. Due to the sampling regime and conditions at the time of sampling, Hanson Point North may be a more accurate representation of the water typically present at Hanson Point South. This is because the sample collected at Hanson Point South was taken off a wave cut platform adjacent to a bathymetric drop off (due to dredging; refer to Figures 8I; 8J \& 9). The wave energy at this sampling location was high due to water churning against the platform, leading to increased suspended sediment load at the sampling site. Due to the proximity $(\sim 150 \mathrm{~m})$ of these two water collection sites, data for Hanson Point North and Hanson Point South waters will both be considered as representative for Hanson Point South. Rangatira and Red Bluff water samples also have multiple elements that were too high to analyse accurately, including Ti, Mn Fe, Co and La (Table 10). The samples from Rangatira were also collected in unfavourable, choppy conditions caused by the strong winds at the time of sampling (Figure $8 \mathrm{H}$ ). At Red Bluff samples were collected in slightly shallower water which increased the wave energy, and both sites therefore also had a higher suspended sediment load in the water samples, despite best efforts at obtaining clear water when sampling. Interestingly, Kaingaroa South was also collected in a high-energy environment but water samples do not show the same sediment levels seen in the Hanson Point South, Rangatira and Red Bluff waters.

Other notable features of the water data include: $\mathrm{Zn}$ is below the limit of detection threshold for Hanson Point North, Waitangi Bay and Kaingaroa West (Table 10); Ti is consistently high across most sites and $\mathrm{V}$ exhibits little variation between sites (Table 10). Cadmium is highest at Hanson Point South, Kaingaroa West and Cape Pattisson, of the five primary sites, and overall highest at Rangatira and Red Bluff (Table 10) 
Table 10: Concentrations and standard deviations of water samples collected from all sampling sites.

\begin{tabular}{|c|c|c|c|c|c|c|c|c|}
\hline & \multicolumn{2}{|c|}{$\begin{array}{l}\text { Hanson Point } \\
\text { North }\end{array}$} & \multicolumn{2}{|c|}{$\begin{array}{l}\text { Hanson Point } \\
\text { South }\end{array}$} & \multicolumn{2}{|c|}{ Rangatira } & \multicolumn{2}{|c|}{ Red Bluff } \\
\hline & $p p b$ & $1 S D$ & $p p b$ & $1 S D$ & $p p b$ & $1 S D$ & $p p b$ & $1 S D$ \\
\hline Sc & 0.00013 & 0.00005 & 0.0023 & 0.0001 & 0.0052 & 0.0002 & 0.0022 & 0.0001 \\
\hline $\mathbf{T i}$ & 0.581 & 0.08 & - & - & - & - & - & - \\
\hline $\mathbf{V}$ & 1.5 & 0.1 & 2 & 0.2 & 1.9 & 0.2 & 2 & 0.2 \\
\hline Mn & 0.054 & 0.02 & - & - & - & - & - & - \\
\hline $\mathrm{Fe}$ & 5.6 & 0.03 & - & - & - & - & - & - \\
\hline Co & 0.014 & 0.0007 & 0.31 & 0.02 & - & - & 0.147 & 0.007 \\
\hline $\mathbf{N i}$ & 0.26 & 0.006 & 2.08 & 0.04 & 1.11 & 0.02 & 0.97 & 0.02 \\
\hline $\mathbf{C u}$ & 0.052 & 0.001 & 1.34 & 0.03 & 0.307 & 0.008 & 0.109 & 0.004 \\
\hline Zn & $<\mathrm{LOD}$ & - & 3.6 & 0.2 & 1.08 & 0.05 & 0.66 & 0.03 \\
\hline $\mathbf{G a}$ & 0.0041 & 0.0006 & 0.07 & 0.01 & 0.058 & 0.008 & 0.042 & 0.006 \\
\hline $\mathbf{Y}$ & 0.01 & 0.0002 & 0.208 & 0.006 & 0.48 & 0.02 & 0.88 & 0.02 \\
\hline Cd & 0.0053 & 0.0002 & 0.0173 & 0.0006 & 0.062 & 0.002 & 0.04 & 0.002 \\
\hline La & 0.0055 & 0.0002 & 0.45 & 0.02 & 0.68 & 0.03 & & \\
\hline \multirow[t]{3}{*}{$\mathbf{P b}$} & 0.009 & 0.0004 & 0.132 & 0.005 & 0.088 & 0.004 & 0.057 & 0.002 \\
\hline & \multicolumn{2}{|c|}{ Port Hutt } & \multicolumn{2}{|c|}{ Cape Pattisson } & \multicolumn{2}{|c|}{ Waitangi Bay } & \multicolumn{2}{|l|}{ Owenga } \\
\hline & $p p b$ & $1 S D$ & $p p b$ & $1 S D$ & & $p p b$ & $1 S D$ & $p p b$ \\
\hline Sc & 0.00044 & 0.00005 & 0.00116 & 0.00008 & 0.00027 & 0.00001 & 0.00074 & 0.00006 \\
\hline $\mathbf{T i}$ & 0.19 & 0.03 & 0.43 & 0.06 & 0.55 & 0.08 & & \\
\hline $\mathbf{V}$ & 1.6 & 0.1 & 1.7 & 0.2 & 1.4 & 0.1 & 1.7 & 0.2 \\
\hline Mn & 0.29 & 0.01 & 0.43 & 0.02 & 1.02 & 0.03 & 1.49 & 0.05 \\
\hline $\mathbf{F e}$ & 5 & 0.2 & - & - & - & - & - & \\
\hline Co & 0.0118 & 0.0006 & 0.0075 & 0.0004 & 0.022 & 0.001 & 0.057 & 0.003 \\
\hline $\mathbf{N i}$ & 0.19 & 0.005 & 0.248 & 0.004 & 0.278 & 0.006 & 0.5 & 0.01 \\
\hline $\mathrm{Cu}$ & 0.092 & 0.003 & 0.061 & 0.002 & 0.045 & 0.001 & 0.27 & 0.006 \\
\hline $\mathbf{Z n}$ & 0.085 & 0.004 & 1.09 & 0.06 & $<\mathrm{LOD}$ & - & 0.57 & 0.03 \\
\hline $\mathbf{G a}$ & 0.0028 & 0.0004 & 0.0036 & 0.0006 & 0.0044 & 0.0007 & 0.013 & 0.002 \\
\hline $\mathbf{Y}$ & 0.0103 & 0.0003 & 0.0147 & 0.001 & 0.0147 & 0.0004 & 0.051 & 0.001 \\
\hline Cd & 0.0066 & 0.0003 & 0.0109 & 0.0004 & 0.0071 & 0.0002 & 0.0095 & 0.0003 \\
\hline La & 0.0057 & 0.0002 & 0.045 & 0.001 & 0.01 & 0.0004 & 0.055 & 0.002 \\
\hline \multirow[t]{3}{*}{$\mathbf{P b}$} & 0.027 & 0.001 & 0.104 & 0.004 & $<\mathrm{LOD}$ & - & 0.073 & 0.003 \\
\hline & \multicolumn{2}{|c|}{ Kaingaroa West } & \multicolumn{2}{|c|}{ Kaingaroa East } & \multicolumn{2}{|c|}{ Kaingaroa South } & \multicolumn{2}{|l|}{ LOD } \\
\hline & $p p b$ & $1 S D$ & $p p b$ & $1 S D$ & $p p b$ & $1 S D$ & $p p b$ & \\
\hline Sc & 0.00059 & 0.00008 & 0.0001 & 0.00002 & 0.00028 & 0.00001 & 0.003 & \\
\hline $\mathbf{T i}$ & 0.7 & 0.1 & 0.25 & 0.04 & 0.48 & 0.07 & 0.007 & \\
\hline $\mathbf{V}$ & 1.6 & 0.2 & 1.5 & 0.1 & 1.7 & 0.2 & 0.009 & \\
\hline Mn & 0.48 & 0.02 & 0.147 & 0.004 & 0.31 & 0.01 & 0.05 & \\
\hline $\mathbf{F e}$ & - & - & 3.1 & 0.1 & - & - & 0.0009 & \\
\hline Co & 0.007 & 0.0004 & 0.0029 & 0.0001 & 0.0062 & 0.0004 & 0.01 & \\
\hline $\mathbf{N i}$ & 0.243 & 0.008 & 0.177 & 0.004 & 0.207 & 0.005 & 0.01 & \\
\hline $\mathbf{C u}$ & 0.045 & 0.002 & 0.057 & 0.001 & 0.069 & 0.002 & 0.2 & \\
\hline $\mathbf{Z n}$ & $<\mathrm{LOD}$ & - & 0.147 & 0.007 & 0.037 & 0.002 & 0.0005 & \\
\hline $\mathbf{G a}$ & 0.0033 & 0.0005 & 0.0019 & 0.0003 & 0.0031 & 0.0004 & 0.00002 & \\
\hline $\mathbf{Y}$ & 0.148 & 0.004 & 0.00143 & 0.0004 & 0.038 & 0.001 & 0.00005 & \\
\hline Cd & 0.0224 & 0.0008 & 0.0047 & 0.0002 & 0.0083 & 0.0003 & 0.00004 & \\
\hline La & 0.064 & 0.002 & 0.0066 & 0.0002 & 0.0224 & 0.0008 & 0.007 & \\
\hline $\mathbf{P b}$ & 0.024 & 0.001 & 0.0217 & 0.0009 & 0.026 & 0.001 & 0.0001 & \\
\hline
\end{tabular}

1 all red values are near the maximum range, 2 LOD below limit of detection, 3 all dash (-) values were too high to be measured. 


\subsection{Sediments}

\subsubsection{Grain size}

The substrate samples collected from all 11 sites are characterised by a sand or gravel texture (Table 11, Figure 15, Figure 16). Red Bluff and Cape Pattisson sediments are categorised as a variation of gravel, the samples collected from Kaingaroa West, Kaingaroa East, Kaingaroa South, Port Hutt, Rangatira, Hanson Point North, Hanson Point South, Waitangi Bay and Owenga are sands (Table 11). Hanson Point South has the highest percentage of mud (16.2\%), followed by Hanson Point North (1.6\%) (Table 11, Figure 15). These two localities are the only sites with a mud percentage greater than $0.5 \%$. Cape Pattisson, Port Hutt, Rangatira, Red Bluff and Waitangi Bay have no measurable mud in the sampled substrate (Table 11, Figure 15). Cape Pattisson, Rangatira and Hanson Point South are the only sites that have poorly sorted sediment, whereas the sediments at Kaingaroa West, Kaingaroa East, Port Hutt, Red Bluff, Hanson Point North, and Waitangi Bay are well sorted and Kaingaroa South and Owenga are moderately sorted (Table 11). 
Chapter 3 - Results

Table 11: Grain size characteristics of surficial sediments

\begin{tabular}{|c|c|c|c|c|c|c|}
\hline Site & $\begin{array}{l}\text { Gravel } \\
(\%)\end{array}$ & $\begin{array}{l}\text { Sand } \\
(\%)\end{array}$ & $\begin{array}{l}\text { Mud } \\
(\%)\end{array}$ & Mean $(\Phi)$ & Sorting $(\Phi)$ & $\begin{array}{l}\text { Textural group: } \\
\text { (Folk and Ward } \\
\text { 1957) }\end{array}$ \\
\hline $\begin{array}{l}\text { Kaingaroa } \\
\text { West** }\end{array}$ & 0.0 & 99.5 & 0.5 & $\begin{array}{l}\text { Medium Sand } \\
1.014\end{array}$ & $\begin{array}{l}\text { Moderately } \\
\text { Well Sorted } \\
0.699\end{array}$ & Sand \\
\hline $\begin{array}{l}\text { Kaingaroa } \\
\text { East }\end{array}$ & 2.6 & 96.9 & 0.5 & $\begin{array}{l}\text { Coarse Sand } \\
0.593\end{array}$ & $\begin{array}{l}\text { Moderately } \\
\text { Well Sorted } \\
0.680\end{array}$ & $\begin{array}{l}\text { Slightly } \\
\text { Gravelly Sand }\end{array}$ \\
\hline $\begin{array}{l}\text { Kaingaroa } \\
\text { South }\end{array}$ & 7.8 & 91.8 & 0.5 & $\begin{array}{l}\text { Coarse Sand } \\
0.154\end{array}$ & $\begin{array}{l}\text { Moderately } \\
\text { Sorted } \\
0.769\end{array}$ & Gravelly Sand \\
\hline $\begin{array}{l}\text { Cape } \\
\text { Pattisson* }\end{array}$ & 44.2 & 55.8 & 0.0 & $\begin{array}{l}\text { Coarse Sand } \\
0.218\end{array}$ & $\begin{array}{l}\text { Poorly } \\
\text { Sorted } \\
1.531\end{array}$ & Sandy Gravel \\
\hline Port Hutt* & 12.2 & 87.8 & 0.0 & $\begin{array}{l}\text { Very Coarse } \\
\text { Sand } \\
-0.506\end{array}$ & $\begin{array}{l}\text { Well Sorted } \\
0.470\end{array}$ & Gravelly Sand \\
\hline Rangatira & 11.6 & 88.4 & 0.0 & $\begin{array}{l}\text { Coarse Sand } \\
0.283\end{array}$ & $\begin{array}{l}\text { Poorly } \\
\text { Sorted } \\
1.141\end{array}$ & Gravelly Sand \\
\hline Red Bluff & 99.6 & 0.4 & 0.0 & $\begin{array}{l}\text { Very Fine } \\
\text { Gravel } \\
-1.242\end{array}$ & $\begin{array}{l}\text { Very Well } \\
\text { Sorted } \\
0.149\end{array}$ & Gravel \\
\hline $\begin{array}{l}\text { Hanson Point } \\
\text { North }\end{array}$ & 1.1 & 97.3 & 1.6 & $\begin{array}{l}\text { Medium Sand } \\
1.048\end{array}$ & $\begin{array}{l}\text { Moderately } \\
\text { Well Sorted } \\
0.664\end{array}$ & $\begin{array}{l}\text { Slightly } \\
\text { Gravelly Sand }\end{array}$ \\
\hline $\begin{array}{l}\text { Hanson Point } \\
\text { South * }\end{array}$ & 11.9 & 71.8 & 16.2 & $\begin{array}{l}\text { Medium Sand } \\
1.039\end{array}$ & $\begin{array}{l}\text { Very Poorly } \\
\text { Sorted } \\
2.388\end{array}$ & $\begin{array}{l}\text { Gravelly Muddy } \\
\text { Sand }\end{array}$ \\
\hline Waitangi Bay & 0.5 & 99.5 & 0.0 & $\begin{array}{l}\text { Fine Sand } \\
2.526\end{array}$ & $\begin{array}{l}\text { Moderately } \\
\text { Well Sorted } \\
0.593\end{array}$ & $\begin{array}{l}\text { Slightly } \\
\text { Gravelly Sand }\end{array}$ \\
\hline Owenga* & 4.8 & 95.1 & 0.1 & $\begin{array}{l}\text { Coarse Sand } \\
0.091\end{array}$ & $\begin{array}{l}\text { Moderately } \\
\text { Sorted } \\
0.788\end{array}$ & $\begin{array}{l}\text { Slightly } \\
\text { Gravelly Sand }\end{array}$ \\
\hline
\end{tabular}

Percentage of grains falling into mud, sand and gravel size fractions, the mean, the degree of sorting and the textural group using the Logarithmic Folk and Ward (1957) Graphical Measures method. Sampling sites are listed in order from north to south with an asterisk(*) representing the five priority sites. 


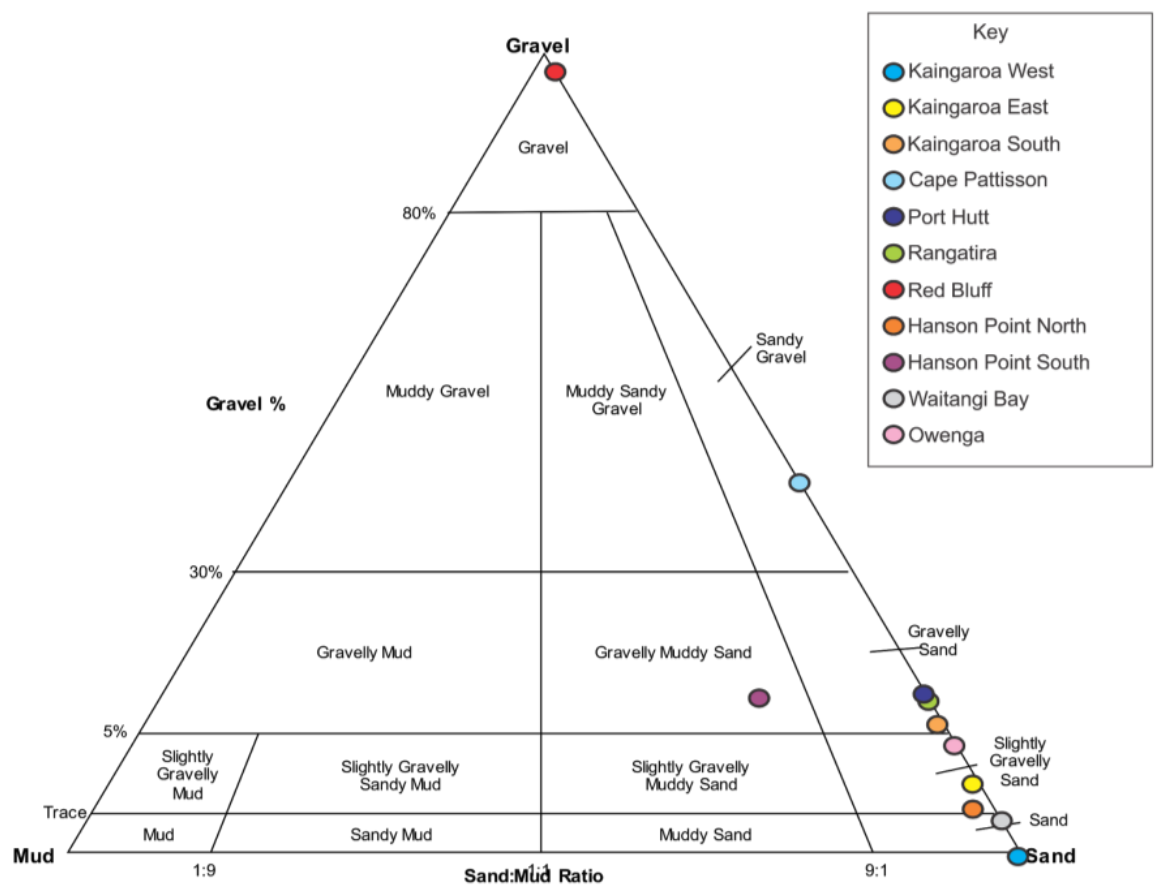

Figure 15: Textural groups of the 11 samples using a mud: sand: gravel ratio.

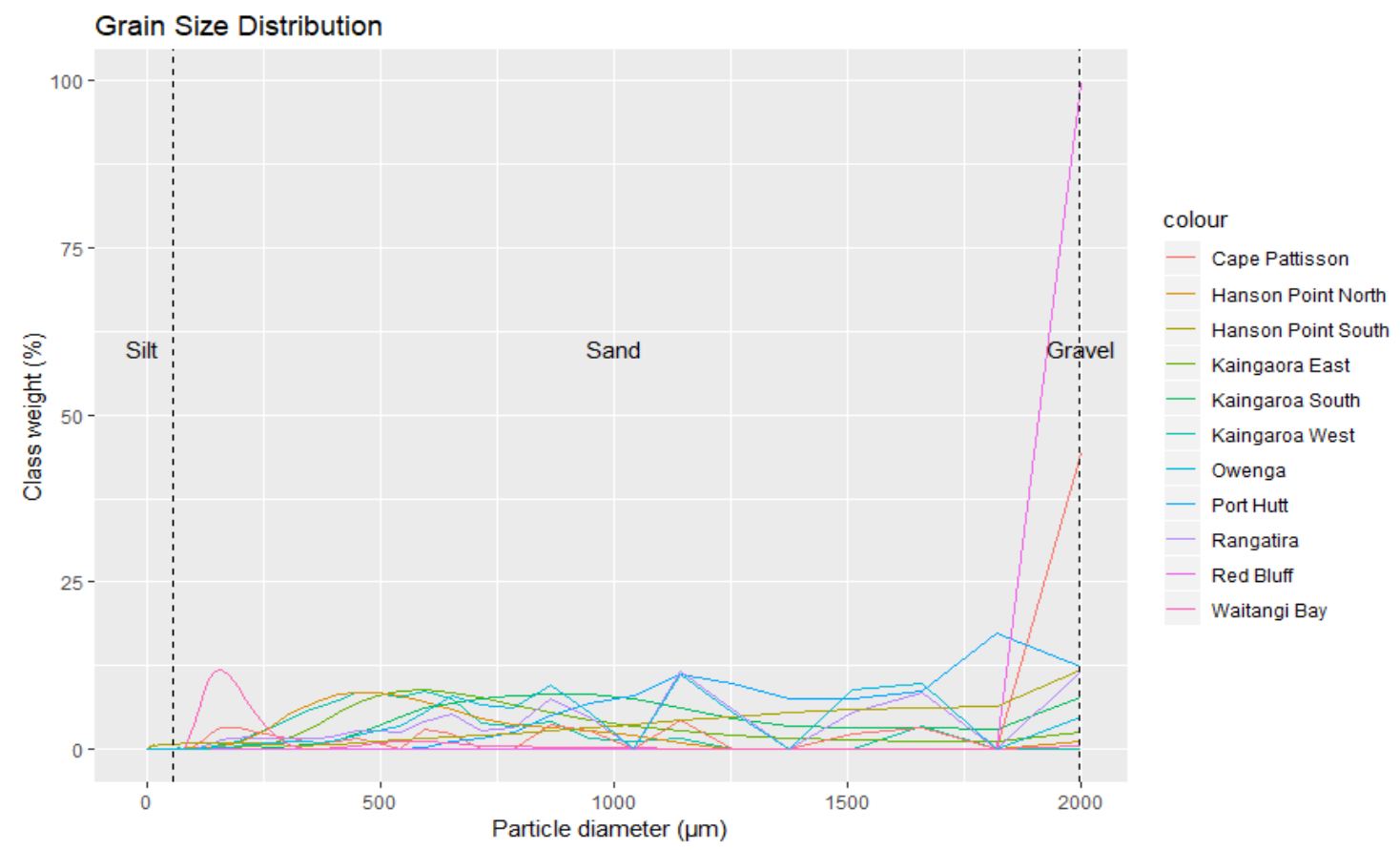

Figure 16: Grain size distribution of substrate for all 11 sampling sites. Distribution is split into three fractions (silt, sand and gravel) using the Udden (1914) and Wentworth (1922) grade scales. 


\subsubsection{Calcium carbonate content}

The calcium carbonate contents range widely, from $0.8-93.7 \%$ (Table 12) Kaingaroa East and Kaingaroa West have the highest percentage (>90\%) of calcium carbonate present in their substrate, consistent with a sand comprised of shell fragments (Figure 17). Port Hutt was significantly lower than all other sediments analysed with only $0.8 \%$ of material being carbonate (Figure 17).

Table 12: Calcium carbonate proportion of the substrate from all sampling sites

\begin{tabular}{|ll|}
\hline Site & Carbonate (\%) \\
\hline Kaingaroa West* & 91.8 \\
Kaingaroa East & 93.7 \\
Kaingaroa South & 9.4 \\
Cape Pattisson* & 60.4 \\
Port Hutt* & 0.8 \\
Rangatira & 21.3 \\
Red Bluff & 70.8 \\
Hanson Point North & 74.3 \\
Hanson Point South * & 25.3 \\
Waitangi Bay & 59.1 \\
Owenga * & 43.7 \\
\hline
\end{tabular}

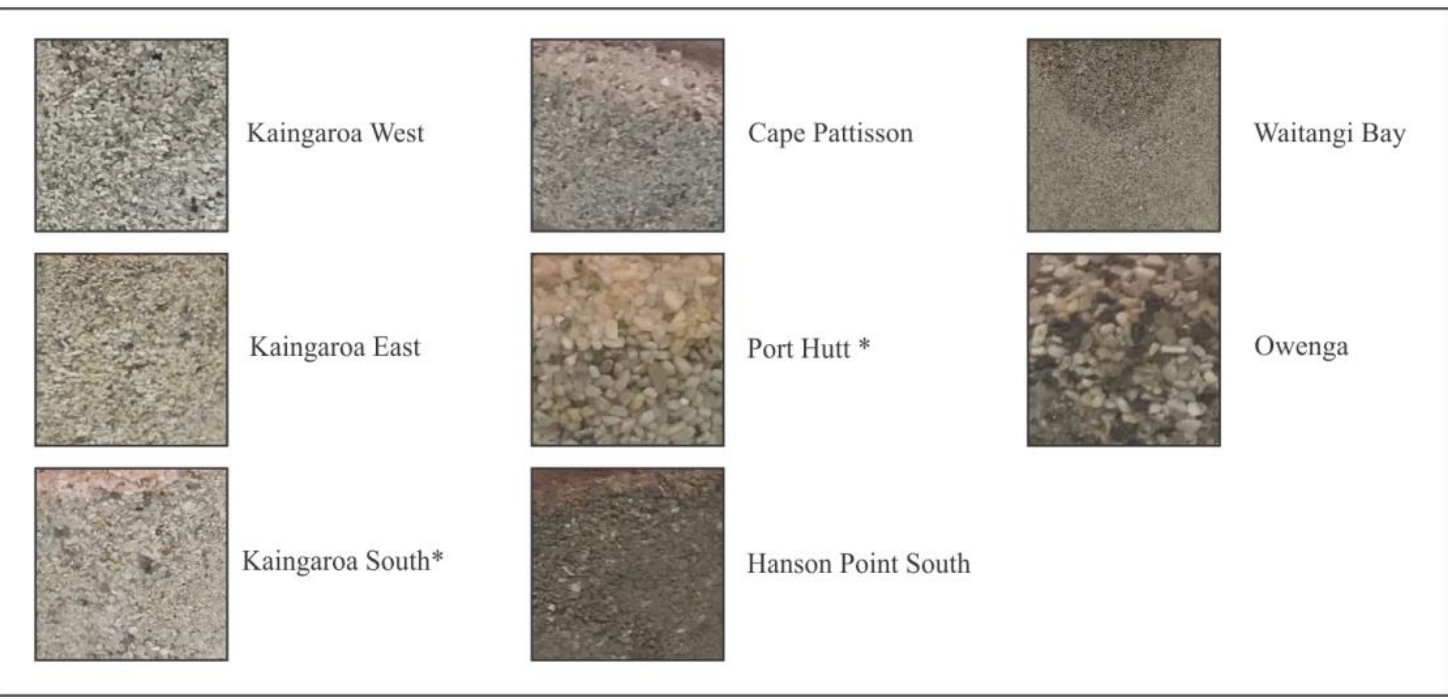

Figure 17: Images of substrates anaylsed (sieved $<1 \mathrm{~mm}$ ), listed from north to south. * sites are dominanted by quartz. Images are approximately $2 \mathrm{~cm}$ by $2 \mathrm{~cm}$. 


\subsubsection{Total organic carbon}

The total organic matter (TOM) was measured for both bulk sediment and $<1 \mathrm{~mm}$ grain size fractions, and ranges from 0.297 to $9.38 \%$ (Table 13). Hanson Point South, with the highest mud fraction of all the sediment samples also has the highest percentage of TOM in both bulk $(8.46 \%)$ and $<1 \mathrm{~mm}$ sediments $(9.38 \%)$. Kaingaroa South contains the least amount in bulk $(0.297 \%)$ and third least in $<1 \mathrm{~mm}$ sediments $(1.01 \%)$. Sites that had no mud fraction in their substrate (i.e. Cape Pattisson, Port Hutt, Rangatira, Red Bluff and Waitangi Bay) all have low TOM $(<3 \%)$ in their $<1 \mathrm{~mm}$ size fraction. Samples collected from the three Kaingaroa sites show a comparable percent of TOM in bulk sediments and $<1 \mathrm{~mm}$ sediments for both Kaingaroa West and Kaingaroa East $(>3 \%)$, while Kaingaroa South is considerably lower for both fractions $(<1.01)$.

Table 13: Percent of total organic matter in bulk sediments and sediments $<1 \mathrm{~mm}$ from all sampling sites.

\begin{tabular}{|lll|}
\hline Site & TOM Bulk (\%) & TOM <1mm (\%) \\
\hline Kaingaroa West* & 3.52 & 3.29 \\
Kaingaroa East & 3.53 & 3.01 \\
Kaingaroa South & 0.297 & 1.01 \\
Cape Pattisson* & 3.79 & 2.71 \\
Port Hutt* & 5.27 & 1.04 \\
Rangatira & 3.41 & 0.733 \\
Red Bluff & 2.05 & 0.733 \\
Hanson Point North & 3.55 & 3.40 \\
Hanson Point South * & 8.46 & 9.38 \\
Waitangi Bay & 2.13 & 1.76 \\
Owenga * & 5.74 & 2.32 \\
\hline
\end{tabular}




\subsubsection{Major element compositions}

The major element data are broadly consistent with the carbonate and grainsize data, with samples with high carbonate content, Kaingaroa West and Kaingaroa East, equating to $>45 \% \mathrm{CaO}$ (Figure 18). Interestingly, the sediments on schist basement tend to have higher calcium carbonate content, except for Port Hutt which has the least, whereas the volcanic basement regions have sediment with around $20 \%$ calcium and are consistently higher in other major elements ( $\mathrm{FeO}, \mathrm{MgO}, \mathrm{MnO}$ and $\mathrm{Al}_{2} \mathrm{O}_{3}$ ) (Figure 18). The low major element contents for sediment from Kaingaroa South and Port Hutt are consistent with being dominantly quartz sand and are likely to be predominantly $\mathrm{SiO}_{2}$. Unfortunately, $\mathrm{Si}$ was not measured here, due to the loss of $\mathrm{Si}$ (as volatile $\mathrm{SiF}_{4}$ ) during the sample dissolution process, however, visually the sediment samples from these localities appear to be predominately quartz, consistent with general descriptions of the sediments around Chatham Island (Figure 17; Table 2) (Hay et al., 1970; Campbell, 1993). As expected, the correlation between $\mathrm{CaO}$ and calcium carbonate is strong (Figure 18). 

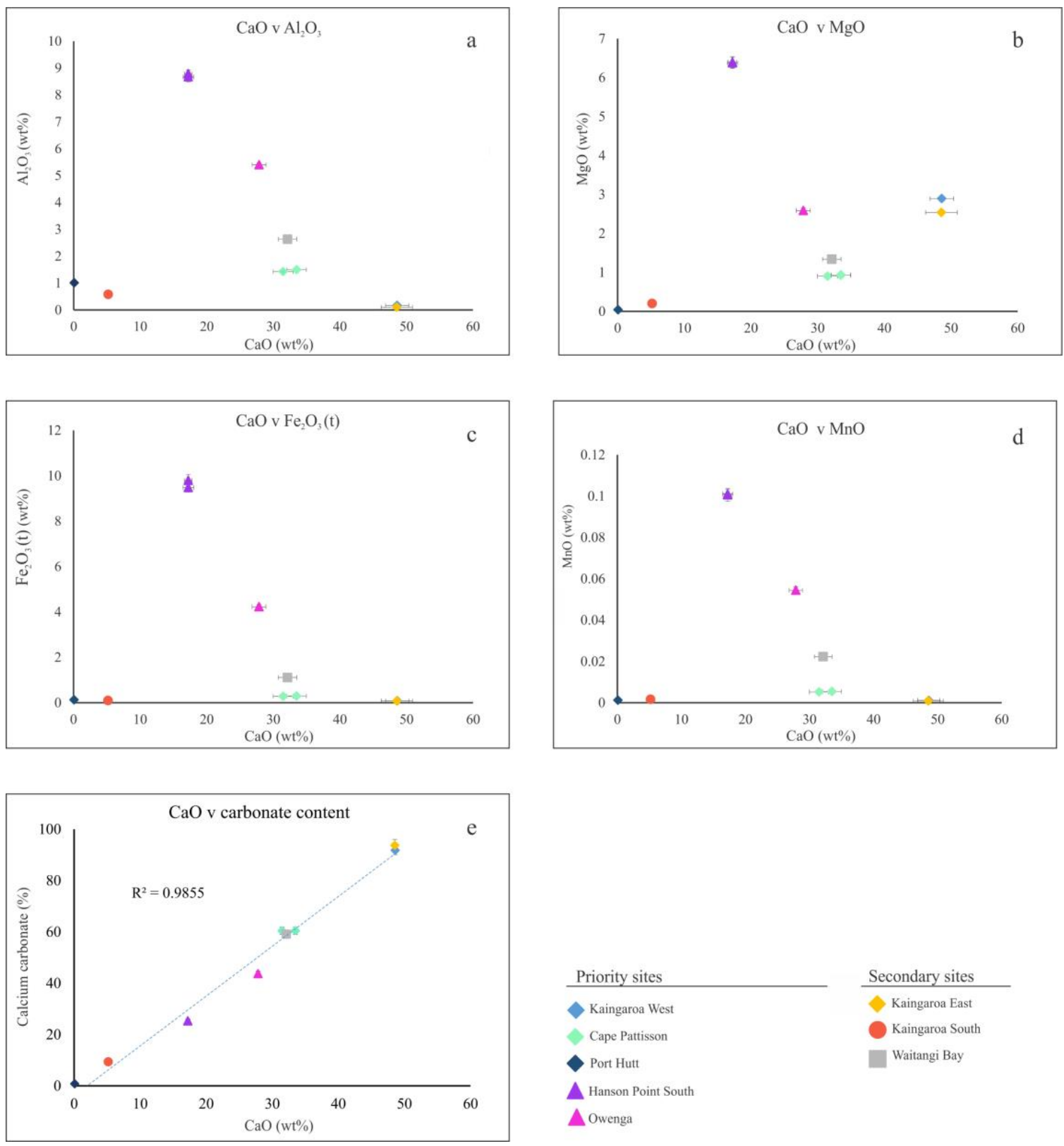

Secondary sites

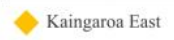

Kaingaroa South

Waitangi Bay

Figure 18: Major element relationships for substrate from all primary and secondary sites.

Diamond represents schist basement geology, square is sand dune, circle is non-marine deposits and triangles are basaltic. 


\subsubsection{Trace element data}

The suite of elements analysed for the sediment samples varied slightly from the amphipod and algae, and excluded $\mathrm{Li}, \mathrm{Nb}$ and $\mathrm{Cs}$. Trace element profiles, normalised to Upper Continental Crust, are broadly similar for each site with variable enrichments at $\mathrm{Ba}, \mathrm{U}, \mathrm{Sr}, \mathrm{Cd}, \mathrm{Cr}, \mathrm{Ni}$ and $\mathrm{As}$, and variable relative enrichments or depletions in $\mathrm{Pb}$ (Figure 19). Hanson Point South commonly has highest values for all elements excluding $\mathrm{Pb}$ and $\mathrm{Sr}$ (Figure 19). Owenga sediments are enriched in $\mathrm{Pb}$ and Kaingaroa West, Kaingaroa East, and Cape Pattisson have highest concentration of $\mathrm{Sr}$ (Figure 19). Port Hutt consistently has low concentrations for most elements (Figure 19).

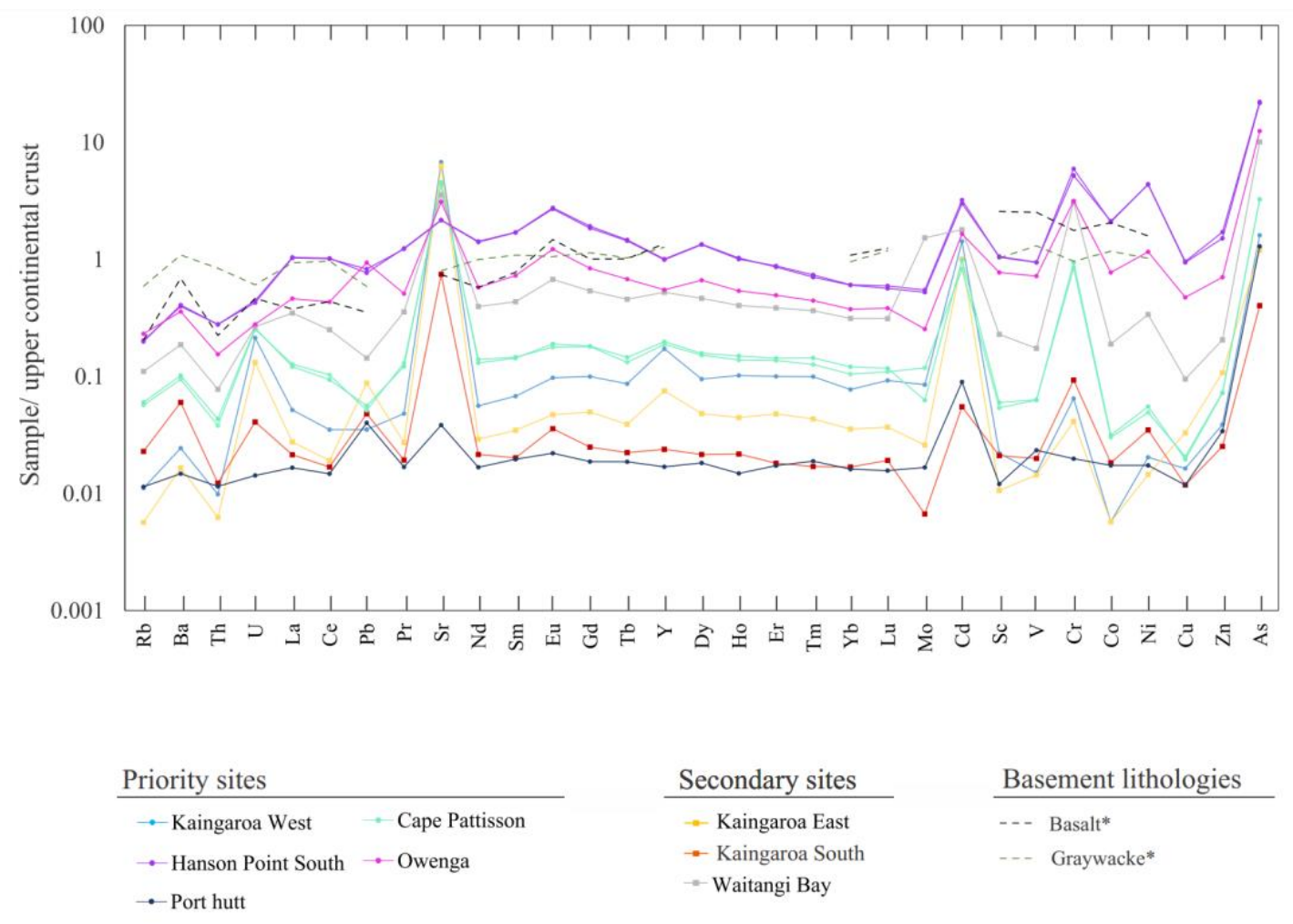

Figure 19: Trace element concentrations of sediments collected from all five primary sites and three secondary sites. Raw concentrations (ppm) were normalized using average chemical composition of the upper continental crust from McLennan (2001). *Average chemical compositions of Palaeozoic Basalt and Greywacke, using values from Condie (1993), are shown as indicative of the dominant basement lithologies in the two parts of Chatham Island (i.e. volcanic and schist). 
A moderate to strong correlation (e.g. $\mathrm{R}_{2}>0.5$ ), with the exclusion of the two quartz dominated sites, is observed between element concentration and calcium carbonate for most elements (Figure 20). A transition is observed between Hanson Point South, which has the highest concentrations for most elements, through to Kaingaroa East with the highest calcium carbonate content (93.7\%) (Figure 20).
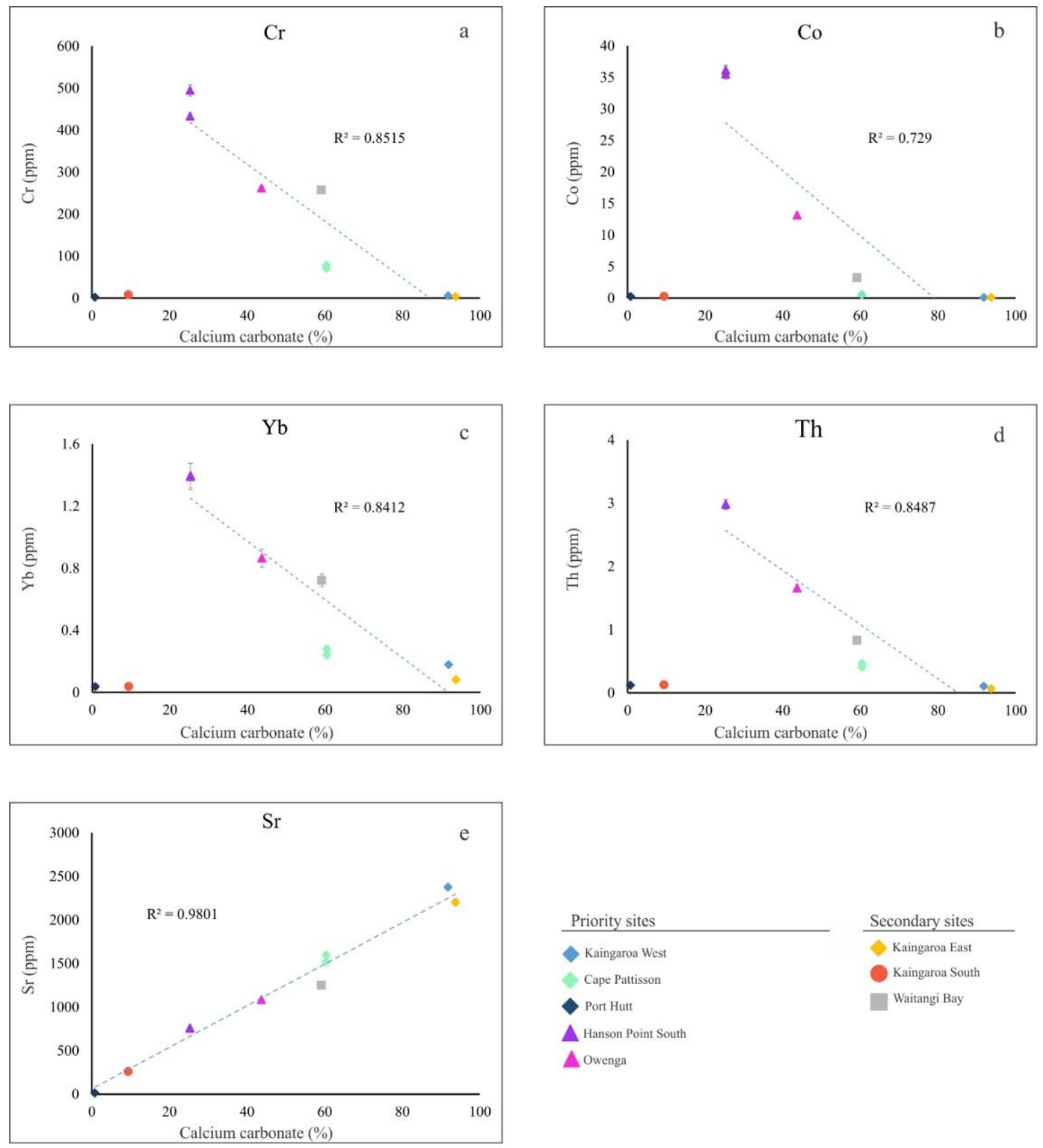

Figure 20: Correlations between calcium carbonate and elements. a, b, c and d correlations exclude the two quartz dominated sites (Port Hutt and Kaingaroa South). (a) \& (b) are elements of interest which are elevated at Hanson Point South, (c) \& (d) are rare earth elements. (e) is the strong correlation between $\mathrm{Sr}$ and calcium carbonate across all sites. 


\section{DISCUSSION}

The overall aim of this thesis was to investigate the use of amphipod species in evaluating the levels of heavy metals, using key coastal marine sites around Chatham Island as a case study. Three species of algal-dwelling amphipods, Aora sp. 1, Apohyale sp. 1 and Eusiroides sp. 1, were found to be common in the samples, were of sufficient numbers to be analysed and formed the basis for this investigation. Thirty one elements were consistently measured in all three amphipod species at quantifiable levels: $\mathrm{Ca}, \mathrm{Mg}$, Sr, Al, Fe, Zn, Cd, Ba, Mn, Ti, As, Cu, Pb, Ni, V, U, Mo, Cr, Rb, Li, Co, Ce, Y, La, Nb, $\mathrm{Nd}, \mathrm{Sc}, \mathrm{Th}, \mathrm{Sm}, \mathrm{Cs}$ and $\mathrm{Yb}$. These elements are considered further in the discussion.

\subsection{Size effect}

In order to compare trace element concentrations in the amphipods between sites, it must be first established whether there are any systematic variations in concentrations with size of amphipod specimen. This was evaluated using statistical analyses including t-tests and regression analyses on two species, for elements for which enough specimens were obtained from single locations. Only two elements for both Aora sp. $1(\mathrm{~Pb}, \mathrm{U})$ and B. chathamensis ( $\mathrm{Sr}, \mathrm{Mn}$ ) were determined significantly different (Table 8). This demonstrates that the means between the two weight classes, for both species, do not vary significantly and no size effect is present for majority of the elements investigated.

When using regression analyses to investigate possible amphipod size effects, an exponential relationship was investigated as previous studies have reported an exponential decrease in elemental concentrations with an increase in specimen size (e.g. Rainbow \& Moore, 1986). Low $\mathrm{R}_{2}$ values $(<0.5)$ are considered to have a weak relationship between the two variables, and therefore have little to no steady increase or decrease in element concentrations with increased weight. This was the case for over half of the elements investigated, which, for these elements, demonstrates no size effect (Table 9). However, size-related variations do appear to occur for some elements.

Elements with a high $\mathrm{R}_{2}$ value ( $\left.>0.7\right)$ demonstrate a variation in element concentration with varying specimen weight, although it should be noted that the regression factors do not take the uncertainties in the concentration data measurements into account. $\mathrm{Ca}, \mathrm{Mg}$, $\mathrm{Sr}, \mathrm{Mn}$ and $\mathrm{U}$ all appear to have a strong relationship between element concentrations and dry weight for both an exponential and linear relationship for both types of samples 
(i.e. algal-dwelling amphipods and sand hoppers) (Table 9; Figure 12). Amphipods are calcifying species, meaning their exoskeletons are comprised, in part, of calcium carbonate $\left(\mathrm{CaCO}_{3}\right)$ (Egilsdottir et al., 2009). When organisms calcify, $\mathrm{Ca} 2+$ and $\mathrm{Sr} 2+$ can substitute readily, and $\mathrm{Mg}_{2+}$ to a lesser extent (Brečević \& Kralj, 2007). The substitutive properties of these ions may explain why the strongest relationships are observed for $\mathrm{Ca}, \mathrm{Mg}$ and $\mathrm{Sr}$ in both sample types. The uptake of these three elements in biota are typically a function of seawater temperature (Egilsdottir et al., 2009)

The negative relationship observed for $\mathrm{Ca}, \mathrm{Mg}$ and $\mathrm{Sr}$ in the B. chathamensis are consistent with a surface area effect and the exoskeleton proportionally a larger component of the smaller specimen (Rainbow \& Moore, 1986) (Table 9; Figure 12). By contrast, when the errors associated with the Ca analyses for Aora sp. 1 from Hanson Point South were included, a correlation with size was less apparent (Figure 12a).

Studies have demonstrated that amphipod species $(n>5)$ from multiple genera $(n=3)$ show higher concentrations of some trace metals $(\mathrm{Cu}, \mathrm{Zn}, \mathrm{Fe}$ and $\mathrm{Pb})$ in smaller specimens, as a consequence of surface area (Rainbow \& Moore, 1986). Of these elements, only $\mathrm{Pb}$ shows an apparent correlation with size for Aora sp. 1 (Table 9; Figure 12e) but with the opposite relationship to that observed in other studies (Rainbow \& Moore, 1986).

As with the t-test results, $\mathrm{Sr}$ and $\mathrm{Mn}$ concentrations show a size effect for the sand hopper samples (Table 8; Table 9; Figure 12) and $\mathrm{Pb}$ and $\mathrm{U}$ for Aora sp. 1 (Table 8; Table 9; Figure 12). On the basis of these results any elements with a P-value $<0.05$ or a $R_{2}$ value $>0.7$ will only be compared within the same weight class across study sites for that sample type. This includes $\mathrm{Ca}, \mathrm{Mg}, \mathrm{Sr}, \mathrm{Mn}, \mathrm{Pb}, \mathrm{U}$ and $\mathrm{Li}$ for algal-dwelling amphipods and $\mathrm{Ca}, \mathrm{Mg}, \mathrm{Sr}, \mathrm{Mn}, \mathrm{U}, \mathrm{Mo}$ and $\mathrm{Sc}$ for sand hopper samples (Table 8; Table 9). Note, that of these elements, only $\mathrm{Mn}$ and $\mathrm{Pb}$ are trace metals as defined in this study. The other trace metals analysed show no evidence for a significant size effect.

\subsection{Interspecific variations}

Different amphipod species exhibit different chemistry, particularly with respect to absolute abundances of elements (Figure 13). In general, Eusiroides sp. 1 appears to be the most sensitive and have the highest concentrations of most metals in all three algaldwelling amphipods at a given site (Figure 13). Aora sp. 1 commonly shows the second 
highest concentrations, however, there are many instances when Apohyale sp. 1 has the second highest concentrations (Figure 13). Although broadly true, these general observations do vary in detail, for example Apohyale sp. 1 has higher $\mathrm{Cu}$ at Hanson Point South than Aora sp. 1, whereas Aora sp. 1 has higher $\mathrm{Cu}$ at Owenga and Port Hutt (Figure 11). The varying sensitivity of species may be influenced by dietary preferences of specimens - i.e. Aora sp. 1 species have more general food preferences, compared to Apohyale sp. 1 which are considered to be more predominantly herbivorous (Taylor \& Brown, 2006; Tavares et al., 2013). The elements in sand hopper species do not appear to be consistently more or less concentrated compared to the algal-dwelling amphipods (Figure 11), however, as these amphipods inhabit different environments and no site has both sand hopper species and algal-dwelling amphipods analysed, it is difficult to directly evaluate this. Interspecific variations in element concentration may be explained by distinct lifestyle and food source as well as different accumulation strategies, which can be species dependent (Weeks \& Rainbow, 1991; Strode \& Blade, 2013).

\subsection{Inter-site variations}

Each amphipod species demonstrates spatial variations in trace elements concentrations. Importantly, there are some significant and consistent variations in the concentrations of certain metals at specific sites observed in all the algal dwelling species analysed. This consistency of relative metal signatures across all (two - three) species indicates real variations in the environment shown in the biology and thence the food web.

Many of the trace elements (>19) have the highest concentrations at Hanson Point South for all three algal dwelling amphipods. Of these 19 trace elements, nine (Ti, V, Cr, Mn, $\mathrm{Co}, \mathrm{Ni}, \mathrm{Cu}, \mathrm{Ga}$ and $\mathrm{Fe}$ ) are trace metals as defined in this study and considered ecotoxic. These elements are also elevated at Owenga in the Aora sp. 1 samples compared with Cape Pattisson, Port Hutt and Kaingaroa (e.g. Figure 11 a and b), although to a lesser extent than at Hanson Point South, however, the Apohyale sp. 1 sample from Owenga does not show elevated levels of these elements compared to the other localities. By contrast, As is elevated at Owenga in both amphipod species analysed from this locality (Figure 11a). 
Cadmium concentrations vary across sampling sites and are noticeably enriched at Cape Pattisson and Kaingaroa West in all algal dwelling amphipod species analysed, again with Eusiroides sp showing the highest signal.

Inter-site variations in some trace metals are also observed in the sand hopper Bellorchestia sp. however as this was the only species sampled from the three beach localities, Kaingaroa East, South and Waitangi Bay, it will be discussed separately to the algal dwelling species.

The trace metals in the amphipods will be intricately related to the environment in which they live. Sediment, water and algae data were obtained for all five marine sites, and the trace metal profiles of these may provide insights into the origin of the metal patterns observed in the amphipod species. Of these, the sediment composition data are most complex to interpret and are considered first

\subsubsection{Sediments}

The dominance of coarse grains, lack of mud and the moderate- to well-sorting at most sampling sites are consistent with a high energy coastal marine environment around the island. This is supported by the significant wave energy present around the island (Godoi et al., 2017) and corroborates previous research that sediments around the island predominantly lie within the sand fraction (Bostock et al., 2018). Dominance of sands can be explained by resuspension processes caused by the high wave activity in these coastal environments (Ujević et al., 2000).

The main source of variation in the sediment major and trace element compositions is the mineralogy of the substrate, and in particular, relative proportions of shelly to silicate clasts. The major and trace elements for Port Hutt and Kaingaroa South sediments are consistent with primarily quartz grains and would thus be dominated by $\mathrm{SiO}_{2}$. This results in low concentrations across the suite of elements investigated.

The Hanson Point South sediment is the most enriched in many of the elements analysed (i.e. Ba, Th, U, La, Ce, Pr, Nd, Sm, Eu, Gd, Tb, Y, Dy, Ho, Er, Tm, Yb, Lu, $\mathrm{Cd}, \mathrm{Sb}, \mathrm{Sc}, \mathrm{V}, \mathrm{Cr}, \mathrm{Co}, \mathrm{Ni}, \mathrm{Cu}, \mathrm{Zn}$ and As) (Figure 19). Hanson Point South had the highest percent mud out of surficial sediments collected from all sites (Table 11). Muds have the ability to influence enrichment of elements due to metal retention and organic 
affinity. Relative to other size fractions, trace elements are predominantly concentrated in the $<63 \mu \mathrm{m}$ fraction (i.e. muds -which encompasses both clays $(<2 \mu \mathrm{m})$ and silts (2$63 \mu \mathrm{m})$ ) (Udden, 1914; Wentworth, 1922). This is the result of preferential binding of trace elements to this fraction of sediment as a result of increased surface area and the ionic attraction and absorption properties on the surface of clay minerals (Krumgalz, 1989). Clay particles typically hold a negative charge and are balanced by elements that are adsorbed externally on interlamellar surfaces (Odom, 1984). Furthermore, organic matter is also predominantly enriched in fine-grained sediment, which the TOM results corroborate with highest percent in both bulk and $<1 \mathrm{~mm}$ fractions being at Hanson Point South (Table 13). This organic matter creates a biofilm that can encourage the binding of a variety of trace metals to this fraction (Morillo et al., 2005; Zhang et al., 2007; Fox et al., 2014).

It should also be noted that the collection of sediments from Hanson Point South differed from the collection of the other localities, excluding Cape Pattisson. Due to the nature of this sampling site, sediment samples were collected from small rock pools on a wave cut platform. As indicated in Chapter 2, it was not possible to collect soft sediment from adjacent to the wave cut platform that may have been more representative of the loose sediment in this location. Rock pools provide protection to small particles from wave activity and may explain the high percentage of mud and poor sorting of sediments recovered from Hanson Point South. Consequently, the sediment collected from Hanson Point South may not accurately represent this environment. That said, the amphipods from Hanson Point South were enriched in many of the trace elements that are also highest in the sediment.

There appears to be limited influence on the composition of the sediments from whether the sediments have been deposited on the schist or the volcanic basement areas. Instead, the key controlling factor appears to be the proportion of shell material (Figure 20). A transition is observed between Hanson Point South which has the highest concentrations for most elements due to the high organic content and clays amongst the mineral component coupled with low carbonate fragments, through to Kaingaroa East with the highest calcium carbonate content (93.7\%) (Figure 20; Table 12). This demonstrates that element concentrations in the sediments are primarily controlled by the proportions of shell component and silicate + oxide minerals + organic material. 
An obvious exception to this trend is the anomalous spike observed for Sr. This enrichment of Sr, notably at Kaingaroa West, Kaingaroa East and Cape Pattisson, is directly related to the carbonate content and is confirmed by the strong $\mathrm{R}_{2}$ value of 0.9801 for the relationship between calcium carbonate and $\mathrm{Sr}$ (Figure 20). This relationship is unsurprising, as the iconic traits of $\mathrm{Sr}_{2}+$ and $\mathrm{Ca} 2+$ mean these ions are substitutive in the carbonate structure.

\subsubsection{Elevated metal levels at Hanson Point South and Owenga}

All three algae-dwelling amphipod species at Hanson Point South show relative enrichments in a large suite $(\mathrm{n}=19)$ of trace elements. Aora sp. 1 (but not Apohyale sp. 1) shows lesser concentrations in many of these elements at Owenga.

Algae collected from Hanson Point South (Carpophyllum sp.) and Owenga

(Cystophora scalaris) cannot be directly compared for their trace metal contents due to species specific metal uptake in algae (Escobar et al., 2010; Caliceti, 2002).

When compared with samples of the same algal species, Owenga has the highest values for all previously listed 19 elements in addition to $\mathrm{Ba}, \mathrm{Zn}, \mathrm{V}$ and $\mathrm{Pb}$. This correlation in elevated trace metals between Aora sp. 1 and associated macroalgae, C. scalaris, is unsurprising, as one of the primary means of bioaccumulation by amphipods is through their diet. Algal dwelling amphipods are often herbivores and their primary diet consists of the macroalgae they inhabit (Taylor \& Brown, 2006). Although, it should be noted that contrary to these results, certain species of Aora have shown that host seaweeds are not a major dietary component of these amphipods (Taylor \& Brown, 2006). Trace metal contents in the seawater from Owenga were also high, with Ti concentrations too high to be measured, and second to Hanson Point South, the Owenga water also had the highest concentrations of $\mathrm{V}, \mathrm{Co}, \mathrm{Ni}, \mathrm{Cu}$ and $\mathrm{Mn}$. Interestingly, the high metal contents were not observed in Apohyale sp. 1 from Owenga. Given that this is also an algal dwelling species, it is not clear why it has not picked up the high metal concentrations observed in the Aora species. This suggests that the metal levels may be less significant and/or heterogeneously distributed at Owenga compared with Hanson Point South. Furthermore, possible differences in life-spans between the two species may have caused Aora sp. 1 to pick up an earlier transient signal that the Apohyale sp. 1 missed. 
In contrast to Owenga, the algae from Hanson Point South are not enriched in most of these elements compared with those from Port Hutt and Waitangi Bay, and only had the highest values for $\mathrm{Ti}, \mathrm{Rb}$ and $\mathrm{Cu}$ of the Carpophyllum sp. There is therefore, no consistent, direct correlation between elevated trace metals in the amphipods and associated analysed algae. It should be noted that most sites sampled have a conglomerate of multiple algae species however, and only one species of macroalgae from each site was analysed. The individual amphipod specimens that were analysed may not have been primarily consuming this species of algae analysed from that site over their lifespan. Furthermore, the time frame of bioaccumulation must be considered. The lifespan of an amphipod is commonly 1-2 years. Amphipods therefore provide a running average of trace element concentrations over this time frame. Fucoid algae (e.g. C. scalaris) generally live longer, commonly in the order of 7-10 years (Dunmore, 2006). The longevity of the lifespan of algae mean they represent a running average over a longer period than the amphipods.

Out of the 19 trace elements elevated in the algal amphipod species at Hanson Point and Owenga, only Sc, V, Ti, Mn, Fe, Co, Ni, Cu, Y and La were measured in the seawater samples. Of these 11 elements measured, Hanson Point South either had highest concentrations measured ( $\mathrm{V}, \mathrm{Co}, \mathrm{Ni}, \mathrm{Cu}, \mathrm{Sc}, \mathrm{Y}$ and $\mathrm{La})$, or had concentrations too high to be measured (Mn, Ti \& Fe). Iron concentration was too high to be measured accurately in the water samples collected from both Hanson Point South and Owenga, however, this was true of all other sampling sites analysed other than Port Hutt. The elevations observed in the metals in both the amphipod and seawater data could be anticipated as marine amphipods interact directly with their environment by adsorbing trace elements from the surrounding water column. Overall, this suggests that the amphipods may more likely be reflecting the water than the algae, indicating the trace metals are primarily coming to them from the water directly than indirectly through the algae.

While Hanson Point South has high values for all elements measured in the seawater samples, as previously mentioned there was high wave energy at this sampling locality. This may have increased suspended particles to be captured while sampling. As the water samples were not filtered prior to acidification, suspended elements may leach into the water from the suspended sediments. A water sample was also collected from 
Hanson Point North, $150 \mathrm{~m}$ from the amphipod collection site at Hanson Point South. The Hanson Point South locality was more sheltered within the bay and protected by the wharf, whereas Hanson Point North is more exposed and more heavily influenced by ocean currents. The 11 elements measured in the seawater sample collected from Hanson Point North have comparable concentrations to the other sites (e.g. Port Hutt) and do not show the significant metal elevations in the Owenga and Hanson Point South waters. It may be that the amphipods may be accumulating metals from suspended particles in the water at Hanson Point South, or that the more open site of Hanson Point North means a higher turn over of water and dilution of any point source pollutants.

It should also be noted that both Hanson Point South and Owenga are the southernmost sites analysed, and are located on or in close proximity to the volcanic basement forming the southern part of Chatham Island. Despite there not being a clear distinction in the sediment substrates, it cannot be discounted that at least some of the elevated metal contents may have a natural source from the volcanic basement, for example via runoff from the adjacent uplands.

In order to disentangle what more accurately represents the Hanson Point South environment and the extent of the area that shows the high metal signal additional sampling is required. This would include, sampling in and around the Hanson Point South location, including the collection of filtered and unfiltered water samples and a range of different algae types. This could better distinguish a diffuse natural origin from adjacent volcanic uplands versus an anthropogenic point source, and would also help to determine the pathways of the metals getting into the amphipods.

High levels of As were observed for both amphipod species at Owenga (but not Hanson Point South). These levels were not mirrored in the algal samples collected from Owenga and As was not measured in the seawater samples. As levels were also not notably higher in the sediment substrate at Owenga. Since no other analysed locations exhibited this heightened As concentration it suggests that it is from a local source.

As discussed for Hanson Point South, the amphipods collected from Owenga may not have been predominantly feeding on the algae sampled from this site. Alternatively, the amphipods at Owenga may have been directly bioaccumulating As from the seawater, which was not measured. Arsenic is a metalloid that can be both highly toxic (inorganic 
form species), or non-toxic (organic form) (Ratnaike, 2003; Lewis, 2007). The analytical method here measures total As present and cannot distinguish between the two forms. Therefore, although there are apparently high concentrations of As at Owenga, it must be stressed that it may not be in the toxic inorganic form.

\subsubsection{Elevated Cd levels in the northern localities}

Cadmium was significantly elevated at the two northernmost localities, Cape Pattisson and Kaingaroa West. It should be noted that Cape Pattisson was originally selected as a relatively pristine site.

$\mathrm{Cd}$ is also elevated in the algal samples at these sites relative to the other C. scalaris samples and all additional algae species. Furthermore, Cd concentrations are elevated in the seawater samples collected from Cape Pattisson and Kaingaroa West compared with Port Hutt, Hanson Point South and Owenga. However, they are comparable to Hanson Point South seawater, which has a higher concentration than Cape Pattisson seawater (Table 10). This higher concentration at Hanson Point South may be explained by the leaching of suspended sediments, as previously discussed. There is no evidence for elevated $\mathrm{Cd}$ in the Cape Pattisson and Kaingaroa West sediments relative to the other three primary sites that do not show elevated $\mathrm{Cd}$ in their amphipods. Furthermore, Port Hutt resides on the same basement geology as Cape Pattisson and Kaingaroa West, however $\mathrm{Cd}$ is not elevated in the amphipod samples collected from Port Hutt. This suggests that the Cd source at Cape Pattisson and Kaingaroa West may be a local influence on the northern coast of the Island.

The pattern of high $\mathrm{Cd}$ in the amphipod specimens reflected in their related algae and seawater samples from both Cape Pattisson and Kaingaroa West is consistent with previous studies that have demonstrated that amphipods primarily accumulate trace metals through their diet and adsorption from the surrounding water column (Rainbow, 1995; Marsden \& Rainbow, 2004; Pastorinho et al., 2009). Furthermore, studies have shown much of the uptake of $\mathrm{Cd}$ in amphipods is primarily internal as opposed to adsorption on the body surface (Wright, 1980), consistent with the high Cd observed in the macroalgae.

A possible localised Cd contamination source is the use of superphosphate fertilizers. New Zealand traditionally sourced their superphosphate from Nauru, which had a high 
Cd content in the phosphate (McDowell et al., 2013). Despite a lack of clear records of fertilizers use on Chatham Island, there has been documentation of the Department of Conservation (DOC) using slow release fertilizers in the 1990s in the Kaingaroa Region to help restore Leptinella featherstonii, a woody shrub that thrives on high nutrient overload (de Longe, 2019). Additionally, grasslands can have intensive grazing and farm management practices, such as the use of fertilizer, to improve the land's productivity (Figure 2) (Ministry for the Environment, 2010). Exact locations and types of fertilizer used are not well documented. The application of Cd-bearing phosphates causes leaching of $\mathrm{Cd}$ into the soils and can accumulate long term. Subsequent runoff from contaminated land may continue to leach $\mathrm{Cd}$ in to the waters of the adjacent coastline. If phosphate fertilisers were used in the northern parts of the Island, this could explain the elevated $\mathrm{Cd}$ observed in the amphipods from this coastline.

\subsubsection{Sand hoppers}

As only one species of amphipod, Bellorchestia chathamensis was analysed from the three beach locations, Kaingaroa East, Kaingaroa South and Waitangi Bay, it is not possible to look for consistent patterns of trace element concentrations across multiple species. Also, only single specimen of these larger amphipods were analysed for each sample, making these analyses more vulnerable to outliers. For example, $\mathrm{Ni}$ and $\mathrm{Cr}$ are notably enriched in only one of the B. chathamensis samples from Kaingaroa South, in contrast to the additional three samples of the same species from the same locality. These anomalous concentrations highlight the importance for sample replicates to allow for more rigorous interpretations. Since this enrichment of $\mathrm{Ni}$ and $\mathrm{Cr}$ is not reproduced or duplicated in any of the other data from this locality, this specimen may be unrepresentative of its environment or may have become contaminated with these elements during processing. A larger sample number would be needed to confirm whether these values are an accurate representation of this environment or are a consequent of analytical error.

Rubidium, As, $\mathrm{Cu}$ and $\mathrm{Cs}$ are elevated in the sand hoppers from both Kaingaroa sites (East and South), compared with the Waitangi Bay specimen. These animals inhabit a different environment to the algal-dwelling amphipods and do not live directly in or on the seawater and algae collected nearby. Direct comparisons of these data will be less meaningful, although their environment is close so there may be some influence. Algae 
was not collected from Kaingaroa South, and those collected from Kaingaroa East and Waitangi Bay were of different species and thus cannot be compared directly. Relative to the same algal species $\mathrm{Rb}$, As and $\mathrm{Cu}$ are not highest at either Kaingaroa East or Waitangi Bay. Of these elements, only $\mathrm{Cu}$ was measured in the seawater samples. Consistent with the sand hopper data, $\mathrm{Cu}$ is elevated at the two Kaingaroa sites relative to Waitangi Bay (Table 10).

Aluminium, Ba, Mn, V, Ce, Y, La, Fe, Nb, Nd, Sc, Th, Sm and Yb have a notable elevation in concentrations in the sand hoppers collected from Waitangi Bay. Of these 14 elements only V, Mn, Fe, Y and La were measured in the seawater samples. Mn was the only element which was more elevated in water collected from Waitangi Bay relative to the two Kaingaroa sites. Iron was too concentrated to be measured accurately, however this is comparable with Kaingaroa South. No direct comparisons can be made with the algae as they are of different species, however, the algae sample from Waitangi Bay has the highest Mn regardless of which species or site.

Unlike algal-dwelling amphipod, trace metal concentrations in the sand hopper species are not strongly reflected in the associated seawater and/or algal samples. This is most likely due to the habitat of sand hopper amphipods being within the supralittoral zone and hence their limited interaction with seawater and living seaweed. 


\section{CONCLUSIONS AND FUTURE WORK}

\subsection{Conclusions}

This study sought to provide an initial spatial assessment of trace metal contamination at coastal marine sites around Chatham Island using amphipods species as biomonitors. Element concentrations observed in amphipod species varied spatially with notably high concentrations for many trace metals at Hanson Point South. These high levels (>19 elements) were reflected in the associated seawater but not algae. This indicates that amphipods at Hanson Point South most likely receive their trace metal signal directly from the surrounding seawater and possibly suspended sediments, rather than indirectly through the algae.

By contrast, strikingly elevated concentrations of arsenic were present in all amphipod species from Owenga, an enrichment that was duplicated in the algal samples.

Relatively elevated Cd levels were measured in algal-dwelling amphipods at the two northernmost sites (Cape Pattisson and Kaingaroa West), which were reflected in both water and algae collected from these sites and may reflect land use activities introducing Cd bearing phosphates. Despite distinct spatial patterns in trace metal concentrations, further work is required in order to accurately pinpoint direct pollutant sources.

The second aim of this research was to aid in the ground-truthing and application of a biomonitoring tool that can be applied to New Zealand's coastal marine environments. This included examining the interspecific variations observed between different amphipod species, (with Eusiroides sp. 1 being the most sensitive to metal uptake) and statistical analyses to determine the effect of different size classes absent for most elements investigated. The results confirm the need to investigate species specific uptake and ensure comparable spatial comparisons are only made using the same species. In general, the element levels in amphipod specimens analysed were broadly reflected in their related algae and/or seawater, with some variation as noted above. By contrast, sediments analysed in this research provided little insight to the bio-available metals that were being taken up by the amphipod specimen. Consequently, the amphipods studied here appear to provide a comprehensive reflection of the bioavailable trace metals in their environment. To rigorously use amphipods as biomonitors in New Zealand coastal waters, it is imperative that species sensitivity to elements and possible size effects are constrained. Furthermore, since a single 
biomonitor is only capable of reflecting availability of trace metal pollutants to one lifestyle, a suite of biomonitor species is recommended to enable a rigorous analysis of an environment (Rainbow et al., 1998). Greater confidence can be place on interpreting elevated metals in an environment when multiple amphipod species demonstrate relative enrichments in the same metal at the same locality, as demonstrated in this study. However, since amphipods are prey species and considering the biomagnification of trace metals up the food chain, reasonable conclusions may be drawn about contamination in higher trophic levels using only a single biomonitor. Once accumulation strategies of amphipods (i.e. species specific uptake and size effects) have been considered, amphipods can be used successfully as a biomonitoring tool.

The third and final aim of this research was to provide a case study that can be used in further research to understand temporal changes in the marine environment and the possible effects of human activities such as mining, urban development, trawling and ocean acidification. Monitoring studies are important for assessing heavy metal pollution in different marine environments and compiling baseline data for future monitoring (Chakraborty et al., 2014). Baseline data can serve as a starting point for further investigations into possible temporal environmental changes (Metcheva et al., 2010). This research provides a baseline for $>31$ elements in multiple amphipod species, algae, sediment and waters at >8 sampling localities across Chatham Island.

\subsection{Future work}

This research was successful in achieving the aims set out. It confirms that amphipods are effective as biomonitors in New Zealand coastal waters. This research discovered that amphipods provide more relevant data, compared to other environmental sample types, for evaluating trace metals that may be entering the food chain. However, like most studies, it raises questions and areas that would benefit from further work. The following future work is suggested to aid in providing answers to some of the questions raised.

\section{Detailed re-examination of the Hanson Point South Site}

Hanson Point South was the most contaminated site investigated, with respect to trace metals, as seen in all sample types. The nature of the sediment (collected from rock pools) and water samples (with suspended particles) and the possibility that they do not 
fully represent this environment makes interpretation of the amphipod data for this location difficult. To determine the origin and scale of this apparent trace metal contamination, a detailed investigation into the area is required. This would involve collection of soft sediments in deeper waters, and filtered and unfiltered waters. Further sampling, of amphipod, algae and water in a sampling grid would help to constrain how wide this contamination spreads and may aid in pinpointing possible contamination source(s).

\section{Species specific bioaccumulation in algae}

Literature states that the bioaccumulation of trace metals varies in different species of algae. In order to accurately investigate the relationship between metal levels in the amphipods and their associated macroalgae, more samples would need to be collected and analysed. This would include analysis of all algae species present at each sampling site to determine species specific variations in algae present. Stable isotope data could potentially be utilized to establish the diet of specific amphipod specimens and to determine which plant(s) they are primarily consuming.

\section{Cadmium enrichment at Kaingaroa West and Cape Pattisson}

Remeasuring samples from Cape Pattisson and Kaingaroa West to verify this Cd enrichment together with analysis of soils adjacent to the coastlines at these sites. This would give insight to whether these Cd concentrations observed in the biota are sourced from soil runoff. Exploring the runoff patterns in this region would help discover where and how the contaminated soils may be leaching into the marine environment.

\section{Arsenic enrichment at Owenga}

To determine the severity of the As enrichment observed at Owenga, the arsenic speciation must be determined (i.e. .what proportion of this concentration is in an organic and inorganic form). This would show if the higher levels of As are of the toxic form and hence of concern to the environment. It may also assist in pinpointing the source(s) of contamination. 


\section{REFERENCES}

Adriano, D. C. (2001). Biogeochemistry, bioavailability and risks of metals. Trace Elements in the Terrestrial Environment (2nd ed.). New York, NY: SpringerVerlag.

Agardh, J. G. (1870). Om Chatham-öarnes alger. Öfversigt af Kongl. VetenskapsAdademiens Förhandlingar, 27, 435-456.

Agardh, J. G. (1876). Species genera et ordines algarum, seu descriptiones succinctae specierum, generum et ordinum, quibus algarum regnum constituitur. Volumen tertium: de Florideis curae posteriores. Leipzig, Germany: C.W.K. Gleerup.

Al-Mur, B. A., Quicksall, A. N., \& Al-Ansari, A. M. (2017). Spatial and temporal distribution of heavy metals in coastal core sediments from the Red Sea, Saudi Arabia. Oceanologia, 59(3), 262-270.

Anderson, B. S., Phillips, B. M., Voorhees, J. P., Deng, X., Geraci, J., Worcester, K., \& Tjeerdema, R. S. (2018). Changing patterns in water toxicity associated with current use pesticides in three California agriculture regions. Integrated environmental assessment and management, 14(2), 270-281.

Barka, S., Pavillon, J. F., \& Amiard-Triquet, C. (2010). Metal distributions in Tigriopus brevicornis (Crustacea, Copepoda) exposed to copper, zinc, nickel, cadmium, silver, and mercury, and implication for subsequent transfer in the food web. Environmental toxicology, 25(4), 350-360.

Blott, S. J., \& Pye, K. (2001). GRADISTAT: a grain size distribution and statistics package for the analysis of unconsolidated sediments. Earth surface processes and Landforms, 26(11), 1237-1248.

Bostock, H., Jenkins, C., Mackay, K., Carter, L., Nodder, S., Orpin, A., \& Wysoczanski, R. (2018). Distribution of surficial sediments in the ocean around New Zealand/Aotearoa. Part A: continental slope and deep ocean. New Zealand Journal of Geology and Geophysics, 62(1), 1-23.

Brečević, L., \& Kralj, D. (2007). On calcium carbonates: from fundamental research to application. Croatica Chemica Acta, 80(3-4), 467-484.

Breitholtz, M., Hill, C., \& Bengtsson, B. E. (2001). Toxic substances and reproductive disorders in Baltic fish and crustaceans. AMBIO: A Journal of the Human Environment, 30(4), 210-216.

Burger, J. (2008). Assessment and management of risk to wildlife from cadmium. Science of the Total Environment, 389(1), 37-45.

Caliceti, M., Argese, E., Sfriso, A., \& Pavoni, B. (2002). Heavy metal contamination in the seaweeds of the Venice lagoon. Chemosphere, 47(4), 443-454.

Campbell, H. J. (1993). Cretaceous-Cenozoic geology and biostratigraphy of the 
Chatham Islands, New Zealand (Vol. 2). Lower Hutt, New Zealand: Institute of Geological \& Nuclear Sciences.

Campbell, H. J., \& Christie, A. B. (1994). Sheet QM405 Chatham Island Geological Resource Map of New Zealand 1:250 000 (Report No. 94/25). Lower Hutt, New Zealand: Institute of Geological \& Nuclear Sciences.

Canli, M., \& Atli, G. (2003). The relationships between heavy metal (Cd, Cr, Cu, Fe, $\mathrm{Pb}, \mathrm{Zn}$ ) levels and the size of six Mediterranean fish species. Environmental pollution, 121(1), 129-136.

Carbines, M. J., Walker, J. W., Cameron, M. J., \& Vaughan, M. (2013). Marine Monitoring Plan (Technical Report No. TR2013/025). Auckland, New Zealand: Auckland Council.

Chaalali, A., Brind'Amour, A., Dubois, S. F., \& Le Bris, H. (2017). Functional roles of an engineer species for coastal benthic invertebrates and demersal fish. Ecology and evolution, 7(15), 5542-5559.

Chiswell, S. M., Bostock, H. C., Sutton, P. J., \& Williams, M. J. (2015). Physical oceanography of the deep seas around New Zealand: a review. New Zealand Journal of Marine and Freshwater Research, 49(2), 286-317.

Company, R., Serafim, A., Lopes, B., Cravo, A., Kalman, J., Riba, I., Del Valls, T. A., Blasco, J., Delgado, J., Sarmiento, A. M., Nieto, J. M., Shepherd, T. J., Nowell, G., \& Bebianno, M. J. (2011). Source and impact of lead contamination on $\delta$ aminolevulinic acid dehydratase activity in several marine bivalve species along the Gulf of Cadiz. Aquatic toxicology, 101(1), 146-154.

Condie, K. C. (1993). Chemical composition and evolution of the upper continental crust: contrasting results from surface samples and shales. Chemical geology, 104(1-4), 1-37.

Conti, E., Dattilo, S., Costa, G., \& Puglisi, C. (2016). Bioaccumulation of trace elements in the sandhopper Talitrus saltator (Montagu) from the Ionian sandy coasts of Sicily. Ecotoxicology and environmental safety, 129, 57-65.

Dallinger, R., \& Rainbow, P. S. (1993). Ecotoxicology of metals in invertebrates. Boca Raton, FL: CRC Press.

de Longe, P. J. (2019). Chatham oddities - the anomalous Chatham Island button daisy. Retrieved from https://chathams.co.nz/chatham-oddities-the-anomalouschatham-island-button-daisy/

Department of Conservation. (2019). Chatham Island plants. Retrieved 26 March, 2019, from https://www.doc.govt.nz/nature/native-plants/chatham-islands-plants/

Dos Santos, I. R., Silva-Filho, E. V., Schaefer, C., Sella, S. M., Silva, C. A., Gomes, V., 
Passos, M. J., \& Van Ngan, P. (2006). Baseline mercury and zinc concentrations in terrestrial and coastal organisms of Admiralty Bay, Antarctica. Environmental Pollution, 140(2), 304-311.

Dunmore, R. A. (2006). Demography of early life stages of habitat-forming intertidal fucoid algae (Doctoral dissertation, Canterbury University, Christchurch, New Zealand). Retrieved from https://ir.canterbury.ac.nz/bitstream/handle/10092/1364/thesis_fulltext.pdf?sequ ence $=1 \&$ isAllowed $=\mathrm{y}$

Dunn, D. A. (1980). Revised techniques for quantative calcium carbonate analysis using the "Karbonat-Bombe", and comparisons to other methods. Journal of Sedimentary Research, 50, 631-637.

Dunne, M. (2007). New Zealand Customs Service: Changes over the Last Decade and into the Future. World Customs Journal, 1(1), 41-47.

Duquesne, S., Riddle, M., Schulz, R., \& Liess, M. (2000). Effects of contaminants in the Antarctic environment - potential of the gammarid amphipod crustacean Paramorea walkeri as a biological indicator for Antarctic ecosystems based on toxicity and bioacccumulation of copper and cadmium. Aquatic Toxicology, 49(1-2), 131-143.

Duquesne, S., \& Riddle, M. (2002). Biological monitoring of heavy-metal contamination in coastal waters off Casey Station, Windmill Islands, East Antarctica. Polar Biology, 25(3), 206-215.

Egilsdottir, H., Spicer, J. I., \& Rundle, S. D. (2009). The effect of CO2 acidified sea water and reduced salinity on aspects of the embryonic development of the amphipod Echinogammarus marinus (Leach). Marine Pollution Bulletin, 58(8), 1187-1191.

Eisenring, M., Altermatt, F., Westram, A. M., \& Jokela, J. (2016). Habitat requirements and ecological niche of two cryptic amphipod species at landscape and local scales. Ecosphere, 7(5), 1-13.

Escobar, J., Curtis, J. H., Brenner, M., Hodell, D. A., \& Holmes, J. A. (2010). Isotope measurements of single ostracod valves and gastropod shells for climate reconstruction: evaluation of within-sample variability and determination of optimum sample size. Journal of Paleolimnology, 43(4), 921-938.

Faul, F., Erdfelder, E., Buchner, A., \& Lang, A.-G. (2009). Statistical power analyses using G*Power 3.1: Tests for correlation and regression analyses. Behavior Research Methods, 41, 1149-1160.

Folk, R. L. and Ward, W. C. (1957). Brazos River bar: a study in the significance of grain size parameters. Journal of Sedimentary Petrology, 27, 3-26.

Forsyth, P. J., Barrell, D. J. A., \& Jongens, R. (2008). Geology of the Christchurch 
area: 1:250 000. Lower Hutt, New Zealand: Institute of Geological \& Nuclear Sciences.

Fox, A. L., Hughes, E. A., Trocine, R. P., Trefry, J. H., Schonberg, S. V., McTigue, N. D., Lasorsa, B. K., Konar, B., \& Cooper, L. W. (2014). Mercury in the northeastern Chukchi Sea: Distribution patterns in seawater and sediments and biomagnification in the benthic food web. Deep Sea Research Part II: Topical Studies in Oceanography, 102, 56-67.

Friend, J. A., \& Richardson, A. M. M. (1986). Biology of terrestrial amphipods. Annual Review of Entomology, 31(1), 25-48.

Frontin-Rollet, G. E. (2017). The geochemistry and ecotoxicity of offshore New Zealand phosphorites (Master's thesis, Victoria University of Wellington, Wellington, New Zealand). Retrieved from https://researcharchive.vuw.ac.nz/xmlui/bitstream/handle/10063/7706/thesis_acc ess.pdf? sequence $=1$

García, M. E., \& Ferrari, L. (2012). Age differential response of Hyalella curvispina to a cadmium pulse: influence of sediment particle size. Ecotoxicology and environmental safety, 80, 314-320.

Ghrefat, H., \& Yusuf, N. (2006). Assessing Mn, Fe, Cu, Zn, and Cd pollution in bottom sediments of Wadi Al-Arab Dam, Jordan. Chemosphere, 65(11), 2114-2121.

Godoi, V. A., Bryan, K. R., Stephens, S. A., \& Gorman, R. M. (2017). Extreme waves in New Zealand waters. Ocean Modelling, 117, 97-110.

Gonçalves, S. C., \& Marques, J. C. (2017). Assessment and management of environmental quality conditions in marine sandy beaches for its sustainable use-Virtues of the population based approach. Ecological Indicators, 74, 140146.

Gordon, D. P. (2013). New Zealand's Genetic Diversity. In J. Dymond (Ed.), Ecosystem services in New Zealand - conditions and trends (pp. 162-191). Lincoln, New Zealand: Manaaki Whenua Press.

Guerra-García, J. M., Baeza-Rojano, E., Cabezas, M. P., Díaz-Pavón, J. J., Pacios, I., \& García-Gómez, J. C. (2009). The amphipods Caprella penantis and Hyale schmidtii as biomonitors of trace metal contamination in intertidal ecosystems of Algeciras Bay, Southern Spain. Marine Pollution Bulletin, 58(5), 783-786.

Guerra-García, J. M., De Figueroa, J. T., Navarro-Barranco, C., Ros, M., SánchezMoyano, J. E., \& Moreira, J. (2014). Dietary analysis of the marine Amphipoda (Crustacea: Peracarida) from the Iberian Peninsula. Journal of Sea Research, 85, 508-517.

Guerra-García, J. M., Ruiz-Tabares, A., Baeza-Rojano, E., Cabezas, M. P., Díaz-Pavón, 
J. J., Pacios, I., Maestre, M., González, A. R., Espinosa, F., \& García-Gómez, J. C. (2010). Trace metals in Caprella (Crustacea: Amphipoda). A new tool for monitoring pollution in coastal areas?. Ecological Indicators, 10(3), 734-743.

Gust, K. A., \& Fleeger, J. W. (2005). Exposure-related effects on Cd bioaccumulation explain toxicity of Cd-phenanthrene mixtures in Hyalella azteca. Environmental Toxicology and Chemistry: An International Journal, 24(11), 2918-2926.

Hay, R. F., Mutch, A. R., \& Watters, W. A. (1970). Geology of the Chatham Islands (No. 83). Lower Hutt, New Zealand: New Zealand Geological Survey.

Hayward, B. W., \& Grenfell, H. R. (1999). Chatham Island foraminifera (Protista), New Zealand. New Zealand Natural Sciences, 24, 69-88.

Holt, K. A. (2008). The quaternary history of Chatham Island, New Zealand (Doctoral dissertation, Massey University, Palmerston North, New Zealand). Retrieved from https://mro.massey.ac.nz/bitstream/handle/10179/757/1front.pdf?sequence $=2$ \&is Allowed $=\mathrm{y}$

Horton, T., Lowry, J., \& De Broyer, C. (2019). World Amphipoda Database: Amphipoda. In World Register of Marine Species. Retrieved 21 September, 2019, from http://www.marinespecies.org/aphia.php?p=taxdetails\&id=1135 on 2019-09-21

Hurley D.E. (1956). Studies on the New Zealand Amphipodan Fauna. 13. Sandhoppers of the Genus Talorchestia. Transactions of the Royal Society of New Zealand, $84,2,359-383$.

Hurley, D. E. (1958). A key to the families of New Zealand amphipods. Tuatara, 7(2), 71-83.

Hyne, R. V. (2011). Review of the reproductive biology of amphipods and their endocrine regulation: identification of mechanistic pathways for reproductive toxicants. Environmental toxicology and chemistry, 30(12), 2647-2657.

Ikemoto, T., Tu, N. P. C., Okuda, N., Iwata, A., Omori, K., Tanabe, S., Tuyen, B. C., \& Takeuchi, I. (2008). Biomagnification of trace elements in the aquatic food web in the Mekong Delta, South Vietnam using stable carbon and nitrogen isotope analysis. Archives of environmental contamination and toxicology, 54(3), 504515 .

Jochum, K. P., Weis, U., Schwager, B., Stoll, B., Wilson, S. A., Haug, G. H., Andreae, M. O., \& Enzweiler, J. (2016). Reference values following ISO guidelines for frequently requested rock reference materials. Geostandards and Geoanalytical Research, 40(3), 333-350.

Kahle, J., \& Zauke, G. P. (2003). Bioaccumulation of trace metals in the Antarctic amphipod Orchomene plebs: evaluation of toxicokinetic models. Marine Environmental Research, 55(5), 359-384. 
Karuppasamy, M. P., Qurban, M. A., Krishnakumar, P. K., Mushir, S. A., \& Abuzaid, N. (2017). Evaluation of toxic elements $\mathrm{As}, \mathrm{Cd}, \mathrm{Cr}, \mathrm{Cu}, \mathrm{Ni}, \mathrm{Pb}$ and $\mathrm{Zn}$ in the surficial sediments of the Red Sea (Saudi Arabia). Marine pollution bulletin, 119(2), 181-190.

Keil, S., De Broyer, C., \& Zauke, G. P. (2008). Significance and interspecific variability of accumulated trace metal concentrations in Antarctic benthic crustaceans. International Review of Hydrobiology, 93(1), 106-126.

King, C. K., Gale, S. A., Hyne, R. V., Stauber, J. L., Simpson, S. L., \& Hickey, C. W. (2006). Sensitivities of Australian and New Zealand amphipods to copper and zinc in waters and metal-spiked sediments. Chemosphere, 63(9), 1466-1476.

Krumbein, W. C. \& Pettijohn, F. J. (1938). Manual of Sedimentary Petrography. New York, NY: Appleton-Century-Crofts.

Krumgalz, B. S. (1989). Unusual grain size effect on trace metals and organic matter in contaminated sediments. Marine Pollution Bulletin, 20(12), 608-611.

Leung-Wai, J., \& Borren, T. (2017). Chatham Islands Economic Profile: Final Report. Retrieved from https://www.cic.govt.nz/assets/CIC/Documents/ChathamIslands-Economic-Profile-Report-2017.pdf

Lewis, A. S. (2007). Organic versus inorganic arsenic in herbal kelp supplements. Environmental health perspectives, 115(12), A575.

Madrid, L. (2010). Heavy metals: Reminding a long-standing and sometimes forgotten controversy. Geoderma, 1(155), 128-129.

Marin, I. N. (2017). The invaders as natural biondicators using the example invasive amphipod Gmelinoides fasciatus (Stebbing, 1899) in the Moscow River Basin: the suggestion of G. lacustris/G. fasciatus bioindication pair. Ukrainian Journal of Ecology, 7(4), 457-461.

Marsden, I. D. (2002). Life-history traits of a tube-dwelling corophioid amphipod, Paracorophium excavatum, exposed to sediment copper. Journal of Experimental Marine Biology and Ecology, 270(1), 57-72.

Marsden, I. D., \& Rainbow, P. S. (2004). Does the accumulation of trace metals in crustaceans affect their ecology - the amphipod example?. Journal of Experimental Marine Biology and Ecology, 300(1-2), 373-408.

Mathews, T., \& Fisher, N. S. (2008). Trophic transfer of seven trace metals in a fourstep marine food chain. Marine Ecology Progress Series, 367, 23-33.

McDowell, R. W., Taylor, M. D., \& Stevenson, B. A. (2013). Natural background and anthropogenic contributions of cadmium to New Zealand soils. Agriculture, Ecosystems \& Environment, 165, 80-87. 
McLennan, S. M. (2001). Relationships between the trace element composition of sedimentary rocks and upper continental crust. Geochemistry, Geophysics, Geosystems, 2(4).

Mehanna, S. F., El-Azim, H. A., \& Belal, A. A. (2016). Impact of metal pollution, food availability, and excessive fishing on Rhabdosargus haffara stock (family: Sparidae) in Timsah lake. Environmental Science and Pollution Research, 23(16), 15888-15898.

Ministry for the Environment. (2010). Land: Land Use. Retrieved from https://www. mfe.govt.nz/sites/default/files/media/Land/landuse_0_0.pdf?fbclid=IwAR04Dc VBp9jQkLqincr9-1wplfA63IHoYXgJridCzvFWMC8PmVswqQurvsc

Morillo, J., Usero, J., \& Gracia, I. (2004). Heavy metal distribution in marine sediments from the southwest coast of Spain. Chemosphere, 55(3), 431-442.

Morrison, L., Bennion, M., McGrory, E., Hurley, W., \& Johnson, M. P. (2017). Talitrus saltator as a biomonitor: An assessment of trace element contamination on an urban coastline gradient. Marine pollution bulletin, 120(1-2), 232-238.

Muller, G., \& Gastner, M. (1971). The "Karbonat-Bombe", a simple device for the determination of carbonate content in sediments, soils and other materials. Neues Jahrbuch für Mineralogie, 10, 466-469.

Muniz, P., Danulat, E., Yannicelli, B., Garcia-Alonso, J., Medina, G., \& Bicego, M. C. (2004). Assessment of contamination by heavy metals and petroleum hydrocarbons in sediments of Montevideo Harbour (Uruguay). Environment International, 29(8), 1019-1028.

New Zealand Department of Internal Affairs. (2016). Waitangi Wharf upgrade: Project summary. Retrieved from https://www.xbloc.com/sites/default/files/domain671/documents/waitangi-wharf-upgrade-project-and-resource-consentssummary-671-14895647081274776841.pdf

Nieboer, E., \& Richardson, D. H. (1980). The replacement of the nondescript term 'heavy metals' by a biologically and chemically significant classification of metal ions. Environmental Pollution Series B, Chemical and Physical, 1(1), 326.

Odom, I. E. (1984). Smectite clay minerals: properties and uses. Philosophical Transactions of the Royal Society of London A, 311(1517), 391-409.

Olmedo, P., Hernández, A. F., Pla, A., Femia, P., Navas-Acien, A., \& Gil, F. (2013). Determination of essential elements (copper, manganese, selenium and zinc) in fish and shellfish samples. Risk and nutritional assessment and mercuryselenium balance. Food and chemical toxicology, 62, 299-307.

Pallas, P. S. (1766). Miscellanea zoologica quibus novae imprimis atque obscurae animalium species describuntur et observationibus iconibusque illustrantur. https://doi.org/10.5962/bhl.title.69851 
Pan, K., \& Wang, W. X. (2012). Trace metal contamination in estuarine and coastal environments in China. Science of the total environment, 421, 3-16.

Pastorinho, M. R., Telfer, T. C., \& Soares, A. M. (2009). Amphipod susceptibility to metals: cautionary tales. Chemosphere, 75(11), 1423-1428.

Pearce, P. R. (2016). The climate and weather of the Chatham Islands (2nd ed.) (Report No. 73). Retrieved from https://www.niwa.co.nz/files/Chathams_Climate.pdf

Phillips, D. J. (1977). The use of biological indicator organisms to monitor trace metal pollution in marine and estuarine environments - a review. Environmental Pollution, 13(4), 281-317.

Pourret, O. (2018). Letter on the necessity of banning the term "Heavy Metal" from the scientific literature. Sustainability, 10, 2879.

Rainbow, P. S. (1995). Biomonitoring of heavy metal availability in the marine environment. Marine pollution bulletin, 31(4-12), 183-192.

Rainbow, P. S. (2002). Trace metal concentrations in aquatic invertebrates: why and so what?. Environmental pollution, 120(3), 497-507.

Rainbow, P. S. (2007). Trace metal bioaccumulation: models, metabolic availability and toxicity. Environment international, 33(4), 576-582.

Rainbow, P. S., Amiard-Triquet, C., Amiard, J. C., Smith, B. D., \& Langston, W. J. (2000). Observations on the interaction of zinc and cadmium uptake rates in crustaceans (amphipods and crabs) from coastal sites in UK and France differentially enriched with trace metals. Aquatic Toxicology, 50(3), 189-204.

Rainbow, P. S., Emson, R. H., Smith, B. D., Moore, P. G., \& Mladenov, P. V. (1993). Talitrid amphipods as biomonitors of trace metals near Dunedin, New Zealand. New Zealand journal of marine and freshwater research, 27(2), 201207.

Rainbow, P. S., \& Moore, P. G. (1986). Comparative metal analyses in amphipod crustaceans. Hydrobiologia, 141(3), 273-289.

Rainbow, P. S., Moore, P. G., \& Watson, D. (1989). Talitrid amphipods (Crustacea) as biomonitors for copper and zinc. Estuarine, Coastal and Shelf Science, 28(6), 567-582.

Ratnaike, R. N. (2003). Acute and chronic arsenic toxicity. Postgraduate medical journal, 79(933), 391-396.

Ratte, H. T. (1999). Bioaccumulation and toxicity of silver compounds: a review. Environmental Toxicology and Chemistry: An International Journal, 18(1), 89-108. 
Reish, D. J. (1993). Effects of metals and organic compounds on survival and bioaccumulation in two species of marine gammaridean amphipod, together with a summary of toxicological research on this group. Journal of Natural History, 27(4), 781-794.

Rodrigues, S. K., Abessa, D. M., Rodrigues, A. P. D. C., Soares-Gomes, A., Freitas, C. B., Santelli, R. E., Freire, A., \& Machado, W. (2017). Sediment quality in a metal-contaminated tropical bay assessed with a multiple lines of evidence approach. Environmental Pollution, 228, 265-276.

Rodríguez-Romero, A., Khosrovyan, A., Del Valls, T. A., Obispo, R., Serrano, F., Conradi, M., \& Riba, I. (2013). Several benthic species can be used interchangeably in integrated sediment quality assessment. Ecotoxicology and environmental safety, 92, 281-288.

Sabater, S., Guasch, H., Ricart, M., Romaní, A., Vidal, G., Klünder, C., \& SchmittJansen, M. (2007). Monitoring the effect of chemicals on biological communities. The biofilm as an interface. Analytical and bioanalytical chemistry, 387(4), 1425-1434.

Schäfer, S., Buchmeier, G., Claus, E., Duester, L., Heininger, P., Körner, A., Mayer, P., Paschke, A., Rauert, C., Reifferscheid, G., Rüdel, H., Schlechtriem, C., Schröter-Kermani, C., Schudoma, D., Smedes, F., Steffen, D., \& Vietoris, F. (2015). Bioaccumulation in aquatic systems: methodological approaches, monitoring and assessment. Environmental Sciences Europe, 27(1), 5.

Strode, E., \& Balode, M. (2013). Toxico-resistance of Baltic amphipod species to heavy metals. Crustaceana, 86(7-8), 1007-1024.

Sutton, P. (2001). Detailed structure of the subtropical front over Chatham Rise, east of New Zealand. Journal of Geophysical Research: Oceans, 106(C12), 3104531056.

Tavares, M. R., Grande, H., \& Jacobucci, G. B. (2013). Habitat and food selection by herbivorous amphipods associated with macroalgal beds on the southeast coast of Brazil. Nauplius, 21(1), 09-15.

Taylor, R. B., \& Brown, P. J. (2006). Herbivory in the gammarid amphipod Aora typica: relationships between consumption rates, performance and abundance across ten seaweed species. Marine Biology, 149(3), 455-463.

Titjen, J. Q. (2007). Tertiary limestones and sedimentary dykes on Chatham Islands, southwest Pacific Ocean, New Zealand (Doctoral dissertation, University of Waikato, Hamilton, New Zealand). Retrieved from https://hdl.handle.net/10 $289 / 2411$

Tornero, V., \& Hanke, G. (2016). Chemical contaminants entering the marine environment from sea-based sources: a review with a focus on European seas. Marine Pollution Bulletin, 112(1-2), 17-38. 
Udden, J. A. (1914). Mechanical composition of clastic sediments. Bulletin of the Geological Society of America, 25, 655-744.

Ujević, I., Odžak, N., \& Barić, A. (2000). Trace metal accumulation in different grain size fractions of the sediments from a semi-enclosed bay heavily contaminated by urban and industrial wastewaters. Water Research, 34(11), 3055-3061.

Vijayram, K., \& Geraldine, P. (1996). Regulation of essential heavy metals ( $\mathrm{Cu}, \mathrm{Cr}$, and $\mathrm{Zn}$ ) by the freshwater prawn Macrobrachium malcolmsonii (Milne

Edwards). Bulletin of Environmental Contamination and Toxicology, 56(2), 335342.

Wang, M., Tong, Y., Chen, C., Liu, X., Lu, Y., Zhang, W., He, W., Wang, X., Zhao, S., \& Lin, Y. (2018). Ecological risk assessment to marine organisms induced by heavy metals in China's coastal waters. Marine Pollution Bulletin, 126, 349-356.

Weeks, J. M., \& Rainbow, P. S. (1991). The uptake and accumulation of zinc and copper from solution by two species of talitrid amphipods (Crustacea). Journal of the Marine Biological Association of the United Kingdom, 71(4), 811-826.

Wentworth, C. K. (1922). A scale of grade and class terms for clastic sediments. Journal of Geology, 30, 377-392.

Wiltsche, H., \& Knapp, G. (2014). Flow digestion systems with microwave and conductive heating. In E. M. de Moraes Flores (ed.), Microwave-Assisted Sample Preparation for Trace Element Analysis (pp. 253-280). Amsterdam, Netherlands: Elsevier.

Wood, R. A., Andrews, P. B., Herzer, R. H., Cook, R. A., Hornibrook, N. de B., Hoskins, R. H., Beu, A. G., Maxwell, P. A., Keyes. I. W., Raine, J. I., Mildenhall, D. C., Wilson, G. J., Smale, D., Soong, C. W. R., \& Watters, W. A. (1989). New Zealand Geological Survey Basin Studies 3: Cretaceous and Cenozoic geology of the Chatham Rise region, South Island, New Zealand. Lower Hutt, New Zealand: New Zealand Geological Survey.

Wright, D. A. (1980). Cadmium and calcium interactions in the freshwater amphipod Gammarus pulex. Freshwater Biology, 10, 123-133.

Wright, D. A., \& Frain, J. W. (1981). The effect of calcium on cadmium toxicity in the freshwater amphipod, Gammarus pulex (L.). Archives of Environmental Contamination and Toxicology, 10(3), 321-328.

Wurl, O., \& Obbard, J. P. (2004). A review of pollutants in the sea-surface microlayer (SML): a unique habitat for marine organisms. Marine pollution bulletin, 48(1112), 1016-1030.

Yong, J., Jie, Z., Liwei, Z., Xiaoli, L., Dingding, W., Jiali, L., \& Jing, L. (2017). 
References

Analysis of heavy metals in the surface sediments of shallow lakes in Nanjishan (Poyang Lake) Natural Wetland in China. Journal of Environmental

Biology, 38(4), 561-570.

Zhang, L., Ye, X., Feng, H., Jing, Y., Ouyang, T., Yu, X., Liang, R., Gao, C., \& Chen, W. (2007). Heavy metal contamination in western Xiamen Bay sediments and its vicinity, China. Marine pollution bulletin, 54(7), 974-982. 
APPENDIX A: STANDARD REFERENCE MATERIAL

\begin{tabular}{|c|c|c|c|c|c|c|c|c|c|c|}
\hline \multirow{3}{*}{ Run } & \multicolumn{2}{|c|}{ DOLT-5 (1)1 } & \multicolumn{2}{|c|}{ DOLT-5 (2)1 } & \multicolumn{2}{|c|}{ DOLT-51 } & \multicolumn{2}{|c|}{$\begin{array}{l}\text { DOLT-5 } \\
\text { average }\end{array}$} & \multicolumn{2}{|c|}{$\begin{array}{l}\text { Certified } \\
\text { values }\end{array}$} \\
\hline & Algae & & Algae & & Amphip & ods & & & & \\
\hline & $w t \%$ & $1 S D$ & $w t \%$ & $1 S D$ & $w t \%$ & $1 S D$ & $w t \%$ & $1 S D$ & $w t \%$ & $1 S D$ \\
\hline $\mathbf{C a}$ & 0.036 & 0.004 & 0.038 & 0.003 & 0.036 & 0.002 & 0.037 & 0.003 & 0.055 & 0.008 \\
\hline Mg & 0.098 & 0.004 & 0.098 & 0.006 & 0.084 & 0.005 & 0.093 & 0.005 & 0.09 & 0.01 \\
\hline & ppm & $1 S D$ & $p p m$ & $1 S D$ & ppm & $1 S D$ & ppm & $1 S D$ & ppm & $1 S D$ \\
\hline $\mathbf{L i}$ & 0.079 & 0.007 & 0.084 & 0.005 & 0.068 & 0.003 & 0.077 & 0.005 & & \\
\hline Al & 13.2 & 0.9 & 13.4 & 0.9 & 15.0 & 0.6 & 13.9 & 0.8 & 31.7 & 4.2 \\
\hline Sc & 0.0019 & 0.0019 & 0.0043 & 0.0007 & 0.0017 & 0.0007 & 0.0026 & 0.0011 & & \\
\hline $\mathbf{T i}$ & 0.417 & 0.023 & 0.428 & 0.035 & 0.30 & 0.03 & 0.38 & 0.03 & & \\
\hline V & 0.50 & 0.02 & 0.50 & 0.02 & 0.47 & 0.01 & 0.49 & 0.02 & 0.51 & 0.06 \\
\hline $\mathrm{Cr}$ & 1.88 & 0.05 & 1.87 & 0.07 & 2.36 & 0.04 & 2.04 & 0.05 & 2.35 & 0.58 \\
\hline Mn & 9.1 & 0.3 & 9.2 & 0.2 & 8.87 & 0.16 & 9.06 & 0.22 & 8.91 & 0.7 \\
\hline $\mathrm{Fe}$ & 1110 & 76 & 1070 & 82 & 1010 & 55 & 1063 & 71 & 1070 & 80 \\
\hline Co & 0.26 & 0.01 & 0.3 & 0.01 & 0.256 & 0.006 & 0.272 & 0.009 & 0.267 & 0.026 \\
\hline $\mathrm{Ni}$ & 1.42 & 0.04 & 1.41 & 0.05 & 1.73 & 0.02 & 1.52 & 0.04 & 1.71 & 0.56 \\
\hline $\mathrm{Cu}$ & 36.3 & 0.9 & 36.3 & 0.7 & 34.3 & 0.5 & 35.6 & 0.7 & 35 & 2.4 \\
\hline Zn & 110 & 3 & 109 & 4 & 120 & 2 & 113 & 3 & & \\
\hline Ga & 0.0034 & 0.0006 & 0.0034 & 0.0006 & 0.005 & 0.001 & 0.004 & 0.001 & & \\
\hline As & 33.1 & 1.6 & 34.7 & 7.6 & 34.3 & 1.0 & 34 & 3.4 & 34.6 & 2.4 \\
\hline $\mathbf{R b}$ & 5.08 & 0.08 & 5.14 & 0.11 & 4.73 & 0.08 & 4.98 & 0.09 & & \\
\hline $\mathrm{Sr}$ & 3.92 & 0.15 & 3.74 & 4.58 & 3.43 & 0.12 & 3.7 & 1.62 & 3.73 & \\
\hline Y & 0.017 & 0.001 & 0.016 & 0.001 & 0.015 & 0.0003 & 0.016 & 0.0008 & & \\
\hline Nb & 0.0025 & 0.0007 & 0.0039 & 0.0005 & 0.0031 & 0.0002 & 0.0032 & 0.0005 & & \\
\hline Mo & 1.39 & 0.03 & 1.3678 & 0.0194 & 1.34 & 0.02 & 1.37 & 0.02 & 1.41 & 0.22 \\
\hline Cd & 13.9 & 0.7 & 13.85 & 2.14 & 14.6 & 0.3 & 14.1 & 1 & 14.5 & 0.6 \\
\hline Sn & 0.282 & 0.01 & 0.288 & 0.014 & 0.072 & 0.005 & 0.214 & 0.010 & 0.069 & 0.036 \\
\hline Cs & 0.07 & 0.002 & 0.071 & 0.002 & 0.065 & 0.001 & 0.069 & 0.002 & & \\
\hline Ba & 0.095 & 0.006 & 0.101 & 0.004 & 0.096 & 0.007 & 0.097 & 0.006 & & \\
\hline $\mathbf{L a}$ & 0.021 & 0.001 & 0.022 & 0.001 & 0.021 & 0.001 & 0.021 & 0.001 & & \\
\hline $\mathrm{Ce}$ & 0.038 & 0.001 & 0.04 & 0.0004 & 0.038 & 0.001 & 0.039 & 0.001 & & \\
\hline Nd & 0.019 & 0.001 & 0.019 & 0.002 & 0.02 & 0.001 & 0.019 & 0.001 & & \\
\hline Sm & 0.0046 & 0.0004 & 0.0034 & 0.0006 & 0.0033 & 0.0003 & 0.0038 & 0.0004 & & \\
\hline Yb & 0.001 & 0.0002 & 0.0013 & 0.0005 & 0.0009 & 0.0001 & 0.0011 & 0.0003 & & \\
\hline TI & 0.0135 & 0.0004 & 0.0126 & 0.0004 & 0.0126 & 0.0002 & 0.0129 & 0.0003 & & \\
\hline $\mathbf{P b}$ & 0.178 & 0.005 & 0.179 & 0.005 & 0.149 & 0.002 & 0.169 & 0.004 & 0.162 & 0.032 \\
\hline $\mathbf{B i}$ & 0.02 & 0.001 & 0.021 & 0.001 & 0.038 & 0.001 & 0.026 & 0.001 & & \\
\hline Th & 0.0032 & 0.0002 & 0.0047 & 0.0004 & 0.0024 & 0.0003 & 0.0034 & 0.0003 & & \\
\hline $\mathbf{U}$ & 0.084 & 0.003 & 0.084 & 0.001 & 0.077 & 0.001 & 0.082 & 0.002 & & \\
\hline
\end{tabular}

DOLT-5 (dogfish liver) - sourced from the Canadian National Research Council, SRM used for amphipod and algal samples. 


\begin{tabular}{|c|c|c|c|c|c|c|}
\hline \multirow[t]{2}{*}{ Sample } & \multicolumn{6}{|c|}{ Dolt running average, from CAIME project 2018 - $2019(n=13)$} \\
\hline & $w t \%$ & $R S D$ & $\begin{array}{l}\text { Average measured/ } \\
\text { SRM reference } \\
\text { value }\end{array}$ & $\begin{array}{l}\text { SRM reference } \\
\text { values }\end{array}$ & $95 C I$ & $\begin{array}{l}95 \% \\
C I \%\end{array}$ \\
\hline TiO2 & 0.70 & 34.2 & & & & \\
\hline Al2O3 & 16.9 & 20.0 & 0.53 & 31.7 & 4.2 & 13 \\
\hline $\mathrm{Fe} 2 \mathrm{O3}(\mathrm{t})$ & 1,141 & 20.3 & 1.07 & 1070 & 80 & 7 \\
\hline MgO & 958 & 23.0 & 1.02 & 940 & 100 & 11 \\
\hline MnO & 10 & 21.8 & 1.09 & 8.91 & 0.7 & 8 \\
\hline \multirow[t]{2}{*}{$\mathrm{CaO}$} & 408 & 22.9 & 0.74 & 550 & 80 & 15 \\
\hline & ppm & $R S D$ & $\begin{array}{l}\text { Average measured/ } \\
\text { SRM reference } \\
\text { value }\end{array}$ & $\begin{array}{l}\text { SRM reference } \\
\text { values }\end{array}$ & $95 C I$ & $\begin{array}{l}95 \% \\
C I \%\end{array}$ \\
\hline Sc & 0.004 & 57.9 & & & & \\
\hline V & 0.542 & 20.1 & 1.06 & 0.51 & 0.06 & 12 \\
\hline $\mathrm{Cr}$ & 2.67 & 24.9 & 1.13 & 2.35 & 0.58 & 25 \\
\hline Co & 0.279 & 20.1 & 1.04 & 0.267 & 0.026 & 10 \\
\hline $\mathbf{N i}$ & 1.98 & 23.9 & 1.16 & 1.71 & 0.56 & 33 \\
\hline $\mathrm{Cu}$ & 36.5 & 20.4 & 1.04 & 35 & 2.4 & 7 \\
\hline $\mathbf{Z n}$ & 108 & 16.2 & 1.02 & 105.3 & 5.4 & 5 \\
\hline As & 31.9 & 20.5 & 0.92 & 34.6 & 2.4 & 7 \\
\hline $\mathbf{R b}$ & 5.37 & 20.3 & & & & \\
\hline $\mathrm{Sr}$ & 4.09 & 29.1 & 1.10 & 3.73 & 0.26 & 7 \\
\hline $\mathbf{Y}$ & 0.018 & 23.1 & & & & \\
\hline Mo & 1.489 & 21.6 & 1.06 & 1.41 & 0.22 & 16 \\
\hline Cd & 13.8 & 18.2 & 0.95 & 14.5 & 0.6 & 4 \\
\hline Sn & 0.081 & 25.3 & 1.17 & 0.069 & 0.036 & 52 \\
\hline Ba & 0.14 & 44.6 & & & & \\
\hline La & 0.023 & 17.0 & & & & \\
\hline Ce & 0.042 & 17.0 & & & & \\
\hline Nd & 0.022 & 17.8 & & & & \\
\hline Sm & 0.004 & 22.0 & & & & \\
\hline Yb & 0.001 & 20.4 & & & & \\
\hline Tl & 0.014 & 18.6 & 1.09 & 0.013 & & \\
\hline $\mathbf{P b}$ & 0.193 & 39.5 & 1.19 & 0.162 & 0.032 & 20 \\
\hline $\mathbf{B i}$ & 0.021 & 32.0 & & & & \\
\hline Th & 0.004 & 38.1 & & & & \\
\hline $\mathbf{U}$ & 0.084 & 21.6 & 1.03 & 0.082 & & \\
\hline
\end{tabular}

Red text: concentrations are either very low $(\mathrm{Ga}, \mathrm{Sc}, \mathrm{Nb}, \mathrm{Th})$ or appear to be heterogeneous at

50mg level analysed here (e.g. Pb), and hence have high RSDs.

Values certified in the SRM have a 95CI shown, other values are indicative only.

Only $\mathrm{Ca}$ and $\mathrm{Al}$ appear to be systematically different from the the reference values - these are at very low levels in the SRM compared to the samples (amphipods \& algae) for which the method has been optimised.

All other elements are within (or very close to) the 95CI of the certified values. 


\begin{tabular}{|c|c|c|c|c|c|c|c|c|}
\hline \multirow[t]{2}{*}{$\begin{array}{l}\text { Sample } \\
\text { Run }\end{array}$} & \multicolumn{2}{|c|}{$\begin{array}{l}\text { JA-2 (1)1 } \\
\text { Sediments }\end{array}$} & \multicolumn{2}{|c|}{$\begin{array}{l}\text { JA-2 (2)1 } \\
\text { Sediments }\end{array}$} & \multicolumn{2}{|c|}{$\begin{array}{l}\text { JA-2 (3)1 } \\
\text { Sediments }\end{array}$} & \multicolumn{2}{|c|}{$\begin{array}{l}\text { JA-2 (4)1 } \\
\text { Sediments }\end{array}$} \\
\hline & $w t \%$ & $1 S D$ & $w t \%$ & $1 S D$ & $w t \%$ & $1 S D$ & $w t \%$ & $1 S D$ \\
\hline TiO2 & 0.6547 & 0.0143 & 0.6726 & 0.0254 & 0.6573 & 0.0174 & 0.6476 & 0.0170 \\
\hline Al2O3 & 15.56 & 0.33 & 15.55 & 0.34 & 15.16 & 0.49 & 15.33 & 0.38 \\
\hline $\mathrm{Fe} 2 \mathrm{O3}(\mathrm{t})$ & 6.202 & 0.165 & 6.223 & 0.096 & 6.122 & 0.119 & 6.129 & 0.144 \\
\hline MgO & 7.864 & 0.210 & 7.952 & 0.149 & 7.734 & 0.175 & 7.713 & 0.220 \\
\hline MnO & 0.106 & 0.004 & 0.107 & 0.002 & 0.108 & 0.002 & 0.107 & 0.002 \\
\hline \multirow[t]{2}{*}{$\mathrm{CaO}$} & 6.322 & 0.245 & 6.316 & 0.268 & 6.312 & 0.184 & 6.311 & 0.182 \\
\hline & ppm & $1 S D$ & ppm & $1 S D$ & ppm & $1 S D$ & $p p m$ & $1 S D$ \\
\hline Sc & 19.19 & 0.37 & 19.88 & 0.37 & 19.12 & 0.47 & 19.07 & 0.60 \\
\hline V & 121.4 & 3.6 & 125.9 & 2.6 & 121.7 & 1.9 & 122.3 & 3.3 \\
\hline $\mathrm{Cr}$ & 441.5 & 8.0 & 446.6 & 10.6 & 439.7 & 8.5 & 437.4 & 8.3 \\
\hline Co & 29.25 & 0.97 & 30.17 & 0.68 & 29.60 & 0.81 & 29.11 & 0.94 \\
\hline $\mathbf{N i}$ & 143.1 & 3.9 & 143.9 & 4.2 & 139.9 & 5.0 & 143.7 & 5.1 \\
\hline $\mathrm{Cu}$ & 28.9 & 0.7 & 29.1 & 1.1 & 28.0 & 0.8 & 28.1 & 0.8 \\
\hline Zn & 61.0 & 2.8 & 62.5 & 2.6 & 60.0 & 1.9 & 61.4 & 3.3 \\
\hline As & 1.14 & 0.66 & 1.31 & 0.88 & 1.46 & 1.06 & 0.96 & 0.63 \\
\hline $\mathbf{R b}$ & 71.0 & 1.4 & 71.8 & 1.3 & 71.0 & 2.0 & 70.6 & 1.8 \\
\hline $\mathbf{S r}$ & 243.9 & 3.3 & 246.9 & 3.7 & 243.5 & 4.0 & 242.5 & 4.1 \\
\hline Y & 16.79 & 0.48 & 17.45 & 0.45 & 16.80 & 0.41 & 16.82 & 0.45 \\
\hline Мo & 0.41 & 0.03 & 0.44 & 0.04 & 0.41 & 0.06 & 0.42 & 0.06 \\
\hline Cd & 0.09 & 0.04 & 0.11 & 0.05 & 0.09 & 0.03 & 0.09 & 0.03 \\
\hline Sn & 1.53 & 0.17 & 1.56 & 0.17 & 1.58 & 0.16 & 1.53 & 0.15 \\
\hline Sb & 0.16 & 0.05 & 0.17 & 0.05 & 0.14 & 0.05 & 0.15 & 0.05 \\
\hline Ba & 312.2 & 6.4 & 312.3 & 7.1 & 305.4 & 6.5 & 306.0 & 5.1 \\
\hline La & 15.54 & 0.23 & 15.92 & 0.25 & 15.50 & 0.30 & 15.44 & 0.29 \\
\hline $\mathrm{Ce}$ & 32.67 & 0.45 & 33.27 & 0.39 & 32.66 & 0.44 & 32.49 & 0.50 \\
\hline Pr & 3.667 & 0.084 & 3.777 & 0.053 & 3.666 & 0.075 & 3.661 & 0.049 \\
\hline Nd & 14.08 & 0.29 & 14.27 & 0.28 & 14.06 & 0.27 & 13.85 & 0.34 \\
\hline Sm & 2.957 & 0.087 & 3.093 & 0.088 & 3.056 & 0.140 & 2.950 & 0.112 \\
\hline Eu & 0.916 & 0.030 & 0.930 & 0.042 & 0.920 & 0.0215 & 0.913 & 0.027 \\
\hline Gd & 3.193 & 0.126 & 3.231 & 0.103 & 3.230 & 0.103 & 3.188 & 0.116 \\
\hline Tb & 0.4823 & 0.0146 & 0.4934 & 0.0114 & 0.4752 & 0.0154 & 0.4849 & 0.01677 \\
\hline Dy & 2.924 & 0.070 & 2.971 & 0.092 & 2.894 & 0.108 & 2.905 & 0.098 \\
\hline Ho & 0.600 & 0.034 & 0.609 & 0.019 & 0.604 & 0.028 & 0.604 & 0.023 \\
\hline Er & 1.745 & 0.103 & 1.722 & 0.076 & 1.725 & 0.064 & 1.725 & 0.049 \\
\hline Tm & 0.2634 & 0.0163 & 0.2611 & 0.0116 & 0.2575 & 0.0128 & 0.2553 & 0.0092 \\
\hline Yb & 1.648 & 0.096 & 1.674 & 0.096 & 1.634 & 0.050 & 1.606 & 0.067 \\
\hline Lu & 0.2443 & 0.0230 & 0.2591 & 0.0213 & 0.2523 & 0.0209 & 0.2493 & 0.0174 \\
\hline Tl & 0.354 & 0.139 & 0.473 & 0.170 & 0.386 & 0.117 & 0.308 & 0.095 \\
\hline $\mathbf{P b}$ & 19.81 & 0.58 & 20.16 & 0.56 & 20.02 & 0.54 & 19.66 & 0.55 \\
\hline Bi & 0.1288 & 0.0655 & 0.1253 & 0.0632 & 0.0968 & 0.0388 & 0.1063 & 0.0416 \\
\hline Th & 4.92 & 0.13 & 4.93 & 0.12 & 4.96 & 0.16 & 4.83 & 0.16 \\
\hline $\mathbf{U}$ & 2.30 & 0.10 & 2.31 & 0.09 & 2.19 & 0.11 & 2.23 & 0.11 \\
\hline
\end{tabular}

JA-2 (Andesitic rock sourced from Goshikidai sanukitoid, Sakaide, Kanagawa prefecture,

Japan.) - The SRM sourced from the Geological Survey of Japan used for sediment samples. 


\begin{tabular}{|c|c|c|c|c|}
\hline \multirow[t]{2}{*}{$\begin{array}{l}\text { Sample } \\
\text { Run } \\
\end{array}$} & \multicolumn{2}{|c|}{$\begin{array}{l}\text { JA2 average }(n=4) \text {. } \\
\text { Sediments }\end{array}$} & \multicolumn{2}{|c|}{ Certified values } \\
\hline & $w t \%$ & $1 S D$ & $w t \%$ & $1 S D$ \\
\hline TiO2 & 0.66 & 0.02 & 0.6695 & 0.007 \\
\hline $\mathrm{Al2O3}$ & 15.40 & 0.38 & 15.51 & 0.11 \\
\hline $\mathrm{Fe} 2 \mathrm{O3}(\mathrm{t})$ & 6.17 & 0.13 & 6.289 & 0.042 \\
\hline MgO & 7.82 & 0.19 & 7.841 & 0.091 \\
\hline MnO & 0.110 & 0.002 & 0.1092 & 0.0021 \\
\hline \multirow[t]{2}{*}{$\mathrm{CaO}$} & 6.32 & 0.22 & 6.259 & 0.056 \\
\hline & ppm & $1 S D$ & $p p m$ & $1 S D$ \\
\hline Sc & 19.31 & 0.45 & 18.93 & 0.34 \\
\hline V & 122.8 & 2.8 & 119.7 & 2.4 \\
\hline $\mathrm{Cr}$ & 441.3 & 8.8 & 424.8 & 9.3 \\
\hline Co & 29.53 & 0.85 & 28.33 & 0.97 \\
\hline $\mathrm{Ni}$ & 142.6 & 4.6 & 136 & 2.2 \\
\hline $\mathrm{Cu}$ & 28.5 & 0.9 & 29 & 1.5 \\
\hline $\mathbf{Z n}$ & 61.2 & 2.6 & 64.5 & 2.3 \\
\hline As & 1.22 & 0.81 & 0.71 & 0.28 \\
\hline $\mathbf{R b}$ & 71.1 & 1.6 & 69.8 & 1.3 \\
\hline $\mathbf{S r}$ & 244.2 & 3.8 & 245.8 & 3 \\
\hline $\mathbf{Y}$ & 16.96 & 0.45 & 16.89 & 0.58 \\
\hline Mo & 0.42 & 0.05 & 0.581 & 0.035 \\
\hline Cd & 0.10 & 0.04 & 0.069 & 0.019 \\
\hline Sn & 1.55 & 0.16 & 1.69 & 0.15 \\
\hline $\mathbf{S b}$ & 0.15 & 0.05 & 0.15 & 0.03 \\
\hline Ba & 309.0 & 6.3 & 308.4 & 5.1 \\
\hline La & 15.60 & 0.27 & 15.46 & 0.4 \\
\hline $\mathrm{Ce}$ & 32.78 & 0.45 & 32.86 & 0.85 \\
\hline Pr & 3.69 & 0.07 & 3.691 & 0.079 \\
\hline Nd & 14.06 & 0.30 & 14.04 & 0.24 \\
\hline Sm & 3.01 & 0.11 & 3.032 & 0.043 \\
\hline Eu & 0.92 & 0.030 & 0.893 & 0.018 \\
\hline Gd & 3.21 & 0.11 & 3.013 & 0.085 \\
\hline Tb & 0.48 & 0.02 & 0.4786 & 0.0076 \\
\hline Dy & 2.92 & 0.09 & 2.851 & 0.071 \\
\hline Ho & 0.60 & 0.03 & 0.591 & 0.015 \\
\hline Er & 1.73 & 0.07 & 1.676 & 0.031 \\
\hline Tm & 0.26 & 0.01 & 0.2546 & 0.0065 \\
\hline Yb & 1.64 & 0.08 & 1.645 & 0.036 \\
\hline Lu & 0.25 & 0.02 & 0.2549 & 0.0092 \\
\hline Tl & 0.38 & 0.13 & 0.33 & 0.013 \\
\hline $\mathbf{P b}$ & 19.91 & 0.56 & 18.88 & 0.29 \\
\hline $\mathbf{B i}$ & 0.11 & 0.05 & 0.0922 & 0.0073 \\
\hline Th & 4.91 & 0.14 & 4.8 & 0.11 \\
\hline $\mathbf{U}$ & 2.26 & 0.10 & 2.182 & 0.061 \\
\hline
\end{tabular}

Averaged JA-2 values based of four samples and certified values. 


\begin{tabular}{|l|ll|ll|}
\hline Element $(\boldsymbol{\mu g} / \mathbf{k g})$ & $\begin{array}{l}\text { U.Otago } \\
(\mathbf{n = 4 )}\end{array}$ & + /- 1 SD & Certified Value & $+/-1$ SD \\
\hline $\mathbf{M n}$ & 0.713 & 0.009 & 0.74 & 0.06 \\
$\mathbf{F e}$ & 0.315 & 0.004 & 0.34 & 0.03 \\
$\mathbf{C o}$ & 0.0137 & 0.000197 & 0.014 & 0.001 \\
$\mathbf{N i}$ & 0.227 & 0.001 & 0.24 & 0.02 \\
$\mathbf{C u}$ & 0.181 & 0.002 & 0.20 & 0.01 \\
$\mathbf{Z n}$ & 0.416 & 0.005 & 0.41 & 0.08 \\
$\mathbf{C d}$ & 0.0133 & 0.0001 & 0.016 & 0.002 \\
$\mathbf{P b}$ & 0.002323 & 0.00005 & 0.0025 & 0.0008 \\
\hline
\end{tabular}

Standard reference material NASS 7 (seawater standard reference material) - sourced from the

National Research Council Canada. Data are based on 4 analyses during the same analytical session as when the samples were run. 


\begin{tabular}{|l|l|l|l|l|l|}
\hline $\begin{array}{l}\text { Sample } \\
\#\end{array}$ & Species & $\begin{array}{l}\text { Species } \\
\text { type }\end{array}$ & Location & $\begin{array}{l}\text { \# of } \\
\text { specimens }\end{array}$ & $\begin{array}{l}\text { Weight of individual } \\
\text { specimen (mg) }\end{array}$ \\
\hline 18 & $\begin{array}{l}\text { Bellorchestia } \\
\text { sp.1 }\end{array}$ & Sandhopper & $\begin{array}{l}\text { Kaingaroa } \\
\text { East }\end{array}$ & 1 & 8.158 \\
\hline 19 & $\begin{array}{l}\text { Bellorchestia } \\
\text { sp.1 }\end{array}$ & Sandhopper & $\begin{array}{l}\text { Kaingaroa } \\
\text { East }\end{array}$ & 1 & 18.24 \\
\hline 20 & $\begin{array}{l}\text { Bellorchestia } \\
\text { sp.1 }\end{array}$ & Sandhopper & $\begin{array}{l}\text { Kaingaroa } \\
\text { South }\end{array}$ & 1 & 8.22 \\
\hline 21 & $\begin{array}{l}\text { Bellorchestia } \\
\text { sp.1 }\end{array}$ & Sandhopper & $\begin{array}{l}\text { Kaingaroa } \\
\text { South }\end{array}$ & 1 & 18.924 \\
\hline 22 & $\begin{array}{l}\text { Bellorchestia } \\
\text { sp.1 }\end{array}$ & Sandhopper & $\begin{array}{l}\text { Waitangi } \\
\text { Bay }\end{array}$ & 1 & 6.97 \\
\hline 23 & $\begin{array}{l}\text { Bellorchestia } \\
\text { sp.1 }\end{array}$ & Sandhopper & $\begin{array}{l}\text { Kaingaroa } \\
\text { South }\end{array}$ & 1 & 8.228 \\
\hline 24 & $\begin{array}{l}\text { Bellorchestia } \\
\text { sp.1 }\end{array}$ & Sandhopper & $\begin{array}{l}\text { Kaingaroa } \\
\text { South }\end{array}$ & 1 & 16.492 \\
\hline
\end{tabular}




\begin{tabular}{|c|c|c|c|c|c|}
\hline $\begin{array}{l}\text { Sample } \\
\text { \# }\end{array}$ & Species & $\begin{array}{l}\text { Species } \\
\text { type }\end{array}$ & Location & $\begin{array}{l}\text { \# of } \\
\text { specimens }\end{array}$ & $\begin{array}{l}\text { Weight of individual specimen } \\
\text { (mg) }\end{array}$ \\
\hline 1 & $\begin{array}{l}\text { Apohyale } \\
\text { sp.1 }\end{array}$ & $\begin{array}{l}\text { Algal } \\
\text { dwelling } \\
\text { amphipod }\end{array}$ & $\begin{array}{l}\text { Cape } \\
\text { Pattisson }\end{array}$ & 11 & $\begin{array}{l}0.04,0.044,0.049,0.051,0.053 \\
0.058,0.066,0.076,0.087,0.156 \\
0.165\end{array}$ \\
\hline 2 & $\begin{array}{l}\text { Apohyale } \\
\text { sp.1 }\end{array}$ & $\begin{array}{l}\text { Algal } \\
\text { dwelling } \\
\text { amphipod }\end{array}$ & $\begin{array}{l}\text { Cape } \\
\text { Pattisson }\end{array}$ & 5 & $0.273,0.344,0.402,0.437,0.751$. \\
\hline 3 & $\begin{array}{l}\text { Apohyale } \\
\text { sp.1 }\end{array}$ & $\begin{array}{l}\text { Algal } \\
\text { dwelling } \\
\text { amphipod }\end{array}$ & Owenga & 7 & $\begin{array}{l}0.207,0.245,0.377,0.425,0.54 \\
0.572,0.661\end{array}$ \\
\hline 4 & $\begin{array}{l}\text { Apohyale } \\
\text { sp.1 }\end{array}$ & $\begin{array}{l}\text { Algal } \\
\text { dwelling } \\
\text { amphipod }\end{array}$ & Port Hutt & 25 & $\begin{array}{l}0.022,0.027,0.036,0.038,0.039, \\
0.04,0.042,0.046,0.047,0.049 \\
0.051,0.053,0.054,0.066,0.068 \text {, } \\
0.077,0.083,0.088,0.09,0.09 \\
0.108,0.111,0.114,0.174,0.188\end{array}$ \\
\hline 5 & $\begin{array}{l}\text { Apohyale } \\
\text { sp.1 }\end{array}$ & $\begin{array}{l}\text { Algal } \\
\text { dwelling } \\
\text { amphipod }\end{array}$ & $\begin{array}{l}\text { Kaingaroa } \\
\text { West }\end{array}$ & 2 & $0.359,0.508$ \\
\hline 6 & $\begin{array}{l}\text { Apohyale } \\
\text { sp.1 }\end{array}$ & $\begin{array}{l}\text { Algal } \\
\text { dwelling } \\
\text { amphipod }\end{array}$ & $\begin{array}{l}\text { Kaingaroa } \\
\text { West }\end{array}$ & 3 & $0.714,0.755,0.968$ \\
\hline 7 & $\begin{array}{l}\text { Apohyale } \\
\text { sp.1 }\end{array}$ & $\begin{array}{l}\text { Algal } \\
\text { dwelling } \\
\text { amphipod }\end{array}$ & $\begin{array}{l}\text { Hanson } \\
\text { Point } \\
\text { South }\end{array}$ & 19 & $\begin{array}{l}0.25,0.292,0.319,0.177,0.19 \\
0.144,0.371,0.079,0.155,0.068, \\
0.09,0.054,0.198,0.253,0.102, \\
0.045,0.036,0.122,0.181\end{array}$ \\
\hline 8 & Aora sp.l & $\begin{array}{l}\text { Algal } \\
\text { dwelling } \\
\text { amphipod }\end{array}$ & $\begin{array}{l}\text { Cape } \\
\text { Pattisson }\end{array}$ & 4 & $0.437,0.582,0.756,1.535$ \\
\hline 9 & Aora sp.1 & $\begin{array}{l}\text { Algal } \\
\text { dwelling } \\
\text { amphipod }\end{array}$ & $\begin{array}{l}\text { Kaingaroa } \\
\text { West }\end{array}$ & 3 & $0.486,0.887,1.65$ \\
\hline 10 & Aora sp.1 & $\begin{array}{l}\text { Algal } \\
\text { dwelling } \\
\text { amphipod }\end{array}$ & $\begin{array}{l}\text { Hanson } \\
\text { Point } \\
\text { South }\end{array}$ & 11 & $\begin{array}{l}0.091,0.113,0.139,0.145,0.156, \\
0.17,0.178,0.178,0.179,0.183 \text {, } \\
0.188 .\end{array}$ \\
\hline 11 & Aora sp. 1 & $\begin{array}{l}\text { Algal } \\
\text { dwelling } \\
\text { amphipod }\end{array}$ & $\begin{array}{l}\text { Hanson } \\
\text { Point } \\
\text { South }\end{array}$ & 7 & $\begin{array}{l}0.19,0.192,0.203,0.203,0.24 \\
0.262,0.268\end{array}$ \\
\hline 12 & Aora sp. 1 & $\begin{array}{l}\text { Algal } \\
\text { dwelling } \\
\text { amphipod }\end{array}$ & $\begin{array}{l}\text { Hanson } \\
\text { Point } \\
\text { South }\end{array}$ & 3 & $0.55,0.559,0.675$ \\
\hline 13 & Aora sp.l & $\begin{array}{l}\text { Algal } \\
\text { dwelling } \\
\text { amphipod }\end{array}$ & $\begin{array}{l}\text { Hanson } \\
\text { Point } \\
\text { South }\end{array}$ & 2 & $0.814,0.836$. \\
\hline 14 & Aora sp.1 & $\begin{array}{l}\text { Algal } \\
\text { dwelling } \\
\text { amphipod }\end{array}$ & Owenga & 5 & $0.478,0.492,0.56,0.668,1.076$ \\
\hline 15 & Aora sp.1 & $\begin{array}{l}\text { Algal } \\
\text { dwelling } \\
\text { amphipod }\end{array}$ & Port Hutt & 4 & $0.673,0.752,1.006,1.015$ \\
\hline 16 & $\begin{array}{l}\text { Eusiroides } \\
\text { sp.1 }\end{array}$ & $\begin{array}{l}\text { Algal } \\
\text { dwelling } \\
\text { amphipod }\end{array}$ & $\begin{array}{l}\text { Cape } \\
\text { Pattisson }\end{array}$ & 11 & $\begin{array}{l}0.179,0.182,0.189,0.207,0.233 \text {, } \\
0.243,0.251,0.319,0.339,0.386 \text {, } \\
0.568 .\end{array}$ \\
\hline 17 & $\begin{array}{l}\text { Eusiroides } \\
\text { sp.1 }\end{array}$ & $\begin{array}{l}\text { Algal } \\
\text { dwelling } \\
\text { amphipod }\end{array}$ & $\begin{array}{l}\text { Hanson } \\
\text { Point } \\
\text { South }\end{array}$ & 14 & $\begin{array}{l}0.15,0.159,0.177,0.208,0.216, \\
0.303,0.359,0.394,0.434,0.556, \\
0.574,0.581,0.599,1.195\end{array}$ \\
\hline
\end{tabular}


APPENDIX C: TRACE ELEMENT DATA

\begin{tabular}{|c|c|c|c|c|c|c|c|c|}
\hline $\begin{array}{l}\text { Sample \# } \\
\text { Location } \\
\text { Species }\end{array}$ & \multicolumn{2}{|c|}{$\begin{array}{l}1 \\
\text { Cape Pattisson } \\
\text { Apohyale sp. } 11\end{array}$} & \multicolumn{2}{|c|}{$\begin{array}{l}2 \\
\text { Cape Pattison } \\
\text { Apohyale sp. } 11\end{array}$} & \multicolumn{2}{|c|}{$\begin{array}{l}3 \\
\text { Owenga } \\
\text { Apohyale sp. } 11\end{array}$} & \multicolumn{2}{|c|}{$\begin{array}{l}4 \\
\text { Port Hutt } \\
\text { Apohyale sp. } 11\end{array}$} \\
\hline & $w t \%$ & $1 S D$ & $w t \%$ & $1 S D$ & $w t \%$ & $1 S D$ & $w t \%$ & $1 S D$ \\
\hline $\mathbf{M g}$ & 0.62 & 0.03 & 0.82 & 0.04 & 1.01 & 0.05 & 0.64 & 0.03 \\
\hline $\mathrm{Ca}$ & 7.12 & 0.58 & 9.38 & 1.00 & 8.05 & 0.86 & 7.9 & 0.8 \\
\hline \multirow[t]{2}{*}{$\mathrm{Sr}$} & 0.133 & 0.006 & 0.165 & 0.006 & 0.151 & 0.006 & 0.143 & 0.006 \\
\hline & ppm & $1 S D$ & $p p m$ & $1 S D$ & $p p m$ & $1 S D$ & ppm & $1 S D$ \\
\hline $\mathbf{L i}$ & 0.083 & 0.004 & 0.071 & 0.004 & 0.193 & 0.006 & 0.05 & 0.006 \\
\hline Al & 63 & 3 & 26 & 1 & 48 & 2 & 46 & 2 \\
\hline Sc & 0.0081 & 0.0005 & 0.005 & 0.002 & 0.013 & 0.001 & 0.01 & 0.001 \\
\hline $\mathbf{T i}$ & 4.9 & 0.1 & 1.33 & 0.05 & 4.99 & 0.01 & 2.21 & 0.08 \\
\hline V & 0.55 & 0.01 & 0.43 & 0.01 & 0.67 & 0.02 & 0.36 & 0.01 \\
\hline $\mathrm{Cr}$ & 0.221 & 0.004 & 0.094 & 0.003 & 0.37 & 0.01 & 0.146 & 0.005 \\
\hline Mn & 8.1 & 0.2 & 7.6 & 0.2 & 12.9 & 0.3 & 15.9 & 0.4 \\
\hline $\mathbf{F e}$ & 50 & 2 & 29 & 1 & 109 & 6 & 60 & 3 \\
\hline Co & 0.061 & 0.002 & 0.072 & 0.002 & 0.086 & 0.003 & 0.045 & 0.001 \\
\hline $\mathbf{N i}$ & 0.59 & 0.01 & 0.48 & 0.01 & 0.54 & 0.01 & 0.66 & 0.03 \\
\hline $\mathbf{C u}$ & 3.92 & 0.08 & 3.34 & 0.04 & 5.23 & 0.08 & 4.17 & 0.06 \\
\hline Zn & 28.1 & 0.4 & 23.2 & 0.3 & 51 & 1 & 32 & 1 \\
\hline Ga & 0.018 & 0.002 & 0.007 & 0.002 & 0.015 & 0.001 & 0.0134 & 0.0008 \\
\hline As & 4.6 & 0.2 & 4.7 & 0.1 & 17.1 & 0.4 & 4.4 & 0.1 \\
\hline $\mathbf{R b}$ & 0.107 & 0.003 & 0.085 & 0.002 & 0.149 & 0.002 & 0.107 & 0.002 \\
\hline Y & 0.029 & 0.001 & 0.021 & 0.001 & 0.044 & 0.001 & 0.032 & 0.001 \\
\hline Nb & 0.025 & 0.002 & 0.007 & 0.001 & 0.017 & 0.001 & 0.013 & 0.001 \\
\hline Mo & 0.231 & 0.005 & 0.148 & 0.003 & 0.204 & 0.004 & 0.15 & 0.005 \\
\hline Cd & 13.5 & 0.3 & 15.8 & 0.4 & 0.72 & 0.02 & 0.554 & 0.012 \\
\hline Sn & 0.235 & 0.007 & 0.126 & 0.004 & 0.172 & 0.006 & 0.172 & 0.007 \\
\hline Cs & 0.004 & 0.0001 & 0.0011 & 0.0001 & 0.0022 & 0.0001 & 0.0037 & 0.0002 \\
\hline Ba & 9.5 & 0.4 & 8.4 & 0.3 & 8.3 & 0.3 & 11.3 & 0.3 \\
\hline $\mathbf{L a}$ & 0.025 & 0.001 & 0.0094 & 0.0004 & 0.04 & 0.001 & 0.0341 & 0.0007 \\
\hline $\mathrm{Ce}$ & 0.041 & 0.001 & 0.0119 & 0.0004 & 0.069 & 0.001 & 0.055 & 0.001 \\
\hline Nd & 0.0209 & 0.0004 & 0.0057 & 0.0008 & 0.034 & 0.001 & 0.026 & 0.001 \\
\hline Sm & 0.0043 & 0.0007 & 0.0008 & 0.0002 & 0.008 & 0.001 & 0.005 & 0.0004 \\
\hline $\mathbf{Y b}$ & 0.0015 & 0.0001 & 0.0004 & 0.0002 & 0.0025 & 0.0003 & 0.0018 & 0.0004 \\
\hline Tl & 0.0042 & 0.0001 & 0.0026 & 0.0002 & 0.004 & 0.0001 & 0.0037 & 0.0003 \\
\hline $\mathbf{P b}$ & 0.787 & 0.007 & 0.242 & 0.003 & 0.366 & 0.008 & 0.468 & 0.005 \\
\hline $\mathbf{B i}$ & 0.0014 & 0.0002 & 0.015 & 0.001 & 0.001 & 0.0001 & 0.0012 & 0.0001 \\
\hline Th & 0.0056 & 0.0003 & 0.0012 & 0.0002 & 0.002 & 0.0002 & 0.0094 & 0.0003 \\
\hline $\mathbf{U}$ & 0.354 & 0.004 & 0.294 & 0.003 & 0.194 & 0.002 & 0.517 & 0.005 \\
\hline
\end{tabular}

1 Algal-dwelling amphipod species 


\begin{tabular}{|c|c|c|c|c|c|c|c|c|}
\hline \multirow[t]{2}{*}{\begin{tabular}{|l} 
Sample \# \\
Location \\
Species
\end{tabular}} & \multicolumn{2}{|c|}{$\begin{array}{l}5 \\
\text { Kaingaroa West } \\
\text { Apohyale sp. } 11\end{array}$} & \multicolumn{2}{|c|}{$\begin{array}{l}6 \\
\text { Kaingaroa West } \\
\text { Apohyale sp. } 11\end{array}$} & \multicolumn{2}{|c|}{$\begin{array}{l}7 \\
\text { Hanson Point South } \\
\text { Apohyale sp. } 11\end{array}$} & \multicolumn{2}{|c|}{$\begin{array}{l}8 \\
\text { Cape Pattisson } \\
\text { Aora sp. } 1_{1}\end{array}$} \\
\hline & $w t \%$ & $1 S D$ & $w t \%$ & $1 S D$ & $w t \%$ & $1 S D$ & $w t \%$ & $1 S D$ \\
\hline Mg & 0.84 & 0.05 & 1.04 & 0.05 & 0.78 & 0.04 & 0.89 & 0.05 \\
\hline $\mathbf{C a}$ & 6.98 & 0.45 & 9.67 & 1.02 & 8.63 & 0.93 & 10.1 & 1.0 \\
\hline \multirow[t]{2}{*}{$\mathrm{Sr}$} & 0.135 & 0.005 & 0.169 & 0.006 & 0.151 & 0.006 & 0.173 & 0.002 \\
\hline & ppm & $1 S D$ & ppm & $1 S D$ & ppm & $1 S D$ & ppm & $1 S D$ \\
\hline $\mathbf{L i}$ & 0.188 & 0.006 & 0.159 & 0.004 & 0.229 & 0.008 & 0.428 & 0.008 \\
\hline Al & 77 & 4 & 32 & 1 & 305 & 15 & 45 & 1 \\
\hline Sc & 0.025 & 0.002 & 0.0048 & 0.0001 & 0.071 & 0.002 & 0.0058 & 0.0005 \\
\hline $\mathbf{T i}$ & 9.2 & 0.2 & 2.3 & 0.04 & 40.7 & 0.1 & 1.82 & 0.04 \\
\hline V & 1.22 & 0.02 & 0.377 & 0.009 & 1.78 & 0.08 & 0.36 & 0.01 \\
\hline $\mathrm{Cr}$ & 0.61 & 0.02 & 0.43 & 0.02 & 1.04 & 0.03 & 0.13 & 0.01 \\
\hline Mn & 9 & 0.2 & 7.6 & 0.2 & 156 & 4 & 8.8 & 0.1 \\
\hline $\mathrm{Fe}$ & 156 & 5 & 50 & 3 & 490 & 20 & 52 & 2 \\
\hline Co & 0.124 & 0.004 & 0.06 & 0.004 & 0.403 & 0.001 & 0.075 & 0.003 \\
\hline $\mathrm{Ni}$ & 0.67 & 0.02 & 0.46 & 0.02 & 1.8 & 0.05 & 0.36 & 0.01 \\
\hline $\mathrm{Cu}$ & 3.6 & 0.1 & 3.78 & 0.06 & 21 & 0.3 & 3.3 & 0.06 \\
\hline Zn & 29.1 & 0.4 & 29 & 1 & 51 & 1 & 40 & 1 \\
\hline Ga & 0.038 & 0.002 & 0.009 & 0.001 & 0.099 & 0.002 & 0.012 & 0.001 \\
\hline As & 5.6 & 0.2 & 4.3 & 0.1 & 4.2 & 0.1 & 5.5 & 0.2 \\
\hline Rb & 0.265 & 0.004 & 0.166 & 0.002 & 0.202 & 0.004 & 0.12 & 0.002 \\
\hline Y & 0.126 & 0.003 & 0.041 & 0.002 & 0.188 & 0.003 & 0.035 & 0.001 \\
\hline Nb & 0.034 & 0.002 & 0.01 & 0.001 & 0.105 & 0.001 & 0.01 & 0.001 \\
\hline Mo & 0.268 & 0.004 & 0.208 & 0.007 & 0.154 & 0.003 & 0.121 & 0.002 \\
\hline Cd & 13.1 & 0.2 & 12.1 & 0.3 & 0.68 & 0.02 & 18.5 & 0.5 \\
\hline Sn & 0.342 & 0.005 & 0.75 & 0.02 & 0.08 & 0.003 & 0.049 & 0.005 \\
\hline Cs & 0.0094 & 0.0003 & 0.0029 & 0.0002 & 0.0073 & 0.0002 & 0.0028 & 0.0002 \\
\hline Ba & 8.5 & 0.3 & 7.8 & 0.2 & 9.8 & 0.3 & 7.7 & 0.2 \\
\hline La & 0.102 & 0.002 & 0.048 & 0.001 & 0.245 & 0.004 & 0.025 & 0.001 \\
\hline $\mathrm{Ce}$ & 0.161 & 0.002 & 0.085 & 0.002 & 0.486 & 0.006 & 0.0418 & 0.0007 \\
\hline Nd & 0.103 & 0.003 & 0.046 & 0.002 & 0.253 & 0.004 & 0.021 & 0.001 \\
\hline Sm & 0.0197 & 0.0004 & 0.008 & 0.001 & 0.049 & 0.002 & 0.0041 & 0.0005 \\
\hline Yb & 0.0071 & 0.0003 & 0.0018 & 0.0001 & 0.0132 & 0.0003 & 0.0015 & 0.0004 \\
\hline Tl & 0.0044 & 0.0001 & 0.0036 & 0.0001 & 0.0039 & 0.0004 & 0.0034 & 0.0001 \\
\hline $\mathbf{P b}$ & 0.272 & 0.005 & 0.297 & 0.004 & 0.204 & 0.003 & 0.183 & 0.003 \\
\hline $\mathbf{B i}$ & 0.0039 & 0.0003 & 0.0018 & 0.0002 & 0.0006 & 0.0001 & 0.0012 & 0.0002 \\
\hline Th & 0.0084 & 0.0002 & 0.0021 & 0.0002 & 0.0151 & 0.0003 & 0.0025 & 0.0003 \\
\hline $\mathbf{U}$ & 0.268 & 0.005 & 0.258 & 0.004 & 0.198 & 0.002 & 0.19 & 0.003 \\
\hline
\end{tabular}

1 Algal-dwelling amphipod species 


\begin{tabular}{|c|c|c|c|c|c|c|c|c|}
\hline $\begin{array}{l}\text { Sample \# } \\
\text { Location }\end{array}$ & \multicolumn{2}{|c|}{$\begin{array}{l}9 \\
\text { Kaingaroa West } \\
\text { Aora sp. } 1_{1}\end{array}$} & \multicolumn{2}{|c|}{$\begin{array}{l}10 \\
\text { Hanson Point } \\
\text { South } \\
\text { Aora sp. } 1_{1}\end{array}$} & \multicolumn{2}{|c|}{$\begin{array}{l}11 \\
\text { Hanson Point } \\
\text { South } \\
\text { Aora sp. } 11\end{array}$} & \multicolumn{2}{|c|}{$\begin{array}{l}12 \\
\text { Hanson Point } \\
\text { South } \\
\text { Aora sp. } 11\end{array}$} \\
\hline & $w t \%$ & $1 S D$ & $w t \%$ & $1 S D$ & $w t \%$ & $1 S D$ & $w t \%$ & $1 S D$ \\
\hline Mg & 0.95 & 0.05 & 0.71 & 0.03 & 0.75 & 0.03 & 0.90 & 0.03 \\
\hline $\mathrm{Ca}$ & 8.9 & 0.9 & 10.5 & 0.9 & 9.9 & 0.8 & 11.8 & 1.0 \\
\hline \multirow[t]{2}{*}{$\mathbf{S r}$} & 0.152 & 0.006 & 0.174 & 0.009 & 0.175 & 0.009 & 0.217 & 0.009 \\
\hline & ppm & $1 S D$ & ppm & $1 S D$ & ppm & $1 S D$ & ppm & $1 S D$ \\
\hline $\mathbf{L i}$ & 0.688 & 0.019 & 0.735 & 0.019 & 0.763 & 0.023 & 0.778 & 0.023 \\
\hline Al & 39 & 2 & 397 & 19 & 347 & 20 & 304 & 13 \\
\hline Sc & 0.005 & 0.002 & 0.132 & 0.004 & 0.069 & 0.005 & 0.079 & 0.003 \\
\hline $\mathbf{T i}$ & 4.6 & 0.1 & 64.4 & 1.3 & 41.7 & 0.8 & 42.5 & 0.8 \\
\hline $\mathbf{V}$ & 0.35 & 0.01 & 3.18 & 0.06 & 2.86 & 0.07 & 2.38 & 0.07 \\
\hline $\mathrm{Cr}$ & 0.22 & 0.01 & 1.32 & 0.03 & 1.17 & 0.03 & 1.03 & 0.04 \\
\hline Mn & 7.5 & 0.2 & 127 & 2 & 87 & 2 & 60 & 1 \\
\hline $\mathrm{Fe}$ & 58 & 3 & 587 & 25 & 546 & 23 & 465 & 18 \\
\hline Co & 0.083 & 0.003 & 0.46 & 0.01 & 0.39 & 0.01 & 0.33 & 0.01 \\
\hline $\mathrm{Ni}$ & 0.47 & 0.01 & 2.2 & 0.04 & 1.95 & 0.05 & 1.59 & 0.04 \\
\hline $\mathrm{Cu}$ & 3.55 & 0.05 & 16 & 0.2 & 12.1 & 0.2 & 11.8 & 0.2 \\
\hline $\mathbf{Z n}$ & 38 & 1 & 50 & 1 & 127 & 2 & 62 & 1 \\
\hline Ga & 0.012 & 0.002 & 0.135 & 0.004 & 0.115 & 0.003 & 0.101 & 0.005 \\
\hline As & 5.8 & 0.2 & 5.8 & 0.2 & 3.6 & 0.1 & 3.3 & 0.2 \\
\hline $\mathbf{R b}$ & 0.13 & 0.002 & 0.256 & 0.004 & 0.258 & 0.003 & 0.212 & 0.003 \\
\hline $\mathbf{Y}$ & 0.044 & 0.001 & 0.279 & 0.004 & 0.246 & 0.004 & 0.198 & 0.002 \\
\hline $\mathrm{Nb}$ & 0.017 & 0.001 & 0.168 & 0.004 & 0.114 & 0.003 & 0.115 & 0.002 \\
\hline Mo & 0.141 & 0.003 & 0.132 & 0.004 & 0.111 & 0.007 & 0.131 & 0.003 \\
\hline Cd & 15.2 & 0.3 & 0.195 & 0.011 & 0.141 & 0.008 & 0.21 & 0.01 \\
\hline Sn & 0.616 & 0.016 & 0.118 & 0.004 & 0.113 & 0.006 & 0.096 & 0.006 \\
\hline Cs & 0.0024 & 0.0002 & 0.0105 & 0.0002 & 0.0094 & 0.0002 & 0.0078 & 0.0002 \\
\hline Ba & 7.8 & 0.2 & 11.7 & 0.4 & 11 & 0.4 & 9.5 & 0.3 \\
\hline La & 0.03 & 0.001 & 0.378 & 0.006 & 0.312 & 0.009 & 0.277 & 0.004 \\
\hline $\mathrm{Ce}$ & 0.054 & 0.001 & 0.81 & 0.012 & 0.624 & 0.009 & 0.562 & 0.008 \\
\hline Nd & 0.028 & 0.001 & 0.413 & 0.008 & 0.333 & 0.006 & 0.303 & 0.003 \\
\hline Sm & 0.0051 & 0.0003 & 0.085 & 0.003 & 0.068 & 0.002 & 0.062 & 0.004 \\
\hline Yb & 0.0019 & 0.0002 & 0.02 & 0.001 & 0.0173 & 0.001 & 0.013 & 0.002 \\
\hline Tl & 0.0031 & 0.0002 & 0.0057 & 0.0002 & 0.0066 & 0.0002 & 0.0061 & 0.0005 \\
\hline $\mathbf{P b}$ & 0.317 & 0.005 & 0.297 & 0.003 & 0.281 & 0.003 & 0.359 & 0.003 \\
\hline $\mathbf{B i}$ & 0.0012 & 0.0001 & 0.0015 & 0.0001 & 0.0024 & 0.0001 & 0.0015 & 0.0004 \\
\hline Th & 0.0016 & 0.0002 & 0.036 & 0.001 & 0.011 & 0.001 & 0.019 & 0.001 \\
\hline $\mathbf{U}$ & 0.221 & 0.002 & 0.154 & 0.002 & 0.174 & 0.002 & 0.093 & 0.001 \\
\hline
\end{tabular}

1 Algal-dwelling amphipod species 


\begin{tabular}{|c|c|c|c|c|c|c|c|c|}
\hline $\begin{array}{l}\text { Sample \# } \\
\text { Location } \\
\text { Species }\end{array}$ & \multicolumn{2}{|c|}{$\begin{array}{l}13 \\
\text { Hanson Point South } \\
\text { Aora sp. } 11\end{array}$} & \multicolumn{2}{|c|}{$\begin{array}{l}14 \\
\text { Owenga } \\
\text { Aora sp. } 11\end{array}$} & \multicolumn{2}{|c|}{$\begin{array}{l}15 \\
\text { Port Hutt } \\
\text { Aora sp. } 11\end{array}$} & \multicolumn{2}{|c|}{$\begin{array}{l}16 \\
\text { Cape Pattisson } \\
\text { Eusiroides } \\
\text { sp. } 11\end{array}$} \\
\hline & $w t \%$ & $1 S D$ & $w t \%$ & $1 S D$ & 16 & $1 S D$ & $w t \%$ & $1 S D$ \\
\hline Mg & 0.85 & 0.04 & 0.96 & 0.05 & 0.89 & 0.05 & 0.67 & 0.04 \\
\hline $\mathbf{C a}$ & 12.0 & 1.0 & 11.1 & 1.1 & 10.7 & 1.1 & 6.7 & 0.7 \\
\hline \multirow[t]{2}{*}{$\mathrm{Sr}$} & 0.21 & 0.01 & 0.184 & 0.005 & 0.193 & 0.006 & 0.119 & 0.005 \\
\hline & $p p m$ & $1 S D$ & $p p m$ & $1 S D$ & ppm & $1 S D$ & ppm & $1 S D$ \\
\hline $\mathbf{L i}$ & 0.862 & 0.024 & 0.793 & 0.017 & 0.607 & 0.012 & 0.489 & 0.013 \\
\hline Al & 710 & 32 & 333 & 11 & 105 & 4 & 49 & 2 \\
\hline Sc & 0.206 & 0.007 & 0.044 & 0.002 & 0.012 & 0.002 & 0.006 & 0.003 \\
\hline $\mathbf{T i}$ & 95 & 2 & 35.1 & 0.6 & 4.3 & 0.2 & 1.82 & 0.04 \\
\hline V & 6.5 & 0.1 & 1.64 & 0.03 & 0.497 & 0.006 & 0.44 & 0.01 \\
\hline $\mathrm{Cr}$ & 2.32 & 0.05 & 4.5 & 0.1 & 0.32 & 0.01 & 0.26 & 0.01 \\
\hline Mn & 48 & 1 & 14 & 0.2 & 10.1 & 0.2 & 11.8 & 0.2 \\
\hline $\mathrm{Fe}$ & 1115 & 39 & 554 & 25 & 135 & 6 & 58 & 3 \\
\hline Co & 0.59 & 0.02 & 0.252 & 0.005 & 0.079 & 0.002 & 0.089 & 0.003 \\
\hline $\mathrm{Ni}$ & 3.63 & 0.06 & 1.42 & 0.05 & 0.46 & 0.02 & 1.08 & 0.04 \\
\hline $\mathrm{Cu}$ & 11.3 & 0.2 & 7.65 & 0.13 & 4.65 & 0.08 & 9.7 & 0.2 \\
\hline Zn & 48 & 1 & 45 & 1 & 42 & 1 & 53 & 1 \\
\hline Ga & 0.219 & 0.007 & 0.098 & 0.003 & 0.3 & 0.003 & 0.015 & 0.001 \\
\hline As & 3.1 & 0.1 & 13.6 & 0.4 & 5.6 & 0.2 & 8 & 0.2 \\
\hline Rb & 0.401 & 0.006 & 0.331 & 0.005 & 0.333 & 0.005 & 0.07 & 0.001 \\
\hline $\mathbf{Y}$ & 0.514 & 0.006 & 0.209 & 0.004 & 0.056 & 0.002 & 0.029 & 0.001 \\
\hline $\mathrm{Nb}$ & 0.259 & 0.005 & 0.099 & 0.001 & 0.015 & 0.001 & 0.01 & 0.001 \\
\hline Mo & 0.176 & 0.005 & 0.156 & 0.005 & 0.112 & 0.003 & 0.126 & 0.003 \\
\hline Cd & 0.116 & 0.008 & 0.577 & 0.021 & 0.161 & 0.006 & 34.7 & 0.7 \\
\hline Sn & 0.177 & 0.007 & 0.095 & 0.005 & 0.056 & 0.004 & 0.06 & 0.01 \\
\hline Cs & 0.0174 & 0.0002 & 0.0117 & 0.0001 & 0.0131 & 0.0003 & 0.0023 & 0.0001 \\
\hline Ba & 12.4 & 0.4 & 10 & 0.3 & 9.4 & 0.2 & 8.5 & 0.3 \\
\hline La & 0.608 & 0.009 & 0.249 & 0.004 & 0.068 & 0.001 & 0.024 & 0.001 \\
\hline $\mathrm{Ce}$ & 1.31 & 0.02 & 0.506 & 0.005 & 0.126 & 0.001 & 0.043 & 0.001 \\
\hline Nd & 0.673 & 0.008 & 0.263 & 0.007 & 0.054 & 0.002 & 0.0183 & 0.0005 \\
\hline Sm & 0.143 & 0.004 & 0.053 & 0.001 & 0.01 & 0.001 & 0.0037 & 0.0004 \\
\hline $\mathbf{Y b}$ & 0.035 & 0.002 & 0.014 & 0.001 & 0.0031 & 0.0003 & 0.0015 & 0.0002 \\
\hline Tl & 0.0112 & 0.0004 & 0.0035 & 0.0002 & 0.005 & 0.0001 & 0.0036 & 0.0002 \\
\hline $\mathbf{P b}$ & 0.393 & 0.003 & 0.527 & 0.009 & 0.297 & 0.005 & 0.385 & 0.007 \\
\hline $\mathbf{B i}$ & 0.0092 & 0.0002 & 0.0028 & 0.0002 & 0.0014 & 0.0001 & 0.0021 & 0.0001 \\
\hline Th & 0.049 & 0.001 & 0.01 & 0.002 & 0.007 & 0.001 & 0.0016 & 0.0005 \\
\hline $\mathbf{U}$ & 0.083 & 0.001 & 0.175 & 0.002 & 0.223 & 0.003 & 0.375 & 0.004 \\
\hline
\end{tabular}

1 Algal-dwelling amphipod species 


\begin{tabular}{|c|c|c|c|c|c|c|c|c|}
\hline \multirow[t]{2}{*}{$\begin{array}{l}\text { Sample \# } \\
\text { Location } \\
\text { Species }\end{array}$} & \multicolumn{2}{|c|}{$\begin{array}{l}17 \\
\text { Hanson Point South } \\
\text { Eusiroides } \\
\text { sp. } 11\end{array}$} & \multicolumn{2}{|c|}{$\begin{array}{l}18 \\
\text { Kaingaora East } \\
\text { B. chathamensis2 }\end{array}$} & \multicolumn{2}{|c|}{$\begin{array}{l}19 \\
\text { Kaingaroa East } \\
\text { B. chathamensis2 }\end{array}$} & \multicolumn{2}{|c|}{\begin{tabular}{|l|}
20 \\
Kaingaora South \\
B. chathamensis2
\end{tabular}} \\
\hline & $w t \%$ & $I S D$ & $w t \%$ & $1 S D$ & $w t \%$ & $I S D$ & $w t \%$ & $1 S D$ \\
\hline $\mathbf{M g}$ & 0.68 & 0.04 & 0.48 & 0.03 & 0.60 & 0.04 & 0.47 & 0.03 \\
\hline $\mathrm{Ca}$ & 66.7 & 0.7 & 4.19 & 0.41 & 5.03 & 0.29 & 5.58 & 0.32 \\
\hline \multirow[t]{2}{*}{$\mathrm{Sr}$} & 0.119 & 0.001 & 0.099 & 0.002 & 0.129 & 0.002 & 0.116 & 0.002 \\
\hline & ppm & $1 S D$ & ppm & $1 S D$ & ppm & $1 S D$ & ppm & $1 S D$ \\
\hline $\mathbf{L i}$ & 0.523 & 0.016 & 0.441 & 0.009 & 0.777 & 0.016 & 0.142 & 0.007 \\
\hline Al & 352 & 12 & 2.2 & 0.1 & 3 & 0.1 & 4.5 & 0.1 \\
\hline Sc & 0.032 & 0.004 & 0.003 & 0.002 & 0.0037 & 0.0008 & 0.004 & 0.002 \\
\hline $\mathbf{T i}$ & 31.2 & 0.7 & 0.13 & 0.01 & 8 & 0.31 & 0.43 & 0.02 \\
\hline V & 1.62 & 0.02 & 0.074 & 0.003 & 0.245 & 0.005 & 0.21 & 0.003 \\
\hline $\mathrm{Cr}$ & 0.76 & 0.02 & 0.059 & 0.002 & 0.081 & 0.003 & 0.099 & 0.004 \\
\hline Mn & 72 & 1 & 2.27 & 0.04 & 2.21 & 0.03 & 3.7 & 0.1 \\
\hline $\mathrm{Fe}$ & 451 & 20 & 15 & 1 & 23 & 1 & 24 & 1 \\
\hline Co & 0.33 & 0.01 & 0.109 & 0.004 & 0.11 & 0.003 & 0.103 & 0.003 \\
\hline $\mathrm{Ni}$ & 1.97 & 0.04 & 0.32 & 0.01 & 0.209 & 0.008 & 0.381 & 0.008 \\
\hline $\mathrm{Cu}$ & 28.2 & 0.3 & 27.3 & 0.3 & 21.4 & 0.3 & 13.6 & 0.2 \\
\hline Zn & 59 & 1 & 84 & 2 & 72 & 1 & 66 & 1 \\
\hline Ga & 0.101 & 0.003 & 0.0007 & 0.0003 & 0.0013 & 0.0005 & 0.0009 & 0.0008 \\
\hline As & 6.5 & 0.2 & 19.4 & 0.7 & 15 & 1 & 40 & 1 \\
\hline $\mathbf{R b}$ & 0.148 & 0.003 & 2.99 & 0.05 & 3.63 & 0.06 & 2.82 & 0.05 \\
\hline Y & 0.165 & 0.004 & 0.01 & 0.001 & 0.028 & 0.001 & 0.015 & 0.001 \\
\hline Nb & 0.084 & 0.003 & 0.0023 & 0.0003 & 0.009 & 0.001 & 0.007 & 0.001 \\
\hline Mo & 0.302 & 0.006 & 0.229 & 0.006 & 0.26 & 0.005 & 0.303 & 0.01 \\
\hline Cd & 1.97 & 0.06 & 13.2 & 0.4 & 15.8 & 0.3 & 11.4 & 0.2 \\
\hline Sn & 0.047 & 0.003 & 0.028 & 0.004 & 0.019 & 0.002 & 0.045 & 0.004 \\
\hline Cs & 0.0055 & 0.0004 & 0.0223 & 0.0002 & 0.0391 & 0.0003 & 0.027 & 0.001 \\
\hline Ba & 9.4 & 0.2 & 1.97 & 0.05 & 5.1 & 0.2 & 5.3 & 0.2 \\
\hline La & 0.228 & 0.005 & 0.0038 & 0.0003 & 0.0123 & 0.0005 & 0.0055 & 0.0006 \\
\hline $\mathrm{Ce}$ & 0.414 & 0.005 & 0.0035 & 0.0003 & 0.0129 & 0.0001 & 0.0064 & 0.0002 \\
\hline Nd & 0.238 & 0.007 & 0.002 & 0.0004 & 0.0083 & 0.0006 & 0.0038 & 0.0003 \\
\hline Sm & 0.049 & 0.001 & 0.0004 & 0.0003 & 0.0014 & 0.0003 & 0.0005 & 0.0003 \\
\hline Yb & 0.01 & 0.001 & 0.0002 & 0.0001 & 0.001 & 0.0002 & 0.0004 & 0.0001 \\
\hline Tl & 0.0025 & 0.0002 & 0.0042 & 0.0002 & 0.003 & 0.0003 & 0.0032 & 0.0001 \\
\hline $\mathbf{P b}$ & 0.157 & 0.003 & 0.045 & 0.001 & 0.055 & 0.001 & 0.067 & 0.001 \\
\hline Bi & 0.0012 & 0.0001 & 0.0002 & 0.0001 & 0.0002 & 0.0001 & 0.0004 & 0.0001 \\
\hline Th & 0.01 & 0.002 & 0.0003 & 0.0001 & 0.0008 & 0.0001 & 0.0056 & 0.0008 \\
\hline $\mathbf{U}$ & 0.178 & 0.003 & 0.046 & 0.001 & 0.085 & 0.001 & 0.066 & 0.001 \\
\hline
\end{tabular}

1 Algal-dwelling amphipod species

2 Sandhopper amphipod species 


\begin{tabular}{|c|c|c|c|c|c|c|c|c|}
\hline $\begin{array}{l}\text { Sample \# } \\
\text { Location } \\
\text { Species }\end{array}$ & \multicolumn{2}{|c|}{$\begin{array}{l}21 \\
\text { Kaingaroa South } \\
\text { B. chathamensis2 }\end{array}$} & \multicolumn{2}{|c|}{$\begin{array}{l}22 \\
\text { Waitangi Bay } \\
\text { B. chathamensis2 }\end{array}$} & \multicolumn{2}{|c|}{$\begin{array}{l}23 \\
\text { Kaingarao South } \\
\text { B. chathamensis2 }\end{array}$} & \multicolumn{2}{|c|}{$\begin{array}{l}24 \\
\text { Kaingaora South } \\
\text { B. chathamensis2 }\end{array}$} \\
\hline & $w t \%$ & $1 S D$ & $w t \%$ & $1 S D$ & $w t \%$ & $1 S D$ & $w t \%$ & $1 S D$ \\
\hline Mg & 0.36 & 0.02 & 0.53 & 0.03 & 0.54 & 0.04 & 0.44 & 0.03 \\
\hline Ca & 3.98 & 0.25 & 8.43 & 0.86 & 5.56 & 0.33 & 4.69 & 0.27 \\
\hline \multirow[t]{2}{*}{$\mathrm{Sr}$} & 0.097 & 0.004 & 0.222 & 0.002 & 0.123 & 0.002 & 0.102 & 0.002 \\
\hline & ppm & $1 S D$ & ppm & $1 S D$ & ppm & $1 S D$ & ppm & $1 S D$ \\
\hline $\mathbf{L i}$ & 0.126 & 0.004 & 0.124 & 0.004 & 0.336 & 0.012 & 0.327 & 0.012 \\
\hline Al & 5.2 & 0.2 & 44 & 1 & 5.6 & 0.2 & 2.3 & 0.1 \\
\hline Sc & 0.002 & 0.001 & 0.025 & 0.002 & 0.006 & 0.002 & 0.002 & 0.001 \\
\hline $\mathrm{Ti}$ & 0.42 & 0.01 & 8.31 & 0.28 & 0.24 & 0.01 & 0.186 & 0.025 \\
\hline V & 0.156 & 0.002 & 0.47 & 0.01 & 0.153 & 0.003 & 0.093 & 0.001 \\
\hline $\mathrm{Cr}$ & 0.057 & 0.002 & 0.36 & 0.01 & 11.46 & 0.01 & 0.028 & 0.004 \\
\hline Mn & 2.3 & 0.03 & 7.2 & 0.1 & 3.79 & 0.06 & 2.32 & 0.03 \\
\hline $\mathbf{F e}$ & 17 & 1 & 99 & 5 & 83 & 3 & 13.5 & 0.5 \\
\hline Co & 0.069 & 0.003 & 0.165 & 0.004 & 0.183 & 0.004 & 0.084 & 0.003 \\
\hline $\mathrm{Ni}$ & 0.38 & 0.01 & 0.48 & 0.01 & 6 & 0.1 & 0.259 & 0.008 \\
\hline $\mathrm{Cu}$ & 12.7 & 0.2 & 6.9 & 0.1 & 15.8 & 0.2 & 20 & 1 \\
\hline Zn & 74 & 1 & 69 & 1 & 99 & 2 & 92 & 2 \\
\hline Ga & 0.001 & 0.0004 & 0.011 & 0.001 & 0.003 & 0.001 & 0.0007 & 0.0004 \\
\hline As & 19 & 1 & 9.7 & 0.3 & 26 & 1 & 38 & 2 \\
\hline $\mathbf{R b}$ & 2.81 & 0.05 & 0.476 & 0.007 & 2.93 & 0.06 & 3.02 & 0.05 \\
\hline Y & 0.013 & 0.001 & 0.153 & 0.003 & 0.0136 & 0.0004 & 0.0114 & 0.0003 \\
\hline $\mathrm{Nb}$ & 0.004 & 0.0004 & 0.0227 & 0.0005 & 0.012 & 0.001 & 0.003 & 0.0003 \\
\hline Mo & 0.194 & 0.003 & 0.237 & 0.006 & 0.414 & 0.006 & 0.172 & 0.005 \\
\hline Cd & 10.3 & 0.2 & 15.7 & 0.4 & 10.4 & 0.2 & 17.1 & 0.4 \\
\hline Sn & 0.034 & 0.002 & 0.05 & 0.01 & 0.052 & 0.005 & 0.021 & 0.001 \\
\hline Cs & 0.027 & 0.001 & 0.0048 & 0.0001 & 0.021 & 0.001 & 0.0214 & 0.0002 \\
\hline Ba & 3.6 & 0.1 & 12.3 & 0.3 & 3.2 & 0.1 & 2.8 & 0.1 \\
\hline $\mathbf{L a}$ & 0.0098 & 0.0002 & 0.187 & 0.004 & 0.008 & 0.0004 & 0.0074 & 0.0003 \\
\hline $\mathrm{Ce}$ & 0.0135 & 0.0004 & 0.253 & 0.004 & 0.009 & 0.0002 & 0.0086 & 0.0003 \\
\hline Nd & 0.006 & 0.001 & 0.158 & 0.004 & 0.0042 & 0.0003 & 0.0038 & 0.0005 \\
\hline Sm & 0.001 & 0.0003 & 0.026 & 0.001 & 0.0004 & 0.0002 & 0.0005 & 0.0003 \\
\hline $\mathbf{Y b}$ & 0.0003 & 0.0001 & 0.01 & 0.001 & 0.0003 & 0.0001 & 0.0003 & 0.0001 \\
\hline Tl & 0.0035 & 0.0003 & 0.0062 & 0.0001 & 0.0036 & 0.0001 & 0.0034 & 0.0001 \\
\hline $\mathbf{P b}$ & 0.07 & 0.002 & 0.064 & 0.002 & 0.0231 & 0.0003 & 0.0214 & 0.0003 \\
\hline $\mathbf{B i}$ & 0.0012 & 0.0002 & 0.0007 & 0.0002 & 0.0001 & 0.0001 & 0.00014 & 0.00008 \\
\hline Th & 0.0007 & 0.0001 & 0.0078 & 0.0006 & 0.0014 & 0.0002 & 0.0005 & 0.0001 \\
\hline $\mathbf{U}$ & 0.035 & 0.001 & 0.092 & 0.001 & 0.062 & 0.001 & 0.046 & 0.001 \\
\hline
\end{tabular}

2 Sandhopper amphipod species 


\begin{tabular}{|c|c|c|c|c|c|c|c|c|}
\hline \multirow[t]{2}{*}{$\begin{array}{l}\text { Sample \# } \\
\text { Location } \\
\text { Species }\end{array}$} & \multicolumn{2}{|c|}{\begin{tabular}{l}
\multicolumn{1}{c}{25} \\
Waitangi Bay \\
\\
Carpophyllum \\
maschalocarpum \\
(brown) 3
\end{tabular}} & \multicolumn{2}{|c|}{$\begin{array}{l}{ }^{26} \\
\text { Owenga } \\
\text { Cystophora scalaris } 3\end{array}$} & \multicolumn{2}{|c|}{\begin{tabular}{l}
\multicolumn{1}{c}{27} \\
Hanson Point \\
North \\
Champia (red) 3
\end{tabular}} & \multicolumn{2}{|c|}{\begin{tabular}{l}
\multicolumn{1}{c}{28} \\
Kaingaroa West \\
Cystophora \\
scalaris3
\end{tabular}} \\
\hline & $w t \%$ & $1 S D$ & $w t \%$ & $1 S D$ & $w t \%$ & $1 S D$ & $w t \%$ & $1 S D$ \\
\hline Mg & 0.81 & 0.04 & 1.05 & 0.06 & 0.41 & 0.03 & 1.07 & 0.06 \\
\hline $\mathrm{Ca}$ & 1.39 & 0.11 & 1.19 & 0.09 & 0.26 & 0.02 & 1.20 & 0.09 \\
\hline \multirow[t]{2}{*}{$\mathbf{S r}$} & 0.170 & 0.007 & 0.119 & 0.005 & 0.0040 & 0.0001 & 0.116 & 0.004 \\
\hline & ppm & $1 S D$ & ppm & $1 S D$ & ppm & $1 S D$ & ppm & $1 S D$ \\
\hline $\mathbf{L i}$ & 0.176 & 0.009 & 0.324 & 0.011 & 0.38 & 0.012 & 0.27 & 0.01 \\
\hline Al & 63 & 4 & 311 & 17 & 129 & 7 & 61 & 4 \\
\hline Sc & 0.046 & 0.001 & 0.143 & 0.009 & 0.056 & 0.002 & 0.024 & 0.003 \\
\hline $\mathbf{T i}$ & 7.3 & 0.2 & 67.5 & 1.5 & 20.6 & 0.5 & 10.9 & 0.5 \\
\hline V & 1.18 & 0.04 & 4.3 & 0.1 & 6.4 & 0.2 & 2.03 & 0.07 \\
\hline $\mathrm{Cr}$ & 0.64 & 0.02 & 2.2 & 0.1 & 0.83 & 0.03 & 0.44 & 0.02 \\
\hline Mn & 16.5 & 0.6 & 9.8 & 0.3 & 9.7 & 0.3 & 3.5 & 0.1 \\
\hline $\mathbf{F e}$ & 178 & 10 & 607 & 38 & 293 & 17 & 76 & 6 \\
\hline Co & 1.7 & 0.03 & 0.55 & 0.01 & 0.41 & 0.01 & 0.136 & 0.003 \\
\hline $\mathbf{N i}$ & 0.99 & 0.03 & 1.7 & 0.06 & 7.6 & 0.2 & 0.87 & 0.03 \\
\hline $\mathbf{C u}$ & 1.59 & 0.06 & 10.2 & 0.3 & 3.3 & 0.1 & 0.76 & 0.02 \\
\hline $\mathbf{Z n}$ & 6.6 & 0.3 & 18.8 & 0.6 & 22 & 1 & 4.5 & 0.2 \\
\hline Ga & 0.011 & 0.001 & 0.089 & 0.004 & 0.036 & 0.004 & 0.02 & 0.002 \\
\hline As & 50 & 2 & 41 & 2 & 18 & 1 & 28 & 1 \\
\hline $\mathbf{R b}$ & 5.5 & 0.11 & 4.26 & 0.1 & 1.41 & 0.03 & 8.16 & 0.16 \\
\hline Y & 0.123 & 0.003 & 0.272 & 0.007 & 0.097 & 0.003 & 0.113 & 0.003 \\
\hline Nb & 0.038 & 0.002 & 0.169 & 0.007 & 0.058 & 0.003 & 0.035 & 0.002 \\
\hline Mo & 0.285 & 0.013 & 0.323 & 0.007 & 0.33 & 0.01 & 0.27 & 0.01 \\
\hline Cd & 0.63 & 0.04 & 0.25 & 0.02 & 0.421 & 0.033 & 4.02 & 0.25 \\
\hline Sn & 0.034 & 0.005 & 0.081 & 0.007 & 0.077 & 0.006 & 0.0578 & 0.039 \\
\hline Cs & 0.017 & 0.001 & 0.0209 & 0.0005 & 0.0062 & 0.0004 & 0.026 & 0.001 \\
\hline $\mathbf{B a}$ & 16.2 & 0.3 & 10.9 & 0.3 & 0.51 & 0.01 & 9.8 & 0.2 \\
\hline $\mathbf{L a}$ & 0.078 & 0.002 & 0.246 & 0.005 & 0.137 & 0.002 & 0.061 & 0.001 \\
\hline $\mathrm{Ce}$ & 0.157 & 0.003 & 0.493 & 0.009 & 0.244 & 0.005 & 0.113 & 0.002 \\
\hline Nd & 0.106 & 0.003 & 0.276 & 0.009 & 0.134 & 0.003 & 0.063 & 0.002 \\
\hline Sm & 0.024 & 0.001 & 0.058 & 0.002 & 0.027 & 0.002 & 0.012 & 0.001 \\
\hline $\mathbf{Y b}$ & 0.009 & 0.001 & 0.021 & 0.001 & 0.006 & 0.001 & 0.008 & 0.001 \\
\hline Tl & 0.0018 & 0.0003 & 0.0016 & 0.0002 & 0.0078 & 0.0004 & 0.0015 & 0.0002 \\
\hline $\mathbf{P b}$ & 0.152 & 0.005 & 0.46 & 0.01 & 0.276 & 0.006 & 0.105 & 0.003 \\
\hline $\mathbf{B i}$ & 0.0042 & 0.0005 & 0.0019 & 0.0004 & 0.0011 & 0.0004 & 0.0009 & 0.0004 \\
\hline Th & 0.02 & 0.001 & 0.0344 & 0.0008 & 0.016 & 0.001 & 0.011 & 0.001 \\
\hline $\mathbf{U}$ & 0.523 & 0.007 & 0.926 & 0.009 & 0.121 & 0.002 & 0.81 & 0.013 \\
\hline
\end{tabular}

3 Algal species 


\begin{tabular}{|c|c|c|c|c|c|c|c|c|}
\hline $\begin{array}{l}\text { Sample \# } \\
\text { Location } \\
\text { Species }\end{array}$ & \multicolumn{2}{|c|}{\begin{tabular}{l}
\multicolumn{1}{c}{29} \\
Kaingaroa East \\
Cystophora scalaris \\
(brown)3
\end{tabular}} & \multicolumn{2}{|c|}{\begin{tabular}{l}
\multicolumn{1}{c}{30} \\
Cape Pattisson \\
Cystophora \\
scalaris3
\end{tabular}} & \multicolumn{2}{|c|}{\begin{tabular}{l}
\multicolumn{1}{c}{31} \\
Port Hutt \\
Carpophyllum \\
plumosum3
\end{tabular}} & \multicolumn{2}{|c|}{\begin{tabular}{l}
\multicolumn{1}{c}{32} \\
Red Bluff \\
Gigartina clavifera \\
(red)3
\end{tabular}} \\
\hline & $w t \%$ & $1 S D$ & $w t \%$ & $1 S D$ & $w t \%$ & $1 S D$ & $w t \%$ & $1 S D$ \\
\hline Mg & 0.95 & 0.06 & 1.14 & 0.09 & 0.88 & 0.04 & 1.14 & 0.06 \\
\hline Ca & 0.94 & 0.07 & 1.3 & 0.1 & 1.58 & 0.12 & 0.35 & 0.03 \\
\hline \multirow[t]{2}{*}{$\mathbf{S r}$} & 0.131 & 0.005 & 0.141 & 0.007 & 0.28 & 0.01 & 0.0110 & 0.0004 \\
\hline & $p p m$ & $1 S D$ & ppm & $1 S D$ & $p p m$ & $1 S D$ & ppm & $1 S D$ \\
\hline $\mathbf{L i}$ & 0.167 & 0.007 & 0.31 & 0.01 & 0.212 & 0.017 & 0.484 & 0.015 \\
\hline Al & 5 & 0.3 & 61 & 3 & 53 & 3 & 16 & 1 \\
\hline Sc & 0.008 & 0.001 & 0.034 & 0.002 & 0.038 & 0.002 & 0.015 & 0.001 \\
\hline $\mathbf{T i}$ & 0.89 & 0.07 & 18 & 0.5 & 3.8 & 0.1 & 2.8 & 0.1 \\
\hline $\mathbf{V}$ & 0.49 & 0.02 & 1.3 & 0.05 & 1.18 & 0.04 & 6.5 & 0.2 \\
\hline $\mathrm{Cr}$ & 0.19 & 0.01 & 0.4 & 0.02 & 0.4 & 0.01 & 0.17 & 0.01 \\
\hline Mn & 3.8 & 0.1 & 5.5 & 0.2 & 6.6 & 0.2 & 3 & 0.1 \\
\hline $\mathbf{F e}$ & 50 & 3 & 89 & 5 & 192 & 13 & 48 & 3 \\
\hline Co & 0.058 & 0.005 & 0.33 & 0.01 & 0.424 & 0.008 & 0.98 & 0.02 \\
\hline $\mathbf{N i}$ & 0.37 & 0.02 & 1.52 & 0.05 & 1.91 & 0.08 & 1.73 & 0.05 \\
\hline $\mathrm{Cu}$ & 2.18 & 0.08 & 0.73 & 0.02 & 0.74 & 0.05 & 2.15 & 0.07 \\
\hline $\mathbf{Z n}$ & 5.2 & 0.2 & 7.54 & 0.3 & 6.3 & 0.2 & 15.3 & 0.4 \\
\hline Ga & 0.0033 & 0.0004 & 0.019 & 0.002 & 0.0088 & 0.0005 & 0.005 & 0.001 \\
\hline As & 34 & 1 & 64 & 3 & 55 & 2 & 12 & 1 \\
\hline $\mathbf{R b}$ & 8.53 & 0.17 & 9.21 & 0.19 & 4.63 & 0.1 & 9.8 & 0.19 \\
\hline Y & 0.036 & 0.002 & 0.112 & 0.003 & 0.202 & 0.005 & 0.022 & 0.001 \\
\hline $\mathrm{Nb}$ & 0.0067 & 0.0003 & 0.035 & 0.002 & 0.018 & 0.002 & 0.011 & 0.001 \\
\hline Mo & 0.249 & 0.008 & 0.408 & 0.015 & 0.179 & 0.005 & 0.961 & 0.026 \\
\hline Cd & 0.4 & 0.03 & 3.79 & 0.24 & 0.25 & 0.02 & 0.362 & 0.026 \\
\hline Sn & 0.024 & 0.005 & 0.024 & 0.004 & 0.029 & 0.005 & 0.069 & 0.003 \\
\hline Cs & 0.0142 & 0.0003 & 0.0187 & 0.0005 & 0.0103 & 0.0005 & 0.0172 & 0.0008 \\
\hline Ba & 10.2 & 0.3 & 11.2 & 0.3 & 25.3 & 0.5 & 0.33 & 0.01 \\
\hline La & 0.015 & 0.001 & 0.075 & 0.002 & 0.11 & 0.002 & 0.015 & 0.001 \\
\hline $\mathrm{Ce}$ & 0.018 & 0.001 & 0.128 & 0.003 & 0.201 & 0.005 & 0.024 & 0.002 \\
\hline Nd & 0.012 & 0.001 & 0.071 & 0.003 & 0.132 & 0.004 & 0.019 & 0.001 \\
\hline Sm & 0.0026 & 0.0007 & 0.013 & 0.001 & 0.029 & 0.001 & 0.005 & 0.001 \\
\hline $\mathbf{Y b}$ & 0.002 & 0.001 & 0.008 & 0.001 & 0.017 & 0.001 & 0.0013 & 0.0003 \\
\hline Tl & 0.0008 & 0.0001 & 0.0019 & 0.0002 & 0.0025 & 0.0004 & 0.0046 & 0.0003 \\
\hline $\mathbf{P b}$ & 0.112 & 0.004 & 0.169 & 0.003 & 0.736 & 0.014 & 0.856 & 0.017 \\
\hline $\mathbf{B i}$ & 0.0006 & 0.0002 & 0.0011 & 0.0004 & 0.0023 & 0.0004 & 0.0006 & 0.0002 \\
\hline Th & 0.0046 & 0.0002 & 0.032 & 0.001 & 0.019 & 0.001 & 0.0021 & 0.0001 \\
\hline $\mathbf{U}$ & 0.426 & 0.003 & 0.933 & 0.008 & 0.865 & 0.009 & 0.092 & 0.001 \\
\hline
\end{tabular}

3 Algal species 


\begin{tabular}{|c|c|c|c|c|c|c|c|c|}
\hline \multirow{2}{*}{$\begin{array}{l}\text { Sample \# } \\
\text { Location } \\
\text { Species } \\
\end{array}$} & \multicolumn{2}{|c|}{\begin{tabular}{l}
\multicolumn{1}{c}{33} \\
Hanson Point \\
South \\
Carpophyllum sp.3
\end{tabular}} & \multicolumn{2}{|c|}{\begin{tabular}{l}
\multicolumn{1}{c}{34} \\
Kaingaroa West \\
Cystophora \\
scalaris3
\end{tabular}} & \multicolumn{2}{|c|}{\begin{tabular}{l}
\multicolumn{1}{c}{35} \\
Cape Pattisson \\
Cystophora \\
scalaris3
\end{tabular}} & \multicolumn{2}{|c|}{\begin{tabular}{l}
\multicolumn{1}{c}{36} \\
Port Hutt \\
Carpophyllum \\
plumosum3
\end{tabular}} \\
\hline & $w t \%$ & $1 S D$ & $w t \%$ & $1 S D$ & $w t \%$ & $1 S D$ & $w t \%$ & $1 S D$ \\
\hline Mg & 0.86 & 1.14 & 1.21 & 0.06 & 1.13 & 0.09 & 1.13 & 0.07 \\
\hline Ca & 1.38 & 0.35 & 1.18 & 0.09 & 1.2 & 0.1 & 1.52 & 0.12 \\
\hline \multirow[t]{2}{*}{$\underline{\mathbf{S r}}$} & 0.17 & 0.01 & 0.127 & 0.004 & 0.14 & 0.01 & 0.19 & 0.01 \\
\hline & ppm & $1 S D$ & ppm & $1 S D$ & ppm & $1 S D$ & ppm & $1 S D$ \\
\hline $\mathbf{L i}$ & 0.214 & 0.484 & 0.295 & 0.009 & 0.229 & 0.011 & 0.244 & 0.006 \\
\hline Al & 105 & 16 & 48 & 3 & 49 & 2 & 162 & 7 \\
\hline Sc & 0.04 & 0.015 & 0.023 & 0.002 & 0.029 & 0.002 & 0.106 & 0.005 \\
\hline $\mathbf{T i}$ & 20.8 & 2.8 & 6.7 & 0.3 & 16.1 & 0.4 & 21 & 0.6 \\
\hline V & 0.85 & 6.5 & 1.5 & 0.1 & 1.27 & 0.04 & 1.82 & 0.05 \\
\hline $\mathrm{Cr}$ & 0.37 & 0.17 & 0.41 & 0.02 & 0.37 & 0.02 & 0.91 & 0.03 \\
\hline Mn & 12.5 & 3 & 3.7 & 0.1 & 5.1 & 0.1 & 8.4 & 0.2 \\
\hline $\mathrm{Fe}$ & 177 & 48 & 62 & 4 & 88 & 5 & 409 & 17 \\
\hline Co & 0.164 & 0.98 & 0.183 & 0.004 & 0.27 & 0.01 & 0.44 & 0.008 \\
\hline $\mathrm{Ni}$ & 0.56 & 1.73 & 1.24 & 0.05 & 1.1 & 0.05 & 3.6 & 0.1 \\
\hline $\mathrm{Cu}$ & 2.75 & 2.15 & 0.52 & 0.02 & 0.67 & 0.03 & 1.2 & 0.04 \\
\hline Zn & 4.7 & 15.3 & 4.3 & 0.1 & 4.3 & 0.1 & 11.9 & 0.5 \\
\hline Ga & 0.03 & 0.005 & 0.017 & 0.002 & 0.02 & 0.003 & 0.041 & 0.002 \\
\hline As & 47 & 12 & 53 & 2 & 24 & 5 & 28 & 6 \\
\hline $\mathbf{R b}$ & 8.68 & 9.8 & 8.09 & 0.16 & 8.82 & 0.19 & 3.52 & 0.08 \\
\hline Y & 0.28 & 0.022 & 0.106 & 0.003 & 0.089 & 0.003 & 0.51 & 0.01 \\
\hline Nb & 0.056 & 0.011 & 0.023 & 0.001 & 0.024 & 0.001 & 0.066 & 0.002 \\
\hline Mo & 0.149 & 0.961 & 0.363 & 0.012 & 0.5 & 0.01 & 0.27 & 0.01 \\
\hline Cd & 0.046 & 0.362 & 3.1 & 0.2 & 4.35 & 0.25 & 0.48 & 0.03 \\
\hline Sn & 0.035 & 0.069 & 0.023 & 0.003 & 0.024 & 0.005 & 0.159 & 0.123 \\
\hline Cs & 0.009 & 0.0172 & 0.023 & 0.001 & 0.017 & 0.001 & 0.0145 & 0.0005 \\
\hline Ba & 12.5 & 0.33 & 9.8 & 0.24 & 10.9 & 0.2 & 16.2 & 0.2 \\
\hline La & 0.246 & 0.015 & 0.048 & 0.001 & 0.106 & 0.002 & 0.381 & 0.008 \\
\hline $\mathrm{Ce}$ & 0.282 & 0.024 & 0.081 & 0.003 & 0.164 & 0.003 & 0.729 & 0.011 \\
\hline Nd & 0.25 & 0.019 & 0.047 & 0.002 & 0.065 & 0.002 & 0.408 & 0.007 \\
\hline Sm & 0.051 & 0.005 & 0.01 & 0.001 & 0.011 & 0.002 & 0.086 & 0.004 \\
\hline Yb & 0.017 & 0.0013 & 0.007 & 0.001 & 0.0059 & 0.0004 & 0.042 & 0.002 \\
\hline TI & 0.0037 & 0.0046 & 0.0013 & 0.0002 & 0.0015 & 0.0001 & 0.0049 & 0.0004 \\
\hline $\mathbf{P b}$ & 0.262 & 0.856 & 0.101 & 0.003 & 0.102 & 0.003 & 1.51 & 0.04 \\
\hline $\mathbf{B i}$ & 0.0009 & 0.0006 & 0.001 & 0.0003 & 0.0021 & 0.0003 & 0.0039 & 0.0005 \\
\hline Th & 0.0099 & 0.0021 & 0.008 & 0.0004 & 0.009 & 0.0003 & 0.053 & 0.001 \\
\hline $\mathbf{U}$ & 0.261 & 0.092 & 0.86 & 0.02 & 1.21 & 0.01 & 1.2 & 0.02 \\
\hline
\end{tabular}

3 Algal species 


\begin{tabular}{|c|c|c|}
\hline $\begin{array}{l}\text { Sample \# } \\
\text { Location } \\
\text { Species }\end{array}$ & \multicolumn{2}{|c|}{$\begin{array}{c}37 \\
\text { Hanson Point South } \\
\text { Carpophyllum sp.3 }\end{array}$} \\
\hline & $w t \%$ & $1 S D$ \\
\hline Mg & 0.91 & 0.06 \\
\hline Ca & 1.38 & 0.11 \\
\hline \multirow[t]{2}{*}{$\underline{\mathrm{Sr}}$} & 0.22 & 0.01 \\
\hline & ppm & $1 S D$ \\
\hline $\mathbf{L i}$ & 0.135 & 0.009 \\
\hline Al & 92 & 5 \\
\hline Sc & 0.041 & 0.003 \\
\hline $\mathrm{Ti}$ & 21.1 & 0.7 \\
\hline V & 0.85 & 0.03 \\
\hline $\mathrm{Cr}$ & 0.47 & 0.02 \\
\hline Mn & 12.2 & 0.4 \\
\hline $\mathbf{F e}$ & 202 & 13 \\
\hline Co & 0.221 & 0.007 \\
\hline $\mathbf{N i}$ & 0.66 & 0.03 \\
\hline $\mathbf{C u}$ & 2.6 & 0.08 \\
\hline Zn & 5.7 & 0.2 \\
\hline Ga & 0.032 & 0.001 \\
\hline As & 27 & 6 \\
\hline $\mathbf{R b}$ & 6.16 & 0.13 \\
\hline Y & 0.12 & 0.005 \\
\hline Nb & 0.056 & 0.003 \\
\hline Mo & 0.16 & 0.01 \\
\hline Cd & 0.038 & 0.003 \\
\hline Sn & 0.043 & 0.005 \\
\hline Cs & 0.0071 & 0.0003 \\
\hline $\mathbf{B a}$ & 22.5 & 0.4 \\
\hline $\mathbf{L a}$ & 0.102 & 0.003 \\
\hline $\mathrm{Ce}$ & 0.187 & 0.003 \\
\hline Nd & 0.113 & 0.003 \\
\hline Sm & 0.025 & 0.003 \\
\hline Yb & 0.0078 & 0.0003 \\
\hline Tl & 0.007 & 0.001 \\
\hline $\mathbf{P b}$ & 0.193 & 0.007 \\
\hline $\mathbf{B i}$ & 0.015 & 0.0006 \\
\hline Th & 0.01 & 0.001 \\
\hline $\mathbf{U}$ & 0.371 & 0.005 \\
\hline
\end{tabular}

3 Algal species 


\begin{tabular}{|c|c|c|c|c|c|c|c|c|}
\hline $\begin{array}{l}\text { Sample \# } \\
\text { Location } \\
\text { Sample }\end{array}$ & \multicolumn{2}{|c|}{$\begin{array}{l}38 \\
\text { Waitangi Bay } \\
\text { Sediment }\end{array}$} & \multicolumn{2}{|c|}{$\begin{array}{l}39 \\
\text { Owenga } \\
\text { Sediment } \\
\end{array}$} & \multicolumn{2}{|c|}{$\begin{array}{l}40 \\
\text { Hanson Point South } \\
\text { Sediment }\end{array}$} & \multicolumn{2}{|c|}{$\begin{array}{l}41 \\
\text { Kaingarora West } \\
\text { Sediment }\end{array}$} \\
\hline & $w t \%$ & $1 S D$ & $w t \%$ & $1 S D$ & $w t \%$ & $1 S D$ & $w t \%$ & $1 S D$ \\
\hline TiO2 & 0.26 & 0.01 & 1.25 & 0.02 & 2.44 & 0.05 & 0.01 & 0.00 \\
\hline Al2O3 & 2.64 & 0.06 & 5.40 & 0.08 & 8.79 & 0.14 & 0.17 & 0.00 \\
\hline $\mathrm{Fe} 2 \mathrm{O3}(\mathrm{t})$ & 1.11 & 0.02 & 4.23 & 0.09 & 9.80 & 0.26 & 0.08 & 0.00 \\
\hline MgO & 1.34 & 0.04 & 2.59 & 0.07 & 6.40 & 0.14 & 2.89 & 0.06 \\
\hline MnO & 0.02 & 0.00 & 0.05 & 0.00 & 0.10 & 0.00 & 0.00 & 0.00 \\
\hline \multirow{2}{*}{$\mathrm{CaO}$} & 32.1 & 1.4 & 27.9 & 1.0 & 17.2 & 0.6 & 48.6 & 1.8 \\
\hline & ppm & $1 S D$ & ppm & $1 S D$ & ppm & $1 S D$ & ppm & $I S D$ \\
\hline Sc & 3.11 & 0.16 & 10.52 & 0.17 & 14.42 & 0.39 & 0.30 & 0.01 \\
\hline V & 18.6 & 0.6 & 77.14 & 2.53 & 101.4 & 3.0 & 1.61 & 0.07 \\
\hline $\mathrm{Cr}$ & 257.6 & 6.3 & 261.9 & 4.4 & 432.8 & 8.9 & 5.38 & 0.12 \\
\hline Co & 3.22 & 0.11 & 13.16 & 0.38 & 36.13 & 0.77 & 0.097 & 0.021 \\
\hline $\mathbf{N i}$ & 14.9 & 0.6 & 51.1 & 1.4 & 192.0 & 5.1 & 0.90 & 0.11 \\
\hline $\mathrm{Cu}$ & 2.38 & 0.23 & 11.9 & 0.4 & 23.6 & 0.7 & 0.409 & 0.036 \\
\hline Zn & 14.59 & 1.18 & 50.03 & 2.99 & 107.50 & 4.02 & 2.76 & 0.51 \\
\hline As & 15.1 & 7.3 & 18.8 & 9.0 & 32.6 & 15.6 & 2.41 & 1.58 \\
\hline $\mathbf{R b}$ & 12.4 & 0.2 & 26.0 & 0.5 & 22.7 & 0.4 & 1.25 & 0.03 \\
\hline $\mathbf{S r}$ & 1249 & 15 & 1085 & 13 & 761 & 11 & 2376 & 31 \\
\hline Y & 11.53 & 0.20 & 12.11 & 0.20 & 22.16 & 0.38 & 3.80 & 0.11 \\
\hline Мo & 2.297 & 0.089 & 0.381 & 0.057 & 0.786 & 0.060 & 0.128 & 0.025 \\
\hline Cd & 0.176 & 0.082 & 0.162 & 0.072 & 0.294 & 0.119 & 0.140 & 0.061 \\
\hline Sn & 0.669 & 0.175 & 5.78 & 0.53 & 1.87 & 0.19 & 0.143 & 0.085 \\
\hline Sb & 0.104 & 0.037 & 0.331 & 0.111 & 0.463 & 0.150 & 0.041 & 0.017 \\
\hline Ba & 103.0 & 1.5 & 197.3 & 3.7 & 218.8 & 4.2 & 13.4 & 0.4 \\
\hline La & 10.5 & 0.5 & 13.9 & 0.2 & 31.3 & 0.5 & 1.55 & 0.03 \\
\hline $\mathrm{Ce}$ & 16.1 & 0.2 & 27.7 & 0.4 & 66 & 1 & 2.25 & 0.03 \\
\hline Pr & 2.53 & 0.04 & 3.63 & 0.07 & 8.83 & 0.14 & 0.34 & 0.02 \\
\hline Nd & 10.3 & 0.2 & 15.0 & 0.4 & 37.1 & 0.8 & 1.46 & 0.05 \\
\hline Sm & 1.96 & 0.07 & 3.27 & 0.13 & 7.67 & 0.28 & 0.31 & 0.01 \\
\hline Eu & 0.59 & 0.03 & 1.08 & 0.05 & 2.43 & 0.09 & 0.09 & 0.01 \\
\hline Gd & 2.05 & 0.09 & 3.19 & 0.09 & 7.31 & 0.22 & 0.38 & 0.04 \\
\hline Tb & 0.293 & 0.011 & 0.434 & 0.017 & 0.941 & 0.029 & 0.055 & 0.004 \\
\hline Dy & 1.63 & 0.06 & 2.33 & 0.05 & 4.73 & 0.12 & 0.333 & 0.024 \\
\hline Ho & 0.324 & 0.016 & 0.432 & 0.018 & 0.824 & 0.029 & 0.082 & 0.005 \\
\hline $\mathbf{E r}$ & 0.886 & 0.045 & 1.14 & 0.06 & 1.98 & 0.11 & 0.230 & 0.024 \\
\hline Tm & 0.121 & 0.009 & 0.147 & 0.007 & 0.233 & 0.011 & 0.033 & 0.004 \\
\hline $\mathbf{Y b}$ & 0.721 & 0.042 & 0.865 & 0.058 & 1.39 & 0.09 & 0.178 & 0.018 \\
\hline Lu & 0.100 & 0.015 & 0.123 & 0.015 & 0.181 & 0.017 & 0.030 & 0.006 \\
\hline Tl & 0.079 & 0.033 & 0.129 & 0.050 & 0.061 & 0.025 & 0.028 & 0.012 \\
\hline $\mathbf{P b}$ & 2.44 & 0.07 & 15.97 & 0.45 & 13.05 & 0.34 & 0.60 & 0.02 \\
\hline $\mathbf{B i}$ & 0.0191 & 0.0102 & 0.021 & 0.012 & 0.026 & 0.015 & 0.003 & 0.004 \\
\hline Th & 0.834 & 0.026 & 1.66 & 0.06 & 2.98 & 0.08 & 0.105 & 0.007 \\
\hline $\mathbf{U}$ & 0.744 & 0.028 & 0.782 & 0.029 & 1.25 & 0.05 & 0.599 & 0.023 \\
\hline
\end{tabular}




\begin{tabular}{|c|c|c|c|c|c|c|c|c|}
\hline $\begin{array}{l}\text { Sample \# } \\
\text { Location } \\
\text { Sample } \\
\end{array}$ & \multicolumn{2}{|c|}{$\begin{array}{l}2 \\
\text { Kaingaroa East } \\
\text { Sediment }\end{array}$} & \multicolumn{2}{|c|}{$\begin{array}{l}43 \\
\text { Cape } \\
\text { Pattisson } \\
\text { Sediment } \\
\end{array}$} & \multicolumn{2}{|c|}{$\begin{array}{l}44 \\
\text { Kaingaroa South } \\
\text { Sediment } \\
\end{array}$} & \multicolumn{2}{|c|}{$\begin{array}{l}45 \\
\text { Port Hutt } \\
\text { Sediment } \\
\end{array}$} \\
\hline & $w t \%$ & $1 S D$ & $w t \%$ & $1 S D$ & $w t \%$ & $1 S D$ & $w t \%$ & $1 S D$ \\
\hline TiO2 & 0.01 & 0.00 & 0.06 & 0.00 & 0.02 & 0.00 & 0.01 & 0.00 \\
\hline Al203 & 0.10 & 0.00 & 1.43 & 0.03 & 0.58 & 0.01 & 1.01 & 0.02 \\
\hline $\mathrm{Fe} 2 \mathrm{O3}(\mathrm{t})$ & 0.08 & 0.00 & 0.28 & 0.00 & 0.10 & 0.00 & 0.13 & 0.00 \\
\hline MgO & 2.54 & 0.05 & 0.90 & 0.02 & 0.20 & 0.01 & 0.04 & 0.00 \\
\hline MnO & 0.00 & 0.00 & 0.01 & 0.00 & 0.00 & 0.00 & 0.00 & 0.00 \\
\hline \multirow{2}{*}{$\mathrm{CaO}$} & 48.6 & 2.4 & 31.5 & 1.5 & 5.2 & 0.2 & 0.08 & 0.01 \\
\hline & ppm & $1 S D$ & ppm & $1 S D$ & ppm & $1 S D$ & ppm & $1 S D$ \\
\hline Sc & 0.14 & 0.02 & 0.73 & 0.05 & 0.29 & 0.05 & 0.16 & 0.03 \\
\hline V & 1.54 & 0.11 & 6.72 & 0.25 & 2.14 & 0.13 & 2.51 & 0.09 \\
\hline $\mathrm{Cr}$ & 3.43 & 0.10 & 70.5 & 1.2 & 7.75 & 0.27 & 1.65 & 0.11 \\
\hline Co & 0.097 & 0.026 & 0.514 & 0.016 & 0.311 & 0.024 & 0.296 & 0.0217 \\
\hline $\mathrm{Ni}$ & 0.64 & 0.13 & 2.17 & 0.13 & 1.54 & 0.14 & 0.77 & 0.17 \\
\hline $\mathrm{Cu}$ & 0.826 & 0.116 & 0.518 & 0.101 & 0.296 & 0.062 & 0.296 & 0.055 \\
\hline $\mathbf{Z n}$ & 7.66 & 0.65 & 5.19 & 0.39 & 1.79 & 0.21 & 2.42 & 0.36 \\
\hline As & 1.80 & 0.94 & 4.87 & 2.35 & 0.605 & 0.425 & 1.94 & 1.20 \\
\hline $\mathbf{R b}$ & 0.635 & 0.016 & 6.37 & 0.10 & 2.57 & 0.05 & 1.28 & 0.05 \\
\hline $\mathrm{Sr}$ & 2202 & 36 & 1518 & 19 & 261 & 4 & 13.5 & 0.5 \\
\hline Y & 1.68 & 0.05 & 4.13 & 0.08 & 0.52 & 0.02 & 0.37 & 0.02 \\
\hline Мo & 0.039 & 0.019 & 0.178 & 0.020 & 0.010 & 0.026 & 0.025 & 0.023 \\
\hline Cd & 0.099 & 0.047 & 0.081 & 0.040 & 0.0054 & 0.0240 & 0.0088 & 0.0203 \\
\hline Sn & 0.125 & 0.089 & 0.19 & 0.08 & 0.10 & 0.07 & 0.139 & 0.069 \\
\hline $\mathbf{S b}$ & 0.025 & 0.017 & 0.097 & 0.037 & 0.036 & 0.016 & 0.025 & 0.015 \\
\hline $\mathbf{B a}$ & 9.1 & 0.2 & 52.1 & 1.1 & 33.0 & 0.8 & 8.1 & 0.2 \\
\hline $\mathbf{L a}$ & 0.83 & 0.03 & 3.83 & 0.06 & 0.64 & 0.02 & 0.50 & 0.02 \\
\hline $\mathrm{Ce}$ & 1.22 & 0.03 & 6.62 & 0.11 & 1.08 & 0.02 & 0.94 & 0.01 \\
\hline Pr & 0.194 & 0.006 & 0.93 & 0.03 & 0.137 & 0.007 & 0.120 & 0.009 \\
\hline Nd & 0.76 & 0.03 & 3.6 & 0.1 & 0.56 & 0.03 & 0.44 & 0.019 \\
\hline Sm & 0.16 & 0.02 & 0.66 & 0.03 & 0.09 & 0.02 & 0.088 & 0.016 \\
\hline Eu & 0.04 & 0.01 & 0.16 & 0.01 & 0.03 & 0.01 & 0.02 & 0.01 \\
\hline Gd & 0.19 & 0.04 & 0.69 & 0.05 & 0.095 & 0.014 & 0.071 & 0.014 \\
\hline Tb & 0.025 & 0.003 & 0.085 & 0.003 & 0.014 & 0.002 & 0.012 & 0.002 \\
\hline Dy & 0.169 & 0.012 & 0.533 & 0.024 & 0.075 & 0.006 & 0.064 & 0.012 \\
\hline Ho & 0.036 & 0.002 & 0.110 & 0.007 & 0.017 & 0.003 & 0.012 & 0.002 \\
\hline $\mathbf{E r}$ & 0.110 & 0.006 & 0.316 & 0.016 & 0.042 & 0.003 & 0.040 & 0.003 \\
\hline Tm & 0.014 & 0.002 & 0.042 & 0.004 & 0.006 & 0.002 & 0.006 & 0.002 \\
\hline Yb & 0.082 & 0.007 & 0.241 & 0.023 & 0.039 & 0.007 & 0.037 & 0.010 \\
\hline Lu & 0.012 & 0.003 & 0.035 & 0.004 & 0.006 & 0.004 & 0.005 & 0.003 \\
\hline Tl & 0.011 & 0.006 & 0.074 & 0.031 & 0.023 & 0.010 & 0.009 & 0.005 \\
\hline $\mathbf{P b}$ & 1.49 & 0.04 & 0.874 & 0.052 & 0.818 & 0.029 & 0.683 & 0.022 \\
\hline Bi & $<\mathrm{LOD}$ & $<\mathrm{LOD}$ & 0.007 & 0.005 & 0.001 & 0.004 & 0.0029 & 0.0045 \\
\hline Th & 0.067 & 0.005 & 0.41 & 0.014 & 0.131 & 0.007 & 0.123 & 0.008 \\
\hline $\mathbf{U}$ & 0.369 & 0.017 & 0.709 & 0.034 & 0.115 & 0.009 & 0.040 & 0.004 \\
\hline
\end{tabular}




\begin{tabular}{|c|c|c|c|c|}
\hline $\begin{array}{l}\text { Sample \# } \\
\text { Location } \\
\text { Sample }\end{array}$ & \multicolumn{2}{|c|}{$\begin{array}{l}46 \\
\text { Hanson Point South } \\
\text { Sediment } \\
\end{array}$} & \multicolumn{2}{|c|}{$\begin{array}{l}47 \\
\text { Cape Pattisson } \\
\text { Sediment }\end{array}$} \\
\hline & $w t \%$ & $1 S D$ & $w t \%$ & $1 S D$ \\
\hline TiO2 & 2.41 & 0.07 & 0.06 & 0.00 \\
\hline Al2O3 & 8.67 & 0.18 & 1.50 & 0.03 \\
\hline $\mathrm{Fe} 2 \mathrm{O3}(\mathrm{t})$ & 9.48 & 0.20 & 0.29 & 0.01 \\
\hline MgO & 6.38 & 0.14 & 0.93 & 0.03 \\
\hline MnO & 0.10 & 0.00 & 0.01 & 0.00 \\
\hline \multirow[t]{2}{*}{$\mathrm{CaO}$} & 17.2 & 0.8 & 33.5 & 1.5 \\
\hline & ppm & $1 S D$ & ppm & $1 S D$ \\
\hline Sc & 14.18 & 0.28 & 0.81 & 0.04 \\
\hline V & 101.4 & 2.3 & 6.77 & 0.21 \\
\hline $\mathrm{Cr}$ & 494.5 & 13.5 & 78.1 & 1.5 \\
\hline Co & 35.5 & 0.8 & 0.536 & 0.027 \\
\hline $\mathbf{N i}$ & 193.6 & 6.4 & 2.44 & 0.16 \\
\hline $\mathrm{Cu}$ & 24.0 & 0.7 & 0.49 & 0.054 \\
\hline Zn & 121.5 & 4.7 & 5.12 & 0.65 \\
\hline As & 33.3 & 19.5 & 4.91 & 2.90 \\
\hline $\mathbf{R b}$ & 22.3 & 0.4 & 6.74 & 0.16 \\
\hline $\mathbf{S r}$ & 756 & 11 & 1597 & 24 \\
\hline Y & 21.87 & 0.49 & 4.37 & 0.12 \\
\hline Mo & 0.823 & 0.070 & 0.094 & 0.020 \\
\hline Cd & 0.316 & 0.126 & 0.097 & 0.053 \\
\hline Sn & 2.14 & 0.20 & 0.218 & 0.072 \\
\hline Sb & 0.405 & 0.124 & 0.079 & 0.030 \\
\hline Ba & 224.4 & 4.0 & 56.1 & 1.3 \\
\hline $\mathbf{L a}$ & 30.9 & 0.5 & 3.64 & 0.07 \\
\hline $\mathrm{Ce}$ & 64.9 & 0.7 & 6.01 & 0.06 \\
\hline Pr & 8.72 & 0.15 & 0.87 & 0.03 \\
\hline Nd & 36.6 & 0.7 & 3.4 & 0.1 \\
\hline Sm & 7.63 & 0.20 & 0.65 & 0.06 \\
\hline Eu & 2.38 & 0.08 & 0.17 & 0.01 \\
\hline Gd & 7.03 & 0.20 & 0.69 & 0.04 \\
\hline $\mathbf{T b}$ & 0.923 & 0.020 & 0.093 & 0.009 \\
\hline Dy & 4.67 & 0.12 & 0.553 & 0.031 \\
\hline Ho & 0.805 & 0.027 & 0.120 & 0.006 \\
\hline $\mathbf{E r}$ & 2.03 & 0.08 & 0.329 & 0.022 \\
\hline Tm & 0.244 & 0.011 & 0.048 & 0.003 \\
\hline Yb & 1.40 & 0.08 & 0.278 & 0.022 \\
\hline Lu & 0.190 & 0.018 & 0.038 & 0.003 \\
\hline $\mathbf{T l}$ & 0.051 & 0.020 & 0.076 & 0.030 \\
\hline $\mathbf{P b}$ & 14.1 & 0.4 & 0.955 & 0.035 \\
\hline $\mathbf{B i}$ & 0.021 & 0.011 & 0.007 & 0.005 \\
\hline Th & 2.98 & 0.07 & 0.464 & 0.021 \\
\hline $\mathbf{U}$ & 1.20 & 0.05 & 0.728 & 0.034 \\
\hline
\end{tabular}

